\title{
Spectral Addressability in a Modular Two Qubit System
}

Stephen von Kugelgen, ${ }^{\mathrm{a}}$ Matthew D. Krzyaniak, ${ }^{\mathrm{a}, \mathrm{b}}$ Mingqiang Gu, ${ }^{\mathrm{c}}$ Danilo Puggioni, ${ }^{\mathrm{c}}$ James M. Rondinelli, ${ }^{\mathrm{c} *}$ Michael R. Wasielewski, ${ }^{\mathrm{a}, b^{*}}$ and Danna E. Freedman ${ }^{\mathrm{a}, \mathrm{d} *}$

${ }^{a}$ Department of Chemistry, Northwestern University, Evanston, IL, 60208, USA.

${ }^{\mathrm{b}}$ The Institute for Sustainability and Energy at Northwestern, Northwestern University, Evanston, IL, 60208, USA.

${ }^{\mathrm{c}}$ Department of Materials Science and Engineering, Northwestern University, Evanston, Illinois 60208, USA.

${ }^{\mathrm{d}}$ Department of Chemistry, Massachusetts Institute of Technology, Cambridge, MA, 02139, USA. 


\section{Table of Contents}

$\begin{array}{lr}\text { Full experimental details } & \text { S8 }\end{array}$

$\begin{array}{ll}\text { Materials and general methods } & \text { S8 }\end{array}$

$\begin{array}{ll}\text { Synthetic procedures } & \mathbf{S 8}\end{array}$

$\begin{array}{ll}\text { Analytical methods } & \text { S16 }\end{array}$

$\begin{array}{lr}\text { Computational details } & \text { S18 }\end{array}$

$\begin{array}{ll}\text { EPR spectroscopy details } & \mathbf{S 1 8}\end{array}$

Table S1 | Best fit EPR simulation parameters for 2a, 2b, 1, 2, and 3 322

Table S2 | DFT calculated local moments on $\mathrm{Cu}$ and Ti for the bimetallic molecules 1, 2, and $\mathbf{3} \quad \mathbf{S 2 2}$

Table S3 | Variable temperature pulse EPR data summary for 1, 2, 3, 2a, 2b in toluene $\quad$ S23

Table S4 | Variable temperature pulse EPR data summary for 1, 2, 3, 2a, 2b in 1:1 $\mathrm{CS}_{2}:$ toluene- $d_{8} \quad$ S24

Table S5 | Saturation recovery fit parameters for 1 at $331 \mathrm{mT}\left(\mathrm{Cu}^{2+} g_{\mathrm{x} / \mathrm{y}}\right)$ in toluene $\mathbf{S 2 5}$

Table S6 | Saturation recovery fit parameters for 1 at $348 \mathrm{mT}\left(\mathrm{Ti}^{3+} g_{\mathrm{y}}\right)$ toluene $\quad$ S25

Table S7 | Hahn echo decay fit parameters for 1 at $331 \mathrm{mT}\left(\mathrm{Cu}^{2+} g_{x / y}\right)$ in toluene $\quad$ S26

Table S8 | Hahn echo decay fit parameters for 1 at $348 \mathrm{mT}\left(\mathrm{Ti}^{3+} g_{\mathrm{y}}\right)$ in toluene $\quad$ S26

Table S9 | Saturation recovery fit parameters for 1 at $329 \mathrm{mT}\left(\mathrm{Cu}^{2+} g_{\mathrm{x} / \mathrm{y}}\right)$ in $1: 1 \mathrm{CS}_{2}:$ toluene- $d_{8} \quad$ S27

Table S10 | Saturation recovery fit parameters for 1 at $342 \mathrm{mT}\left(\mathrm{Ti}^{3+} g_{z}\right)$ in $1: 1 \mathrm{CS}_{2}:$ toluene- $d_{8} \quad$ S27

Table S11 | Hahn echo decay fit parameters for 1 at $329 \mathrm{mT}\left(\mathrm{Cu}^{2+} g_{\mathrm{x} / \mathrm{y}}\right)$ in $1: 1 \mathrm{CS}_{2}:$ toluene- $d_{8} \quad$ S28

Table S12 | Hahn echo decay fit parameters for 1 at $342 \mathrm{mT}\left(\mathrm{Ti}^{3+} g_{z}\right)$ in $1: 1 \mathrm{CS}_{2}$ :toluene- $d_{8} \quad$ S28

Table S13 | Variable turning angle Hahn echo decay fit parameters for 1 at $328 \mathrm{mT}$ and $9.3673 \mathrm{GHz} \mathbf{S 2 8}$ $\left(\mathrm{Cu}^{2+} g_{\mathrm{x} / \mathrm{y}}\right)$ in $1: 1 \mathrm{CS}_{2}:$ toluene- $d_{8}$

Table S14 | Variable turning angle Hahn echo decay fit parameters for 1 at $334 \mathrm{mT}$ and $9.3673 \mathrm{GHz} \mathbf{S 2 9}$ $\left(\mathrm{Ti}^{3+} g_{z}\right)$ in $1: 1 \mathrm{CS}_{2}:$ toluene- $d_{8}$

Table S15 | Saturation recovery fit parameters for 2 at $330 \mathrm{mT}\left(\mathrm{Cu}^{2+} g_{\mathrm{x} / \mathrm{y}}\right)$ in toluene $\quad$ S29

Table S16 | Saturation recovery fit parameters for $\mathbf{2}$ at $347 \mathrm{mT}\left(\mathrm{Ti}^{3+} g_{\mathrm{y}}\right)$ in toluene $\quad$ S30

Table S17 | Hahn echo decay fit parameters for 2 at $330 \mathrm{mT}\left(\mathrm{Cu}^{2+} g_{x / y}\right)$ in toluene $\quad$ S30

Table S18 | Hahn echo decay fit parameters for 2 at $347 \mathrm{mT}\left(\mathrm{Ti}^{3+} g_{\mathrm{y}}\right)$ in toluene $\mathbf{S 3 1}$

Table S19 | Saturation recovery fit parameters for 2 at $329 \mathrm{mT}\left(\mathrm{Cu}^{2+} g_{\mathrm{x} / \mathrm{y}}\right)$ in $1: 1 \mathrm{CS}_{2}:$ toluene- $d_{8} \quad \mathbf{S 3 1}$

Table S20 | Saturation recovery fit parameters for 2 at $341 \mathrm{mT}\left(\mathrm{Ti}^{3+} g_{z}\right)$ in $1: 1 \mathrm{CS}_{2}:$ toluene- $d_{8} \quad \mathbf{S 3 2}$ 
Table S21 | Hahn echo decay fit parameters for 2 at $329 \mathrm{mT}\left(\mathrm{Cu}^{2+} g_{\mathrm{x} / \mathrm{y}}\right)$ in 1:1 $\mathrm{CS}_{2}:$ toluene- $d_{8}$

Table S22 | Hahn echo decay fit parameters for 2 at $341 \mathrm{mT}\left(\mathrm{Ti}^{3+} g_{z}\right)$ in 1:1 $\mathrm{CS}_{2}:$ toluene- $d_{8}$

Table S23 | Variable turning angle Hahn echo decay fit parameters for 2 at $328 \mathrm{mT}\left(\mathrm{Cu}^{2+} g_{x / y}\right)$ in 1:1 $\mathrm{CS}_{2}:$ toluene- $d_{8}$

Table S24 | Variable turning angle Hahn echo decay fit parameters for 2 at $342 \mathrm{mT}\left(\mathrm{Ti}^{3+} g_{\mathrm{z}}\right)$ in $1: 1 \quad \mathbf{S 3 3}$ $\mathrm{CS}_{2}$ :toluene- $d_{8}$

Table S25 | Saturation recovery fit parameters for 3 at $329 \mathrm{mT}\left(\mathrm{Cu}^{2+} g_{\mathrm{x} / \mathrm{y}}\right)$ in toluene

Table S26 | Saturation recovery fit parameters for 3 at $347 \mathrm{mT}\left(\mathrm{Ti}^{3+} g_{\mathrm{y}}\right)$ in toluene

Table S27 | Hahn echo decay fit parameters for 3 at $329 \mathrm{mT}\left(\mathrm{Cu}^{2+} g_{\mathrm{x} / \mathrm{y}}\right)$ in toluene

Table S28 | Hahn echo decay fit parameters for 3 at $347 \mathrm{mT}\left(\mathrm{Ti}^{3+} g_{\mathrm{y}}\right)$ in toluene

Table S29 | Saturation recovery fit parameters for 3 at $331 \mathrm{mT}\left(\mathrm{Cu}^{2+} g_{\mathrm{x} / \mathrm{y}}\right)$ in 1:1 $\mathrm{CS}_{2}:$ toluene- $d_{8}$

Table S30 | Saturation recovery fit parameters for 3 at $342 \mathrm{mT}\left(\mathrm{Ti}^{3+} g_{z}\right)$ in 1:1 $\mathrm{CS}_{2}:$ toluene- $d_{8}$

Table S31 | Hahn echo decay fit parameters for 3 at $331 \mathrm{mT}\left(\mathrm{Cu}^{2+} g_{\mathrm{x} / \mathrm{y}}\right)$ in $\mathrm{CS}_{2}:$ toluene- $d_{8}$

Table S32 | Hahn echo decay fit parameters for 3 at $342 \mathrm{mT}\left(\mathrm{Ti}^{3+} g_{z}\right)$ in 1:1 $\mathrm{CS}_{2}:$ toluene- $d_{8}$

Table S33 | Variable turning angle Hahn echo decay fit parameters for 3 at $328 \mathrm{mT}\left(\mathrm{Cu}^{2+} g_{x / y}\right)$ in 1:1 $\mathrm{CS}_{2}:$ toluene- $d_{8}$

Table S34 | Variable turning angle Hahn echo decay fit parameters for 3 at $342 \mathrm{mT}\left(\mathrm{Ti}^{3+} g_{z}\right)$ in 1:1 $\mathrm{CS}_{2}:$ toluene- $d_{8}$

Table S35 | Saturation recovery fit parameters for $\mathbf{2 a}$ at $334 \mathrm{mT}\left(\mathrm{Cu}^{2+} g_{\mathrm{x} / \mathrm{y}}\right)$ in toluene

Table S36 | Hahn echo decay fit parameters for $\mathbf{2 a}$ at $334 \mathrm{mT}\left(\mathrm{Cu}^{2+} g_{\mathrm{x} / \mathrm{y}}\right)$ in toluene

Table S37 | Saturation recovery fit parameters for 2a at $334 \mathrm{mT}\left(\mathrm{Cu}^{2+} g_{\mathrm{x} / \mathrm{y}}\right)$ in 1:1 $\mathrm{CS}_{2}:$ toluene- $d_{8}$

Table S38 | Hahn echo decay fit parameters for $\mathbf{2 a}$ at $334 \mathrm{mT}\left(\mathrm{Cu}^{2+} g_{\mathrm{x} / \mathrm{y}}\right)$ in 1:1 $\mathrm{CS}_{2}:$ toluene- $d_{8}$

Table S39 | Variable turning angle Hahn echo decay fit parameters for $2 \mathbf{a}$ at $323 \mathrm{mT}\left(\mathrm{Cu}^{2+} g_{\mathrm{x} / \mathrm{y}}\right)$ in

1:1 $\mathrm{CS}_{2}:$ toluene- $d_{8}$

Table S40 | Saturation recovery fit parameters for $\mathbf{2 b}$ at $348 \mathrm{mT}\left(\mathrm{Ti}^{3+} g_{\mathrm{z}}\right)$ in toluene

Table S41 | Hahn echo decay fit parameters for $\mathbf{2 b}$ at $348 \mathrm{mT}\left(\mathrm{Ti}^{3+} g_{z}\right)$ in toluene

Table S42 | Saturation recovery fit parameters for $\mathbf{2 b}$ at $342 \mathrm{mT}\left(\mathrm{Ti}^{3+} g_{\mathrm{z}}\right)$ in 1:1 $\mathrm{CS}_{2}:$ toluene- $d_{8}$

Table S43 | Hahn echo decay fit parameters for $\mathbf{2 b}$ at $342 \mathrm{mT}\left(\mathrm{Ti}^{3+} g_{z}\right)$ in 1:1 $\mathrm{CS}_{2}:$ toluene- $d_{8}$

Table S44 | Variable turning angle Hahn echo decay fit parameters for $\mathbf{2 b}$ at $342 \mathrm{mT}\left(\mathrm{Ti}^{3+} g_{\mathrm{z}}\right)$ in 1:1 
Table S45 | Crystallographic information for the structural refinement of $\mathbf{1 b} \bullet \mathbf{M e C N}$

Table S46 | Crystallographic information for the structural refinement of $\mathbf{2 \bullet 0 . 5}\left(\mathbf{C}_{7} \mathbf{H}_{8}\right)$

Table S47 | Crystallographic information for the structural refinement of 3

Figure S1 | Calculated 80\% spin density surfaces for 1, 2, and $\mathbf{3}$

Figure S2 | CW EPR spectra of 2a, 2b, 1, 2, and $\mathbf{3}$ with best fit simulations

Figure S3 | Comparison of experimental CW EPR spectra of 1, 2, and 3 with uncoupled simulations

Figure S4 | EDFS EPR spectrum of 1 in frozen toluene solution at $20 \mathrm{~K}$ and $9.5072 \mathrm{GHz}$

Figure S5 | Variable temperature saturation recovery data for 1 at $331 \mathrm{mT}\left(\mathrm{Cu}^{2+} \mathrm{g}_{\mathrm{x} / \mathrm{y}}\right)$ in toluene

Figure S6 | Variable temperature saturation recovery data for $\mathbf{1}$ at $348 \mathrm{mT}\left(\mathrm{Ti}^{3+} g_{\mathrm{y}}\right)$ in toluene

Figure S7 | Variable temperature two-pulse Hahn echo data for 1 at $331 \mathrm{mT}\left(\mathrm{Cu}^{2+} g_{\mathrm{x} / \mathrm{y}}\right)$ in toluene

Figure S8 | Variable temperature two-pulse Hahn echo data for 1 at $348 \mathrm{mT}\left(\mathrm{Ti}^{3+} g_{\mathrm{y}}\right)$ in toluene

Figure S9 | EDFS EPR spectrum of 1 in $1: 1 \mathrm{CS}_{2}:$ toluene- $d_{8}$ solution at $30 \mathrm{~K}$ and $9.4921 \mathrm{GHz}$

Figure S10 | Variable temperature saturation recovery data for $\mathbf{1}$ at $329 \mathrm{mT}\left(\mathrm{Cu}^{2+} g_{\mathrm{x} / \mathrm{y}}\right)$ in $1: 1$ $\mathrm{CS}_{2}:$ toluene- $d_{8}$

Figure S11 | Variable temperature saturation recovery data for 1 at $342 \mathrm{mT}\left(\mathrm{Ti}^{3+} g_{\mathrm{z}}\right)$ in $1: 1$ $\mathrm{CS}_{2}$ :toluene- $d_{8}$

Figure S12 | Variable temperature two-pulse Hahn echo data for $\mathbf{1}$ at $329 \mathrm{mT}\left(\mathrm{Cu}^{2+} g_{\mathrm{x} / \mathrm{y}}\right)$ in 1:1 $C S_{2}:$ toluene- $d_{8}$

Figure S13 | Variable temperature two-pulse Hahn echo data for 1 at $342 \mathrm{mT}\left(\mathrm{Ti}^{3+} g_{\mathrm{z}}\right)$ in 1:1 $\mathrm{CS}_{2}:$ toluene- $d_{8}$

Figure S14 | Variable turning angle two-pulse $\left(\frac{\theta}{2}, \theta\right)$ Hahn echo data for 1 at $324 \mathrm{mT}$ in 1:1 $\mathrm{CS}_{2}:$ toluene- $d_{8}$ at $10 \mathrm{~K}$ and $9.3673 \mathrm{GHz}$

Figure S15 | Variable turning angle two-pulse $\left(\frac{\theta}{2}, \theta\right)$ Hahn echo data for $\mathbf{1}$ at $334 \mathrm{mT}$ in 1:1 $\mathrm{CS}_{2}:$ toluene- $d_{8}$ at $10 \mathrm{~K}$ and $9.3673 \mathrm{GHz}$

Figure S16 | EDFS EPR spectrum of 2 in frozen toluene solution at $20 \mathrm{~K}$ and $9.4985 \mathrm{GHz}$

Figure S17 | Variable temperature saturation recovery data for 2 at $330 \mathrm{mT}\left(\mathrm{Cu}^{2+} g_{\mathrm{x} / \mathrm{y}}\right)$ in toluene

Figure S18 | Variable temperature saturation recovery data for 2 at $347 \mathrm{mT}\left(\mathrm{Ti}^{3+} g_{\mathrm{y}}\right)$ in toluene

Figure S19 | Variable temperature Hahn echo data for 2 at $330 \mathrm{mT}\left(\mathrm{Cu}^{2+} \mathrm{g}_{\mathrm{x} / \mathrm{y}}\right)$ in toluene

Figure S20 | Variable temperature Hahn echo data for 2 at $347 \mathrm{mT}\left(\mathrm{Ti}^{3+} g_{\mathrm{y}}\right)$ in toluene 
Figure S21 | EDFS EPR spectrum of 2 in 1:1 $\mathrm{CS}_{2}$ :toluene- $d_{8}$ solution at $30 \mathrm{~K}$ and $9.4798 \mathrm{GHz}$

Figure S22 | Variable temperature saturation recovery data for 2 at $329 \mathrm{mT}\left(\mathrm{Cu}^{2+} g_{\mathrm{x} / \mathrm{y}}\right)$ in $1: 1 \quad \mathbf{S 5 7}$ $\mathrm{CS}_{2}$ :toluene- $d_{8}$

Figure S23 | Variable temperature saturation recovery data for 2 at $341 \mathrm{mT}\left(\mathrm{Ti}^{3+} g_{\mathrm{z}}\right)$ in $1: 1 \quad \mathbf{S 5 8}$ $\mathrm{CS}_{2}:$ toluene- $d_{8}$

Figure S24 | Variable temperature Hahn echo data for 2 at $329 \mathrm{mT}\left(\mathrm{Cu}^{2+} g_{\mathrm{x} / \mathrm{y}}\right)$ in 1:1 $\mathrm{CS}_{2}:$ toluene- $d_{8}$ S58

Figure S25 | Variable temperature Hahn echo data for 2 at $341 \mathrm{mT}\left(\mathrm{Ti}^{3+} g_{\mathrm{z}}\right)$ in 1:1 $\mathrm{CS}_{2}:$ toluene- $d_{8}$

Figure S26 | Variable turning angle two-pulse $\left(\frac{\theta}{2}, \theta\right)$ Hahn echo data for $\mathbf{2}$ at $328 \mathrm{mT}$ and 9.4906 $\mathrm{GHz}\left(\mathrm{Cu}^{2+} g_{\mathrm{x} / \mathrm{y}}\right)$ in $1: 1 \mathrm{CS}_{2}:$ toluene- $d_{8}$ at $10 \mathrm{~K}$

Figure S27 | Variable turning angle two-pulse $\left(\frac{\theta}{2}, \theta\right)$ Hahn echo data for 2 at $342 \mathrm{mT}$ and 9.4906 $\mathrm{GHz}\left(\mathrm{Ti}^{3+} g_{\mathrm{z}}\right)$ in 1:1 $\mathrm{CS}_{2}:$ toluene- $d_{8}$ at $10 \mathrm{~K}$

Figure S28 | EDFS EPR spectrum of 3 in frozen toluene solution at $80 \mathrm{~K}$ and $9.4990 \mathrm{GHz}$

Figure S29 | Variable temperature saturation recovery data for 3 at $329 \mathrm{mT}\left(\mathrm{Cu}^{2+} g_{x / y}\right)$ in toluene

Figure S30 | Variable temperature saturation recovery data for 3 at $347 \mathrm{mT}\left(\mathrm{Ti}^{3+} g_{\mathrm{y}}\right)$ in toluene

Figure S31 | Variable temperature Hahn echo data for 3 at $333 \mathrm{mT}\left(\mathrm{Cu}^{2+} g_{\mathrm{x} / \mathrm{y}}\right)$ in toluene

Figure S32 | Variable temperature Hahn echo data for 3 at $347 \mathrm{mT}\left(\mathrm{Ti}^{3+} g_{\mathrm{y}}\right)$ in toluene

Figure S33 | EDFS EPR spectrum of 3 in 1:1 $\mathrm{CS}_{2}$ :toluene- $d_{8}$ solution at $30 \mathrm{~K}$ and $9.5128 \mathrm{GHz}$

Figure S34 | Variable temperature saturation recovery data for 3 at $331 \mathrm{mT}\left(\mathrm{Cu}^{2+} g_{\mathrm{x} / \mathrm{y}}\right)$ in 1:1 $C S_{2}:$ toluene- $d_{8}$

Figure S35 | Variable temperature saturation recovery data for 3 at $342 \mathrm{mT}\left(\mathrm{Ti}^{3+} g_{\mathrm{z}}\right)$ in $1: 1$ $\mathrm{CS}_{2}:$ toluene- $d_{8}$

Figure S36 | Variable temperature two-pulse Hahn echo data for 3 at $331 \mathrm{mT}\left(\mathrm{Cu}^{2+} g_{x / y}\right)$ in 1:1 $\mathrm{CS}_{2}:$ toluene- $d_{8}$

Figure S37 | Variable temperature two-pulse Hahn echo data for 3 at $342 \mathrm{mT}\left(\mathrm{Ti}^{3+} g_{\mathrm{z}}\right)$ in 1:1 $\mathrm{CS}_{2}$ :toluene- $d_{8}$

Figure S38 | Variable turning angle two-pulse $\left(\frac{\theta}{2}, \theta\right)$ Hahn echo data for 3 at $328 \mathrm{mT}$ and $\left(\mathrm{Cu}^{2+} g_{\mathrm{x} / \mathrm{y}}\right)$ in $1: 1 \mathrm{CS}_{2}:$ toluene- $d_{8}$ at $10 \mathrm{~K}$

Figure S39 | Variable turning angle two-pulse $\left(\frac{\theta}{2}, \theta\right)$ Hahn echo data for 3 at $342 \mathrm{mT}$ and 9.4907 S66 $\mathrm{GHz}\left(\mathrm{Ti}^{3+} g_{z}\right)$ in 1:1 $\mathrm{CS}_{2}:$ toluene- $d_{8}$ at $10 \mathrm{~K}$ 
Figure S40 | EDFS EPR spectrum of 2a in frozen toluene solution at $20 \mathrm{~K}$ and $9.5090 \mathrm{GHz}$

Figure S41 | Variable temperature saturation recovery data for $\mathbf{2 a}$ at $334 \mathrm{mT}\left(\mathrm{Cu}^{2+} g_{x / y}\right)$ in toluene

Figure S42 | Variable temperature Hahn echo data for $\mathbf{2 a}$ at $334 \mathrm{mT}\left(\mathrm{Cu}^{2+} g_{\mathrm{x} / \mathrm{y}}\right)$ in toluene

Figure S43 | EDFS EPR spectrum of 2a in 1:1 $\mathrm{CS}_{2}:$ toluene- $d_{8}$ at $30 \mathrm{~K}$ and $9.4544 \mathrm{GHz}$

Figure S44 | Variable temperature saturation recovery data for $\mathbf{2 a}$ at $334 \mathrm{mT}\left(\mathrm{Cu}^{2+} g_{\mathrm{x} / \mathrm{y}}\right)$ in 1:1 $\mathrm{CS}_{2}:$ toluene- $d_{8}$

Figure S45 | Variable temperature two-pulse Hahn echo data for 2a at $334 \mathrm{mT}\left(\mathrm{Cu}^{2+} g_{\mathrm{x} / \mathrm{y}}\right)$ in 1:1 $\mathrm{CS}_{2}$ :toluene- $d_{8}$

Figure S46 | Variable turning angle two-pulse $\left(\frac{\theta}{2}, \theta\right)$ Hahn echo data for $\mathbf{2 a}$ at $323 \mathrm{mT}$ and 9.4908 S70 $\mathrm{GHz}\left(\mathrm{Cu}^{2+} g_{\mathrm{x} / \mathrm{y}}\right)$ in 1:1 $\mathrm{CS}_{2}:$ toluene- $d_{8}$ at $10 \mathrm{~K}$

Figure S47 | EDFS EPR spectrum of $\mathbf{2 b}$ in toluene at $20 \mathrm{~K}$ and $9.5006 \mathrm{GHz}$

Figure S48 | Variable temperature saturation recovery data for $\mathbf{2 b}$ at $348 \mathrm{mT}\left(\mathrm{Ti}^{3+} g_{z}\right)$ in toluene

Figure S49 | Variable temperature two-pulse Hahn echo data for $\mathbf{2 b}$ at $348 \mathrm{mT}\left(\mathrm{Ti}^{3+} g_{z}\right)$ in toluene

Figure S50 | EDFS EPR spectrum of $\mathbf{2 b}$ in 1:1 $\mathrm{CS}_{2}:$ toluene- $_{8}$ at $30 \mathrm{~K}$ and $9.4892 \mathrm{GHz}$

Figure S51 | Variable temperature saturation recovery data for $\mathbf{2 b}$ at $342 \mathrm{mT}$ and $9.4892 \mathrm{GHz}\left(\mathrm{Ti}^{3+} g_{z}\right)$ in 1:1 $\mathrm{CS}_{2}:$ toluene- $d_{8}$

Figure S52 | Variable temperature two-pulse Hahn echo data for $\mathbf{2 b}$ at $342 \mathrm{mT}$ and $9.4892 \mathrm{GHz}$ $\left(\mathrm{Ti}^{3+} g_{z}\right)$ in $1: 1 \mathrm{CS}_{2}:$ toluene- $d_{8}$

Figure S53 | Variable turning angle two-pulse $\left(\frac{\theta}{2}, \theta\right)$ Hahn echo data for $\mathbf{2 b}$ at $342 \mathrm{mT}$ and 9.4892 $\mathrm{GHz}\left(\mathrm{Ti}^{3+} g_{z}\right)$ in 1:1 $\mathrm{CS}_{2}:$ toluene- $d_{8}$ at $10 \mathrm{~K}$.

Figures S54 | MALDI-TOF MS of 1

Figures S55 | MALDI-TOF MS of $\mathbf{1 b}$

Figures S56 | MALDI-TOF MS of 2

Figures S57 | MALDI-TOF MS of 2b

Figures S58 | MALDI-TOF MS of 3

Figures S59 | MALDI-TOF MS of $\mathbf{3 b}$

Figure $\mathbf{S 6 0} \mid{ }^{1} \mathrm{H}$ NMR $\left(500 \mathrm{MHz}, \mathrm{CDCl}_{3}\right)$ of $\mathbf{S 2}$

Figure $\mathbf{S 6 1} \mid{ }^{13} \mathrm{C}\left\{{ }^{1} \mathrm{H}\right\} \mathrm{NMR}\left(126 \mathrm{MHz}, \mathrm{CDCl}_{3}\right)$ of $\mathbf{S 2}$

Figure $\mathbf{S 6 2} \mid{ }^{1} \mathrm{H} \mathrm{NMR}\left(500 \mathrm{MHz}, \mathrm{CDCl}_{3}\right)$ of $\mathbf{S 3}$ 
Figure $\mathbf{S 6 3} \mid{ }^{13} \mathrm{C}\left\{{ }^{1} \mathrm{H}\right\}$ NMR $\left(126 \mathrm{MHz}, \mathrm{CDCl}_{3}\right)$ of $\mathbf{S 3}$

Figure S64 $\mid{ }^{1} \mathrm{H} \mathrm{NMR}\left(500 \mathrm{MHz}, \mathrm{CDCl}_{3}\right)$ of $\mathbf{1 a}$

Figure $\mathbf{S 6 5} \mid{ }^{1} \mathrm{H}$ NMR $\left(500 \mathrm{MHz}, \mathrm{CDCl}_{3}\right)$ of $\mathbf{2 a}$

Figure $\mathbf{S 6 6} \mid{ }^{13} \mathrm{C}\left\{{ }^{1} \mathrm{H}\right\} \mathrm{NMR}\left(126 \mathrm{MHz}, \mathrm{CDCl}_{3}\right)$ of $\mathbf{2 a}$

Figure S67 | ${ }^{1} \mathrm{H}$ NMR $\left(500 \mathrm{MHz}, \mathrm{CDCl}_{3}\right)$ of 3a

Figure $\mathbf{S 6 8} \mid{ }^{13} \mathrm{C}\left\{{ }^{1} \mathrm{H}\right\} \mathrm{NMR}\left(126 \mathrm{MHz}, \mathrm{CDCl}_{3}\right)$ of 3a

Figure S69 | ${ }^{1} \mathrm{H}$ NMR (500 MHz, $\left.\mathrm{CDCl}_{3}\right)$ of $\mathbf{1 - N i}$

Figure S70 $\mid{ }^{13} \mathrm{C}\left\{{ }^{1} \mathrm{H}\right\}$ NMR $\left(126 \mathrm{MHz}, \mathrm{CDCl}_{3}\right)$ of $\mathbf{1 - N i}$

Figure S71 | ${ }^{1} \mathrm{H}$ NMR (500 MHz, $\left.\mathrm{CDCl}_{3}\right)$ of $\mathbf{2 - N i}$

Figure S72 $\mid{ }^{13} \mathrm{C}\left\{{ }^{1} \mathrm{H}\right\} \mathrm{NMR}\left(126 \mathrm{MHz}, \mathrm{CDCl}_{3}\right)$ of $\mathbf{2}-\mathbf{N i}$

Figure $\mathbf{S 7 3} \mid{ }^{1} \mathrm{H}$ NMR (500 MHz, $\left.\mathrm{CDCl}_{3}\right)$ of $\mathbf{3 - N i}$

Figure S74 $\mid{ }^{13} \mathrm{C}\left\{{ }^{1} \mathrm{H}\right\}$ NMR $\left(126 \mathrm{MHz}, \mathrm{CDCl}_{3}\right)$ of 3-Ni

Figure $\mathbf{S 7 5} \mid{ }^{1} \mathrm{H}$ NMR $\left(600 \mathrm{MHz}, \mathrm{C}_{6} \mathrm{D}_{6}\right)$ of $\mathbf{1}$

S85

Figure S76 | ${ }^{1} \mathrm{H}$ NMR (600 MHz, protio-THF) of 1

Figure S77 ${ }^{1} \mathrm{H}$ NMR $\left(600 \mathrm{MHz}, \mathrm{C}_{6} \mathrm{D}_{6}\right)$ of $\mathbf{1 b}$

Figure S78 $\mid{ }^{1} \mathrm{H}$ NMR (600 MHz, $\left.\mathrm{C}_{6} \mathrm{D}_{6}\right)$ of 2

Figure S79 | ${ }^{1} \mathrm{H}$ NMR $\left(600 \mathrm{MHz}, \mathrm{C}_{6} \mathrm{D}_{6}\right)$ of $\mathbf{2 b}$

Figure S80 | ${ }^{1} \mathrm{H}$ NMR (600 MHz, $\left.\mathrm{C}_{6} \mathrm{D}_{6}\right)$ of 3 .

Figure S81 | ${ }^{1} \mathrm{H}$ NMR (600 MHz, $\left.\mathrm{C}_{6} \mathrm{D}_{6}\right)$ of $\mathbf{3 b}$ 


\section{Materials and General Methods}

Unless otherwise stated, all manipulations of air and/or moisture sensitive compounds were carried out in oven-dried glassware, under an atmosphere of $\mathrm{N}_{2}$. All solvents and reagents were purchased from Alfa Aesar, Spectrum Chemicals, Acros Organics, TCI America, Matrix Scientific, Strem Chemicals, and Sigma-Aldrich and were used as received unless otherwise noted. Organic solvents were dried with a commercial solvent system from Pure Process Technology and stored over 3 or $4 \AA$ molecular sieves prior to use unless otherwise stated. 2,6-Lutidine was dried $24 \mathrm{~h}$ over $10 \% \mathrm{w} / \mathrm{v} \mathrm{CaH}_{2}$ and distilled under $\mathrm{N}_{2}$ onto activated $4 \AA$ molecular sieves. Triethylamine was sequentially dried for $24 \mathrm{~h}$ twice with $15 \% \mathrm{w} / \mathrm{v} 4 \AA$ sieves and subjected to three freeze-pump-thaw cycles prior to use. Carbon disulfide was washed with aqueous $\mathrm{KMnO}_{4}$, dried $24 \mathrm{~h}$ over $10 \% \mathrm{w} / \mathrm{v} \mathrm{CaH}_{2}$, subjected to three freeze-pump-thaw cycles, and vacuum transferred into a foil-covered storage flask protected from air and light. For air- and moisture-sensitive NMR/EPR, deuterated solvents were stirred $24 \mathrm{~h}$ over $10 \% \mathrm{w} / \mathrm{v}$ drying agent $\left(\mathrm{C}_{6} \mathrm{D}_{6}\right.$ and toluene- $d_{8}, \mathrm{CaH}_{2}$; $\mathrm{CDCl}_{3}, \mathrm{P}_{2} \mathrm{O}_{5}$ ) subjected to three freeze-pump-thaw cycles, and vacuum transferred onto activated molecular sieves. Flash column chromatography was performed on SiliCycle silica gel (particle size 40-63 $\mu \mathrm{m}$ ) or on neutral alumina (Sigma Aldrich, hydrated to Brockman activity III). Thin layer chromatography was performed using SiliCycle silica gel $60 \AA$ F-254 precoated plates $(0.25 \mathrm{~mm}$ thick $)$ and visualized by UV absorption or iodine stain. Methyl 4-(10,15,20-triphenylporphyrin-5-yl)benzoate, ${ }^{1}$ 4-(10,15,20triphenylporphyrin-5-yl)aniline, ${ }^{2}$ methyl 4-((4-ethynylphenyl)ethynyl)benzoate, ${ }^{3}$ and $\left[\mathrm{Cp}_{2} \mathrm{TiCl}_{2}{ }^{4}\right.$ were prepared according to literature procedures.

\section{Synthetic Procedures}

5-(4-iodophenyl)-10,15,20-triphenylporphyrin (S1) A $50 \mathrm{~mL}$ round bottom flask was charged in air with 4-(10,15,20-triphenylporphyrin-5-yl)aniline ${ }^{2}(314 \mathrm{mg}, 0.5 \mathrm{mmol})$ in trifluoroacetic acid $(5 \mathrm{~mL})$ at $0{ }^{\circ} \mathrm{C}$. To the homogenous green solution $\mathrm{NaNO}_{2}\left(69 \mathrm{mg}, 1 \mathrm{mmol}, 2\right.$ equiv.) in $\mathrm{H}_{2} \mathrm{O}(0.5 \mathrm{~mL})$ was added dropwise over 1 minute. The brown reaction mixture was stirred at $0{ }^{\circ} \mathrm{C}$ for 10 minutes, and then $\mathrm{KI}(0.86 \mathrm{~g}, 5.2$ mmol, 10.4 equiv.) in $\mathrm{H}_{2} \mathrm{O}(1 \mathrm{~mL})$ was added all at once causing gas evolution. After the frothing had subsided, the brown reaction mixture was stirred at $0{ }^{\circ} \mathrm{C}$ for $1 \mathrm{~h}$ and then poured into $\mathrm{H}_{2} \mathrm{O}(100 \mathrm{~mL})$. The mixture was neutralized with concentrated aqueous $\mathrm{NH}_{3}$ to $\mathrm{pH} 8$, extracted once with $\mathrm{CHCl}_{3}(50 \mathrm{~mL})$, and twice with DCM (25 mL). The organic extracts were combined, washed with saturated aqueous $\mathrm{Na}_{2} \mathrm{~S}_{2} \mathrm{O}_{3}$ $(20 \mathrm{~mL})$, dried with $\mathrm{Na}_{2} \mathrm{SO}_{4}$, and concentrated on a rotary evaporator. Column chromatography $\left(\mathrm{SiO}_{2}\right.$, $\left.\mathrm{CHCl}_{3}\right)$ collecting the first purple band gave $\mathbf{S 1}(226 \mathrm{mg}, 0.3 \mathrm{mmol}, 61 \%)$ as a purple solid. ${ }^{1} \mathrm{H}$ NMR (500 $\left.\mathrm{MHz} \mathrm{CDCl}_{3}\right) \delta=8.84(\mathrm{~m}, 8 \mathrm{H}), 8.21(\mathrm{~d}, J=7.1 \mathrm{~Hz}, 6 \mathrm{H}), 8.10(\mathrm{~d}, J=7.9 \mathrm{~Hz}, 2 \mathrm{H}), 7.95(\mathrm{~d}, J=8.0 \mathrm{~Hz}, 2 \mathrm{H})$, $7.76(\mathrm{~m}, 9 \mathrm{H}),-2.80(\mathrm{~s}, 2 \mathrm{H})$ ppm. MS (ESI): m/z: $\left[\mathrm{C}_{44} \mathrm{H}_{29} \mathrm{IN}_{4}+\mathrm{H}\right]^{+}$calcd. 741.14; found 741.11 . Spectroscopic data are consistent with a previous report. ${ }^{5}$ 
methyl 4-((4-(10,15,20-triphenylporphyrin-5-yl)phenyl)ethynyl)benzoate (S2) In an $\mathrm{N}_{2}$-filled glove box, a $20 \mathrm{~mL}$ vial was charged with $\mathbf{S 1}$ (150 mg, $0.20 \mathrm{mmol}$ ), methyl 4-ethynylbenzoate (42 mg, $0.26 \mathrm{mmol}$, 1.3 equiv.), and triethylamine $(3 \mathrm{~mL})$ in dry toluene $(12 \mathrm{~mL})$. In a separate vial, $\mathrm{Pd}_{2} \mathrm{dba}_{3}(14 \mathrm{mg}, 0.015$ mmol, 0.15 equiv. $\mathrm{Pd}$ ) and $\mathrm{Ph}_{3} \mathrm{As}$ (44 mg, $0.14 \mathrm{mmol}, 0.7$ equiv.) were suspended in dry toluene $(3 \mathrm{~mL})$ and stirred vigorously until the mixture had turned a deep green. The Pd mixture was added to the solution of S1, capped, and heated at $35^{\circ} \mathrm{C}$ for $2.5 \mathrm{~h}$. When $\mathbf{S 1}$ was consumed (TLC, $\mathrm{SiO}_{2}, \mathrm{DCM}$ ), the reaction mixture was removed from the glovebox and concentrated on a rotary evaporator to a solid. Chromatography $\left(\mathrm{SiO}_{2}\right.$, wet loaded as a toluene solution, eluted $30 \%$ to $50 \%$ DCM in hexanes) followed by recrystallization by layering a concentrated solution in $\mathrm{CHCl}_{3}(10 \mathrm{~mL})$ with $\mathrm{MeOH}(30 \mathrm{~mL})$ gave $\mathbf{S 2}$ (101 mg, $0.13 \mathrm{mmol}, 65 \%)$ as a purple crystalline solid. ${ }^{1} \mathrm{H}$ NMR $\left(500 \mathrm{MHz}, \mathrm{CDCl}_{3}\right) \delta=8.90-8.81(\mathrm{~m}$, $8 \mathrm{H}), 8.23(\mathrm{t}, J=7.7 \mathrm{~Hz}, 8 \mathrm{H}), 8.11(\mathrm{~d}, J=8.2 \mathrm{~Hz}, 2 \mathrm{H}), 7.95(\mathrm{~d}, J=7.9 \mathrm{~Hz}, 2 \mathrm{H}), 7.83-7.70(\mathrm{~m}, 12 \mathrm{H}), 3.98$ $(\mathrm{s}, 3 \mathrm{H}),-2.76(\mathrm{~s}, 2 \mathrm{H}) \mathrm{ppm} .{ }^{13} \mathrm{C}\left\{{ }^{1} \mathrm{H}\right\} \mathrm{NMR}\left(126 \mathrm{MHz}, \mathrm{CDCl}_{3}\right) \delta=166.8,143.0,142.2,134.8,134.7,131.8$, $130.2,129.8,129.8,128.2,127.9,126.9,126.9,122.3,120.6,120.5,119.1,92.5,89.9,52.5$ ppm. HRMS (ESI): $\mathrm{m} / \mathrm{z}\left[\mathrm{C}_{54} \mathrm{H}_{36} \mathrm{~N}_{4} \mathrm{O}_{2}+\mathrm{H}\right]^{+}$calcd. 773.2911; found 773.2908.

methyl 4-((4-((4-(10,15,20-triphenylporphyrin-5-yl)phenyl)ethynyl)phenyl)ethynyl)benzoate (S3) In an $\mathrm{N}_{2}$-filled glove box, a $20 \mathrm{~mL}$ vial was charged with $\mathbf{S 1}$ (73 mg, $\left.0.1 \mathrm{mmol}\right)$, methyl 4-((4ethynylphenyl)ethynyl)benzoate (30 mg, $0.12 \mathrm{mmol}, 1.2$ equiv.), and triethylamine ( $3 \mathrm{~mL}$ ) in dry toluene (15 mL). In a separate vial, $\mathrm{Pd}_{2} \mathrm{dba}_{3}\left(13 \mathrm{mg}, 0.014 \mathrm{mmol}, 0.28\right.$ equiv. $\mathrm{Pd}$ ) and $\mathrm{Ph}_{3} \mathrm{As}$ (45 mg, $0.15 \mathrm{mmol}$, 1.5 equiv.) were suspended in dry toluene $(3 \mathrm{~mL})$ and stirred vigorously until the mixture had turned a deep green. The Pd mixture was added to the solution of $\mathbf{S 1}$, capped, and heated at $35^{\circ} \mathrm{C}$ for $2.5 \mathrm{~h}$. When $\mathbf{S 1}$ was consumed (TLC, $\mathrm{SiO}_{2}, \mathrm{DCM}$ ), the reaction mixture was removed from the glovebox and concentrated on a rotary evaporator to a solid. Chromatography $\left(\mathrm{SiO}_{2}\right.$, toluene) followed by recrystallization by layering a concentrated solution in $\mathrm{CHCl}_{3}(10 \mathrm{~mL})$ with $\mathrm{MeOH}(10 \mathrm{~mL})$ gave $\mathbf{S 3}(72 \mathrm{mg}, 0.082 \mathrm{mmol}, 82 \%)$ as a purple crystalline solid. ${ }^{1} \mathrm{H}$ NMR $\left(500 \mathrm{MHz}, \mathrm{CDCl}_{3}\right) \delta=8.87(\mathrm{~m}, 8 \mathrm{H}), 8.26-8.19(\mathrm{~m}, 8 \mathrm{H}), 8.06(\mathrm{~d}, J=$ $8.3 \mathrm{~Hz}, 2 \mathrm{H}), 7.94(\mathrm{~d}, J=8.0 \mathrm{~Hz}, 2 \mathrm{H}), 7.83-7.72(\mathrm{~m}, 9 \mathrm{H}), 7.68(\mathrm{~d}, J=8.2 \mathrm{~Hz}, 2 \mathrm{H}), 7.66-7.57$ (m, 4H), $3.95(\mathrm{~s}, 3 \mathrm{H}),-2.76(\mathrm{~s}, 2 \mathrm{H}) \mathrm{ppm} .{ }^{13} \mathrm{C}\left\{{ }^{1} \mathrm{H}\right\} \mathrm{NMR}\left(126 \mathrm{MHz}, \mathrm{CDCl}_{3}\right) \delta=166.7,142.7,142.2,134.8,134.7$, $131.9,131.9,131.7,130.2,129.8,129.7,127.9,127.9,126.86,126.85,123.8,122.8,122.6,120.6,120.5$, 119.2, 92.2, 91.7, 90.7, 90.3, 52.4 ppm. HRMS (ESI): m/z $\left[\mathrm{C}_{62} \mathrm{H}_{40} \mathrm{~N}_{4} \mathrm{O}_{2}+\mathrm{H}\right]^{+}$calcd. 873.3224; found 873.3219 .

[methyl 4-(10,15,20-triphenylporphyrin-5-yl- $\left.\kappa^{4} \mathbf{N}^{21,22,23,24}\right)$ benzoato(2-)] copper (1a): A round-bottomed flask was charged in air with methyl 4-(10,15,20-triphenylporphyrin-5-yl)benzoate ${ }^{1}$ (29 $\left.\mathrm{mg}, 0.043 \mathrm{mmol}\right)$ in $\mathrm{DCM}(80 \mathrm{~mL})$. A saturated solution of $\mathrm{Cu}(\mathrm{OAc})_{2} \cdot \mathrm{H}_{2} \mathrm{O}(84 \mathrm{mg}, 0.42 \mathrm{mmol}, 10$ equiv. $)$ in $\mathrm{MeOH}(20 \mathrm{~mL})$ 
was added and the reaction mixture was stirred for $16 \mathrm{~h}$ at $24^{\circ} \mathrm{C}$ at which point the reaction was complete

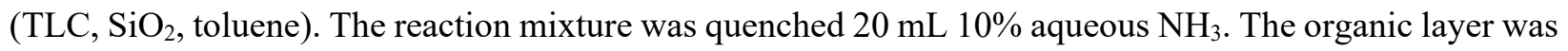
separated, washed with $2 \times 20 \mathrm{~mL} 10 \%$ aqueous $\mathrm{NH}_{3}$ (until the washes were colorless) and water $(20 \mathrm{~mL})$, dried over $\mathrm{K}_{2} \mathrm{CO}_{3}$, and concentrated on a rotary evaporator to a solid. Recrystallization by layering a saturated DCM solution $(\sim 1 \mathrm{~mL})$ with $\mathrm{MeOH}(\sim 10 \mathrm{~mL})$ gave gave 1a $(31.0 \mathrm{mg}, 0.042 \mathrm{mmol}, 98 \%)$ as a reddish-purple solid. ${ }^{1} \mathrm{H}$ NMR $\left(500 \mathrm{MHz}, \mathrm{CDCl}_{3}\right) \delta=8.18$ (br s, FWHM $\left.=24 \mathrm{~Hz}, \sim 2 \mathrm{H}\right), 7.65$ (br s, FWHM $=16 \mathrm{~Hz}, \sim 3 \mathrm{H}), 7.63$ (br s, FWHM = $140 \mathrm{~Hz}, \sim 7 \mathrm{H}), 7.50$ (br s, FWHM=24 Hz, $\sim 6 \mathrm{H}), 4.04(\mathrm{~s}, \mathrm{FWHM}=$ $3.2 \mathrm{~Hz}, 3 \mathrm{H}) \mathrm{ppm}$. HRMS (ESI): $\mathrm{m} / \mathrm{z}\left[\mathrm{C}_{46} \mathrm{H}_{30} \mathrm{CuN}_{4} \mathrm{O}_{2}\right]^{+}$calcd. 733.1659; found 733.1651.

\section{[methyl 4-((4-(10,15,20-triphenylporphyrin-5-yl- $\left.\kappa^{4} \mathrm{~N}^{21,22,23,24}\right)$ phenyl)ethynyl)benzoato(2-)]copper} (2a): A round-bottomed flask was charged in air with $\mathbf{S 2}(78 \mathrm{mg}, 0.10 \mathrm{mmol})$ in DCM (150 mL). A saturated solution of $\mathrm{Cu}(\mathrm{OAc})_{2} \cdot \mathrm{H}_{2} \mathrm{O}(200 \mathrm{mg}, 1 \mathrm{mmol}, 10$ equiv. $)$ in $\mathrm{MeOH}(50 \mathrm{~mL})$ was added and the reaction mixture was stirred for $16 \mathrm{~h}$ at $24^{\circ} \mathrm{C}$ at which point the reaction was complete (TLC, $\mathrm{SiO}_{2}$, toluene). The

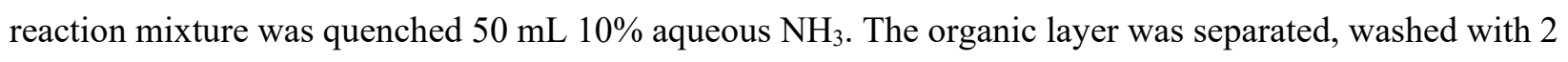

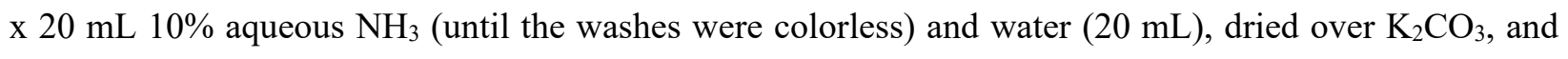
concentrated on a rotary evaporator to a solid. Recrystallization from a concentrated DCM solution $(\sim 4$ $\mathrm{mL}$ ) layered with $\mathrm{MeOH}(\sim 40 \mathrm{~mL})$ gave 2a $(84 \mathrm{mg}, 0.10 \mathrm{mmol}, 99 \%)$ as a reddish-purple solid. ${ }^{1} \mathrm{H}$ NMR $\left(500 \mathrm{MHz}, \mathrm{CDCl}_{3}\right) \delta=8.08(\mathrm{~d}, J=7.3 \mathrm{~Hz}, 2 \mathrm{H}), 7.68(\mathrm{~d}, J=7.5 \mathrm{~Hz}, \sim 1 \mathrm{H}), 7.66(\mathrm{br} \mathrm{s}, \mathrm{FWHM}=40 \mathrm{~Hz}$, $\sim 8 \mathrm{H}$ ), 7.51 (br s, FWHM = 34 Hz, $6 \mathrm{H}), 3.96(\mathrm{~s}, \mathrm{FWHM}=1.7 \mathrm{~Hz}, 3 \mathrm{H}) \mathrm{ppm} .{ }^{13} \mathrm{C}\left\{{ }^{1} \mathrm{H}\right\} \mathrm{NMR}(126 \mathrm{MHz}$, $\left.\mathrm{CDCl}_{3}\right) \delta=166.7,136.2($ br s, FWHM $=49 \mathrm{~Hz}), 131.7,129.9($ br s, FWHM = 6.2 Hz), 129.8, 129.7, 128.2, 127.3 (br s, FWHM = 4.4 Hz), 126.6 (br s, FWHM = 5.3 Hz), 121.6, 92.6, 89.6, 52.5 ppm. HRMS (ESI): $\mathrm{m} / \mathrm{z}\left[\mathrm{C}_{54} \mathrm{H}_{34} \mathrm{CuN}_{4} \mathrm{O}_{2}\right]^{+}$calcd. 833.1972; found 833.1965.

\section{[methyl 4-((4-((4-(10,15,20-triphenylporphyrin-5-yl- $\left.\kappa^{4} \mathbf{N}^{21,22,23,24}\right)$ phenyl)ethynyl)phenyl)ethynyl)} benzoato(2-)]copper (3a): A round-bottomed flask was charged in air with $\mathbf{S 3}$ (43 $\mathrm{mg}, 0.050 \mathrm{mmol})$ in DCM $(90 \mathrm{~mL})$. A saturated solution of $\mathrm{Cu}(\mathrm{OAc})_{2} \bullet \mathrm{H}_{2} \mathrm{O}(100 \mathrm{mg}, 0.5 \mathrm{mmol}, 10$ equiv. $)$ in $\mathrm{MeOH}(25 \mathrm{~mL})$ was added and the reaction mixture was stirred for $16 \mathrm{~h}$ at $24^{\circ} \mathrm{C}$ at which point the reaction was complete (TLC, $\mathrm{SiO}_{2}$, toluene). The reaction mixture was quenched $50 \mathrm{~mL} 10 \%$ aqueous $\mathrm{NH}_{3}$. The organic layer was separated, washed with $2 \times 20 \mathrm{~mL} \mathrm{10 \%}$ aqueous $\mathrm{NH}_{3}$ (until the washes were colorless) and water $(20 \mathrm{~mL})$, dried over $\mathrm{K}_{2} \mathrm{CO}_{3}$, and concentrated on a rotary evaporator to a solid. Recrystallization from a concentrated DCM solution ( $\sim 20 \mathrm{~mL})$ layered with $\mathrm{MeOH}(\sim 20 \mathrm{~mL})$ gave 3a $(46 \mathrm{mg}, 0.050 \mathrm{mmol}, 99 \%)$ as a reddishpurple solid. ${ }^{1} \mathrm{H}$ NMR $\left(500 \mathrm{MHz}, \mathrm{CDCl}_{3}\right) \delta=8.05$ (d, $\left.J=7.9 \mathrm{~Hz}, 1 \mathrm{H}\right), 7.66$ (br s, FWHM $=42 \mathrm{~Hz}, \sim 8 \mathrm{H}$ ), 7.61 (d, $J=7.2 \mathrm{~Hz}, \sim 4 \mathrm{H}), 7.57$ (d, $J=7.4 \mathrm{~Hz}, \sim 2 \mathrm{H}), 7.50$ (br s, FWHM = 34 Hz, 7 H), 3.94 (s, FWHM= $1.5 \mathrm{~Hz}, 3 \mathrm{H}) \mathrm{ppm} .{ }^{13} \mathrm{C}\left\{{ }^{1} \mathrm{H}\right\} \mathrm{NMR}\left(126 \mathrm{MHz}, \mathrm{CDCl}_{3}\right) \delta=166.7,136.1$ (br s, FWHM $\left.=50 \mathrm{~Hz}\right), 131.9,131.8$, 
131.7, 129.8 (br s, FWHM = 8.3 Hz), 129.78, 129.71, 127.9, 127.3 (br s, FWHM = 5.3 Hz), 126.6 (br s,

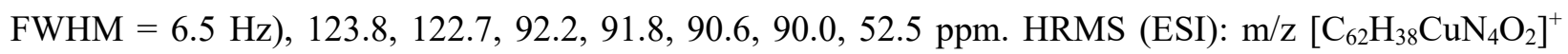
calcd. 933.2285; found 933.2289.

[methyl 4-(10,15,20-triphenylporphyrin-5-yl- $\left.\kappa^{4} \mathrm{~N}^{21,22,23,24}\right)$ benzoato(2-)]nickel (1-Ni): A roundbottomed flask equipped with a reflux condenser was charged in air with methyl 4-(10,15,20triphenylporphyrin-5-yl) benzoate $^{1}(33.6 \mathrm{mg}, 0.05 \mathrm{mmol})$ and $\mathrm{Ni}(\mathrm{acac})_{2}(128 \mathrm{mg}, 0.5 \mathrm{mmol}, 10$ equiv.) in toluene $(50 \mathrm{~mL})$. The purple reaction mixture was heated to reflux in a $120^{\circ} \mathrm{C}$ bath and stirred for $16 \mathrm{~h}$ at which point the reaction was complete ( $\mathrm{TLC}, \mathrm{SiO}_{2}$, toluene). The resulting red reaction mixture was concentrated on a rotary evaporator to a solid. The residue was extracted with DCM $(\sim 60 \mathrm{~mL})$ and filtered through a $1 \mathrm{~cm}$ pad of $\mathrm{SiO}_{2}$ with excess DCM and evaporated. Recrystallization from a concentrated solution in DCM ( $5 \mathrm{~mL})$ layered with $\mathrm{MeOH}(15 \mathrm{~mL})$ gave 1-Ni $(30.9 \mathrm{mg}, 0.042 \mathrm{mmol}, 85 \%)$ as a red solid. ${ }^{1} \mathrm{H}$ NMR $\left(500 \mathrm{MHz}, \mathrm{CDCl}_{3}\right) \delta=8.76(\mathrm{~d}, J=5.0 \mathrm{~Hz}, 2 \mathrm{H}), 8.75(\mathrm{~s}, 4 \mathrm{H}), 8.68(\mathrm{~d}, J=4.9 \mathrm{~Hz}, 2 \mathrm{H}), 8.36$ $(\mathrm{d}, J=8.3 \mathrm{~Hz}, 2 \mathrm{H}), 8.10(\mathrm{~d}, J=8.3 \mathrm{~Hz}, 2 \mathrm{H}), 8.03-7.99(\mathrm{~m}, 6 \mathrm{H}), 7.74-7.64(\mathrm{~m}, 9 \mathrm{H}), 4.08(\mathrm{~s}, 3 \mathrm{H}) .{ }^{13} \mathrm{C}\left\{{ }^{1} \mathrm{H}\right\}$ NMR $\left(126 \mathrm{MHz}, \mathrm{CDCl}_{3}\right) \delta=167.4,146.0,143.0,142.9,142.8,142.2,141.0,140.9,133.9,133.85,133.84$, $132.7,132.51,132.46,131.8,129.8,128.2,127.96,127.95,127.1,127.0,119.5,119.3,117.7,52.5$ ppm. MS (MALDI-TOF): m/z [C $\left.\mathrm{C}_{46} \mathrm{H}_{30} \mathrm{~N}_{4} \mathrm{NiO}_{2}\right]^{+}$calcd. 728.17; found 728.14.

\section{[methyl 4-((4-(10,15,20-triphenylporphyrin-5-yl- $\left.\kappa^{4} \mathrm{~N}^{21,22,23,24}\right)$ phenyl)ethynyl)benzoato(2-)]nickel}

(2-Ni): A round-bottomed flask equipped with a reflux condenser was charged in air with $\mathbf{S 2}(26.0 \mathrm{mg}$, $0.034 \mathrm{mmol})$ and $\mathrm{Ni}(\mathrm{acac})_{2}(91 \mathrm{mg}, 0.35 \mathrm{mmol}, 10$ equiv. $)$ in toluene $(50 \mathrm{~mL})$. The purple reaction mixture was heated to reflux in a $120^{\circ} \mathrm{C}$ bath and stirred for $16 \mathrm{~h}$ at which point the reaction was complete (TLC, $\mathrm{SiO}_{2}$, toluene). The resulting red reaction mixture was concentrated on a rotary evaporator to a solid. The residue was extracted with $\mathrm{DCM}(\sim 60 \mathrm{~mL})$ and filtered through a $1 \mathrm{~cm}$ pad of $\mathrm{SiO}_{2}$ with excess $\mathrm{DCM}$ and evaporated. Recrystallization from a concentrated solution in DCM $(5 \mathrm{~mL})$ layered with $\mathrm{MeOH}(15 \mathrm{~mL})$ gave 2-Ni (24.0 mg, $0.029 \mathrm{mmol}, 86 \%)$ as a red solid. ${ }^{1} \mathrm{H} \mathrm{NMR}\left(500 \mathrm{MHz}, \mathrm{CDCl}_{3}\right) \delta=8.78-8.73(\mathrm{~m}, 8 \mathrm{H})$, $8.10(\mathrm{~d}, J=8.3 \mathrm{~Hz}, 2 \mathrm{H}), 8.05-7.99(\mathrm{~m}, 8 \mathrm{H}), 7.87(\mathrm{~d}, J=8.0 \mathrm{~Hz}, 2 \mathrm{H}), 7.74-7.65(\mathrm{~m}, 11 \mathrm{H}), 3.97(\mathrm{~s}, 3 \mathrm{H})$ ppm. ${ }^{13} \mathrm{C}\left\{{ }^{1} \mathrm{H}\right\} \mathrm{NMR}\left(126 \mathrm{MHz}, \mathrm{CDCl}_{3}\right) \delta=166.8,142.92,142.90,142.8,142.4,141.7,141.0,134.0,133.9$, $132.6,132.5,132.4,132.0,131.8,131.6,130.4,129.8,129.7,128.1,128.0,127.1,122.4,119.4,119.3$, 118.1, 92.4, 89.8, 52.4 ppm. MS (MALDI-TOF): $\mathrm{m} / \mathrm{z}\left[\mathrm{C}_{54} \mathrm{H}_{34} \mathrm{~N}_{4} \mathrm{NiO}_{2}\right]^{+}$calcd. 828.20; found 828.20.

[methyl 4-((4-((4-(10,15,20-triphenylporphyrin-5-yl- $\left.\kappa^{4} \mathbf{N}^{21,22,23,24}\right)$ phenyl)ethynyl)phenyl)ethynyl) benzoato(2-)]nickel (3-Ni): A round-bottomed flask equipped with a reflux condenser was charged in air with $\mathbf{S 3}(26.7 \mathrm{mg}, 0.031 \mathrm{mmol})$ and $\mathrm{Ni}(\mathrm{acac})_{2}$ in toluene $(50 \mathrm{~mL})$. The purple reaction mixture was heated 
to reflux in a $120^{\circ} \mathrm{C}$ bath and stirred for $16 \mathrm{~h}$ at which point the reaction was complete (TLC, $\mathrm{SiO}_{2}$, toluene). The resulting red reaction mixture was concentrated on a rotary evaporator to a solid. The residue suspended in $\mathrm{MeOH}(50 \mathrm{~mL})$ and filtered. The solid was extracted with DCM $(\sim 60 \mathrm{~mL})$ and filtered through a $1 \mathrm{~cm}$ pad of $\mathrm{SiO}_{2}$ with excess DCM and evaporated. Recrystallization from a concentrated solution in DCM (10 $\mathrm{mL})$ layered with $\mathrm{MeOH}(10 \mathrm{~mL})$ gave 3-Ni $(25.3 \mathrm{mg}, 0.027 \mathrm{mmol}, 87 \%)$ as a red solid. ${ }^{1} \mathrm{H}$ NMR (500 $\mathrm{MHz}^{\left.\mathrm{CDCl}_{3}\right)} \delta=8.79-8.72(\mathrm{~m}, 8 \mathrm{H}), 8.05(\mathrm{~d}, J=8.5 \mathrm{~Hz}, 2 \mathrm{H}), 8.04-7.98(\mathrm{~m}, 8 \mathrm{H}), 7.86(\mathrm{~d}, J=8.2 \mathrm{~Hz}$, 2H), $7.75-7.66(\mathrm{~m}, 9 \mathrm{H}), 7.65(\mathrm{~d}, J=8.4 \mathrm{~Hz}, 2 \mathrm{H}), 7.62(\mathrm{~d}, J=8.5 \mathrm{~Hz}, 2 \mathrm{H}), 7.59$ (d, $J=8.5 \mathrm{~Hz}, 2 \mathrm{H}), 3.95$ (s, 3H) ppm. ${ }^{13} \mathrm{C}\left\{{ }^{1} \mathrm{H}\right\}$ NMR $\left(126 \mathrm{MHz}, \mathrm{CDCl}_{3}\right) \delta=166.7,142.9,142.9,142.8,142.5,141.5,141.0,133.94$, $133.85,132.6,132.5,132.4,132.0,131.92,131.89,131.7,130.3,129.8,129.7,127.9,127.9,127.0,123.8$, $122.8,122.6,119.3,119.3,118.2,92.2,91.6,90.7,90.2,52.4 \mathrm{ppm}$. MS (MALDI-TOF): $\mathrm{m} / \mathrm{z}$ $\left[\mathrm{C}_{62} \mathrm{H}_{38} \mathrm{~N}_{4} \mathrm{NiO}_{2}\right]^{+}$calcd. 928.23; found 928.22.

\section{$\boldsymbol{\mu}$-[4-(10,15,20-triphenylporphyrin-5-yl-2 $\left.\kappa^{4} \mathrm{~N}^{21,22,23,24}\right)$ benzoato(3-)-1 $\left.\kappa^{2} \mathrm{O}, \mathrm{O}^{\prime}\right]-$ bis $\left(1 \eta^{5}\right.$-cyclopenta}

dienyl)titaniumcopper (1): A $20 \mathrm{~mL}$ scintillation vial was charged in air with 1a (31.7 $\mathrm{mg}, 0.043 \mathrm{mmol})$ in THF (10 mL). A solution of $\mathrm{KOH}(24 \mathrm{mg}, 0.43 \mathrm{mmol}, 10$ equiv.) in $80 \%$ ethanol $(0.25 \mathrm{~mL})$ was added, the reaction vial capped and heated to $66^{\circ} \mathrm{C}$ for $16 \mathrm{~h}$ or until complete $\left(\mathrm{TLC}, \mathrm{SiO}_{2}, \mathrm{CHCl}_{3}\right.$ ). The reaction mixture was poured into 1:1 water/DCM $(40 \mathrm{~mL})$, allowed to separate (discarding the organic layer and replacing with fresh DCM if colored), and carefully acidified dropwise with 5\% hydrochloric acid to $\mathrm{pH} 3$ while agitating constantly. The red organic layer was quickly separated (the porphyrin carboxylic acid may precipitate if allowed to stand) and the aqueous layer extracted with DCM $(2 \times 10 \mathrm{~mL})$. The organic extracts were concentrated on a rotary evaporator to a damp solid. This residue was dried azeotropically by dissolving in hot toluene $(15 \mathrm{~mL})$ and distilling down to $\sim 5 \mathrm{~mL}$ at atmospheric pressure. The volatiles were removed in vacuo at $24 \mathrm{C}$ and the resulting solid dried at $<0.1$ torr for $16 \mathrm{~h}$ before being brought into a $\mathrm{N}_{2}$ glovebox. The red residue was suspended in dry THF $(\sim 7 \mathrm{~mL})$ and $\left[\mathrm{Cp}_{2} \mathrm{TiCl}\right]_{2}(38 \mathrm{mg}, 0.089 \mathrm{mmol}, 2$ equiv., 4 equiv. Ti) was added immediately followed by 2,6-lutidine ( $50 \mu \mathrm{L}, 0.43 \mathrm{mmol}, 10$ equiv.). The suspension was stirred for $1 \mathrm{~h}$ during which time the colored solids dissolved. The volatiles were removed in vacuo and the residue resuspended in minimal THF $(\sim 2-3 \mathrm{~mL})$ and filtered dropwise into dry MeCN (10

$\mathrm{mL})$, washing the retained solids with minimal THF $(\sim 0.5 \mathrm{~mL})$ until the filtrate's red color faded. The $\mathrm{MeCN}$ suspension was allowed to stand 1 hour before the precipitate was collected by filtration, washed with copious amounts of $\mathrm{MeCN}$ and hexanes, and dried in vacuo at $24^{\circ} \mathrm{C}$ to give 1 (33.7 $\mathrm{mg}, 0.038 \mathrm{mmol}$, $88 \%$ ) as a reddish purple solid. ${ }^{1} \mathrm{H}$ NMR $\left(600 \mathrm{MHz}, \mathrm{C}_{6} \mathrm{D}_{6}\right) \delta=7.61$ (br s, FWHM $\left.=100 \mathrm{~Hz}, \sim 1 \mathrm{H}\right), 7.38$ (br $\mathrm{s}, \mathrm{FWHM}=20 \mathrm{~Hz}, \sim 2 \mathrm{H}), 7.22$ (br s, FWHM $=25 \mathrm{~Hz}, \sim 4 \mathrm{H}) \mathrm{ppm} .{ }^{1} \mathrm{H}$ NMR $(600 \mathrm{MHz}$, protio-THF) $\delta=$ 7.65 (br s, FWHM = 24 Hz, 1H), 7.50 (br s, FWHM = 33 Hz, 2H) ppm. FTIR (ATR) $1445\left(\kappa^{2}-\mathrm{CO}_{2} v_{\text {sym }}\right.$ ), 
$1504\left(\kappa^{2}-\mathrm{CO}_{2} v_{\text {asym }}\right)$. HRMS (MALDI-TOF): $\mathrm{m} / \mathrm{z}\left[\mathrm{C}_{55} \mathrm{H}_{37} \mathrm{CuN}_{4} \mathrm{O}_{2} \mathrm{Ti}\right]^{+}$calcd. 896.1687; found 896.1672. Anal. for $\left[\mathrm{C}_{55} \mathrm{H}_{37} \mathrm{CuN}_{4} \mathrm{O}_{2}\right.$ Ti] calcd. C 73.62, H 4.16, N 6.24; found C 73.32, H 4.26, N 6.15.

\section{$\mu$-[4-(10,15,20-triphenylporphyrin-5-yl-2 $\left.\kappa^{4} N^{21,22,23,24}\right)$ benzoato(3-)-1 $\left.\kappa^{2} O, O^{\prime}\right]-$ bis $\left(1 \eta^{5}\right.$-cyclopenta}

dienyl)titaniumnickel (1b): A $20 \mathrm{~mL}$ scintillation vial was charged in air with 1-Ni (26.4 mg, $0.036 \mathrm{mmol})$ in THF (10 mL). A solution of $\mathrm{KOH}(23 \mathrm{mg}, 0.45 \mathrm{mmol}, 12$ equiv.) in 50\% ethanol ( $3 \mathrm{~mL})$ was added, the reaction vial capped and heated to $66^{\circ} \mathrm{C}$ for $16 \mathrm{~h}$ or until complete (TLC, $\mathrm{SiO}_{2}, \mathrm{CHCl}_{3}$ ). The reaction mixture was poured into 1:1 water/DCM $(40 \mathrm{~mL})$, allowed to separate (discarding the organic layer and replacing with fresh DCM if colored), and carefully acidified dropwise with 5\% hydrochloric acid to $\mathrm{pH} 3$ while agitating constantly. The red organic layer was quickly separated (the porphyrin carboxylic acid may precipitate if allowed to stand $)$ and the aqueous layer extracted with $\operatorname{DCM}(2 \times 10 \mathrm{~mL})$. The organic extracts were concentrated on a rotary evaporator to a damp solid. This residue was dried azeotropically by dissolving in hot toluene $(15 \mathrm{~mL})$ and distilling down to $\sim 5 \mathrm{~mL}$ at atmospheric pressure. The volatiles were removed in vacuo at $24 \mathrm{C}$ and the resulting solid dried at $<0.1$ torr for $16 \mathrm{~h}$ before being brought into a $\mathrm{N}_{2}$ glovebox. The red residue was suspended in dry THF $(\sim 7 \mathrm{~mL})$ and $\left[\mathrm{Cp}_{2} \mathrm{TiCl}\right]_{2}(35 \mathrm{mg}, 0.082 \mathrm{mmol}, 2$ equiv., 4 equiv. Ti) was added immediately followed by 2,6-lutidine (100 $\mu \mathrm{L}, 0.86 \mathrm{mmol}, 20$ equiv.). The suspension was stirred for $1 \mathrm{~h}$ during which time the colored solids dissolved. The volatiles were removed in vacuo and the residue resuspended in minimal THF $(\sim 2-3 \mathrm{~mL})$ and filtered dropwise into dry MeCN (10 $\mathrm{mL})$, washing the retained solids with minimal THF $(\sim 0.5 \mathrm{~mL})$ until the filtrate's red color faded. The $\mathrm{MeCN}$ suspension was allowed to stand 1 hour before the precipitate was collected by filtration, washed with copious amounts of $\mathrm{MeCN}$ and hexanes, and dried in vacuo at $24^{\circ} \mathrm{C}$ to give $\mathbf{1 b}(32.5 \mathrm{mg}, 0.36 \mathrm{mmol}$, $99 \%$ ) as a red solid. ${ }^{1} \mathrm{H}$ NMR $\left(600 \mathrm{MHz}, \mathrm{C}_{6} \mathrm{D}_{6}\right) \delta=8.85$ (br s, FWHM $\left.=13 \mathrm{~Hz}, 2 \mathrm{H}\right), 8.83$ (s, FWHM = 2 $\mathrm{Hz}, 4 \mathrm{H}), 8.77$ (br s, FWHM = 25 Hz, 2H), 8.15 (br s, FWHM = 62 Hz, 2H), 7.92 (t, J = 7.5 Hz, 5H), 7.45 - $7.34(\mathrm{~m}, 9 \mathrm{H})$ ppm. FTIR (ATR) $1440\left(\kappa^{2}-\mathrm{CO}_{2} v_{\text {sym }}\right), 1510\left(\kappa^{2}-\mathrm{CO}_{2} v_{\text {asym }}\right)$. HRMS (MALDI-TOF): m/z $\left[\mathrm{C}_{55} \mathrm{H}_{37} \mathrm{~N}_{4} \mathrm{NiO}_{2} \mathrm{Ti}\right]^{+}$calcd. 891.1744; found 891.1743. Anal. for $\left[\mathrm{C}_{55} \mathrm{H}_{37} \mathrm{~N}_{4} \mathrm{NiO}_{2} \mathrm{Ti}\right]$ calcd. C 74.02, $\mathrm{H} 4.18$, N 6.28; found C 73.85, H 4.46, N 5.97. Single crystals of $\mathbf{1 b} \bullet \mathbf{M e C N}$ suitable for X-ray diffraction were grown from allowing the THF/MeCN filtrate to stand undisturbed at room temperature for 6 weeks.

\section{$\mu$-[4-((4-(10,15,20-triphenylporphyrin-5-yl-2 $\left.\kappa^{4} \mathbf{N}^{21,22,23,24}\right)$ phenyl)ethynyl)benzoato(3-)-1 $\left.\kappa^{2} O, 0^{\prime}\right]-$} bis(1 $\mathbf{1} \mathbf{\eta}^{5}$-cyclopentadienyl)titaniumcopper (2): A $20 \mathrm{~mL}$ scintillation vial was charged in air with 2a (78.3 $\mathrm{mg}, 0.094 \mathrm{mmol})$ in THF (15 mL). A solution of $\mathrm{KOH}(53 \mathrm{mg}, 0.94 \mathrm{mmol}, 10$ equiv.) in 80\% ethanol (0.5 $\mathrm{mL}$ ) was added, the reaction vial capped and heated to $66^{\circ} \mathrm{C}$ for $16 \mathrm{~h}$ or until complete (TLC, $\mathrm{SiO}_{2}, \mathrm{CHCl}_{3}$ ). The reaction mixture was poured into 1:1 water/DCM $(60 \mathrm{~mL})$, allowed to separate (discarding the organic layer and replacing with fresh DCM if colored), and carefully acidified dropwise with 5\% hydrochloric acid 
to $\mathrm{pH} 3$ while agitating constantly. The red organic layer was quickly separated (the porphyrin carboxylic acid may precipitate if allowed to stand) and the aqueous layer extracted with DCM $(2 \times 10 \mathrm{~mL})$. The organic extracts were concentrated on a rotary evaporator to a damp solid. This residue was dried azeotropically by dissolving in hot toluene $(15 \mathrm{~mL})$ and distilling down to $\sim 3 \mathrm{~mL}$ at atmospheric pressure. The volatiles were removed in vacuo at $24 \mathrm{C}$ and the resulting solid dried at $<0.1$ torr for $16 \mathrm{~h}$ before being brought into a $\mathrm{N}_{2}$ glovebox. The red residue was suspended in dry THF $(\sim 10 \mathrm{~mL})$ and $\left[\mathrm{Cp}_{2} \mathrm{TiCl}\right]_{2}(84 \mathrm{mg}$, 0.19 mmol, 2 equiv., 4 equiv. Ti) was added immediately followed by 2,6-lutidine ( $100 \mu \mathrm{L}, 0.86 \mathrm{mmol}, 9$ equiv.). The suspension was stirred for $1 \mathrm{~h}$ during which time the colored solids dissolved. The volatiles were removed in vacuo and the residue resuspended in minimal THF $(\sim 5-6 \mathrm{~mL})$ and filtered dropwise into dry MeCN (15 mL), washing the retained solids with minimal THF $(\sim 0.5 \mathrm{~mL})$ until the filtrate's red color faded. The MeCN suspension was allowed to stand 1 hour before the precipitate was collected by filtration, washed with copious amounts of $\mathrm{MeCN}$ and hexanes, and dried in vacuo at $24^{\circ} \mathrm{C}$ to give $2(78.7 \mathrm{mg}, 0.079$ mmol, 84\%) as a purple solid. ${ }^{1} \mathrm{H}$ NMR $\left(500 \mathrm{MHz}, \mathrm{C}_{6} \mathrm{D}_{6}\right) \delta=7.87$ (br s, FWHM $=128 \mathrm{~Hz}, \sim 2 \mathrm{H}$ ), 7.55 (br $\mathrm{s}, \mathrm{FWHM}=95 \mathrm{~Hz}, \sim 3 \mathrm{H}), 7.39($ br s, FWHM $=23 \mathrm{~Hz}, \sim 2 \mathrm{H}), 7.24$ (br s, FWHM $=26 \mathrm{~Hz}, \sim 3 \mathrm{H}$ ) ppm. FTIR (ATR) $1431\left(\kappa^{2}-\mathrm{CO}_{2} v_{\text {sym }}\right), 1500\left(\kappa^{2}-\mathrm{CO}_{2} v_{\text {asym }}\right)$. HRMS (MALDI-TOF): m/z $\left[\mathrm{C}_{63} \mathrm{H}_{41} \mathrm{CuN}_{4} \mathrm{O}_{2} \mathrm{Ti}^{+}\right.$calcd. 996.2000; found 996.2017. Anal. for $\left[\mathrm{C}_{63} \mathrm{H}_{41} \mathrm{CuN}_{4} \mathrm{O}_{2}\right.$ Ti] calcd. C 75.86, H 4.14, N 5.62; found C 75.36, H 4.60, N 5.26 and C 75.20, H 4.37, N 5.94. $\left[\mathrm{C}_{63} \mathrm{H}_{41} \mathrm{CuN}_{4} \mathrm{O}_{2} \mathrm{Ti}+0.5 \mathrm{MeCN}\right]$ gives C 75.51, H 4.21, N 6.19. Single crystals of $\mathbf{2} \mathbf{\bullet} \mathbf{0 . 5} \mathbf{C}_{\mathbf{7}} \mathbf{H}_{\mathbf{8}}$ suitable for X-ray diffraction were grown from slow evaporation of toluene solution stored over shredded paraffin wax at room temperature.

\section{$\mu$-[4-((4-(10,15,20-triphenylporphyrin-5-yl-2 $\left.\kappa^{4} N^{21,22,23,24}\right)$ phenyl)ethynyl)benzoato(3-)-1 $\left.\kappa^{2} O, O^{\prime}\right]-$}

bis( $1 \eta^{5}$-cyclopentadienyl)titaniumnickel (2b): A $20 \mathrm{~mL}$ scintillation vial was charged in air with 2-Ni (20.6 mg, $0.025 \mathrm{mmol})$ in THF (10 mL). A solution of KOH $(17 \mathrm{mg}, 0.30 \mathrm{mmol}, 12$ equiv.) in 50\% ethanol $(2 \mathrm{~mL})$ was added, the reaction vial capped and heated to $66^{\circ} \mathrm{C}$ for $16 \mathrm{~h}$ or until complete $\left(\mathrm{TLC}, \mathrm{SiO}_{2}\right.$, $\left.\mathrm{CHCl}_{3}\right)$. The reaction mixture was poured into 1:1 water/DCM $(30 \mathrm{~mL})$, allowed to separate (discarding the organic layer and replacing with fresh DCM if colored), and carefully acidified dropwise with 5\% hydrochloric acid to $\mathrm{pH} 3$ while agitating constantly. The red organic layer was quickly separated (the porphyrin carboxylic acid may precipitate if allowed to stand) and the aqueous layer extracted with DCM $(2 \times 10 \mathrm{~mL})$. The organic extracts were concentrated on a rotary evaporator to a damp solid. This residue was dried azeotropically by dissolving in hot toluene $(10 \mathrm{~mL})$ and distilling down to $\sim 3 \mathrm{~mL}$ at atmospheric pressure. The volatiles were removed in vacuo at $24 \mathrm{C}$ and the resulting solid dried at $<0.1$ torr for $16 \mathrm{~h}$ before being brought into a $\mathrm{N}_{2}$ glovebox. The red residue was suspended in dry THF $(\sim 7 \mathrm{~mL})$ and $\left[\mathrm{Cp}_{2} \mathrm{TiCl}_{2}\right.$ (23 mg, $0.054 \mathrm{mmol}, 2$ equiv., 4 equiv. Ti) was added immediately followed by 2,6-lutidine (30 $\mu \mathrm{L}, 0.26 \mathrm{mmol}, 10$ equiv.). The suspension was stirred for $1 \mathrm{~h}$ during which time the colored solids 
dissolved. The volatiles were removed in vacuo and the residue resuspended in minimal THF $(\sim 2 \mathrm{~mL})$ and filtered dropwise into dry $\mathrm{MeCN}(10 \mathrm{~mL})$, washing the retained solids with minimal THF $(\sim 0.5 \mathrm{~mL})$ until the filtrate's red color faded. The $\mathrm{MeCN}$ suspension was allowed to stand 1 hour before the precipitate was collected by filtration, washed with copious amounts of $\mathrm{MeCN}$ and hexanes, and dried in vacuo at $24^{\circ} \mathrm{C}$ to give $2 \mathbf{b}$ (17.4 mg, $0.018 \mathrm{mmol}, 70 \%)$ as a red solid. ${ }^{1} \mathrm{H} \mathrm{NMR}\left(500 \mathrm{MHz}, \mathrm{C}_{6} \mathrm{D}_{6}\right) \delta=8.86(\mathrm{~d}, J=4.8 \mathrm{~Hz}$, 2H), $8.83(\mathrm{~s}, 4 \mathrm{H}), 8.78(\mathrm{~d}, J=4.9 \mathrm{~Hz}, 2 \mathrm{H}), 7.93(\mathrm{~d}, J=7.2 \mathrm{~Hz}, 4 \mathrm{H}), 7.91$ (d, $J=7.2 \mathrm{~Hz}, 2 \mathrm{H}), 7.79$ (br d, $J$ $=7.3 \mathrm{~Hz}, \mathrm{FWHM}=5.8 \mathrm{~Hz}, 2 \mathrm{H}), 7.67$ (br d, $J=7.4 \mathrm{~Hz}, \mathrm{FWHM}=7.4 \mathrm{~Hz}, 2 \mathrm{H}), 7.45-7.34$ (m, 9H) ppm. FTIR (ATR) $1430\left(\kappa^{2}-\mathrm{CO}_{2} v_{\text {sym }}\right), 1499\left(\kappa^{2}-\mathrm{CO}_{2} v_{\text {asym }}\right)$. HRMS (MALDI-TOF): m/z $\left[\mathrm{C}_{63} \mathrm{H}_{41} \mathrm{~N}_{4} \mathrm{NiO}_{2} \mathrm{Ti}\right]^{+}$ calcd. 991.2057; found 993.2064. Anal. for $\left[\mathrm{C}_{63} \mathrm{H}_{41} \mathrm{~N}_{4} \mathrm{NiO}_{2}\right.$ Ti $]$ calcd. C 76.23, H 4.16, N 5.64; found C 76.53, $\mathrm{H} 4.59$, N 5.48. $\left[\mathrm{C}_{63} \mathrm{H}_{41} \mathrm{~N}_{4} \mathrm{NiO}_{2} \mathrm{Ti}+0.5 \mathrm{C}_{6} \mathrm{H}_{14}\right]$ gives $\mathrm{C} 76.54, \mathrm{H} 4.67, \mathrm{~N} 5.41$.

\section{$\boldsymbol{\mu}$-[4-((4-((4-(10,15,20-triphenylporphyrin-5-yl-2 $\left.\kappa^{4} \mathrm{~N}^{21,22,23,24}\right)$ phenyl)ethynyl)phenyl)ethynyl)}

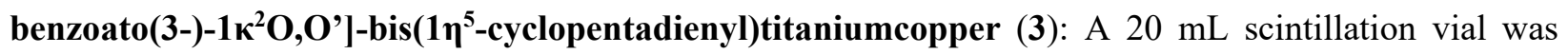
charged in air with 3a $(43.1 \mathrm{mg}, 0.046 \mathrm{mmol})$ in THF $(15 \mathrm{~mL})$. A solution of KOH (26 mg, $0.46 \mathrm{mmol}, 10$ equiv.) in $80 \%$ ethanol $(0.25 \mathrm{~mL})$ was added, the reaction vial capped and heated to $66^{\circ} \mathrm{C}$ for $16 \mathrm{~h}$ or until complete ( $\mathrm{TLC}, \mathrm{SiO}_{2}, \mathrm{CHCl}_{3}$ ). The reaction mixture was poured into 1:1 water/DCM $(60 \mathrm{~mL})$, allowed to separate (discarding the organic layer and replacing with fresh DCM if colored), and carefully acidified dropwise with $5 \%$ hydrochloric acid to $\mathrm{pH} 3$ while agitating constantly. The red organic layer was quickly separated (the porphyrin carboxylic acid may precipitate if allowed to stand) and the aqueous layer extracted with DCM $(2 \times 10 \mathrm{~mL})$. The organic extracts were concentrated on a rotary evaporator to a damp solid. This residue was dried azeotropically by dissolving in hot toluene $(10 \mathrm{~mL})$ and distilling down to $\sim 3 \mathrm{~mL}$ at atmospheric pressure. The volatiles were removed in vacuo at $24 \mathrm{C}$ and the resulting solid dried at $<0.1$ torr for $16 \mathrm{~h}$ before being brought into a $\mathrm{N}_{2}$ glovebox. The red residue was suspended in dry THF $(\sim 10 \mathrm{~mL})$ and $\left[\mathrm{Cp}_{2} \mathrm{TiCl}\right]_{2}$ (84 mg, 0.19 mmol, 2 equiv., 4 equiv. Ti) was added immediately followed by 2,6-lutidine (50 $\mu \mathrm{L}, 0.43 \mathrm{mmol}, 9$ equiv.). The suspension was stirred for $1 \mathrm{~h}$ during which time the colored solids dissolved. The volatiles were removed in vacuo and the residue resuspended in minimal THF $(\sim 9-10 \mathrm{~mL})$ and filtered dropwise into dry $\mathrm{MeCN}(10 \mathrm{~mL})$, washing the retained solids with minimal THF $(\sim 0.5 \mathrm{~mL})$ until the filtrate's red color faded. The MeCN suspension was allowed to stand 1 hour before the precipitate was collected by filtration, washed with copious amounts of $\mathrm{MeCN}$ and hexanes, and dried in vacuo at $24^{\circ} \mathrm{C}$ to give 3 (36.8 mg, $0.033 \mathrm{mmol}, 73 \%$ ) as a reddish purple solid. ${ }^{1} \mathrm{H}$ NMR $\left(600 \mathrm{MHz}, \mathrm{C}_{6} \mathrm{D}_{6}\right) \delta=7.75$ (br s, FWHM = 99 Hz, 2 H), 7.59 (br s, FWHM = 74 Hz, 4 H), 7.49 (br d, FWHM = 11 Hz, J = 7 Hz, $\sim 2 \mathrm{H}$ ), 7.38 (br s, FWHM = $23 \mathrm{~Hz}, \sim 6 \mathrm{H}), 7.24$ (br s, FWHM $=38 \mathrm{~Hz}, \sim 6 \mathrm{H})$ ppm. FTIR (ATR) $1433\left(\kappa^{2}-\right.$ $\left.\mathrm{CO}_{2} v_{\text {sym }}\right), 1508\left(\kappa^{2}-\mathrm{CO}_{2} v_{\text {asym }}\right)$. HRMS (MALDI-TOF): $\mathrm{m} / \mathrm{z}\left[\mathrm{C}_{71} \mathrm{H}_{45} \mathrm{CuN}_{4} \mathrm{O}_{2} \mathrm{Ti}\right]^{+}$calcd. 1096.2313; found 1096.2310. Anal. for $\left[\mathrm{C}_{71} \mathrm{H}_{45} \mathrm{CuN}_{4} \mathrm{O}_{2}\right.$ Ti] calcd. C 77.70, H 4.13, N 5.10; found C 77.92, H 4.51, N 5.37. A 
single crystal of $\mathbf{3}$ of poor quality but sufficient for X-ray diffraction was grown from vapor diffusion of $\mathrm{MeCN}$ into a toluene solution of $\mathbf{3}$ at $25^{\circ} \mathrm{C}$.

\section{$\mu$-[4-((4-((4-(10,15,20-triphenylporphyrin-5-yl-2 $\left.\kappa^{4} \mathrm{~N}^{21,22,23,24}\right)$ phenyl)ethynyl)phenyl)ethynyl)}

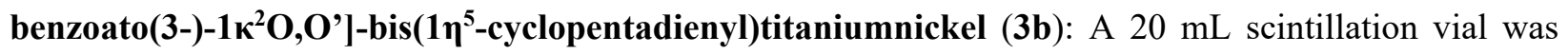
charged in air with 3-Ni $(23.8 \mathrm{mg}, 0.026 \mathrm{mmol})$ in THF $(10 \mathrm{~mL})$. A solution of KOH $(15 \mathrm{mg}, 0.27 \mathrm{mmol}$, 10 equiv.) in $50 \%$ ethanol $(3 \mathrm{~mL})$ was added, the reaction vial capped and heated to $66^{\circ} \mathrm{C}$ for $16 \mathrm{~h}$ or until complete (TLC, $\left.\mathrm{SiO}_{2}, \mathrm{CHCl}_{3}\right)$. The reaction mixture was poured into 1:1 water/DCM $(30 \mathrm{~mL})$, allowed to separate (discarding the organic layer and replacing with fresh DCM if colored), and carefully acidified dropwise with 5\% hydrochloric acid to $\mathrm{pH} 3$ while agitating constantly. The red organic layer was quickly separated (the porphyrin carboxylic acid may precipitate if allowed to stand) and the aqueous layer extracted with DCM (2 x $10 \mathrm{~mL})$. The organic extracts were concentrated on a rotary evaporator to a damp solid. This residue was dried azeotropically by dissolving in hot toluene $(10 \mathrm{~mL})$ and distilling down to $\sim 3 \mathrm{~mL}$ at atmospheric pressure. The volatiles were removed in vacuo at $24 \mathrm{C}$ and the resulting solid dried at $<0.1$ torr for $16 \mathrm{~h}$ before being brought into a $\mathrm{N}_{2}$ glovebox. The red residue was suspended in dry THF ( $\left.\sim \mathrm{mL}\right)$ and $\left[\mathrm{Cp}_{2} \mathrm{TiCl}\right]_{2}(22 \mathrm{mg}, 0.051 \mathrm{mmol}, 2$ equiv., 4 equiv. Ti) was added immediately followed by 2,6-lutidine (30 $\mu \mathrm{L}, 0.26 \mathrm{mmol}, 10$ equiv.). The suspension was stirred for $1 \mathrm{~h}$ during which time the colored solids dissolved. The volatiles were removed in vacuo and the residue resuspended in minimal THF $(\sim 2-3 \mathrm{~mL})$ and filtered dropwise into dry $\mathrm{MeCN}(10 \mathrm{~mL})$, washing the retained solids with minimal THF $(\sim 0.5 \mathrm{~mL})$ until the filtrate's red color faded. The MeCN suspension was allowed to stand overnight for 18 hours before the precipitate was collected by filtration, washed with copious amounts of $\mathrm{MeCN}$ and hexanes, and dried in vacuo at $24^{\circ} \mathrm{C}$ to give $3 \mathbf{b}(22.7 \mathrm{mg}, 0.021 \mathrm{mmol}, 82 \%)$ as a red solid. ${ }^{1} \mathrm{H}$ NMR $\left(500 \mathrm{MHz}, \mathrm{C}_{6} \mathrm{D}_{6}\right) \delta$ $=8.87(\mathrm{~d}, J=4.8 \mathrm{~Hz}, 2 \mathrm{H}), 8.84(\mathrm{~s}, 4 \mathrm{H}), 8.80(\mathrm{~d}, J=4.9 \mathrm{~Hz}, 2 \mathrm{H}), 7.94(\mathrm{~d}, J=6.8 \mathrm{~Hz}, 4 \mathrm{H}), 7.92(\mathrm{~d}, J=6.9$ $\mathrm{Hz}, 2 \mathrm{H}), 7.80$ (d, $J=7.8 \mathrm{~Hz}, 2 \mathrm{H}), 7.73$ (d, $J=7.9 \mathrm{~Hz}, 2 \mathrm{H}), 7.51$ (br d, $J=7.6 \mathrm{~Hz}, \mathrm{FWHM}=5.4 \mathrm{~Hz}, 2 \mathrm{H})$, $7.45-7.36(\mathrm{~m}, 11 \mathrm{H})$. FTIR (ATR) $1434\left(\kappa^{2}-\mathrm{CO}_{2} v_{\text {sym }}\right), 1509\left(\kappa^{2}-\mathrm{CO}_{2} v_{\text {asym }}\right)$. HRMS (MALDI-TOF): m/z $\left[\mathrm{C}_{71} \mathrm{H}_{45} \mathrm{~N}_{4} \mathrm{NiO}_{2} \mathrm{Ti}^{+}\right.$calcd. 1091.2370; found 1091.2489. Anal. for $\left[\mathrm{C}_{71} \mathrm{H}_{45} \mathrm{~N}_{4} \mathrm{NiO}_{2} \mathrm{Ti}\right]$ calcd. C 78.04, $\mathrm{H} 4.15$, N 5.13; found C 78.02, H 4.09, N 4.88 .

\section{Analytical Methods}

NMR Spectroscopy All ${ }^{1} \mathrm{H}$, and ${ }^{13} \mathrm{C}\left\{{ }^{1} \mathrm{H}\right\}$ spectra were recorded on 500, or $600 \mathrm{MHz}$ Bruker NMR spectrometers at Northwestern's IMSERC facility and are referenced to (residual) solvent peaks $\left(\mathrm{CDCl}_{3}{ }^{1} \mathrm{H}\right.$ NMR $\delta=7.26 \mathrm{ppm},{ }^{13} \mathrm{C}$ NMR $\delta=77.16 \mathrm{ppm} ; \mathrm{C}_{6} \mathrm{D}_{6}{ }^{1} \mathrm{H}$ NMR $\delta=7.16 \mathrm{ppm},{ }^{13} \mathrm{C}$ NMR $\left.\delta=128.06 \mathrm{ppm}\right)$. Approximate integrations of paramagnetically broadened, overlapping NMR resonances were estimated by 
deconvolution with the peak fitting functionality in MestReNova v. 14.1.2 and indicated with a preceding $\sim$ mark.

Mass Spectrometry ESI mass spectrometry was performed on a Bruker AmaZon-SL spectrometer in positive mode. MALDI-TOF MS was performed on a Bruker Rapidflex MALDI-TOF in positive mode, using FlexControl data acquisition software, processed using FlexAnalysis software, and plotted with mMass. ${ }^{6}$ Adapting a literature method ${ }^{7,8}$ samples for MALDI-TOF were prepared by dissolving the analyte in a saturated solution of anthracene in benzene (containing ca. $0.01 \%$ wt 1a, 2a, and 3a as internal calibrants for high resolution data acquisition), spotted on the plate in a $\mathrm{N}_{2}$ glovebox, removed from the glovebox in an airtight container, and quickly inserted to the instrument in air to minimize hydrolysis and oxidation. Laser intensity was adjusted to minimize photochemical fragmentation, which could not be completely prevented at any laser intensity that led to ionization.

Other Physical Measurements Elemental analysis (CHN) was performed by Midwest Microlabs (values are given in \%). ATR-IR spectra were obtained under $\mathrm{N}_{2}$ on a Bruker Alpha II FTIR spectrometer equipped with an attenuated total reflectance accessory and diamond anvil, which was cleaned with toluene between samples.

X-ray Crystallography X-ray crystallography of $\mathbf{1 b} \bullet \mathbf{M e C N}$ and $\mathbf{2} \bullet \mathbf{0 . 5} \mathrm{C}_{7} \mathrm{H}_{\mathbf{8}}$ was performed on a Bruker APEX II diffractometer, using a Mo K $\alpha$ microsource (Quazar ${ }^{\mathrm{TM}}$ optics), a Bruker APEX II detector, and Oxford Cryostream at $100 \mathrm{~K}$. X-ray crystallography of $\mathbf{3}$ was performed on a Bruker APEX II diffractometer, using a $\mathrm{Cu}-\mathrm{K} \alpha$ Microsource (MX optics), a Bruker APEX II detector, and Oxford Cryostream at $100 \mathrm{~K}$. Crystals were coated in Paratone-N oil under inert atmosphere, mounted on kapton loops under air, and frozen in a stream of nitrogen. Inspection of the diffraction patterns revealed that the $\mathrm{Cu}$ pin of the sample holder had eclipsed the X-ray beam on a few frames, leading to powder rings that had to be subtracted. Crystallographic data were integrated and scaled with APEX2, a multi-scan X-ray absorption correction applied with SADABS, initial solutions obtained with SHELXT ${ }^{9}$ and refined with SHELXL ${ }^{10}$ as implemented in Olex2. ${ }^{11}$ Hydrogen atoms were placed in calculated positions and refined using a riding model. Heavy atoms were refined anisotropically unless otherwise stated. Structures were finalized with Olex2 and visualized with Mercury and POV-Ray.

For $\mathbf{2} \cdot \mathbf{0 . 5} \mathbf{C}_{7} \mathbf{H}_{8}$, the best crystals exhibited negligible diffraction intensity beyond $1.0 \AA$, but still enabled structure solution that yielded unambiguous connectivity and acceptable precision on the Cu-Ti distances due to the larger scattering factors of these atoms. The combination of low resolution and large asymmetric unit led to a low data to parameter ratio of 7.22. The disordered toluene molecule occupying an inversion 
center was constrained to be planar with FLAT, the ring constrained to be a regular hexagon with AFIX66 , and displacement parameters refined isotropically.

For 3 , the best crystals exhibited negligible diffraction intensity beyond $1.2 \AA$ but still yielded a structure solution with unambiguous connectivity and acceptable precision on the $\mathrm{Cu}$ - $\mathrm{Ti}$ distances, due to the larger scattering factors of these atoms. Diffraction due to electron density within a solvent-accessible void around an inversion center (containing 22 electrons, likely corresponding to one disordered acetonitrile) was treated with PLATON SQUEEZE as implemented in the Solvent Mask function in Olex2. Limited high-angle diffraction intensity combined with a large asymmetric unit led to an unacceptably low data-to-parameter ratio, so the structure of $\mathbf{3}$ was refined with geometric constraints enforcing regular ngon geometry of phenyl and cyclopentadienyl rings and heavy atom displacement parameters were restrained with the advanced rigid bond restraint RIGU to increase this to a ratio of 4.36 but could not be improved without compromising the structural model. One phenyl ring was disordered over two rotational conformations and was modeled with isotropic displacement parameters as anisotropic parameters gave poor refinement of the minor conformation.

\section{Computational Details}

Density functional theory (DFT) calculations were performed within the Perdew-Burke-Ernzerhof exchange-correlation $(\mathrm{PBE})^{12}$ as implemented in the Vienna $\mathrm{Ab}$ initio Simulation Package (VASP) ${ }^{13}$ to examine changes in the spin density distribution with intermetal distance in the bimetallic molecules. The projector augmented wave $(\mathrm{PAW})^{14}$ method was used to treat the core and valence electrons using the following electronic configurations: $1 s^{1}$ for $\mathrm{H}, 2 \mathrm{~s}^{2} 2 \mathrm{p}^{2}$ for $\mathrm{C}, 2 \mathrm{~s}^{2} 2 \mathrm{p}^{3}$ for $\mathrm{N}, 2 \mathrm{~s}^{2} 2 \mathrm{p}^{4}$ for $\mathrm{O}, 3 \mathrm{p}^{6} 3 \mathrm{~d}^{2} 4 \mathrm{~s}^{2}$ for Ti, and $3 \mathrm{~d}^{10} 4 \mathrm{~s}^{1}$ for $\mathrm{Cu}$. The energy cutoff was set to $600 \mathrm{eV}$ and the molecular geometries were optimized until the forces on each atom were less than $3 \mathrm{meV} / \AA$. Both ferromagnetic and antiferromagnetic configurations were analyzed. At convergence, the local spin distribution from the ferromagnetic and antiferromagnetic alignments were nearly indistinguishable. The local spin moments on the $\mathrm{Cu}$ and Ti centers in $\mathbf{1}, \mathbf{2}$, and $\mathbf{3}$ are tabulated in Table S2.

\section{Electron Paramagnetic Resonance (EPR) Spectroscopy Details}

All EPR samples were prepared in dry, deoxygenated solvents in an $\mathrm{N}_{2}$ glovebox. Solutions were loaded in $4 \mathrm{~mm}$ OD Wilmad quartz tubes, capped with rubber septa, removed from the glovebox, attached to a Schlenk line by a needle, and frozen under positive pressure of $\mathrm{N}_{2}$. The tubes were then evacuated to $<50$ mTorr and flame sealed with a hydrogen-oxygen torch. Samples prepared in this way are stable for months stored in the dark at ambient temperature. 
CW-EPR spectra were acquired in perpendicular mode at $9.5287 \mathrm{GHz}$ at $77 \mathrm{~K}$ on a Bruker EMXplus spectrometer equipped with an ER-4116DM resonator fitted with a quartz finger dewar operated at Loyola University, Chicago. CW-EPR spectra were fit using the esfit function of Easyspin 5.2.3. ${ }^{15} \mathrm{We}$ fit these spectra using a Hamiltonian for a static magnetic field $\boldsymbol{B}$ that includes the $\mathrm{Cu}^{2+} g$-tensor $\boldsymbol{g}^{\mathrm{Cu}}$ and hyperfine tensor $\boldsymbol{A}^{C u}$, the Ti ${ }^{3+} g$-tensor $\boldsymbol{g}^{T i}$ and hyperfine tensor $\boldsymbol{A}^{T i}$ and the electron-electron interaction matrix $\mathbf{J}$ :

$$
\begin{aligned}
& H=\mu_{B} \boldsymbol{B} \boldsymbol{g}^{C u} \hat{S}^{C u}+\hat{S}^{C u} \boldsymbol{A}^{C u} \hat{I}^{C u, N}+\mu_{B} \boldsymbol{B} \boldsymbol{g}^{T i} \hat{S}^{T i}+\hat{S}^{T i} \boldsymbol{A}^{T i} \hat{I}^{T i}+\hat{S}^{C u} \boldsymbol{J} \hat{S}^{T i} \\
& \boldsymbol{J}=J+\mathbf{d}+\mathbf{D}=\left[\begin{array}{lll}
J & 0 & 0 \\
0 & J & 0 \\
0 & 0 & J
\end{array}\right]+\left[\begin{array}{ccc}
0 & d_{z} & -d_{y} \\
-d_{z} & 0 & d_{x} \\
d_{y} & -d_{x} & 0
\end{array}\right]+\left[\begin{array}{ccc}
D_{x x} & D_{x y} & D_{x z} \\
D_{y x} & D_{y y} & D_{y z} \\
D_{z x} & D_{z y} & D_{z z}
\end{array}\right] \\
& \approx\left[\begin{array}{ccc}
J+D_{x x} & 0 & 0 \\
0 & J+D_{y y} & 0 \\
0 & 0 & J+D_{z z}
\end{array}\right]
\end{aligned}
$$

Combining both electron spins with the many nuclear hyperfine interactions of ${ }^{63} \mathrm{Cu},{ }^{65} \mathrm{Cu},{ }^{47} \mathrm{Ti},{ }^{49} \mathrm{Ti}$ and ${ }^{14} \mathrm{~N}$ nuclei, fitting such a large spin system can be a computationally daunting task. ${ }^{16}$ Here our synthetic approach can simplify the problem. First, our ligand design gives a priori information on the alignment of the $\mathrm{Cu}$ and $\mathrm{Ti}$ g-tensors to each other and to the inter-metallic axis. Second, because we have access to monometallic models $\mathbf{2 a}$ and $\mathbf{2 b}$, fixing $g$ and $A$ parameters of the $\mathrm{Cu}$ and Ti components reduces the spectral fitting process to only the $\mathrm{Cu}^{2+}-\mathrm{Ti}^{3+}$ electron-electron interaction. Finally, due to their $C_{2 \mathrm{v}}$ symmetry, the antisymmetric exchange component of $\mathbf{d}$ is zero for these complexes. ${ }^{17}$ Fit parameters were manually initialized from reported literature values for copper tetraphenylporphyrin ${ }^{18}$ and titanocene benzoate, ${ }^{19}$ fit first using a Nelder-Mead simplex algorithm against the raw CW-EPR spectrum, then refined using the Levenberg-Marquardt algorithm as implemented in Matlab r2019b fitting iteratively by alternating between the raw data and its $1^{\text {st }}$ derivative, and the fit was deemed to have converged when the best fit parameters fit against the CW-EPR spectrum and against its $1^{\text {st }}$ derivative agreed. 2 a was fit to an axial spin system $\left(g_{\mathrm{z}} \neq g_{\mathrm{x}}=g_{\mathrm{y}}\right)$ consisting of an $S=1 / 2$ electron coupled to a Cu nucleus, assuming natural isotopic abundance of ${ }^{63} \mathrm{Cu}(I=3 / 2)$ and ${ }^{65} \mathrm{Cu}(I=3 / 2)$, and four equivalent ${ }^{14} \mathrm{~N}$ nuclei $(I=1)$. 2 b was fit to a rhombic spin system $\left(g_{\mathrm{x}}>g_{\mathrm{z}}>g_{\mathrm{y}}\right)$ consisting of an $S=1 / 2$ electron spin coupled to a Ti nucleus, assuming natural isotopic abundance of ${ }^{47} \mathrm{Ti}$ and ${ }^{49} \mathrm{Ti}$. Line broadening due to conformational strain and ${ }^{1} \mathrm{H}$ hyperfine were implemented as " $g$ strain" to enable applying different line broadenings in the electron-electron coupled simulations of 1-3 ("A strain" and "H strain" parameters representing distributions of hyperfine environments cannot currently be specified per electron in a multi-spin simulation in Easyspin 5.2.3).

Coupled CW-EPR spectra of 1-3 were fit in a two-step process. The $g$ values, hyperfine couplings, and $g$-strain of the $\mathrm{Cu}$ and Ti centers were set to those best fit for $\mathbf{2} \mathbf{a}$ and $\mathbf{2} \mathbf{b}$, and the Euler angles that transform the $\mathrm{Cu} g$-tensor frame into the Ti $g$-tensor frame set to $\{0,90,0\}$. The electron-electron interaction (Sys.ee) 
representing the diagonal elements of $\mathbf{J}$ was given an artificial initial value of $[-10,-10,20]$ and refined using the Levenberg-Marquardt algorithm as implemented in Matlab r2019b fitting iteratively by alternating between the raw data and its $1^{\text {st }}$ derivative, and were deemed to have converged when the best fit parameters fit against the CW-EPR spectrum and against its $1^{\text {st }}$ derivative agreed (the ${ }^{47} \mathrm{Ti}$ and ${ }^{49} \mathrm{Ti}$ hyperfine interactions were omitted during this procedure). Second, a final refinement unfroze and allowed small variation of the linewidths and $g$ factors minimized the fit residuals to give the final fit parameters. The Ti hyperfine (fit from $\mathbf{2 b}$ ) was reintroduced for final spectral simulations. CW-EPR fit parameters of 1-3, 2a, and $\mathbf{2 b}$ are tabulated in Table S1. While analytical error estimates for these fits are not available, artificially fixing the values of Sys.ee $\pm 1 \mathrm{MHz}$ from the best fit values gave measurably larger fit residuals, so we estimate their precision to be of approximately the same order.

Pulse EPR experiments were conducted at X-band frequency $(9.3-9.8 \mathrm{GHz})$ on a Bruker Elexsys E580 EPR spectrometer (Bruker Biospin) equipped with a split ring resonator (ER4118X-MS5) overcoupled to a Q $<200$ and employed a $1 \mathrm{~kW}$ TWT amplifier (Applied Systems Engineering) at Northwestern University. Temperature was controlled between 5 and 80K via an Oxford Instruments CF935 helium flow cryostat and an Oxford Instruments MercuryiTC temperature controller. Unless otherwise stated, microwave power attenuation was adjusted to achieve a $32 \mathrm{~ns}$ (EDFS, $T_{1}$, and $T_{\mathrm{m}}$ measurements) or $48 \mathrm{~ns}$ (tomography) $\pi$ pulse by variable power nutation experiments using a p $1-\pi / 2-\tau-\pi-\tau-$ echo sequence, taking the pulse length at the first minimum to be the $\pi$ pulse. All data were acquired in quadrature and $T_{1}$ and $T_{\mathrm{m}}$ measurements were phased in Matlab r2019b to maximize the real component of the echo.

$T_{1}$ measurements by saturation recovery were conducted with a picket fence, recovery, Hahn echo sequence (p1-T- $)_{8} \mathrm{t}-\pi / 2-\tau-\pi-\tau-$ echo. Saturation was effected with $\mathrm{p} 1$ of $20-24$ ns and $\mathrm{T}$ of $1-3 \mu$ s, with detection employing a $\tau$ of $200 \mathrm{~ns}$ (toluene) or $352 \mathrm{~ns}\left(\mathrm{CS}_{2}\right.$ :toluene- $\left.d_{8}\right)$. Recovery time, t, was varied logarithmically with delays of $(100,148,216,316,464,648 \mathrm{~ns})^{*} 10^{\mathrm{n}}$ from $\mathrm{n}=0$ to 7 . 4-step phase cycling was implemented for experiments with $n<7$, with 2 -step phase cycling used for $n \geq 7$. Saturation recovery data were fit to the following equation with accounts for relaxation via dipolar flip-flops with an aggregated, fast-relaxing defect population ${ }^{20} I(\mathrm{t})=1-A_{0} e^{-\left(\frac{\mathrm{t}}{T_{1}}+\sqrt{\frac{t}{a}}\right)}+A_{1}$, where $T_{1}$ is the spin-lattice relaxation time, $\mathrm{a}$ is the characteristic time for cross relaxation, $\mathrm{A}_{0}$ is the saturation depth, and $\mathrm{A}_{1}$ is the recovered echo intensity offset. Where fits including the "a" term diverged, it was fixed to an arbitrarily large value of $10^{9}$ and reported in the table with a -.

$T_{\mathrm{m}}$ measurements by Hahn-echo employed a $\pi / 2-\tau-\pi-\tau-$ echo sequence, with 4 -step phase cycling and a $\tau$ increment of $28 \mathrm{~ns}$. $T_{\mathrm{m}}$ measurements employing other turning angles were implemented without changing the pulse timings by adjusting the microwave attenuation. Data comparing $T_{\mathrm{m}}$ across temperatures 
were fit to a stretched exponential function which accounts for a continuous variation of the number and nature of dephasing mechanisms: $I(2 \tau)=A_{0} e^{-\left(\frac{2 \tau}{T_{\mathrm{m}}}\right)^{\beta}}$.

To compensate for changes in the echo decay shape from the variation in ESEEM excitation efficiency due to change in microwave power for comparisons of $T_{\mathrm{m}}$ vs turning angle at $10 \mathrm{~K}$, the data were fit to a biexponential function and the longer time constants compared. $I(2 \tau)=A\left((1-B) e^{-\left(\frac{2 \tau}{T_{\mathrm{m}}}\right)}+B e^{-\left(\frac{2 \tau}{b}\right)}\right)$

Quantum state tomography was performed at a center frequency of $9.44 \mathrm{GHz}$ and resonator Q of 116 and employed a [state preparation pulse(s)]- $\tau-\pi-\tau-$ echo sequence to measure $\left\langle S_{x}\right\rangle+i\left\langle S_{y}\right\rangle$ and a [state preparation pulse(s) $]-\tau-\pi-\tau-\pi / 2-\tau-$ echo sequence to measure $\left\langle S_{z}\right\rangle$. A $\tau$ of 400 ns and 4 or 16-step CYCLOPS $^{21}$ phase cycling were used for all measurements but the state preparation pulses were not phasecycled. The echo data were phased using the $+\mathrm{z}$ (no operation) as reference and zero-filled to $4 \mathrm{~K}$ points before windowing (Hamming) and FFT. The zero-frequency component approximately equals the integral over the echo, corresponding to the desired magnetization, whose sum of absolute values was normalized to 1 . The resulting density matrix is constructed by: $\left[\begin{array}{cc}1+\left\langle S_{z}\right\rangle & \left\langle S_{x}\right\rangle \\ \left\langle S_{y}\right\rangle & 1-\left\langle S_{z}\right\rangle\end{array}\right]$ To ensure consistent $T_{\mathrm{m}}$ between samples, toluene solvent and a temperature of $20 \mathrm{~K}$ was used for all tomography experiments. To reduce the potential impact of instantaneous diffusion, the $\mathrm{Ti}^{3+}$ centers were addressed away from the spectral maximum at the $\mathrm{Ti}^{3+} g_{\mathrm{y}}$ transition. 
Table S1 | Best fit EPR parameters for 2a, 2b, 1, 2, and 3. Transition-dependent line broadening due to unresolved hyperfine was modeled in Easyspin as " $g$ strain"

\begin{tabular}{|c|c|c|c|c|c|}
\hline & $2 a$ & $2 \mathbf{b}$ & 1 & 2 & 3 \\
\hline $\mathrm{Cu}^{2+} g_{\mathrm{x}}$ & 2.0486 & - & 2.0402 & 2.0486 & 2.0486 \\
\hline ( $g$ strain) & $(0.0051)$ & & $(0.0051)$ & $(0.0051)$ & $(0.0044)$ \\
\hline $\mathrm{Cu}^{2+} g_{\mathrm{y}}$ & 2.0486 & - & 2.0501 & 2.0486 & 2.0486 \\
\hline ( $g$ strain) & $(0.0051)$ & & $(0.0051)$ & $(0.0051)$ & $(0.0044)$ \\
\hline $\mathrm{Cu}^{2+} g_{\mathrm{z}}$ & 2.1892 & - & 2.1892 & 2.1894 & 2.1894 \\
\hline ( $g$ strain) & $(0.0073)$ & & $(0.0073)$ & $(0.0073)$ & $(0.0071)$ \\
\hline $\mathrm{Ti}^{3+} g_{\mathrm{x}}$ & - & 2.0014 & 2.0022 & 2.0015 & 2.0016 \\
\hline ( $g$ strain) & & $(0.0037)$ & $(0.0037)$ & $(0.0037)$ & $(0.0045)$ \\
\hline $\mathrm{Ti}^{3+} g_{\mathrm{y}}$ & - & 1.9525 & 1.9529 & 1.9523 & 1.9524 \\
\hline ( $g$ strain) & & $(0.0047)$ & $(0.0047)$ & $(0.0047)$ & $(0.0051)$ \\
\hline $\mathrm{Ti}^{3+} g_{z}$ & - & 1.9837 & 1.9841 & 1.9838 & 1.9837 \\
\hline ( $g$ strain) & & $(0.0030)$ & $(0.0050)$ & $(0.0030)$ & $(0.0041)$ \\
\hline $\mathrm{A}_{\mathrm{Cu}}(\mathrm{MHz})$ & [61.1 61.1614$]$ & - & {$\left[\begin{array}{llll}61.1 & 61.1 & 614\end{array}\right]$} & {$\left[\begin{array}{llll}61.1 & 61.1 & 614\end{array}\right]$} & {$\left[\begin{array}{llll}61.1 & 61.1 & 614\end{array}\right]$} \\
\hline $\mathrm{A}_{\mathrm{N}}(\mathrm{MHz})$ & [ 48.4 48.4 43.5] & - & [ 488.448 .4 43.5] & [ $\left.\begin{array}{llll}48.4 & 48.4 & 43.5\end{array}\right]$ & {$\left[\begin{array}{llll}48.4 & 48.4 & 43.5\end{array}\right]$} \\
\hline $\mathrm{A}_{\mathrm{Ti}}(\mathrm{MHz})$ & - & {$\left[\begin{array}{lll}4 & 41 & 32\end{array}\right]$} & {$\left[\begin{array}{lll}4 & 4 & 1\end{array}\right]$} & {$\left[\begin{array}{lll}4 & 41 & 32\end{array}\right]$} & {$\left[\begin{array}{lll}4 & 41 & 32\end{array}\right]$} \\
\hline$J(\mathrm{MHz})$ & - & - & +19.1 & +0.1 & -0.2 \\
\hline $\mathrm{D}_{\mathrm{xx}}(\mathrm{MHz})$ & - & - & -35.4 & -11.4 & -3.7 \\
\hline $\mathrm{D}_{\text {yy }}(\mathrm{MHz})$ & - & - & -32.4 & -6.0 & -2.7 \\
\hline $\mathrm{D}_{\mathrm{zz}}(\mathrm{MHz})$ & - & - & +67.8 & +17.4 & +6.4 \\
\hline
\end{tabular}

Table S2 | DFT calculated local moments on $\mathrm{Cu}$ and Ti for the bimetallic molecules 1, 2, and $\mathbf{3}$.

\begin{tabular}{cccc}
\hline Bimetallic Molecule & $d(\mathrm{Cu}-\mathrm{Ti})$ & $\mathrm{Cu}\left(\mu_{\mathrm{B}}\right)$ & $\mathrm{Ti}\left(\mu_{\mathrm{B}}\right)$ \\
\hline $\mathbf{1}$ & $1.16 \mathrm{~nm}$ & 0.56 & 0.80 \\
$\mathbf{2}$ & $1.85 \mathrm{~nm}$ & 0.55 & 0.78 \\
$\mathbf{3}$ & $2.53 \mathrm{~nm}$ & 0.55 & 0.80
\end{tabular}


Table S3 | Variable temperature pulse EPR data summary for 1, 2, 3, 2a, 2b in frozen toluene

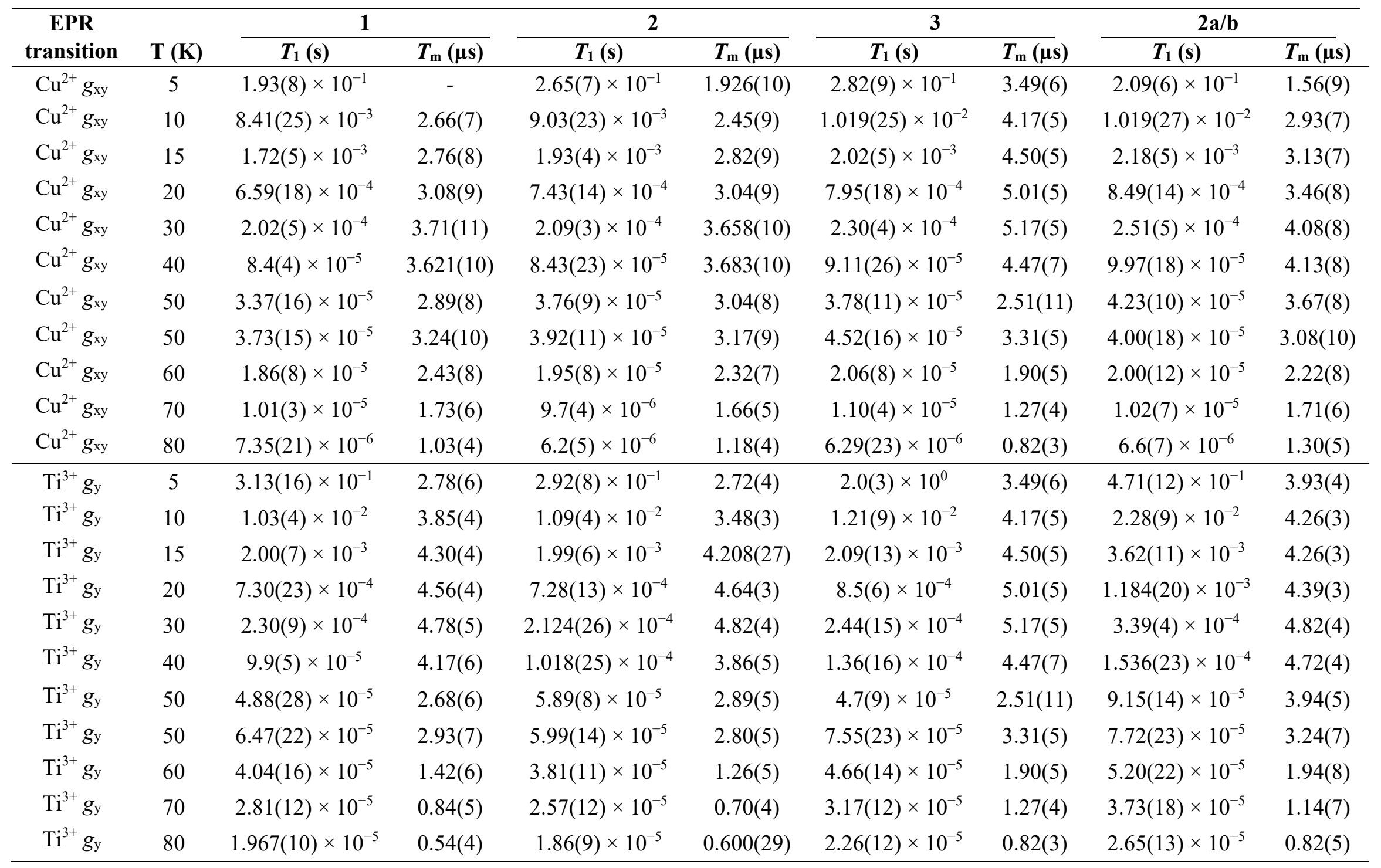


Table S4 | Variable temperature pulse EPR data summary for 1, 2, 3, 2a, 2b in frozen 1:1 CS 2 :toluene- $d_{8}$

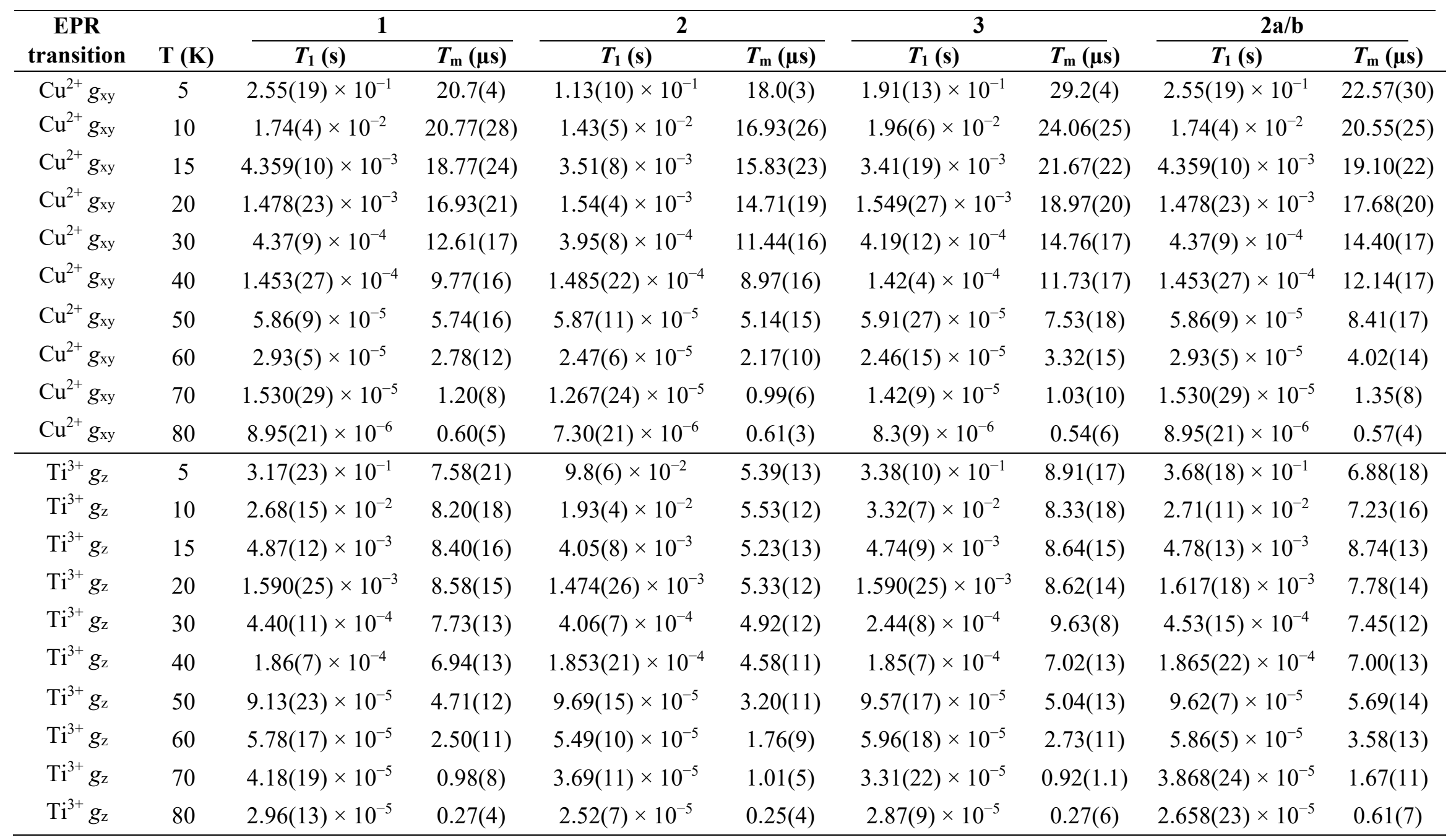


Table S5 | Saturation recovery fit parameters for 1 at $331 \mathrm{mT}$ and $9.5072 \mathrm{GHz}\left(\mathrm{Cu}^{2+} g_{x / y}\right)$ in toluene using the function: $I(\mathrm{t})=1-A_{0} e^{-\left(\frac{\mathrm{t}}{T_{1}}+\sqrt{\frac{t}{a}}\right)}+A_{1}$

\begin{tabular}{cccccc}
\hline $\mathbf{T}(\mathbf{K})$ & $\boldsymbol{T}_{\mathbf{1}} \mathbf{( s )}$ & $\mathbf{a}(\mathbf{s})$ & $\mathbf{A}_{\mathbf{0}}$ & $\mathbf{A}_{\mathbf{1}}$ & Reduced $\boldsymbol{X}^{\mathbf{2}}$ \\
\hline 5 & $1.93(8) \times 10^{-1}$ & $9.99(27) \times 10^{-2}$ & $9.874(20) \times 10^{-1}$ & $-8.7(1.6) \times 10^{-3}$ & $2.14 \times 10^{-5}$ \\
10 & $8.41(25) \times 10^{-3}$ & $2.06(12) \times 10^{-2}$ & $9.949(25) \times 10^{-1}$ & $-6.5(1.9) \times 10^{-3}$ & $3.19 \times 10^{-5}$ \\
15 & $1.72(5) \times 10^{-3}$ & $8.9(8) \times 10^{-3}$ & $9.94(3) \times 10^{-1}$ & $-6.9(2.2) \times 10^{-3}$ & $3.61 \times 10^{-5}$ \\
20 & $6.59(18) \times 10^{-4}$ & $5.3(6) \times 10^{-3}$ & $9.90(3) \times 10^{-1}$ & $-7.7(1.9) \times 10^{-3}$ & $3.56 \times 10^{-5}$ \\
30 & $2.02(5) \times 10^{-4}$ & $2.18(28) \times 10^{-3}$ & $1.001(3) \times 10^{0}$ & $-6.7(1.6) \times 10^{-3}$ & $3.26 \times 10^{-5}$ \\
40 & $8.4(4) \times 10^{-5}$ & $1.3(3) \times 10^{-3}$ & $9.96(6) \times 10^{-1}$ & $-1.92(25) \times 10^{-2}$ & $9.05 \times 10^{-5}$ \\
50 & $3.37(16) \times 10^{-5}$ & $4(3) \times 10^{-3}$ & $9.86(8) \times 10^{-1}$ & $-1.7(3) \times 10^{-2}$ & $1.18 \times 10^{-4}$ \\
50 & $3.73(15) \times 10^{-5}$ & $1.2(5) \times 10^{-3}$ & $1.002(6) \times 10^{0}$ & $-1.65(27) \times 10^{-2}$ & $7.95 \times 10^{-5}$ \\
60 & $1.86(8) \times 10^{-5}$ & $6.1(2.8) \times 10^{-4}$ & $1.028(8) \times 10^{0}$ & $-1.26(26) \times 10^{-2}$ & $8.72 \times 10^{-5}$ \\
70 & $1.01(3) \times 10^{-5}$ & $4.7(2.1) \times 10^{-4}$ & $1.063(7) \times 10^{0}$ & $-4.3(2.4) \times 10^{-3}$ & $4.60 \times 10^{-5}$ \\
80 & $7.35(21) \times 10^{-6}$ & $6.5(1.1) \times 10^{-5}$ & $1.025(6) \times 10^{0}$ & $-7.4(1.5) \times 10^{-3}$ & $2.09 \times 10^{-5}$ \\
\hline
\end{tabular}

Table S6 | Saturation recovery fit parameters for 1 at $348 \mathrm{mT}$ in and $9.5072 \mathrm{GHz}\left(\mathrm{Ti}^{3+} g_{\mathrm{y}}\right)$ toluene using the function: $I(\mathrm{t})=1-A_{0} e^{-\left(\frac{\mathrm{t}}{T_{1}}+\sqrt{\frac{t}{a}}\right)}+A_{1}$

\begin{tabular}{cccccc}
\hline $\mathbf{T}(\mathbf{K})$ & $\boldsymbol{T}_{\mathbf{1}}(\mathbf{s})$ & $\mathbf{a}(\mathbf{s})$ & $\mathbf{A}_{\mathbf{0}}$ & $\mathbf{A}_{\mathbf{1}}$ & Reduced $\boldsymbol{X}^{\mathbf{2}}$ \\
\hline 5 & $3.13(16) \times 10^{-1}$ & $1.47(5) \times 10^{-1}$ & $9.847(25) \times 10^{-1}$ & $-1.48(21) \times 10^{-2}$ & $2.95 \times 10^{-5}$ \\
10 & $1.03(4) \times 10^{-2}$ & $2.34(18) \times 10^{-2}$ & $9.95(3) \times 10^{-1}$ & $-1.01(25) \times 10^{-2}$ & $5.66 \times 10^{-5}$ \\
15 & $2.00(7) \times 10^{-3}$ & $9.9(1.1) \times 10^{-3}$ & $9.99(3) \times 10^{-1}$ & $-7.2(2.1) \times 10^{-3}$ & $5.78 \times 10^{-5}$ \\
20 & $7.30(23) \times 10^{-4}$ & $6.7(9) \times 10^{-3}$ & $9.92(3) \times 10^{-1}$ & $-9.3(2.0) \times 10^{-3}$ & $5.12 \times 10^{-5}$ \\
30 & $2.30(9) \times 10^{-4}$ & $2.1(4) \times 10^{-3}$ & $1.001(5) \times 10^{0}$ & $-1.39(25) \times 10^{-2}$ & $7.47 \times 10^{-5}$ \\
40 & $9.9(5) \times 10^{-5}$ & $2.2(9) \times 10^{-3}$ & $9.93(7) \times 10^{-1}$ & $-1.7(3) \times 10^{-2}$ & $1.39 \times 10^{-4}$ \\
50 & $4.88(28) \times 10^{-5}$ & $5(6) \times 10^{-3}$ & $9.64(9) \times 10^{-1}$ & $-2.9(4) \times 10^{-2}$ & $1.81 \times 10^{-4}$ \\
50 & $6.47(22) \times 10^{-5}$ & $1.2(3) \times 10^{-3}$ & $1.010(5) \times 10^{0}$ & $-1.08(24) \times 10^{-2}$ & $5.71 \times 10^{-5}$ \\
60 & $4.04(16) \times 10^{-5}$ & $5.6(1.4) \times 10^{-4}$ & $1.017(6) \times 10^{0}$ & $-1.49(25) \times 10^{-2}$ & $6.48 \times 10^{-5}$ \\
70 & $2.81(12) \times 10^{-5}$ & $2.1(4) \times 10^{-4}$ & $1.054(7) \times 10^{0}$ & $-5(3) \times 10^{-3}$ & $6.02 \times 10^{-5}$ \\
80 & $1.967(10) \times 10^{-5}$ & $1.32(29) \times 10^{-4}$ & $9.86(8) \times 10^{-1}$ & $-1.3(3) \times 10^{-2}$ & $6.78 \times 10^{-5}$ \\
\hline
\end{tabular}


Table S7 | Two-pulse Hahn echo decay fit parameters for 1 at $331 \mathrm{mT}$ and $9.5072 \mathrm{GHz}\left(\mathrm{Cu}^{2+} g_{\mathrm{x} / \mathrm{y}}\right)$ in toluene using a stretched exponential: $I(2 \tau)=A e^{-\left(\frac{2 \tau}{T_{\mathrm{m}}}\right)^{\beta}}$

\begin{tabular}{ccccc}
\hline $\mathbf{T}(\mathbf{K})$ & $\boldsymbol{T}_{\mathbf{m}}(\boldsymbol{\mu} \mathbf{s})$ & $\boldsymbol{\beta}$ & $\mathbf{A}$ & Reduced $\boldsymbol{X}^{\mathbf{2}}$ \\
\hline 10 & $2.66(7)$ & $0.870(21)$ & $0.986(18)$ & $5.78 \times 10^{-4}$ \\
15 & $2.76(8)$ & $0.863(22)$ & $0.984(19)$ & $6.66 \times 10^{-4}$ \\
20 & $3.08(9)$ & $0.889(24)$ & $0.949(19)$ & $8.31 \times 10^{-4}$ \\
30 & $3.71(11)$ & $0.960(29)$ & $0.888(18)$ & $1.08 \times 10^{-3}$ \\
40 & $3.621(10)$ & $0.967(27)$ & $0.885(17)$ & $9.48 \times 10^{-4}$ \\
50 & $2.89(8)$ & $0.905(22)$ & $0.940(17)$ & $6.27 \times 10^{-4}$ \\
50 & $3.24(10)$ & $0.943(28)$ & $0.971(23)$ & $8.37 \times 10^{-4}$ \\
60 & $2.43(8)$ & $0.867(23)$ & $1.077(27)$ & $5.43 \times 10^{-4}$ \\
70 & $1.73(6)$ & $0.810(20)$ & $1.22(3)$ & $3.16 \times 10^{-4}$ \\
80 & $1.03(4)$ & $0.733(16)$ & $1.53(4)$ & $1.55 \times 10^{-4}$ \\
\hline
\end{tabular}

Table S8 | Two-pulse Hahn echo decay fit parameters for 1 at $348 \mathrm{mT}$ and $9.5072 \mathrm{GHz}\left(\mathrm{Ti}^{3+} g_{\mathrm{y}}\right)$ in toluene using a stretched exponential: $I(2 \tau)=A e^{-\left(\frac{2 \tau}{T_{\mathrm{m}}}\right)^{\beta}}$

\begin{tabular}{ccccc}
\hline $\mathbf{T}(\mathbf{K})$ & $\boldsymbol{T}_{\mathbf{m}}(\boldsymbol{\mu} \mathbf{s})$ & $\boldsymbol{\beta}$ & $\mathbf{A}$ & Reduced $\boldsymbol{X}^{\mathbf{2}}$ \\
\hline 5 & $2.78(6)$ & $0.943(19)$ & $0.922(14)$ & $4.24 \times 10^{-4}$ \\
10 & $3.85(4)$ & $1.232(17)$ & $0.899(7)$ & $2.86 \times 10^{-4}$ \\
15 & $4.30(4)$ & $1.280(18)$ & $0.893(7)$ & $3.54 \times 10^{-4}$ \\
20 & $4.56(4)$ & $1.303(21)$ & $0.873(7)$ & $4.34 \times 10^{-4}$ \\
30 & $4.78(5)$ & $1.295(22)$ & $0.847(8)$ & $5.03 \times 10^{-4}$ \\
40 & $4.17(6)$ & $1.154(22)$ & $0.859(9)$ & $5.10 \times 10^{-4}$ \\
50 & $2.68(6)$ & $0.900(17)$ & $0.950(14)$ & $3.56 \times 10^{-4}$ \\
50 & $2.93(7)$ & $0.976(21)$ & $0.993(17)$ & $4.10 \times 10^{-4}$ \\
60 & $1.42(6)$ & $0.726(18)$ & $1.32(4)$ & $2.84 \times 10^{-4}$ \\
70 & $0.84(5)$ & $0.653(18)$ & $1.66(7)$ & $1.98 \times 10^{-4}$ \\
80 & $0.54(4)$ & $0.628(16)$ & $2.15(9)$ & $1.15 \times 10^{-4}$ \\
\hline
\end{tabular}


Table S9 | Saturation recovery fit parameters for $\mathbf{1}$ at $329 \mathrm{mT}$ and $9.4921 \mathrm{GHz}\left(\mathrm{Cu}^{2+} g_{\mathrm{x} / \mathrm{y}}\right)$ in $1: 1$ $\mathrm{CS}_{2}$ :toluene- $d_{8}$ using the function: $I(\mathrm{t})=1-A_{0} e^{-\left(\frac{\mathrm{t}}{T_{1}}+\sqrt{\frac{t}{a}}\right)}+A_{1}$

\begin{tabular}{cccccc}
\hline $\mathbf{T}(\mathbf{K})$ & $\boldsymbol{T}_{\mathbf{1}}(\mathbf{s})$ & $\mathbf{a}(\mathbf{s})$ & $\mathbf{A}_{\mathbf{0}}$ & $\mathbf{A}_{\mathbf{1}}$ & Reduced $\boldsymbol{X}^{\mathbf{2}}$ \\
\hline 5 & $2.55(19) \times 10^{-1}$ & $1.02(4) \times 10^{-1}$ & $8.784(29) \times 10^{-1}$ & $-4.0(2.4) \times 10^{-3}$ & $4.31 \times 10^{-5}$ \\
10 & $1.74(4) \times 10^{-2}$ & $5.57(26) \times 10^{-2}$ & $8.770(17) \times 10^{-1}$ & $-5.4(1.4) \times 10^{-3}$ & $1.37 \times 10^{-5}$ \\
15 & $4.359(10) \times 10^{-3}$ & $6.1(7) \times 10^{-2}$ & $9.602(25) \times 10^{-1}$ & $-1.47(20) \times 10^{-2}$ & $2.56 \times 10^{-5}$ \\
20 & $1.478(23) \times 10^{-3}$ & $4.1(5) \times 10^{-2}$ & $9.445(19) \times 10^{-1}$ & $-3.1(1.3) \times 10^{-3}$ & $1.35 \times 10^{-5}$ \\
30 & $4.37(9) \times 10^{-4}$ & $1.49(29) \times 10^{-2}$ & $9.080(25) \times 10^{-1}$ & $-1.06(15) \times 10^{-2}$ & $2.38 \times 10^{-5}$ \\
40 & $1.453(27) \times 10^{-4}$ & $1.2(4) \times 10^{-2}$ & $8.847(23) \times 10^{-1}$ & $-5.1(1.2) \times 10^{-3}$ & $1.83 \times 10^{-5}$ \\
50 & $5.86(9) \times 10^{-5}$ & $9(3) \times 10^{-3}$ & $8.937(23) \times 10^{-1}$ & $-4.4(1.1) \times 10^{-3}$ & $1.21 \times 10^{-5}$ \\
60 & $2.93(5) \times 10^{-5}$ & $3.0(9) \times 10^{-3}$ & $9.051(26) \times 10^{-1}$ & $-2.7(1.0) \times 10^{-3}$ & $1.20 \times 10^{-5}$ \\
70 & $1.530(29) \times 10^{-5}$ & $2.1(9) \times 10^{-3}$ & $9.14(3) \times 10^{-1}$ & $-3.5(1.1) \times 10^{-3}$ & $1.45 \times 10^{-5}$ \\
80 & $8.95(21) \times 10^{-6}$ & $1.1(6) \times 10^{-3}$ & $9.24(5) \times 10^{-1}$ & $-7.9(1.2) \times 10^{-3}$ & $2.00 \times 10^{-5}$ \\
\hline
\end{tabular}

Table S10 | Saturation recovery fit parameters for $\mathbf{1}$ at $342 \mathrm{mT}$ and $9.4921 \mathrm{GHz}\left(\mathrm{Ti}^{3+} g_{\mathrm{z}}\right)$ in $1: 1$ $\mathrm{CS}_{2}$ :toluene- $d_{8}$ using the function: $I(\mathrm{t})=1-A_{0} e^{-\left(\frac{\mathrm{t}}{T_{1}}+\sqrt{\frac{t}{a}}\right)}+A_{1}$

\begin{tabular}{cccccc}
\hline $\mathbf{T}(\mathbf{K})$ & $\boldsymbol{T}_{\mathbf{1}} \mathbf{( s )}$ & $\mathbf{a}(\mathbf{s})$ & $\mathbf{A}_{\mathbf{0}}$ & $\mathbf{A}_{\mathbf{1}}$ & Reduced $\boldsymbol{X}^{\mathbf{2}}$ \\
\hline 5 & $3.17(23) \times 10^{-1}$ & $2.96(21) \times 10^{-1}$ & $8.79(4) \times 10^{-1}$ & $-6(4) \times 10^{-3}$ & $8.59 \times 10^{-5}$ \\
10 & $2.68(15) \times 10^{-2}$ & $1.20(18) \times 10^{-1}$ & $8.77(4) \times 10^{-1}$ & $-8(3) \times 10^{-3}$ & $1.14 \times 10^{-4}$ \\
15 & $4.87(12) \times 10^{-3}$ & $2.3(6) \times 10^{-1}$ & $9.73(3) \times 10^{-1}$ & $-8.5(2.5) \times 10^{-3}$ & $3.98 \times 10^{-5}$ \\
20 & $1.590(25) \times 10^{-3}$ & $1.5(3) \times 10^{-1}$ & $9.504(20) \times 10^{-1}$ & $-4.1(1.5) \times 10^{-3}$ & $1.59 \times 10^{-5}$ \\
30 & $4.40(11) \times 10^{-4}$ & $2.9(9) \times 10^{-2}$ & $9.087(29) \times 10^{-1}$ & $-1.32(18) \times 10^{-2}$ & $3.43 \times 10^{-5}$ \\
40 & $1.86(7) \times 10^{-4}$ & $7.7(2.9) \times 10^{-3}$ & $8.88(4) \times 10^{-1}$ & $-1.68(22) \times 10^{-2}$ & $6.37 \times 10^{-5}$ \\
50 & $9.13(23) \times 10^{-5}$ & $3.4(9) \times 10^{-3}$ & $9.15(3) \times 10^{-1}$ & $-4.2(1.8) \times 10^{-3}$ & $2.87 \times 10^{-5}$ \\
60 & $5.78(17) \times 10^{-5}$ & $1.16(25) \times 10^{-3}$ & $9.34(4) \times 10^{-1}$ & $-5.5(1.9) \times 10^{-3}$ & $3.58 \times 10^{-5}$ \\
70 & $4.18(19) \times 10^{-5}$ & $3.6(8) \times 10^{-4}$ & $9.60(6) \times 10^{-1}$ & $-8.1(2.6) \times 10^{-3}$ & $7.38 \times 10^{-5}$ \\
80 & $2.96(13) \times 10^{-5}$ & $1.7(3) \times 10^{-4}$ & $9.86(6) \times 10^{-1}$ & $-3.6(2.3) \times 10^{-3}$ & $6.01 \times 10^{-5}$ \\
\hline
\end{tabular}


Table S11 | Two-pulse Hahn echo decay fit parameters for 1 at $329 \mathrm{mT}$ and $9.4921 \mathrm{GHz}\left(\mathrm{Cu}^{2+} g_{\mathrm{x} / \mathrm{y}}\right)$ in $1: 1$ $\mathrm{CS}_{2}:$ toluene- $d_{8}$ using a stretched exponential: $I(2 \tau)=A e^{-\left(\frac{2 \tau}{T_{\mathrm{m}}}\right)^{\beta}}$

\begin{tabular}{ccccc}
\hline $\mathbf{T}(\mathbf{K})$ & $\boldsymbol{T}_{\mathbf{m}}(\boldsymbol{\mu} \mathbf{s})$ & $\boldsymbol{\beta}$ & $\mathbf{A}$ & Reduced $\boldsymbol{X}^{\mathbf{2}}$ \\
\hline 5 & $20.7(4)$ & $0.797(14)$ & $0.764(9)$ & $9.33 \times 10^{-4}$ \\
10 & $20.77(28)$ & $0.979(16)$ & $0.749(7)$ & $1.06 \times 10^{-3}$ \\
15 & $18.77(24)$ & $1.035(16)$ & $0.749(7)$ & $1.09 \times 10^{-3}$ \\
20 & $16.93(21)$ & $1.125(18)$ & $0.738(7)$ & $1.11 \times 10^{-3}$ \\
30 & $12.61(17)$ & $1.204(22)$ & $0.741(8)$ & $1.14 \times 10^{-3}$ \\
40 & $9.77(16)$ & $1.071(21)$ & $0.795(10)$ & $9.98 \times 10^{-4}$ \\
50 & $5.74(16)$ & $0.866(19)$ & $0.961(18)$ & $8.04 \times 10^{-4}$ \\
60 & $2.78(12)$ & $0.692(16)$ & $1.33(4)$ & $5.32 \times 10^{-4}$ \\
70 & $1.20(8)$ & $0.588(14)$ & $2.06(8)$ & $2.90 \times 10^{-4}$ \\
80 & $0.60(5)$ & $0.555(14)$ & $3.09(16)$ & $1.70 \times 10^{-4}$ \\
\hline
\end{tabular}

Table S12 | Two-pulse Hahn echo decay fit parameters for 1 at $342 \mathrm{mT}$ and $9.4921 \mathrm{GHz}\left(\mathrm{Ti}^{3+} g_{z}\right)$ in 1:1 $\mathrm{CS}_{2}:$ toluene- $d_{8}$ using a stretched exponential function. $I(2 \tau)=A e^{-\left(\frac{2 \tau}{T_{\mathrm{m}}}\right)^{\beta}}$

\begin{tabular}{ccccc}
\hline $\mathbf{T}(\mathbf{K})$ & $\boldsymbol{T}_{\mathbf{m}}(\boldsymbol{\mu} \mathbf{s})$ & $\boldsymbol{\beta}$ & $\mathbf{A}$ & Reduced $\boldsymbol{X}^{\mathbf{2}}$ \\
\hline 5 & $7.58(21)$ & $0.698(11)$ & $0.897(14)$ & $5.06 \times 10^{-4}$ \\
10 & $8.20(18)$ & $0.780(12)$ & $1.026(14)$ & $7.25 \times 10^{-4}$ \\
15 & $8.40(16)$ & $0.832(12)$ & $0.991(12)$ & $6.97 \times 10^{-4}$ \\
20 & $8.58(15)$ & $0.895(14)$ & $0.953(11)$ & $7.05 \times 10^{-4}$ \\
30 & $7.73(13)$ & $0.976(16)$ & $0.927(12)$ & $7.13 \times 10^{-4}$ \\
40 & $6.94(13)$ & $0.951(16)$ & $0.944(13)$ & $6.70 \times 10^{-4}$ \\
50 & $4.71(12)$ & $0.840(16)$ & $1.061(19)$ & $5.68 \times 10^{-4}$ \\
60 & $2.50(11)$ & $0.709(16)$ & $1.36(4)$ & $4.35 \times 10^{-4}$ \\
70 & $0.98(8)$ & $0.584(17)$ & $2.16(10)$ & $2.91 \times 10^{-4}$ \\
80 & $0.27(4)$ & $0.481(18)$ & $4.8(5)$ & $1.84 \times 10^{-4}$ \\
\hline
\end{tabular}

Table S13 | Variable turning angle two-pulse Hahn echo decay fit parameters for 1 at $328 \mathrm{mT}$ and 9.3673 $\mathrm{GHz}\left(\mathrm{Cu}^{2+} g_{\mathrm{x} / \mathrm{y}}\right)$ in 1:1 $\mathrm{CS}_{2}:$ toluene- $d_{8}$ using the function: $I(2 \tau)=A\left((1-B) e^{-\left(\frac{2 \tau}{T_{\mathrm{m}}}\right)}+B e^{-\left(\frac{2 \tau}{b}\right)}\right)$

\begin{tabular}{cccccc}
\hline $\boldsymbol{\theta}$ & $\boldsymbol{T}_{\mathbf{m}}(\boldsymbol{\mu} \mathbf{s})$ & $\mathbf{b}$ & $\mathbf{A}$ & B & Reduced $\boldsymbol{X}^{\mathbf{2}}$ \\
\hline$\pi$ & $20.77(11)$ & $0.374(21)$ & $3.8(4)$ & $0.820(21)$ & $8.20 \times 10^{-1}$ \\
$4 \pi / 7$ & $22.74(12)$ & $0.484(19)$ & $2.86(18)$ & $0.780(13)$ & $7.80 \times 10^{-1}$ \\
$8 \pi / 21$ & $24.00(13)$ & $0.581(18)$ & $2.43(10)$ & $0.7631(10)$ & $7.63 \times 10^{-1}$ \\
\hline
\end{tabular}


Table S14 | Variable turning angle two-pulse Hahn echo decay fit parameters for $\mathbf{1}$ at $334 \mathrm{mT}$ and 9.3673 $\mathrm{GHz}\left(\mathrm{Ti}^{3+} g_{\mathrm{z}}\right)$ in 1:1 $\mathrm{CS}_{2}:$ toluene- $d_{8}$ using the function: $I(2 \tau)=A\left((1-B) e^{-\left(\frac{2 \tau}{T_{\mathrm{m}}}\right)}+B e^{-\left(\frac{2 \tau}{b}\right)}\right)$

\begin{tabular}{cccccc}
\hline $\boldsymbol{\theta}$ & $\boldsymbol{T}_{\mathbf{m}}(\boldsymbol{\mu} \mathbf{s})$ & $\mathbf{b}$ & $\mathbf{A}$ & $\mathbf{B}$ & Reduced $\boldsymbol{X}^{\mathbf{2}}$ \\
\hline$\pi$ & $13.66(29)$ & $3.11(26)$ & $0.995(14)$ & $0.389(18)$ & $3.89 \times 10^{-1}$ \\
$4 \pi / 7$ & $18.58(27)$ & $2.57(12)$ & $1.043(14)$ & $0.503(8)$ & $5.03 \times 10^{-1}$ \\
$8 \pi / 21$ & $22.72(28)$ & $2.27(8)$ & $1.082(15)$ & $0.572(6)$ & $5.72 \times 10^{-1}$ \\
\hline
\end{tabular}

Table S15 | Saturation recovery fit parameters for 2 at $330 \mathrm{mT}$ and $9.4985 \mathrm{GHz}\left(\mathrm{Cu}^{2+} g_{\mathrm{x} / \mathrm{y}}\right)$ in toluene using the function: $I(\mathrm{t})=1-A_{0} e^{-\left(\frac{\mathrm{t}}{T_{1}}+\sqrt{\frac{t}{a}}\right)}+A_{1}$

\begin{tabular}{cccccc}
\hline $\mathbf{T}(\mathbf{K})$ & $\boldsymbol{T}_{\mathbf{1}} \mathbf{( s )}$ & $\mathbf{a}(\mathbf{s})$ & $\mathbf{A}_{\mathbf{0}}$ & $\mathbf{A}_{\mathbf{1}}$ & Reduced $\boldsymbol{X}^{\mathbf{2}}$ \\
\hline 5 & $2.65(7) \times 10^{-1}$ & $3.39(11) \times 10^{-1}$ & $9.863(22) \times 10^{-1}$ & $-1.07(19) \times 10^{-2}$ & $1.74 \times 10^{-5}$ \\
10 & $9.03(23) \times 10^{-3}$ & $4.4(3) \times 10^{-2}$ & $9.895(26) \times 10^{-1}$ & $-6.9(2.0) \times 10^{-3}$ & $2.83 \times 10^{-5}$ \\
15 & $1.93(4) \times 10^{-3}$ & $1.79(17) \times 10^{-2}$ & $9.860(26) \times 10^{-1}$ & $-6.7(2.0) \times 10^{-3}$ & $2.63 \times 10^{-5}$ \\
20 & $7.43(14) \times 10^{-4}$ & $1.26(14) \times 10^{-2}$ & $9.780(22) \times 10^{-1}$ & $-5.0(1.4) \times 10^{-3}$ & $1.86 \times 10^{-5}$ \\
30 & $2.09(3) \times 10^{-4}$ & $7.4(1.0) \times 10^{-3}$ & $9.647(21) \times 10^{-1}$ & $-4.7(1.4) \times 10^{-3}$ & $1.20 \times 10^{-5}$ \\
40 & $8.43(23) \times 10^{-5}$ & $4.1(1.3) \times 10^{-3}$ & $9.50(4) \times 10^{-1}$ & $-1.41(20) \times 10^{-2}$ & $3.67 \times 10^{-5}$ \\
50 & $3.76(9) \times 10^{-5}$ & $2.0(6) \times 10^{-3}$ & $9.53(4) \times 10^{-1}$ & $-6.4(2.2) \times 10^{-3}$ & $2.44 \times 10^{-5}$ \\
50 & $3.92(11) \times 10^{-5}$ & $3.3(1.5) \times 10^{-3}$ & $9.99(5) \times 10^{-1}$ & $-8.9(2.0) \times 10^{-3}$ & $4.47 \times 10^{-5}$ \\
60 & $1.95(8) \times 10^{-5}$ & $6.4(2.8) \times 10^{-4}$ & $1.017(7) \times 10^{0}$ & $-1.79(26) \times 10^{-2}$ & $8.18 \times 10^{-5}$ \\
70 & $9.7(4) \times 10^{-6}$ & $1.4(1.4) \times 10^{-3}$ & $1.036(9) \times 10^{0}$ & $-1.3(3) \times 10^{-2}$ & $7.43 \times 10^{-5}$ \\
80 & $6.2(5) \times 10^{-6}$ & $2.7(2.9) \times 10^{-4}$ & $1.067(19) \times 10^{0}$ & $-2.7(5) \times 10^{-2}$ & $2.32 \times 10^{-4}$ \\
\hline
\end{tabular}


Table S16 | Saturation recovery fit parameters for 2 at $347 \mathrm{mT}$ and $9.4985 \mathrm{GHz}\left(\mathrm{Ti}^{3+} g_{\mathrm{y}}\right)$ in toluene using the function: $I(\mathrm{t})=1-A_{0} e^{-\left(\frac{\mathrm{t}}{T_{1}}+\sqrt{\frac{t}{a}}\right)}+A_{1}$

\begin{tabular}{cccccc}
\hline $\mathbf{T}(\mathbf{K})$ & $\boldsymbol{T}_{\mathbf{1}}(\mathbf{s})$ & $\mathbf{a}(\mathbf{s})$ & $\mathbf{A}_{\mathbf{0}}$ & $\mathbf{A}_{\mathbf{1}}$ & Reduced $\boldsymbol{X}^{\mathbf{2}}$ \\
\hline 5 & $2.92(8) \times 10^{-1}$ & $8.0(4) \times 10^{-1}$ & $9.863(26) \times 10^{-1}$ & $-1.27(23) \times 10^{-2}$ & $2.22 \times 10^{-5}$ \\
10 & $1.09(4) \times 10^{-2}$ & $6.7(8) \times 10^{-2}$ & $9.88(4) \times 10^{-1}$ & $-1.1(3) \times 10^{-2}$ & $5.98 \times 10^{-5}$ \\
15 & $1.99(6) \times 10^{-3}$ & $2.9(5) \times 10^{-2}$ & $9.83(4) \times 10^{-1}$ & $-1.00(29) \times 10^{-2}$ & $5.53 \times 10^{-5}$ \\
20 & $7.28(13) \times 10^{-4}$ & $2.04(28) \times 10^{-2}$ & $9.781(21) \times 10^{-1}$ & $-4.1(1.4) \times 10^{-3}$ & $1.81 \times 10^{-5}$ \\
30 & $2.124(26) \times 10^{-4}$ & $1.37(22) \times 10^{-2}$ & $9.645(18) \times 10^{-1}$ & $-5.2(1.2) \times 10^{-3}$ & $8.71 \times 10^{-6}$ \\
40 & $1.018(25) \times 10^{-4}$ & $7.5(2.6) \times 10^{-3}$ & $9.56(4) \times 10^{-1}$ & $-1.20(20) \times 10^{-2}$ & $3.17 \times 10^{-5}$ \\
50 & $5.89(8) \times 10^{-5}$ & $3.7(6) \times 10^{-3}$ & $9.752(23) \times 10^{-1}$ & $-1.1(1.5) \times 10^{-3}$ & $7.94 \times 10^{-6}$ \\
50 & $5.99(14) \times 10^{-5}$ & $4.3(1.5) \times 10^{-3}$ & $9.96(4) \times 10^{-1}$ & $-1.08(15) \times 10^{-2}$ & $3.21 \times 10^{-5}$ \\
60 & $3.81(11) \times 10^{-5}$ & $1.5(5) \times 10^{-3}$ & $1.006(5) \times 10^{0}$ & $-1.34(20) \times 10^{-2}$ & $4.51 \times 10^{-5}$ \\
70 & $2.57(12) \times 10^{-5}$ & $7(3) \times 10^{-4}$ & $1.023(8) \times 10^{0}$ & $-1.1(4) \times 10^{-2}$ & $9.01 \times 10^{-5}$ \\
80 & $1.86(9) \times 10^{-5}$ & $3.9(1.6) \times 10^{-4}$ & $1.040(9) \times 10^{0}$ & $-1.1(4) \times 10^{-2}$ & $9.74 \times 10^{-5}$ \\
\hline
\end{tabular}

Table S17 | Two-pulse Hahn echo decay fit parameters for 2 at $330 \mathrm{mT}$ and $9.4985 \mathrm{GHz}\left(\mathrm{Cu}^{2+} g_{\mathrm{x} / \mathrm{y}}\right)$ in toluene using a stretched exponential function: $I(2 \tau)=A e^{-\left(\frac{2 \tau}{T_{\mathrm{m}}}\right)^{\beta}}$

\begin{tabular}{ccccc}
\hline $\mathbf{T}(\mathbf{K})$ & $\boldsymbol{T}_{\mathbf{m}}(\boldsymbol{\mu} \mathbf{s})$ & $\boldsymbol{\beta}$ & $\mathbf{A}$ & Reduced $\boldsymbol{X}^{\mathbf{2}}$ \\
\hline 5 & $1.926(10)$ & $0.727(21)$ & $1.23(4)$ & $6.70 \times 10^{-4}$ \\
10 & $2.45(9)$ & $0.814(21)$ & $1.041(26)$ & $6.57 \times 10^{-4}$ \\
15 & $2.82(9)$ & $0.861(22)$ & $1.043(23)$ & $7.65 \times 10^{-4}$ \\
20 & $3.04(9)$ & $0.869(21)$ & $0.957(18)$ & $9.51 \times 10^{-4}$ \\
30 & $3.658(10)$ & $0.935(25)$ & $0.896(17)$ & $1.22 \times 10^{-3}$ \\
40 & $3.683(10)$ & $0.950(25)$ & $0.885(17)$ & $1.25 \times 10^{-3}$ \\
50 & $3.04(8)$ & $0.878(21)$ & $0.942(18)$ & $9.11 \times 10^{-4}$ \\
50 & $3.17(9)$ & $0.908(24)$ & $0.901(17)$ & $1.03 \times 10^{-3}$ \\
60 & $2.32(7)$ & $0.822(19)$ & $0.995(20)$ & $6.80 \times 10^{-4}$ \\
70 & $1.66(5)$ & $0.780(17)$ & $1.085(22)$ & $4.40 \times 10^{-4}$ \\
80 & $1.18(4)$ & $0.754(18)$ & $1.196(29)$ & $3.70 \times 10^{-4}$ \\
\hline
\end{tabular}


Table S18 | Two-pulse Hahn echo decay fit parameters for 2 at $347 \mathrm{mT}$ and $9.4985 \mathrm{GHz}\left(\mathrm{Ti}^{3+} g_{\mathrm{y}}\right)$ in toluene using a stretched exponential function: $I(2 \tau)=A e^{-\left(\frac{2 \tau}{T_{\mathrm{m}}}\right)^{\beta}}$

\begin{tabular}{ccccc}
\hline $\mathbf{T}(\mathbf{K})$ & $\boldsymbol{T}_{\mathbf{m}}(\boldsymbol{\mu} \mathbf{s})$ & $\boldsymbol{\beta}$ & $\mathbf{A}$ & Reduced $\boldsymbol{X}^{\mathbf{2}}$ \\
\hline 5 & $2.72(4)$ & $0.975(12)$ & $0.561(6)$ & $5.82 \times 10^{-5}$ \\
10 & $3.48(3)$ & $1.165(13)$ & $0.935(7)$ & $1.84 \times 10^{-4}$ \\
15 & $4.208(27)$ & $1.299(13)$ & $0.963(6)$ & $2.14 \times 10^{-4}$ \\
20 & $4.64(3)$ & $1.336(16)$ & $0.891(6)$ & $3.89 \times 10^{-4}$ \\
30 & $4.82(4)$ & $1.344(18)$ & $0.873(6)$ & $4.60 \times 10^{-4}$ \\
40 & $3.86(5)$ & $1.144(19)$ & $0.871(9)$ & $5.34 \times 10^{-4}$ \\
50 & $2.89(5)$ & $0.958(15)$ & $0.927(11)$ & $3.74 \times 10^{-4}$ \\
50 & $2.80(5)$ & $0.948(18)$ & $0.918(13)$ & $5.02 \times 10^{-4}$ \\
60 & $1.26(5)$ & $0.680(15)$ & $1.171(28)$ & $3.36 \times 10^{-4}$ \\
70 & $0.70(4)$ & $0.598(14)$ & $1.47(4)$ & $2.32 \times 10^{-4}$ \\
80 & $0.600(29)$ & $0.629(14)$ & $1.55(4)$ & $1.67 \times 10^{-4}$ \\
\hline
\end{tabular}

Table S19 | Saturation recovery fit parameters for 2 at $329 \mathrm{mT}$ and $9.4798 \mathrm{GHz}\left(\mathrm{Cu}^{2+} g_{\mathrm{x} / \mathrm{y}}\right)$ in $1: 1$ $\mathrm{CS}_{2}$ :toluene- $d_{8}$ using the function $I(\mathrm{t})=1-A_{0} e^{-\left(\frac{\mathrm{t}}{T_{1}}+\sqrt{\frac{t}{a}}\right)}+A_{1}$

\begin{tabular}{cccccc}
\hline $\mathbf{T}(\mathbf{K})$ & $\boldsymbol{T}_{\mathbf{1}} \mathbf{( s )}$ & $\mathbf{a}(\mathbf{s})$ & $\mathbf{A}_{\mathbf{0}}$ & $\mathbf{A}_{\mathbf{1}}$ & Reduced $\boldsymbol{X}^{\mathbf{2}}$ \\
\hline 5 & $1.13(10) \times 10^{-1}$ & $2.35(25) \times 10^{-1}$ & $9.65(13) \times 10^{-1}$ & $2.1(1.2) \times 10^{-2}$ & $1.18 \times 10^{-4}$ \\
10 & $1.43(5) \times 10^{-2}$ & $1.66(25) \times 10^{-1}$ & $9.74(4) \times 10^{-1}$ & $-1.2(3) \times 10^{-2}$ & $5.89 \times 10^{-5}$ \\
15 & $3.51(8) \times 10^{-3}$ & $1.36(26) \times 10^{-1}$ & $9.486(29) \times 10^{-1}$ & $-5.8(2.3) \times 10^{-3}$ & $2.70 \times 10^{-5}$ \\
20 & $1.54(4) \times 10^{-3}$ & $5.7(1.5) \times 10^{-2}$ & $9.03(3) \times 10^{-1}$ & $-1.68(25) \times 10^{-2}$ & $4.47 \times 10^{-5}$ \\
30 & $3.95(8) \times 10^{-4}$ & $3.1(9) \times 10^{-2}$ & $8.390(23) \times 10^{-1}$ & $-5.1(1.4) \times 10^{-3}$ & $2.16 \times 10^{-5}$ \\
40 & $1.485(22) \times 10^{-4}$ & $4.5(1.9) \times 10^{-2}$ & $8.173(19) \times 10^{-1}$ & $-2.6(1.1) \times 10^{-3}$ & $9.40 \times 10^{-6}$ \\
50 & $5.87(11) \times 10^{-5}$ & $1.1(5) \times 10^{-2}$ & $8.277(24) \times 10^{-1}$ & $-3.4(1.2) \times 10^{-3}$ & $1.37 \times 10^{-5}$ \\
60 & $2.47(6) \times 10^{-5}$ & $2.9(1.3) \times 10^{-3}$ & $8.38(3) \times 10^{-1}$ & $-4.1(1.3) \times 10^{-3}$ & $2.00 \times 10^{-5}$ \\
70 & $1.267(24) \times 10^{-5}$ & $1.8(8) \times 10^{-3}$ & $8.43(3) \times 10^{-1}$ & $-3.8(9) \times 10^{-3}$ & $1.17 \times 10^{-5}$ \\
80 & $7.30(21) \times 10^{-6}$ & $1.2(9) \times 10^{-3}$ & $8.43(6) \times 10^{-1}$ & $-5.9(1.6) \times 10^{-3}$ & $2.33 \times 10^{-5}$ \\
\hline
\end{tabular}


Table S20 | Saturation recovery fit parameters for 2 at $341 \mathrm{mT}$ and $9.4798 \mathrm{GHz}\left(\mathrm{Ti}^{3+} g_{\mathrm{z}}\right)$ in $1: 1$ $\mathrm{CS}_{2}$ :toluene- $d_{8}$ using the function $I(\mathrm{t})=1-A_{0} e^{-\left(\frac{\mathrm{t}}{T_{1}}+\sqrt{\frac{t}{a}}\right)}+A_{1}$

\begin{tabular}{cccccc}
\hline $\mathbf{T}(\mathbf{K})$ & $\boldsymbol{T}_{\mathbf{1}}(\mathbf{s})$ & $\mathbf{a}(\mathbf{s})$ & $\mathbf{A}_{\mathbf{0}}$ & $\mathbf{A}_{\mathbf{1}}$ & $\mathbf{R e d u c e d} \boldsymbol{X}^{\mathbf{2}}$ \\
\hline 5 & $9.8(6) \times 10^{-2}$ & $1.00(19) \times 10^{0}$ & $9.70(12) \times 10^{-1}$ & $3.3(1.1) \times 10^{-2}$ & $9.68 \times 10^{-5}$ \\
10 & $1.93(4) \times 10^{-2}$ & $10.0(2.3) \times 10^{-1}$ & $9.83(3) \times 10^{-1}$ & $-7.6(2.8) \times 10^{-3}$ & $3.64 \times 10^{-5}$ \\
15 & $4.05(8) \times 10^{-3}$ & $4.5(1.3) \times 10^{-1}$ & $9.630(28) \times 10^{-1}$ & $-5.6(2.3) \times 10^{-3}$ & $2.39 \times 10^{-5}$ \\
20 & $1.474(26) \times 10^{-3}$ & $3.6(1.5) \times 10^{-1}$ & $9.284(23) \times 10^{-1}$ & $-7.8(1.7) \times 10^{-3}$ & $2.03 \times 10^{-5}$ \\
30 & $4.06(7) \times 10^{-4}$ & $3.0(2.3) \times 10^{-1}$ & $8.759(22) \times 10^{-1}$ & $-6.6(1.3) \times 10^{-3}$ & $1.91 \times 10^{-5}$ \\
40 & $1.853(21) \times 10^{-4}$ & $1.7(9) \times 10^{-1}$ & $8.607(15) \times 10^{-1}$ & $-2.45(10) \times 10^{-3}$ & $6.53 \times 10^{-6}$ \\
50 & $9.69(15) \times 10^{-5}$ & $2.1(8) \times 10^{-2}$ & $8.760(22) \times 10^{-1}$ & $-3.8(1.2) \times 10^{-3}$ & $1.21 \times 10^{-5}$ \\
60 & $5.49(10) \times 10^{-5}$ & $3.5(9) \times 10^{-3}$ & $9.058(26) \times 10^{-1}$ & $-3.3(1.3) \times 10^{-3}$ & $1.57 \times 10^{-5}$ \\
70 & $3.69(11) \times 10^{-5}$ & $1.1(3) \times 10^{-3}$ & $9.28(4) \times 10^{-1}$ & $-4.1(1.8) \times 10^{-3}$ & $3.71 \times 10^{-5}$ \\
80 & $2.52(7) \times 10^{-5}$ & $5.1(1.2) \times 10^{-4}$ & $9.45(5) \times 10^{-1}$ & $-3.5(2.2) \times 10^{-3}$ & $2.96 \times 10^{-5}$ \\
\hline
\end{tabular}

Table S21 | Two-pulse Hahn echo decay fit parameters for 2 at $329 \mathrm{mT}$ and $9.4798 \mathrm{GHz}\left(\mathrm{Cu}^{2+} g_{\mathrm{x} / \mathrm{y}}\right)$ in $1: 1$ $\mathrm{CS}_{2}$ :toluene- $d_{8}$ using a stretched exponential function: $I(2 \tau)=A e^{-\left(\frac{2 \tau}{T_{\mathrm{m}}}\right)^{\beta}}$

\begin{tabular}{ccccc}
\hline $\mathbf{T}(\mathbf{K})$ & $\boldsymbol{T}_{\mathbf{m}}(\boldsymbol{\mu} \mathbf{s})$ & $\boldsymbol{\beta}$ & $\mathbf{A}$ & Reduced $\boldsymbol{X}^{\mathbf{2}}$ \\
\hline 5 & $18.0(3)$ & $0.853(14)$ & $0.620(7)$ & $5.53 \times 10^{-4}$ \\
10 & $16.93(26)$ & $0.951(15)$ & $0.488(5)$ & $3.96 \times 10^{-4}$ \\
15 & $15.83(23)$ & $1.029(17)$ & $0.745(8)$ & $1.05 \times 10^{-3}$ \\
20 & $14.71(19)$ & $1.124(19)$ & $0.739(8)$ & $1.07 \times 10^{-3}$ \\
30 & $11.44(16)$ & $1.178(22)$ & $0.750(9)$ & $1.08 \times 10^{-3}$ \\
40 & $8.97(16)$ & $1.079(22)$ & $0.800(11)$ & $9.83 \times 10^{-4}$ \\
50 & $5.14(15)$ & $0.857(19)$ & $0.996(20)$ & $7.54 \times 10^{-4}$ \\
60 & $2.17(10)$ & $0.669(15)$ & $1.51(4)$ & $4.07 \times 10^{-4}$ \\
70 & $0.99(6)$ & $0.591(13)$ & $2.31(8)$ & $1.93 \times 10^{-4}$ \\
80 & $0.61(3)$ & $0.598(12)$ & $3.15(12)$ & $8.40 \times 10^{-5}$ \\
\hline
\end{tabular}


Table S22 | Two-pulse Hahn echo decay fit parameters for 2 at $341 \mathrm{mT}$ and $9.4798 \mathrm{GHz}\left(\mathrm{Ti}^{3+} g_{\mathrm{z}}\right)$ in $1: 1$ $\mathrm{CS}_{2}$ :toluene- $d_{8}$ using a stretched exponential function: $I(2 \tau)=A e^{-\left(\frac{2 \tau}{T_{\mathrm{m}}}\right)^{\beta}}$

\begin{tabular}{ccccc}
\hline $\mathbf{T}(\mathbf{K})$ & $\boldsymbol{T}_{\mathbf{m}}(\boldsymbol{\mu} \mathbf{s})$ & $\boldsymbol{\beta}$ & $\mathbf{A}$ & Reduced $\boldsymbol{X}^{\mathbf{2}}$ \\
\hline 5 & $5.39(13)$ & $0.812(14)$ & $0.865(14)$ & $3.54 \times 10^{-4}$ \\
10 & $5.53(12)$ & $0.855(14)$ & $1.044(16)$ & $5.50 \times 10^{-4}$ \\
15 & $5.23(13)$ & $0.839(15)$ & $1.019(17)$ & $5.46 \times 10^{-4}$ \\
20 & $5.33(12)$ & $0.874(16)$ & $1.036(17)$ & $5.89 \times 10^{-4}$ \\
30 & $4.92(12)$ & $0.895(17)$ & $1.028(17)$ & $5.74 \times 10^{-4}$ \\
40 & $4.58(11)$ & $0.892(18)$ & $1.044(18)$ & $5.53 \times 10^{-4}$ \\
50 & $3.20(11)$ & $0.803(18)$ & $1.200(28)$ & $4.83 \times 10^{-4}$ \\
60 & $1.76(9)$ & $0.697(18)$ & $1.56(5)$ & $3.58 \times 10^{-4}$ \\
70 & $1.01(5)$ & $0.633(15)$ & $1.71(6)$ & $2.37 \times 10^{-4}$ \\
80 & $0.25(4)$ & $0.504(18)$ & $5.5(5)$ & $1.38 \times 10^{-4}$ \\
\hline
\end{tabular}

Table S23 | Variable turning angle two-pulse Hahn echo decay fit parameters for $\mathbf{2}$ at $328 \mathrm{mT}$ and 9.4906 $\mathrm{GHz}\left(\mathrm{Cu}^{2+} g_{\mathrm{x} / \mathrm{y}}\right)$ in 1:1 $\mathrm{CS}_{2}:$ toluene- $d_{8}$ using the function: $I(2 \tau)=A\left((1-B) e^{-\left(\frac{2 \tau}{T_{\mathrm{m}}}\right)}+B e^{-\left(\frac{2 \tau}{b}\right)}\right)$

\begin{tabular}{cccccc}
\hline $\boldsymbol{\theta}$ & $\boldsymbol{T}_{\mathbf{m}}(\boldsymbol{\mu} \mathbf{s})$ & $\mathbf{b}$ & $\mathbf{A}$ & $\mathbf{B}$ & Reduced $\boldsymbol{X}^{\mathbf{2}}$ \\
\hline$\pi$ & $17.65(11)$ & $0.346(28)$ & $3.5(5)$ & $0.79(3)$ & $7.88 \times 10^{-1}$ \\
$4 \pi / 7$ & $20.46(14)$ & $0.35(3)$ & $3.4(6)$ & $0.78(4)$ & $7.80 \times 10^{-1}$ \\
$8 \pi / 21$ & $22.45(16)$ & $0.34(3)$ & $3.6(7)$ & $0.79(4)$ & $7.92 \times 10^{-1}$ \\
\hline
\end{tabular}

Table S24 | Variable turning angle two-pulse Hahn echo decay fit parameters for $\mathbf{2}$ at $342 \mathrm{mT}$ and 9.4906 $\mathrm{GHz}\left(\mathrm{Ti}^{3+} g_{\mathrm{z}}\right)$ in 1:1 $\mathrm{CS}_{2}:$ toluene- $d_{8}$ using the function: $I(2 \tau)=A\left((1-B) e^{-\left(\frac{2 \tau}{T_{\mathrm{m}}}\right)}+B e^{-\left(\frac{2 \tau}{b}\right)}\right)$

\begin{tabular}{cccccc}
\hline $\boldsymbol{\theta}$ & $\boldsymbol{T}_{\mathbf{m}}(\boldsymbol{\mu} \mathbf{s})$ & $\mathbf{b}$ & $\mathbf{A}$ & $\mathbf{B}$ & Reduced $\boldsymbol{X}^{\mathbf{2}}$ \\
\hline$\pi$ & $7.21(5)$ & $0.21(3)$ & $7(4)$ & $0.87(7)$ & $8.67 \times 10^{-1}$ \\
$4 \pi / 7$ & $10.93(8)$ & $0.29(4)$ & $3.8(1.0)$ & $0.78(6)$ & $7.80 \times 10^{-1}$ \\
$8 \pi / 21$ & $15.41(11)$ & $0.37(4)$ & $2.6(5)$ & $0.70(6)$ & $6.98 \times 10^{-1}$ \\
\hline
\end{tabular}


Table S25 | Saturation recovery fit parameters for 3 at $329 \mathrm{mT}$ and $9.4990 \mathrm{GHz}\left(\mathrm{Cu}^{2+} g_{\mathrm{x} / \mathrm{y}}\right)$ in toluene using the function: $I(\mathrm{t})=1-A_{0} e^{-\left(\frac{\mathrm{t}}{T_{1}}+\sqrt{\frac{t}{a}}\right)}+A_{1}$

\begin{tabular}{cccccc}
\hline $\mathbf{T}(\mathbf{K})$ & $\boldsymbol{T}_{\mathbf{1}} \mathbf{( s )}$ & $\mathbf{a}(\mathbf{s})$ & $\mathbf{A}_{\mathbf{0}}$ & $\mathbf{A}_{\mathbf{1}}$ & Reduced $\boldsymbol{X}^{\mathbf{2}}$ \\
\hline 5 & $2.82(9) \times 10^{-1}$ & $2.38(7) \times 10^{-1}$ & $9.803(20) \times 10^{-1}$ & $-1.30(17) \times 10^{-2}$ & $1.85 \times 10^{-5}$ \\
10 & $1.019(25) \times 10^{-2}$ & $4.04(25) \times 10^{-2}$ & $9.919(23) \times 10^{-1}$ & $-6.5(1.7) \times 10^{-3}$ & $2.59 \times 10^{-5}$ \\
15 & $2.02(5) \times 10^{-3}$ & $1.77(19) \times 10^{-2}$ & $9.88(3) \times 10^{-1}$ & $-8.6(2.2) \times 10^{-3}$ & $3.40 \times 10^{-5}$ \\
20 & $7.95(18) \times 10^{-4}$ & $1.17(14) \times 10^{-2}$ & $9.91(3) \times 10^{-1}$ & $-6.0(2.2) \times 10^{-3}$ & $2.47 \times 10^{-5}$ \\
30 & $2.30(4) \times 10^{-4}$ & $6.3(1.0) \times 10^{-3}$ & $9.890(25) \times 10^{-1}$ & $-6.4(1.3) \times 10^{-3}$ & $2.21 \times 10^{-5}$ \\
40 & $9.11(26) \times 10^{-5}$ & $3.6(1.0) \times 10^{-3}$ & $9.85(4) \times 10^{-1}$ & $-1.42(22) \times 10^{-2}$ & $4.21 \times 10^{-5}$ \\
50 & $3.78(11) \times 10^{-5}$ & $3.0(1.4) \times 10^{-3}$ & $9.92(5) \times 10^{-1}$ & $-1.10(21) \times 10^{-2}$ & $4.66 \times 10^{-5}$ \\
50 & $4.52(16) \times 10^{-5}$ & $1.1(3) \times 10^{-3}$ & $1.007(5) \times 10^{0}$ & $-1.13(19) \times 10^{-2}$ & $5.91 \times 10^{-5}$ \\
60 & $2.06(8) \times 10^{-5}$ & $5.6(1.9) \times 10^{-4}$ & $1.028(6) \times 10^{0}$ & $-9.2(2.2) \times 10^{-3}$ & $5.94 \times 10^{-5}$ \\
70 & $1.10(4) \times 10^{-5}$ & $2.7(9) \times 10^{-4}$ & $1.060(7) \times 10^{0}$ & $-9.6(1.9) \times 10^{-3}$ & $5.03 \times 10^{-5}$ \\
80 & $6.29(23) \times 10^{-6}$ & $1.7(6) \times 10^{-4}$ & $1.111(9) \times 10^{0}$ & $-9.2(2.2) \times 10^{-3}$ & $4.65 \times 10^{-5}$ \\
\hline
\end{tabular}

Table S26 | Saturation recovery fit parameters for 3 at $347 \mathrm{mT}$ and $9.4990 \mathrm{GHz}\left(\mathrm{Ti}^{3+} g_{\mathrm{y}}\right)$ in toluene using the function: $(\mathrm{t})=1-A_{0} e^{-\left(\frac{\mathrm{t}}{T_{1}}+\sqrt{\frac{t}{a}}\right)}+A_{1}$

\begin{tabular}{cccccc}
\hline $\mathbf{T}(\mathbf{K})$ & $\boldsymbol{T}_{\mathbf{1}} \mathbf{( s )}$ & $\mathbf{a}(\mathbf{s})$ & $\mathbf{A}_{\mathbf{0}}$ & $\mathbf{A}_{\mathbf{1}}$ & Reduced $\boldsymbol{X}^{\mathbf{2}}$ \\
\hline 5 & $2.0(3) \times 10^{0}$ & $3.49(14) \times 10^{-1}$ & $9.70(5) \times 10^{-1}$ & $-2.4(4) \times 10^{-2}$ & $7.76 \times 10^{-5}$ \\
10 & $1.21(9) \times 10^{-2}$ & $3.9(7) \times 10^{-2}$ & $9.72(7) \times 10^{-1}$ & $-2.3(5) \times 10^{-2}$ & $2.06 \times 10^{-4}$ \\
15 & $2.09(13) \times 10^{-3}$ & $1.6(4) \times 10^{-2}$ & $9.78(7) \times 10^{-1}$ & $-1.5(5) \times 10^{-2}$ & $1.77 \times 10^{-4}$ \\
20 & $8.5(6) \times 10^{-4}$ & $1.1(5) \times 10^{-2}$ & $9.63(9) \times 10^{-1}$ & $-2.1(6) \times 10^{-2}$ & $2.99 \times 10^{-4}$ \\
30 & $2.44(15) \times 10^{-4}$ & $6(3) \times 10^{-3}$ & $9.72(7) \times 10^{-1}$ & $-1.6(4) \times 10^{-2}$ & $2.02 \times 10^{-4}$ \\
40 & $1.36(16) \times 10^{-4}$ & $1.6(1.0) \times 10^{-3}$ & $9.41(14) \times 10^{-1}$ & $-4.9(7) \times 10^{-2}$ & $6.28 \times 10^{-4}$ \\
50 & $4.7(9) \times 10^{-5}$ & $4(14) \times 10^{-3}$ & $9.43(27) \times 10^{-1}$ & $-5.4(1.3) \times 10^{-2}$ & $1.63 \times 10^{-3}$ \\
50 & $7.55(23) \times 10^{-5}$ & $1.08(20) \times 10^{-3}$ & $1.008(4) \times 10^{0}$ & $-8.7(1.7) \times 10^{-3}$ & $4.49 \times 10^{-5}$ \\
60 & $4.66(14) \times 10^{-5}$ & $6.8(1.3) \times 10^{-4}$ & $1.019(4) \times 10^{0}$ & $-6.7(1.9) \times 10^{-3}$ & $3.95 \times 10^{-5}$ \\
70 & $3.17(12) \times 10^{-5}$ & $3.5(7) \times 10^{-4}$ & $1.024(6) \times 10^{0}$ & $-1.53(22) \times 10^{-2}$ & $5.57 \times 10^{-5}$ \\
80 & $2.26(12) \times 10^{-5}$ & $2.0(6) \times 10^{-4}$ & $1.042(9) \times 10^{0}$ & $-1.6(3) \times 10^{-2}$ & $1.12 \times 10^{-4}$ \\
\hline
\end{tabular}


Table S27 | Two-pulse Hahn echo decay fit parameters for 3 at $329 \mathrm{mT}$ and $9.4990 \mathrm{GHz}\left(\mathrm{Cu}^{2+} g_{\mathrm{x} / \mathrm{y}}\right)$ in toluene using a stretched exponential function: $I(2 \tau)=A e^{-\left(\frac{2 \tau}{T_{\mathrm{m}}}\right)^{\beta}}$

\begin{tabular}{ccccc}
\hline $\mathbf{T}(\mathbf{K})$ & $\boldsymbol{T}_{\mathbf{m}}(\boldsymbol{\mu} \mathbf{s})$ & $\boldsymbol{\beta}$ & $\mathbf{A}$ & Reduced $\boldsymbol{X}^{\mathbf{2}}$ \\
\hline 5 & $2.42(9)$ & $0.835(23)$ & $1.072(27)$ & $5.88 \times 10^{-4}$ \\
10 & $2.85(8)$ & $0.907(22)$ & $0.999(19)$ & $6.03 \times 10^{-4}$ \\
15 & $3.11(8)$ & $0.940(23)$ & $0.975(18)$ & $6.34 \times 10^{-4}$ \\
20 & $3.34(9)$ & $0.946(24)$ & $0.957(18)$ & $7.67 \times 10^{-4}$ \\
30 & $4.080(10)$ & $1.06(3)$ & $0.889(16)$ & $1.05 \times 10^{-3}$ \\
40 & $4.109(10)$ & $1.07(3)$ & $0.889(16)$ & $1.12 \times 10^{-3}$ \\
50 & $3.52(9)$ & $1.010(26)$ & $0.916(17)$ & $8.21 \times 10^{-4}$ \\
50 & $2.97(8)$ & $0.888(21)$ & $0.960(18)$ & $8.51 \times 10^{-4}$ \\
60 & $2.21(6)$ & $0.816(17)$ & $1.053(19)$ & $5.03 \times 10^{-4}$ \\
70 & $1.59(4)$ & $0.773(14)$ & $1.166(20)$ & $2.71 \times 10^{-4}$ \\
80 & $1.09(3)$ & $0.731(13)$ & $1.318(26)$ & $1.88 \times 10^{-4}$ \\
\hline
\end{tabular}

Table S28 | Two-pulse Hahn echo decay fit parameters for 3 at $347 \mathrm{mT}$ and $9.4990 \mathrm{GHz}\left(\mathrm{Ti}^{3+} g_{\mathrm{y}}\right)$ in toluene using a stretched exponential function: $I(2 \tau)=A e^{-\left(\frac{2 \tau}{T_{\mathrm{m}}}\right)^{\beta}}$

\begin{tabular}{ccccc}
\hline $\mathbf{T}(\mathbf{K})$ & $\boldsymbol{T}_{\mathbf{m}}(\boldsymbol{\mu} \mathbf{s})$ & $\boldsymbol{\beta}$ & $\mathbf{A}$ & Reduced $\boldsymbol{X}^{\mathbf{2}}$ \\
\hline 5 & $3.49(6)$ & $1.181(25)$ & $0.930(13)$ & $5.42 \times 10^{-4}$ \\
10 & $4.17(5)$ & $1.280(22)$ & $0.862(8)$ & $4.36 \times 10^{-4}$ \\
15 & $4.50(5)$ & $1.310(21)$ & $0.943(8)$ & $4.83 \times 10^{-4}$ \\
20 & $5.01(5)$ & $1.454(28)$ & $0.852(8)$ & $6.92 \times 10^{-4}$ \\
30 & $5.17(5)$ & $1.516(28)$ & $0.835(7)$ & $6.19 \times 10^{-4}$ \\
40 & $4.47(7)$ & $1.34(4)$ & $0.839(12)$ & $1.05 \times 10^{-3}$ \\
50 & $2.51(11)$ & $0.89(3)$ & $1.03(3)$ & $1.30 \times 10^{-3}$ \\
50 & $3.31(5)$ & $1.069(18)$ & $0.8901(10)$ & $4.80 \times 10^{-4}$ \\
60 & $1.90(5)$ & $0.802(16)$ & $1.018(18)$ & $3.71 \times 10^{-4}$ \\
70 & $1.27(4)$ & $0.722(14)$ & $1.159(23)$ & $2.56 \times 10^{-4}$ \\
80 & $0.82(3)$ & $0.673(13)$ & $1.36(3)$ & $1.75 \times 10^{-4}$ \\
\hline
\end{tabular}


Table S29 | Saturation recovery fit parameters for 3 at $331 \mathrm{mT}$ and $9.5128 \mathrm{GHz}\left(\mathrm{Cu}^{2+} g_{\mathrm{x} / \mathrm{y}}\right)$ in $1: 1$ $\mathrm{CS}_{2}:$ toluene- $d_{8}$ using the function $I(\mathrm{t})=1-A_{0} e^{-\left(\frac{\mathrm{t}}{T_{1}}+\sqrt{\frac{t}{a}}\right)}+A_{1}$

\begin{tabular}{cccccc}
\hline $\mathbf{T}(\mathbf{K})$ & $\boldsymbol{T}_{\mathbf{1}}(\mathbf{s})$ & $\mathbf{a}(\mathbf{s})$ & $\mathbf{A}_{\mathbf{0}}$ & $\mathbf{A}_{\mathbf{1}}$ & $\mathbf{R e d u c e d} \boldsymbol{X}^{\mathbf{2}}$ \\
\hline 5 & $1.91(13) \times 10^{-1}$ & $2.58(22) \times 10^{-1}$ & $8.19(4) \times 10^{-1}$ & $-9(3) \times 10^{-3}$ & $7.90 \times 10^{-5}$ \\
10 & $1.96(6) \times 10^{-2}$ & $1.65(20) \times 10^{-1}$ & $8.155(28) \times 10^{-1}$ & $-1.78(23) \times 10^{-2}$ & $3.62 \times 10^{-5}$ \\
15 & $3.41(19) \times 10^{-3}$ & $2.9(2.3) \times 10^{-1}$ & $8.19(6) \times 10^{-1}$ & $-1.7(4) \times 10^{-2}$ & $1.65 \times 10^{-4}$ \\
20 & $1.549(27) \times 10^{-3}$ & $1.7(5) \times 10^{-1}$ & $8.434(20) \times 10^{-1}$ & $-3.7(1.5) \times 10^{-3}$ & $1.62 \times 10^{-5}$ \\
30 & $4.19(12) \times 10^{-4}$ & $1.4(1.2) \times 10^{-1}$ & $8.46(3) \times 10^{-1}$ & $-1.05(21) \times 10^{-2}$ & $4.49 \times 10^{-5}$ \\
40 & $1.42(4) \times 10^{-4}$ & $3(5) \times 10^{-1}$ & $8.55(3) \times 10^{-1}$ & $-8.1(2.1) \times 10^{-3}$ & $3.26 \times 10^{-5}$ \\
50 & $5.91(27) \times 10^{-5}$ & $6(4) \times 10^{-3}$ & $8.64(6) \times 10^{-1}$ & $-2.0(3) \times 10^{-2}$ & $9.18 \times 10^{-5}$ \\
60 & $2.46(15) \times 10^{-5}$ & $8(18) \times 10^{-3}$ & $8.646(10) \times 10^{-1}$ & $-1.5(4) \times 10^{-2}$ & $1.60 \times 10^{-4}$ \\
70 & $1.42(9) \times 10^{-5}$ & $5(3) \times 10^{-4}$ & $8.896(10) \times 10^{-1}$ & $-2.0(3) \times 10^{-2}$ & $1.21 \times 10^{-4}$ \\
80 & $8.3(9) \times 10^{-6}$ & $9(20) \times 10^{-4}$ & $8.79(19) \times 10^{-1}$ & $-2.4(6) \times 10^{-2}$ & $3.10 \times 10^{-4}$ \\
\hline
\end{tabular}

Table S30 | Saturation recovery fit parameters for 3 at $342 \mathrm{mT}$ and $9.5128 \mathrm{GHz}\left(\mathrm{Ti}^{3+} g_{z}\right)$ in $1: 1$ $\mathrm{CS}_{2}$ :toluene- $d_{8}$ using the function: $I(\mathrm{t})=1-A_{0} e^{-\left(\frac{\mathrm{t}}{T_{1}}+\sqrt{\frac{t}{a}}\right)}+A_{1}$

\begin{tabular}{cccccc}
\hline $\mathbf{T}(\mathbf{K})$ & $\boldsymbol{T}_{\mathbf{1}}(\mathbf{s})$ & $\mathbf{a}(\mathbf{s})$ & $\mathbf{A}_{\mathbf{0}}$ & $\mathbf{A}_{\mathbf{1}}$ & Reduced $\boldsymbol{X}^{\mathbf{2}}$ \\
\hline 5 & $3.38(10) \times 10^{-1}$ & $1.55(12) \times 10^{0}$ & $8.237(26) \times 10^{-1}$ & $-7.0(2.3) \times 10^{-3}$ & $2.91 \times 10^{-5}$ \\
10 & $3.32(7) \times 10^{-2}$ & $8.0(1.1) \times 10^{-1}$ & $8.169(22) \times 10^{-1}$ & $-8.1(1.8) \times 10^{-3}$ & $1.79 \times 10^{-5}$ \\
15 & $4.74(9) \times 10^{-3}$ & $3.7(9) \times 10^{-1}$ & $8.265(19) \times 10^{-1}$ & $-9.2(1.4) \times 10^{-3}$ & $2.01 \times 10^{-5}$ \\
20 & $1.590(25) \times 10^{-3}$ & $4.0(1.5) \times 10^{-1}$ & $8.388(19) \times 10^{-1}$ & $-6.4(1.4) \times 10^{-3}$ & $1.34 \times 10^{-5}$ \\
30 & $2.44(8) \times 10^{-4}$ & - & $8.12(4) \times 10^{-1}$ & $-2.2(2.2) \times 10^{-3}$ & $5.71 \times 10^{-5}$ \\
40 & $1.85(7) \times 10^{-4}$ & $7(8) \times 10^{-2}$ & $8.59(5) \times 10^{-1}$ & $-8(3) \times 10^{-3}$ & $7.91 \times 10^{-5}$ \\
50 & $9.57(17) \times 10^{-5}$ & $3(5) \times 10^{-1}$ & $8.741(25) \times 10^{-1}$ & $-1.01(14) \times 10^{-2}$ & $1.63 \times 10^{-5}$ \\
60 & $5.96(18) \times 10^{-5}$ & $6(3) \times 10^{-3}$ & $9.01(4) \times 10^{-1}$ & $-9.7(2.1) \times 10^{-3}$ & $4.33 \times 10^{-5}$ \\
70 & $3.31(22) \times 10^{-5}$ & $1.1(2.4) \times 10^{-2}$ & $9.04(10) \times 10^{-1}$ & $-2.9(4) \times 10^{-2}$ & $2.00 \times 10^{-4}$ \\
80 & $2.87(9) \times 10^{-5}$ & $7.6(2.2) \times 10^{-4}$ & $9.52(5) \times 10^{-1}$ & $-9.9(2.7) \times 10^{-3}$ & $4.01 \times 10^{-5}$ \\
\hline
\end{tabular}


Table S31 | Two-pulse Hahn echo decay fit parameters for 3 at $331 \mathrm{mT}$ and $9.5128 \mathrm{GHz}\left(\mathrm{Cu}^{2+} g_{\mathrm{x} / \mathrm{y}}\right)$ in $\mathrm{CS}_{2}$ :toluene- $d_{8}$ using a stretched exponential function: $I(2 \tau)=A e^{-\left(\frac{2 \tau}{T_{\mathrm{m}}}\right)^{\beta}}$

\begin{tabular}{ccccc}
\hline $\mathbf{T}(\mathbf{K})$ & $\boldsymbol{T}_{\mathbf{m}}(\boldsymbol{\mu} \mathbf{s})$ & $\boldsymbol{\beta}$ & $\mathbf{A}$ & Reduced $\boldsymbol{X}^{\mathbf{2}}$ \\
\hline 5 & $29.2(4)$ & $0.846(16)$ & $0.734(8)$ & $1.00 \times 10^{-3}$ \\
10 & $24.06(25)$ & $1.185(19)$ & $0.708(6)$ & $1.32 \times 10^{-3}$ \\
15 & $21.67(22)$ & $1.253(20)$ & $0.709(6)$ & $1.28 \times 10^{-3}$ \\
20 & $18.97(20)$ & $1.275(21)$ & $0.712(6)$ & $1.25 \times 10^{-3}$ \\
30 & $14.76(17)$ & $1.327(24)$ & $0.702(7)$ & $1.20 \times 10^{-3}$ \\
40 & $11.73(17)$ & $1.162(22)$ & $0.749(9)$ & $1.15 \times 10^{-3}$ \\
50 & $7.53(18)$ & $0.940(20)$ & $0.858(14)$ & $9.84 \times 10^{-4}$ \\
60 & $3.32(15)$ & $0.706(17)$ & $1.23(3)$ & $6.82 \times 10^{-4}$ \\
70 & $1.03(10)$ & $0.543(18)$ & $2.26(13)$ & $5.46 \times 10^{-4}$ \\
80 & $0.54(6)$ & $0.518(16)$ & $3.29(21)$ & $2.65 \times 10^{-4}$ \\
\hline
\end{tabular}

Table S32 | Two-pulse Hahn echo decay fit parameters for 3 at $342 \mathrm{mT}$ and $9.5128 \mathrm{GHz}\left(\mathrm{Ti}^{3+} g_{\mathrm{z}}\right)$ in $1: 1$ $\mathrm{CS}_{2}:$ toluene- $d_{8}$ using a stretched exponential function: $I(2 \tau)=A e^{-\left(\frac{2 \tau}{T_{\mathrm{m}}}\right)^{\beta}}$

\begin{tabular}{ccccc}
\hline $\mathbf{T}(\mathbf{K})$ & $\boldsymbol{T}_{\mathbf{m}}(\boldsymbol{\mu} \mathbf{s})$ & $\boldsymbol{\beta}$ & $\mathbf{A}$ & Reduced $\boldsymbol{X}^{\mathbf{2}}$ \\
\hline 5 & $8.91(17)$ & $0.807(12)$ & $1.028(13)$ & $7.59 \times 10^{-4}$ \\
10 & $8.33(18)$ & $0.747(11)$ & $1.067(14)$ & $6.73 \times 10^{-4}$ \\
15 & $8.64(15)$ & $0.896(14)$ & $0.966(12)$ & $7.21 \times 10^{-4}$ \\
20 & $8.62(14)$ & $0.942(14)$ & $0.942(11)$ & $7.17 \times 10^{-4}$ \\
30 & $9.63(8)$ & $1.218(14)$ & $0.988(7)$ & $5.79 \times 10^{-4}$ \\
40 & $7.02(13)$ & $0.952(16)$ & $0.934(13)$ & $6.76 \times 10^{-4}$ \\
50 & $5.04(13)$ & $0.850(16)$ & $1.023(18)$ & $5.95 \times 10^{-4}$ \\
60 & $2.73(11)$ & $0.719(16)$ & $1.30(3)$ & $4.61 \times 10^{-4}$ \\
70 & $0.92(1.1)$ & $0.566(23)$ & $2.25(16)$ & $5.92 \times 10^{-4}$ \\
80 & $0.27(6)$ & $0.470(24)$ & $4.7(6)$ & $3.51 \times 10^{-4}$ \\
\hline
\end{tabular}

Table S33 | Variable turning angle two-pulse Hahn echo decay fit parameters for $\mathbf{3}$ at $328 \mathrm{mT}$ and 9.4907 $\mathrm{GHz}\left(\mathrm{Cu}^{2+} g_{\mathrm{x} / \mathrm{y}}\right)$ in 1:1 $\mathrm{CS}_{2}:$ toluene- $d_{8}$ using the function: $I(2 \tau)=A\left((1-B) e^{-\left(\frac{2 \tau}{T_{\mathrm{m}}}\right)}+B e^{-\left(\frac{2 \tau}{b}\right)}\right)$

\begin{tabular}{cccccc}
\hline $\boldsymbol{\theta}$ & $\boldsymbol{T}_{\mathbf{m}}(\boldsymbol{\mu} \mathbf{s})$ & $\mathbf{b}$ & $\mathbf{A}$ & B & Reduced $\boldsymbol{X}^{\mathbf{2}}$ \\
\hline$\pi$ & $22.80(12)$ & $0.346(23)$ & $4.1(6)$ & $0.825(24)$ & $8.25 \times 10^{-1}$ \\
$4 \pi / 7$ & $24.35(12)$ & $0.470(19)$ & $2.83(18)$ & $0.774(14)$ & $7.74 \times 10^{-1}$ \\
$8 \pi / 21$ & $25.13(14)$ & $0.592(21)$ & $2.28(10)$ & $0.741(12)$ & $7.41 \times 10^{-1}$ \\
\hline
\end{tabular}


Table S34 | Variable turning angle two-pulse Hahn echo decay fit parameters for 3 at $342 \mathrm{mT}$ and 9.4907 $\mathrm{GHz}\left(\mathrm{Ti}^{3+} g_{\mathrm{z}}\right)$ in 1:1 $\mathrm{CS}_{2}:$ toluene- $d_{8}$ using the function: $I(2 \tau)=A\left((1-B) e^{-\left(\frac{2 \tau}{T_{\mathrm{m}}}\right)}+B e^{-\left(\frac{2 \tau}{b}\right)}\right)$

\begin{tabular}{cccccc}
\hline $\boldsymbol{\theta}$ & $\boldsymbol{T}_{\mathbf{m}}(\boldsymbol{\mu} \mathbf{s})$ & $\mathbf{b}$ & $\mathbf{A}$ & $\mathbf{B}$ & Reduced $\boldsymbol{X}^{\mathbf{2}}$ \\
\hline$\pi$ & $13.410(10)$ & $0.38(4)$ & $3.0(5)$ & $0.75(4)$ & $7.46 \times 10^{-1}$ \\
$4 \pi / 7$ & $20.09(24)$ & $2.32(10)$ & $1.036(15)$ & $0.492(7)$ & $4.92 \times 10^{-1}$ \\
$8 \pi / 21$ & $23.70(27)$ & $2.22(8)$ & $1.073(15)$ & $0.557(6)$ & $5.57 \times 10^{-1}$ \\
\hline
\end{tabular}

Table S35 | Saturation recovery fit parameters for $\mathbf{2 a}$ at $334 \mathrm{mT}$ and $9.5090 \mathrm{GHz}\left(\mathrm{Cu}^{2+} g_{\mathrm{x} / \mathrm{y}}\right)$ in toluene using the function: $I(\mathrm{t})=1-A_{0} e^{-\left(\frac{\mathrm{t}}{T_{1}}+\sqrt{\frac{t}{a}}\right)}+A_{1}$

\begin{tabular}{cccccc}
\hline $\mathbf{T}(\mathbf{K})$ & $\boldsymbol{T}_{\mathbf{1}} \mathbf{( s )}$ & $\mathbf{a}(\mathbf{s})$ & $\mathbf{A}_{\mathbf{0}}$ & $\mathbf{A}_{\mathbf{1}}$ & Reduced $\boldsymbol{X}^{\mathbf{2}}$ \\
\hline 5 & $2.09(6) \times 10^{-1}$ & $3.20(14) \times 10^{-1}$ & $9.846(23) \times 10^{-1}$ & $-9.8(1.9) \times 10^{-3}$ & $2.64 \times 10^{-5}$ \\
10 & $1.019(27) \times 10^{-2}$ & $5.7(5) \times 10^{-2}$ & $9.910(26) \times 10^{-1}$ & $-5.8(2.0) \times 10^{-3}$ & $3.34 \times 10^{-5}$ \\
15 & $2.18(5) \times 10^{-3}$ & $2.6(3) \times 10^{-2}$ & $9.895(24) \times 10^{-1}$ & $-5.3(1.6) \times 10^{-3}$ & $3.01 \times 10^{-5}$ \\
20 & $8.49(14) \times 10^{-4}$ & $1.60(17) \times 10^{-2}$ & $9.870(20) \times 10^{-1}$ & $-4.7(1.3) \times 10^{-3}$ & $1.59 \times 10^{-5}$ \\
30 & $2.51(5) \times 10^{-4}$ & $7.5(1.2) \times 10^{-3}$ & $9.891(23) \times 10^{-1}$ & $-4.7(1.3) \times 10^{-3}$ & $2.01 \times 10^{-5}$ \\
40 & $9.97(18) \times 10^{-5}$ & $3.9(7) \times 10^{-3}$ & $9.882(24) \times 10^{-1}$ & $-6.4(1.1) \times 10^{-3}$ & $1.78 \times 10^{-5}$ \\
50 & $4.23(10) \times 10^{-5}$ & $2.3(7) \times 10^{-3}$ & $9.85(4) \times 10^{-1}$ & $-1.54(14) \times 10^{-2}$ & $3.02 \times 10^{-5}$ \\
50 & $4.00(18) \times 10^{-5}$ & $3.7(2.8) \times 10^{-3}$ & $8.10(6) \times 10^{-1}$ & $-1.48(26) \times 10^{-2}$ & $7.07 \times 10^{-5}$ \\
60 & $2.00(12) \times 10^{-5}$ & $1.3(1.1) \times 10^{-3}$ & $8.16(8) \times 10^{-1}$ & $-1.45(29) \times 10^{-2}$ & $1.05 \times 10^{-4}$ \\
70 & $1.02(7) \times 10^{-5}$ & $2(3) \times 10^{-3}$ & $8.05(12) \times 10^{-1}$ & $-2.0(3) \times 10^{-2}$ & $1.42 \times 10^{-4}$ \\
80 & $6.6(7) \times 10^{-6}$ & $3(5) \times 10^{-4}$ & $8.00(18) \times 10^{-1}$ & $-2.6(4) \times 10^{-2}$ & $2.28 \times 10^{-4}$ \\
\hline
\end{tabular}


Table S36 | Two-pulse Hahn echo decay fit parameters for 2a at $334 \mathrm{mT}$ and $9.5090 \mathrm{GHz}\left(\mathrm{Cu}^{2+} g_{\mathrm{x} / \mathrm{y}}\right)$ in toluene using a stretched exponential function: $I(2 \tau)=A e^{-\left(\frac{2 \tau}{T_{\mathrm{m}}}\right)^{\beta}}$

\begin{tabular}{ccccc}
\hline $\mathbf{T}(\mathbf{K})$ & $\boldsymbol{T}_{\mathbf{m}}(\boldsymbol{\mu} \mathbf{s})$ & $\boldsymbol{\beta}$ & $\mathbf{A}$ & Reduced $\boldsymbol{X}^{\mathbf{2}}$ \\
\hline 5 & $1.56(9)$ & $0.665(22)$ & $1.07(4)$ & $5.77 \times 10^{-4}$ \\
10 & $2.93(7)$ & $0.936(20)$ & $0.953(15)$ & $5.33 \times 10^{-4}$ \\
15 & $3.13(7)$ & $0.955(21)$ & $0.947(15)$ & $6.00 \times 10^{-4}$ \\
20 & $3.46(8)$ & $0.986(24)$ & $0.921(15)$ & $7.28 \times 10^{-4}$ \\
30 & $4.08(8)$ & $1.079(27)$ & $0.871(14)$ & $9.02 \times 10^{-4}$ \\
40 & $4.13(8)$ & $1.097(28)$ & $0.865(13)$ & $9.14 \times 10^{-4}$ \\
50 & $3.67(8)$ & $1.053(26)$ & $0.887(14)$ & $7.78 \times 10^{-4}$ \\
50 & $3.08(10)$ & $0.941(29)$ & $1.005(25)$ & $8.65 \times 10^{-4}$ \\
60 & $2.22(8)$ & $0.854(23)$ & $1.119(28)$ & $5.05 \times 10^{-4}$ \\
70 & $1.71(6)$ & $0.836(19)$ & $1.242(29)$ & $2.85 \times 10^{-4}$ \\
80 & $1.30(5)$ & $0.832(20)$ & $1.35(4)$ & $2.26 \times 10^{-4}$ \\
\hline
\end{tabular}

Table S37 | Saturation recovery fit parameters for 2a at $334 \mathrm{mT}$ and $9.4544 \mathrm{GHz}\left(\mathrm{Cu}^{2+} g_{x / y}\right)$ in $1: 1$ $\mathrm{CS}_{2}$ :toluene- $d_{8}$ using the function: $I(\mathrm{t})=1-A_{0} e^{-\left(\frac{\mathrm{t}}{T_{1}}+\sqrt{\frac{t}{a}}\right)}+A_{1}$

\begin{tabular}{cccccc}
\hline $\mathbf{T}(\mathbf{K})$ & $\boldsymbol{T}_{\mathbf{1}} \mathbf{( s )}$ & $\mathbf{a}(\mathbf{s})$ & $\mathbf{A}_{\mathbf{0}}$ & $\mathbf{A}_{\mathbf{1}}$ & Reduced $\boldsymbol{X}^{\mathbf{2}}$ \\
\hline 5 & $2.55(19) \times 10^{-1}$ & $1.02(4) \times 10^{-1}$ & $8.784(29) \times 10^{-1}$ & $-4.0(2.4) \times 10^{-3}$ & $4.31 \times 10^{-5}$ \\
10 & $1.74(4) \times 10^{-2}$ & $5.57(26) \times 10^{-2}$ & $8.770(17) \times 10^{-1}$ & $-5.4(1.4) \times 10^{-3}$ & $1.37 \times 10^{-5}$ \\
15 & $4.359(10) \times 10^{-3}$ & $6.1(7) \times 10^{-2}$ & $9.602(25) \times 10^{-1}$ & $-1.47(20) \times 10^{-2}$ & $2.56 \times 10^{-5}$ \\
20 & $1.478(23) \times 10^{-3}$ & $4.1(5) \times 10^{-2}$ & $9.445(19) \times 10^{-1}$ & $-3.1(1.3) \times 10^{-3}$ & $1.35 \times 10^{-5}$ \\
30 & $4.37(9) \times 10^{-4}$ & $1.49(29) \times 10^{-2}$ & $9.080(25) \times 10^{-1}$ & $-1.06(15) \times 10^{-2}$ & $2.38 \times 10^{-5}$ \\
40 & $1.453(27) \times 10^{-4}$ & $1.2(4) \times 10^{-2}$ & $8.847(23) \times 10^{-1}$ & $-5.1(1.2) \times 10^{-3}$ & $1.83 \times 10^{-5}$ \\
50 & $5.86(9) \times 10^{-5}$ & $9(3) \times 10^{-3}$ & $8.937(23) \times 10^{-1}$ & $-4.4(1.1) \times 10^{-3}$ & $1.21 \times 10^{-5}$ \\
60 & $2.93(5) \times 10^{-5}$ & $3.0(9) \times 10^{-3}$ & $9.051(26) \times 10^{-1}$ & $-2.7(1.0) \times 10^{-3}$ & $1.20 \times 10^{-5}$ \\
70 & $1.530(29) \times 10^{-5}$ & $2.1(9) \times 10^{-3}$ & $9.14(3) \times 10^{-1}$ & $-3.5(1.1) \times 10^{-3}$ & $1.45 \times 10^{-5}$ \\
80 & $8.95(21) \times 10^{-6}$ & $1.1(6) \times 10^{-3}$ & $9.24(5) \times 10^{-1}$ & $-7.9(1.2) \times 10^{-3}$ & $2.00 \times 10^{-5}$ \\
\hline
\end{tabular}


Table S38 | Two-pulse Hahn echo decay fit parameters for $2 \mathbf{a}$ at $334 \mathrm{mT}$ and $9.4544 \mathrm{GHz}\left(\mathrm{Cu}^{2+} g_{\mathrm{x} / \mathrm{y}}\right)$ in $1: 1$ $\mathrm{CS}_{2}$ :toluene- $d_{8}$ using a stretched exponential function: $I(2 \tau)=A e^{-\left(\frac{2 \tau}{T_{\mathrm{m}}}\right)^{\beta}}$

\begin{tabular}{ccccc}
\hline $\mathbf{T}(\mathbf{K})$ & $\boldsymbol{T}_{\mathbf{m}}(\boldsymbol{\mu} \mathbf{s})$ & $\boldsymbol{\beta}$ & $\mathbf{A}$ & Reduced $\boldsymbol{X}^{\mathbf{2}}$ \\
\hline 5 & $22.57(30)$ & $0.960(15)$ & $0.545(5)$ & $5.27 \times 10^{-4}$ \\
10 & $20.55(25)$ & $1.051(16)$ & $0.705(7)$ & $9.91 \times 10^{-4}$ \\
15 & $19.10(22)$ & $1.109(17)$ & $0.734(7)$ & $1.10 \times 10^{-3}$ \\
20 & $17.68(20)$ & $1.193(19)$ & $0.728(7)$ & $1.13 \times 10^{-3}$ \\
30 & $14.40(17)$ & $1.272(22)$ & $0.721(7)$ & $1.14 \times 10^{-3}$ \\
40 & $12.14(17)$ & $1.156(21)$ & $0.756(8)$ & $1.06 \times 10^{-3}$ \\
50 & $8.41(17)$ & $0.982(19)$ & $0.841(12)$ & $9.25 \times 10^{-4}$ \\
60 & $4.02(14)$ & $0.748(16)$ & $1.131(26)$ & $6.24 \times 10^{-4}$ \\
70 & $1.35(8)$ & $0.578(13)$ & $1.94(7)$ & $2.87 \times 10^{-4}$ \\
80 & $0.57(4)$ & $0.520(11)$ & $3.19(14)$ & $1.33 \times 10^{-4}$ \\
\hline
\end{tabular}

Table S39 | Variable turning angle two-pulse Hahn echo decay fit parameters for 2a at $323 \mathrm{mT}$ and 9.4544 $\mathrm{GHz}\left(\mathrm{Cu}^{2+} g_{\mathrm{x} / \mathrm{y}}\right)$ in 1:1 $\mathrm{CS}_{2}:$ toluene- $d_{8}$ using the function: $I(2 \tau)=A\left((1-B) e^{-\left(\frac{2 \tau}{T_{\mathrm{m}}}\right)}+B e^{-\left(\frac{2 \tau}{b}\right)}\right)$

\begin{tabular}{cccccc}
\hline $\boldsymbol{\theta}$ & $\boldsymbol{T}_{\mathbf{m}}(\boldsymbol{\mu} \mathbf{s})$ & $\mathbf{b}$ & $\mathbf{A}$ & $\mathbf{B}$ & Reduced $\boldsymbol{X}^{\mathbf{2}}$ \\
\hline$\pi$ & $20.60(14)$ & $0.276(27)$ & $5.0(1.3)$ & $0.86(3)$ & $8.63 \times 10^{-1}$ \\
$4 \pi / 7$ & $22.71(16)$ & $0.31(3)$ & $4.1(9)$ & $0.83(4)$ & $8.30 \times 10^{-1}$ \\
$8 \pi / 21$ & $24.39(19)$ & $0.33(4)$ & $3.7(8)$ & $0.80(4)$ & $8.01 \times 10^{-1}$ \\
\hline
\end{tabular}


Table S40 | Saturation recovery fit parameters for $\mathbf{2 b}$ at $348 \mathrm{mT}$ and $9.5006 \mathrm{GHz}\left(\mathrm{Ti}^{3+} g_{z}\right)$ in toluene using the function: $I(\mathrm{t})=1-A_{0} e^{-\left(\frac{\mathrm{t}}{T_{1}}+\sqrt{\frac{t}{a}}\right)}+A_{1}$

\begin{tabular}{cccccc}
\hline $\mathbf{T}(\mathbf{K})$ & $\boldsymbol{T}_{\mathbf{1}}(\mathbf{s})$ & $\mathbf{a}(\mathbf{s})$ & $\mathbf{A}_{\mathbf{0}}$ & $\mathbf{A}_{\mathbf{1}}$ & Reduced $\boldsymbol{X}^{\mathbf{2}}$ \\
\hline 5 & $4.71(12) \times 10^{-1}$ & $1.25(6) \times 10^{0}$ & $9.924(21) \times 10^{-1}$ & $-8.7(1.8) \times 10^{-3}$ & $2.28 \times 10^{-5}$ \\
10 & $2.28(9) \times 10^{-2}$ & $1.56(20) \times 10^{-1}$ & $9.90(4) \times 10^{-1}$ & $-1.3(3) \times 10^{-2}$ & $7.02 \times 10^{-5}$ \\
15 & $3.62(11) \times 10^{-3}$ & $8.3(1.7) \times 10^{-2}$ & $9.94(3) \times 10^{-1}$ & $-7.6(2.3) \times 10^{-3}$ & $6.09 \times 10^{-5}$ \\
20 & $1.184(20) \times 10^{-3}$ & $1.2(3) \times 10^{-1}$ & $9.915(23) \times 10^{-1}$ & $-6.2(1.6) \times 10^{-3}$ & $2.08 \times 10^{-5}$ \\
30 & $3.39(4) \times 10^{-4}$ & $1.2(5) \times 10^{-1}$ & $9.908(16) \times 10^{-1}$ & $-2.60(10) \times 10^{-3}$ & $1.03 \times 10^{-5}$ \\
40 & $1.536(23) \times 10^{-4}$ & $7(4) \times 10^{-2}$ & $9.870(21) \times 10^{-1}$ & $-5.1(1.1) \times 10^{-3}$ & $1.54 \times 10^{-5}$ \\
50 & $9.15(14) \times 10^{-5}$ & $9.8(2.7) \times 10^{-3}$ & $9.923(22) \times 10^{-1}$ & $-7.3(1.0) \times 10^{-3}$ & $1.54 \times 10^{-5}$ \\
50 & $7.72(23) \times 10^{-5}$ & $2.9(9) \times 10^{-3}$ & $8.37(4) \times 10^{-1}$ & $-6.3(1.5) \times 10^{-3}$ & $3.55 \times 10^{-5}$ \\
60 & $5.20(22) \times 10^{-5}$ & $1.2(4) \times 10^{-3}$ & $8.55(5) \times 10^{-1}$ & $-8.5(2.0) \times 10^{-3}$ & $6.55 \times 10^{-5}$ \\
70 & $3.73(18) \times 10^{-5}$ & $5.4(1.7) \times 10^{-4}$ & $8.58(6) \times 10^{-1}$ & $-1.25(21) \times 10^{-2}$ & $7.33 \times 10^{-5}$ \\
80 & $2.65(13) \times 10^{-5}$ & $3.5(1.1) \times 10^{-4}$ & $8.52(6) \times 10^{-1}$ & $-1.52(20) \times 10^{-2}$ & $7.07 \times 10^{-5}$ \\
\hline
\end{tabular}

Table S41 | Two-pulse Hahn echo decay fit parameters for $\mathbf{2 b}$ at $348 \mathrm{mT}$ and $9.5006 \mathrm{GHz}\left(\mathrm{Ti}^{3+} g_{z}\right)$ in toluene using a stretched exponential function: $I(2 \tau)=A e^{-\left(\frac{2 \tau}{T_{\mathrm{m}}}\right)^{\beta}}$

\begin{tabular}{ccccc}
\hline $\mathbf{T}(\mathbf{K})$ & $\boldsymbol{T}_{\mathbf{m}}(\boldsymbol{\mu} \mathbf{s})$ & $\boldsymbol{\beta}$ & $\mathbf{A}$ & Reduced $\boldsymbol{X}^{\mathbf{2}}$ \\
\hline 5 & $3.93(4)$ & $1.279(21)$ & $0.867(8)$ & $4.02 \times 10^{-4}$ \\
10 & $4.26(3)$ & $1.419(18)$ & $0.920(6)$ & $2.87 \times 10^{-4}$ \\
15 & $4.26(3)$ & $1.413(20)$ & $0.909(6)$ & $3.46 \times 10^{-4}$ \\
20 & $4.39(3)$ & $1.434(20)$ & $0.908(6)$ & $3.75 \times 10^{-4}$ \\
30 & $4.82(4)$ & $1.477(22)$ & $0.880(6)$ & $4.19 \times 10^{-4}$ \\
40 & $4.72(4)$ & $1.417(22)$ & $0.861(7)$ & $4.43 \times 10^{-4}$ \\
50 & $3.94(5)$ & $1.224(21)$ & $0.870(8)$ & $4.16 \times 10^{-4}$ \\
50 & $3.24(7)$ & $1.045(24)$ & $0.994(17)$ & $5.47 \times 10^{-4}$ \\
60 & $1.94(8)$ & $0.801(21)$ & $1.18(3)$ & $4.22 \times 10^{-4}$ \\
70 & $1.14(7)$ & $0.668(19)$ & $1.48(5)$ & $2.89 \times 10^{-4}$ \\
80 & $0.82(5)$ & $0.635(16)$ & $1.75(7)$ & $1.86 \times 10^{-4}$ \\
\hline
\end{tabular}


Table S42 | Saturation recovery fit parameters for $\mathbf{2 b}$ at $342 \mathrm{mT}$ and $9.4892 \mathrm{GHz}\left(\mathrm{Ti}^{3+} g_{\mathrm{z}}\right)$ in $1: 1$ $\mathrm{CS}_{2}$ :toluene- $d_{8}$ using the function: $I(\mathrm{t})=1-A_{0} e^{-\left(\frac{\mathrm{t}}{T_{1}}+\sqrt{\frac{t}{a}}\right)}+A_{1}$

\begin{tabular}{cccccc}
\hline $\mathbf{T}(\mathbf{K})$ & $\boldsymbol{T}_{\mathbf{1}}(\mathbf{s})$ & $\mathbf{a}(\mathbf{s})$ & $\mathbf{A}_{\mathbf{0}}$ & $\mathbf{A}_{\mathbf{1}}$ & Reduced $\boldsymbol{X}^{\mathbf{2}}$ \\
\hline 5 & $3.68(18) \times 10^{-1}$ & $5.4(1.3) \times 10^{0}$ & $8.74(5) \times 10^{-1}$ & $-8(4) \times 10^{-3}$ & $1.23 \times 10^{-4}$ \\
10 & $2.71(11) \times 10^{-2}$ & $1.6(7) \times 10^{0}$ & $8.55(4) \times 10^{-1}$ & $-1.78(28) \times 10^{-2}$ & $9.27 \times 10^{-5}$ \\
15 & $4.78(13) \times 10^{-3}$ & $1.2(7) \times 10^{0}$ & $9.51(3) \times 10^{-1}$ & $-2.06(25) \times 10^{-2}$ & $5.28 \times 10^{-5}$ \\
20 & $1.617(18) \times 10^{-3}$ & $3.85(10) \times 10^{-1}$ & $9.428(15) \times 10^{-1}$ & $-4.0(1.1) \times 10^{-3}$ & $8.34 \times 10^{-6}$ \\
30 & $4.53(15) \times 10^{-4}$ & $9(70) \times 10^{0}$ & $9.16(4) \times 10^{-1}$ & $-4.4(2.7) \times 10^{-3}$ & $7.73 \times 10^{-5}$ \\
40 & $1.865(22) \times 10^{-4}$ & $7.0(2.6) \times 10^{-2}$ & $8.976(17) \times 10^{-1}$ & $-4.9(1.1) \times 10^{-3}$ & $7.47 \times 10^{-6}$ \\
50 & $9.62(7) \times 10^{-5}$ & $7(25) \times 10^{0}$ & $9.106(11) \times 10^{-1}$ & $-3.3(6) \times 10^{-3}$ & $3.13 \times 10^{-6}$ \\
60 & $5.86(5) \times 10^{-5}$ & $1.6(1.3) \times 10^{-1}$ & $9.303(13) \times 10^{-1}$ & $-4.5(7) \times 10^{-3}$ & $4.28 \times 10^{-6}$ \\
70 & $3.868(24) \times 10^{-5}$ & $1.2(7) \times 10^{-1}$ & $9.481(11) \times 10^{-1}$ & $-2.5(6) \times 10^{-3}$ & $1.91 \times 10^{-6}$ \\
80 & $2.658(23) \times 10^{-5}$ & $1.3(1.5) \times 10^{-1}$ & $9.608(16) \times 10^{-1}$ & $-3.0(8) \times 10^{-3}$ & $3.87 \times 10^{-6}$ \\
\hline
\end{tabular}

Table S43 | Two-pulse Hahn echo decay fit parameters for $\mathbf{2 b}$ at $342 \mathrm{mT}$ and $9.4892 \mathrm{GHz}\left(\mathrm{Ti}^{3+} g_{\mathrm{z}}\right)$ in $1: 1$ $\mathrm{CS}_{2}$ :toluene- $d_{8}$ using a stretched exponential function: $I(2 \tau)=A e^{-\left(\frac{2 \tau}{T_{\mathrm{m}}}\right)^{\beta}}$

\begin{tabular}{ccccc}
\hline $\boldsymbol{T}(\mathbf{K})$ & $\boldsymbol{T}_{\mathbf{m}}(\boldsymbol{\mu} \mathbf{s})$ & $\boldsymbol{\beta}$ & $\mathbf{A}$ & Reduced $\boldsymbol{X}^{\mathbf{2}}$ \\
\hline 5 & $6.88(18)$ & $0.785(14)$ & $0.923(15)$ & $6.41 \times 10^{-4}$ \\
10 & $7.23(16)$ & $0.841(14)$ & $0.922(14)$ & $6.59 \times 10^{-4}$ \\
15 & $8.74(13)$ & $0.980(14)$ & $1.046(11)$ & $7.97 \times 10^{-4}$ \\
20 & $7.78(14)$ & $0.939(16)$ & $0.968(13)$ & $7.81 \times 10^{-4}$ \\
30 & $7.45(12)$ & $1.009(17)$ & $0.936(12)$ & $7.32 \times 10^{-4}$ \\
40 & $7.00(13)$ & $0.953(17)$ & $0.948(13)$ & $7.37 \times 10^{-4}$ \\
50 & $5.69(14)$ & $0.865(16)$ & $1.007(17)$ & $6.63 \times 10^{-4}$ \\
60 & $3.58(13)$ & $0.738(16)$ & $1.184(28)$ & $5.60 \times 10^{-4}$ \\
70 & $1.67(11)$ & $0.610(16)$ & $1.64(6)$ & $4.24 \times 10^{-4}$ \\
80 & $0.61(7)$ & $0.509(17)$ & $2.82(19)$ & $3.14 \times 10^{-4}$ \\
\hline
\end{tabular}

Table S44 | Variable turning angle two-pulse Hahn echo decay fit parameters for $\mathbf{2 b}$ at $342 \mathrm{mT}$ and 9.4892 $\mathrm{GHz}\left(\mathrm{Ti}^{3+} g_{\mathrm{z}}\right)$ in 1:1 $\mathrm{CS}_{2}:$ toluene- $d_{8}$ using the function: $I(2 \tau)=A\left((1-B) e^{-\left(\frac{2 \tau}{T_{\mathrm{m}}}\right)}+B e^{-\left(\frac{2 \tau}{b}\right)}\right)$

\begin{tabular}{cccccc}
\hline $\boldsymbol{\theta}$ & $\boldsymbol{T}_{\mathbf{m}}(\boldsymbol{\mu} \mathbf{s})$ & $\mathbf{b}$ & $\mathbf{A}$ & $\mathbf{B}$ & Reduced $\boldsymbol{X}^{2}$ \\
\hline$\pi$ & $9.16(7)$ & $0.18(4)$ & $12(9)$ & $0.92(6)$ & $9.21 \times 10^{-1}$ \\
$4 \pi / 7$ & $12.305(10)$ & $0.21(4)$ & $7(4)$ & $0.88(7)$ & $8.83 \times 10^{-1}$ \\
$8 \pi / 21$ & $15.67(12)$ & $0.23(4)$ & $6(3)$ & $0.85(8)$ & $8.53 \times 10^{-1}$ \\
\hline
\end{tabular}


Table S45 | Crystallographic information for the structural refinement of $\mathbf{1 b} \cdot \mathbf{M e C N}$

\begin{tabular}{|c|c|}
\hline Identification code & CCDC 2063308 \\
\hline Empirical formula & $\mathrm{C}_{57} \mathrm{H}_{40} \mathrm{~N}_{5} \mathrm{NiO}_{2} \mathrm{Ti}$ \\
\hline Formula weight & 933.55 \\
\hline Temperature (K) & 100.04 \\
\hline Crystal system & triclinic \\
\hline Space group & $P-1$ \\
\hline $\mathrm{a}(\AA)$ & $12.076(2)$ \\
\hline $\mathrm{b}(\AA)$ & $13.241(3)$ \\
\hline$c(\AA)$ & $14.877(3)$ \\
\hline$\alpha\left(^{\circ}\right)$ & $74.220(9)$ \\
\hline$\beta\left(^{\circ}\right)$ & $80.983(10)$ \\
\hline$\gamma\left({ }^{\circ}\right)$ & $72.995(10)$ \\
\hline Volume $\left(\AA^{3}\right)$ & $2181.4(8)$ \\
\hline $\mathrm{Z}$ & 2 \\
\hline$\rho_{\text {calc }}\left(\mathrm{g} / \mathrm{cm}^{3}\right)$ & 1.421 \\
\hline$\mu\left(\mathrm{mm}^{-1}\right)$ & 0.667 \\
\hline $\mathrm{F}(000)$ & 966.0 \\
\hline Crystal size $/ \mathrm{mm}^{3}$ & $0.12 \times 0.08 \times 0.04$ \\
\hline Radiation & $\operatorname{Mo} K_{\alpha}(\lambda=0.71073 \AA)$ \\
\hline $2 \Theta$ range for data collection $\left({ }^{\circ}\right)$ & 2.854 to 67.104 \\
\hline Index ranges & $-18 \leq \mathrm{h} \leq 12,-20 \leq \mathrm{k} \leq 13,-23 \leq 1 \leq 19$ \\
\hline Reflections collected & 45350 \\
\hline Independent reflections & $16031\left[\mathrm{R}_{\text {int }}=0.0418, \mathrm{R}_{\text {sigma }}=0.0713\right]$ \\
\hline Data/restraints/parameters & $16031 / 0 / 596$ \\
\hline Goodness-of-fit ${ }^{\mathrm{a}}$ on $\mathrm{F}^{2}$ & 1.088 \\
\hline Final $R$ indexes $^{\mathrm{b}}[\mathrm{I}>=2 \sigma(\mathrm{I})]$ & $R_{1}=0.0547, w R_{2}=0.1460$ \\
\hline Final $\mathrm{R}$ indexes $\mathrm{s}^{\mathrm{b}}$ [all data] & $R_{1}=0.0947, w R_{2}=0.1769$ \\
\hline Largest diff. peak/hole $\left(\mathrm{e} / \AA^{-3}\right)$ & $0.96 /-0.86$ \\
\hline
\end{tabular}

${ }^{\mathrm{a}}$ Goodness of fit $=\left[\sum\left[\frac{w\left(F_{o}^{2}-F_{c}^{2}\right)^{2}}{n-p}\right]^{2}\right.$ where $\mathrm{n}$ is the number of reflections and $\mathrm{p}$ is the total number of parameters refined. ${ }^{\mathrm{b}} R_{1}=\sum\left\|F_{o}|-| F_{c}\right\| / \sum|| F_{o} \mid ; w R_{2}=\left[\sum\left[\frac{w\left(F_{o}^{2}-F_{c}^{2}\right)^{2}}{\sum\left[w\left(F_{o}^{2}\right)^{2}\right.}\right]\right]^{\frac{1}{2}}$ 
Table S46 | Crystallographic information for the structural refinement of $\mathbf{2} \cdot \mathbf{0 . 5} \mathbf{C}_{7} \mathbf{H}_{8}$

\begin{tabular}{|c|c|}
\hline Identification code & CCDC 2063311 \\
\hline Empirical formula & $\mathrm{C}_{66.5} \mathrm{H}_{45} \mathrm{CuN}_{4} \mathrm{O}_{2} \mathrm{Ti}$ \\
\hline Formula weight & 1043.50 \\
\hline Temperature $(\mathrm{K})$ & 100.05 \\
\hline Crystal system & triclinic \\
\hline Space group & $P-1$ \\
\hline $\mathrm{a}(\AA)$ & $11.4668(11)$ \\
\hline $\mathrm{b}(\AA)$ & $12.6581(15)$ \\
\hline$c(\AA)$ & $17.915(2)$ \\
\hline$\alpha\left(^{\circ}\right)$ & $77.614(4)$ \\
\hline$\beta\left(^{\circ}\right)$ & $77.109(4)$ \\
\hline$\gamma\left({ }^{\circ}\right)$ & $76.796(4)$ \\
\hline Volume $\left(\AA^{3}\right)$ & $2430.9(5)$ \\
\hline Z & 2 \\
\hline$\rho_{\text {calc }}\left(\mathrm{g} / \mathrm{cm}^{3}\right)$ & 1.426 \\
\hline$\mu\left(\mathrm{mm}^{-1}\right)$ & 0.656 \\
\hline $\mathrm{F}(000)$ & 1078.0 \\
\hline Crystal size $/ \mathrm{mm}^{3}$ & $0.07 \times 0.03 \times 0.01$ \\
\hline Radiation & $\operatorname{Mo} K_{\alpha}(\lambda=0.71073 \AA)$ \\
\hline $2 \Theta$ range for data collection $\left(^{\circ}\right)$ & 2.368 to 41.672 \\
\hline Index ranges & $-11 \leq \mathrm{h} \leq 10,-12 \leq \mathrm{k} \leq 12,-17 \leq 1 \leq 17$ \\
\hline Reflections collected & 19154 \\
\hline Independent reflections & $5002\left[R_{\text {int }}=0.0954, R_{\text {sigma }}=0.0849\right]$ \\
\hline Data/restraints/parameters & $5002 / 0 / 693$ \\
\hline Goodness-of-fit ${ }^{\mathrm{a}}$ on $\mathrm{F}^{2}$ & 1.019 \\
\hline Final $R$ indexes ${ }^{b}[I>=2 \sigma(I)]$ & $R_{1}=0.0524, w R_{2}=0.1315$ \\
\hline Final $\mathrm{R}$ indexes ${ }^{\mathrm{b}}$ [all data] & $R_{1}=0.0765, w R_{2}=0.1460$ \\
\hline Largest diff. peak/hole $\left(\mathrm{e} / \AA^{-3}\right)$ & $0.67 /-0.47$ \\
\hline
\end{tabular}


Table S47 | Crystallographic information for the structural refinement of $\mathbf{3}$

\begin{tabular}{|c|c|}
\hline Identification code & CCDC 2063319 \\
\hline Empirical formula & $\mathrm{C}_{71} \mathrm{H}_{45} \mathrm{CuN}_{4} \mathrm{O}_{2} \mathrm{Ti}$ \\
\hline Formula weight & 1097.55 \\
\hline Temperature $(\mathrm{K})$ & 99.99 \\
\hline Crystal system & triclinic \\
\hline Space group & $P-1$ \\
\hline $\mathrm{a}(\AA)$ & $11.297(8)$ \\
\hline $\mathrm{b}(\AA)$ & $12.740(9)$ \\
\hline $\mathrm{c}(\AA)$ & $19.561(15)$ \\
\hline$\alpha\left(^{\circ}\right)$ & $103.031(18)$ \\
\hline$\beta\left(^{\circ}\right)$ & $93.422(19)$ \\
\hline$\gamma\left(\left(^{\circ}\right)\right.$ & 103.673(19) \\
\hline Volume $\left(\AA^{3}\right)$ & $2646(3)$ \\
\hline Z & 2 \\
\hline$\rho_{\text {calc }}\left(\mathrm{g} / \mathrm{cm}^{3}\right)$ & 1.377 \\
\hline$\mu\left(\mathrm{mm}^{-1}\right)$ & 2.198 \\
\hline $\mathrm{F}(000)$ & 1132.0 \\
\hline Crystal size $/ \mathrm{mm}^{3}$ & $0.05 \times 0.02 \times 0.01$ \\
\hline Radiation & $\mathrm{Cu} K_{\alpha}(\lambda=1.54178 \AA)$ \\
\hline $2 \Theta$ range for data collection $\left(^{\circ}\right)$ & 4.67 to 76.128 \\
\hline Index ranges & $-8 \leq \mathrm{h} \leq 8,-9 \leq \mathrm{k} \leq 10,-15 \leq 1 \leq 15$ \\
\hline Reflections collected & 7319 \\
\hline Independent reflections & $2700\left[R_{\text {int }}=0.0717, R_{\text {sigma }}=0.0957\right]$ \\
\hline Data/restraints/parameters & $2700 / 803 / 619$ \\
\hline Goodness-of-fit ${ }^{\mathrm{a}}$ on $\mathrm{F}^{2}$ & 1.012 \\
\hline Final $R$ indexes ${ }^{b}[I>=2 \sigma(I)]$ & $R_{1}=0.0752, w R_{2}=0.1961$ \\
\hline Final $\mathrm{R}$ indexes ${ }^{\mathrm{b}}$ [all data] & $R_{1}=0.1189, w R_{2}=0.2258$ \\
\hline Largest diff. peak/hole $\left(\mathrm{e} / \AA^{-3}\right)$ & $0.40 /-0.39$ \\
\hline
\end{tabular}

${ }^{\mathrm{a}}$ Goodness of fit $=\left[\sum\left[\frac{w\left(F_{o}^{2}-F_{c}^{2}\right)^{2}}{n-p}\right]^{2}\right.$ where $\mathrm{n}$ is the number of reflections and $\mathrm{p}$ is the total number of parameters refined. ${ }^{\mathrm{b}} R_{1}=\sum\left\|F_{o}|-| F_{c}\right\| / \sum \| F_{o} \mid ; w R_{2}=\left[\sum\left[\frac{w\left(F_{o}^{2}-F_{C}^{2}\right)^{2}}{\sum\left[w\left(F_{o}^{2}\right)^{2}\right.}\right]\right]^{\frac{1}{2}}$ 


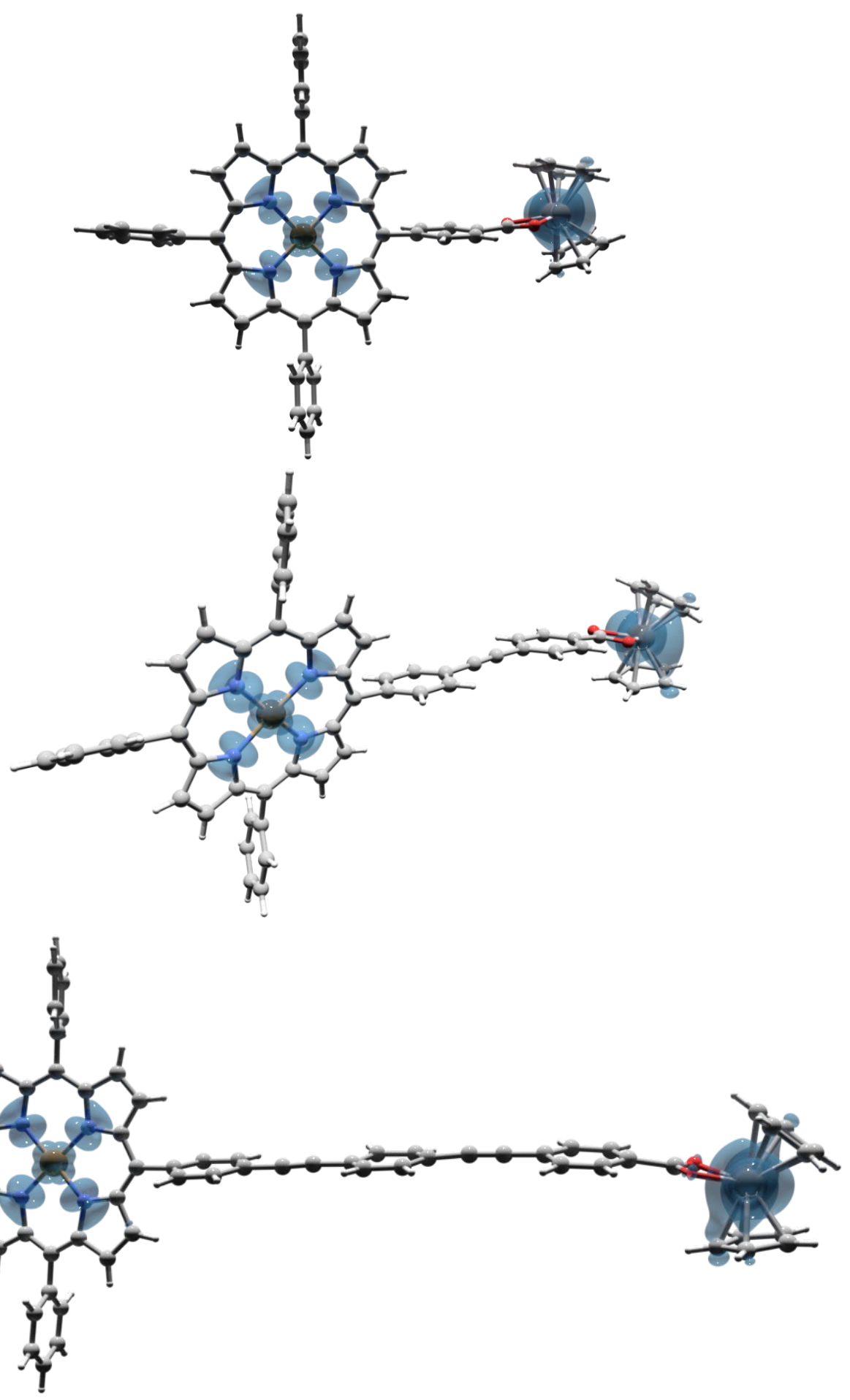

Figure S1 | Rendering of $80 \%$ spin density surfaces for 1 (top), 2. (center), and $\mathbf{3}$ (bottom) showing negligible spin density on the bridge in $\mathbf{2}$ and $\mathbf{3}$ computed by density functional theory (DFT) at the PBE level. The ferromagnetically aligned spin state is depicted for clarity. Color codes: $\mathrm{C}$ (gray), $\mathrm{Cu}$ (orange), H (white), N (blue), O (red), Ti (silver) 


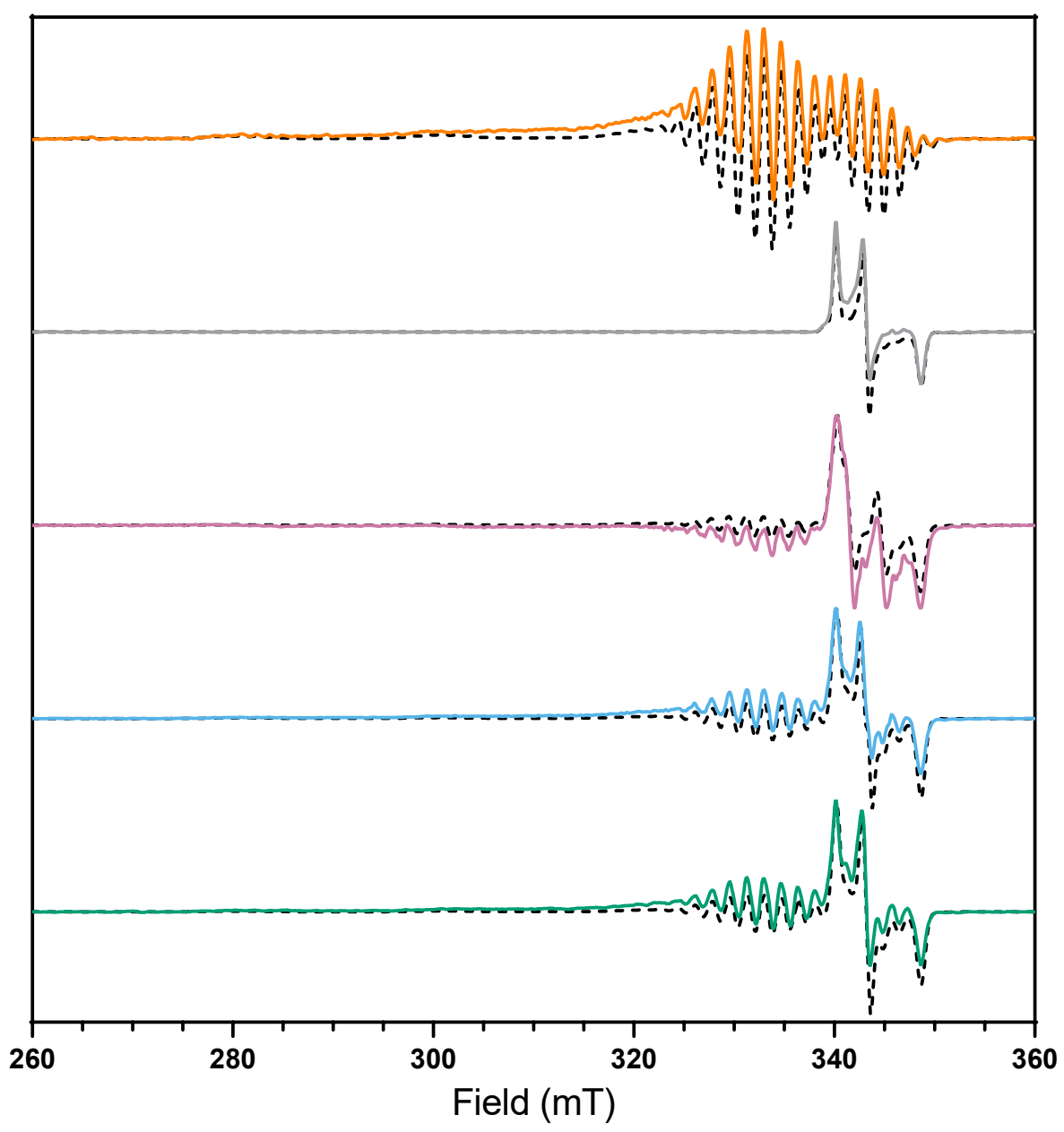

Figure S2 | CW EPR spectra 2a (orange), $2 \mathbf{b}$ (gray), 1 (pink), 2 (blue), and $\mathbf{3}$ (green) (top to bottom) with best fit simulations in dashed lines. All data were acquired on $\sim 0.5 \mathrm{mM}$ frozen $1: 1 \mathrm{CS}_{2}$ :toluene- $d_{8}$ solutions at $77 \mathrm{~K}$ and $9.529 \mathrm{GHz}$. 2a was fit to the Hamiltonian $H=\mu_{B} \boldsymbol{B} \boldsymbol{g}^{C u} \hat{S}^{C u}+\hat{S}^{C u} \boldsymbol{A}^{C u} \hat{I}^{C u, N}$. 2b was fit to the Hamiltonian $H=\mu_{B} \boldsymbol{B} \boldsymbol{g}^{T i} \hat{S}^{T i}+\hat{S}^{T i} \boldsymbol{A}^{T i} \hat{I}^{T i}$. 1-3 were fit to the Hamiltonian $H=\mu_{B} \boldsymbol{B} \boldsymbol{g}^{C u} \hat{S}^{C u}+$ $\hat{S}^{C u} \boldsymbol{A}^{C u} \hat{I}^{C u, N}+\mu_{B} \boldsymbol{B} \boldsymbol{g}^{T i} \hat{S}^{T i}+\hat{S}^{T i} \boldsymbol{A}^{T i} \hat{I}^{T i}+\hat{S}^{C u} \boldsymbol{I} \hat{S}^{T i}$ 


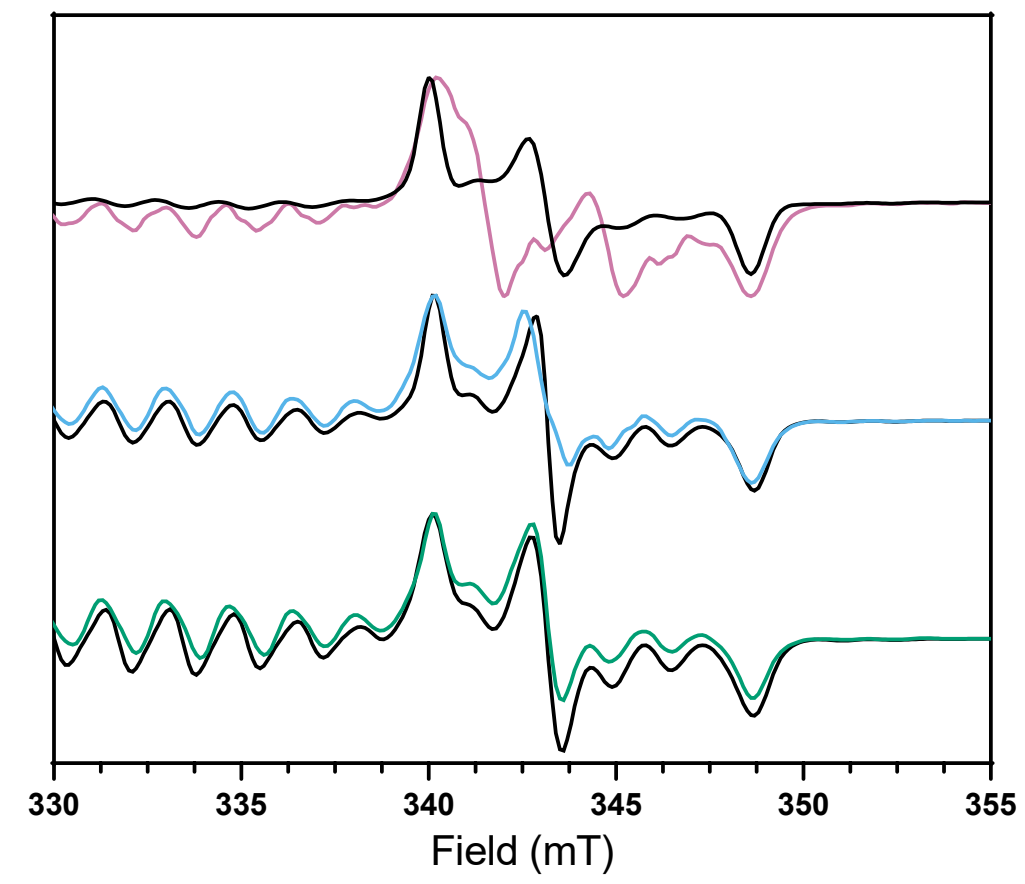

Figure S3 | Comparison of experimental CW EPR spectra in the Ti region with simulations based on a sum of uncoupled spin centers of $\mathbf{1}$ (pink), $\mathbf{2}$ (blue), and $\mathbf{3}$ (green) with simulations in black. All data were acquired on $\sim 0.5 \mathrm{mM}$ frozen 1:1 $\mathrm{CS}_{2}:$ toluene- $d_{8}$ solutions at $77 \mathrm{~K}$ and $9.529 \mathrm{GHz}$.

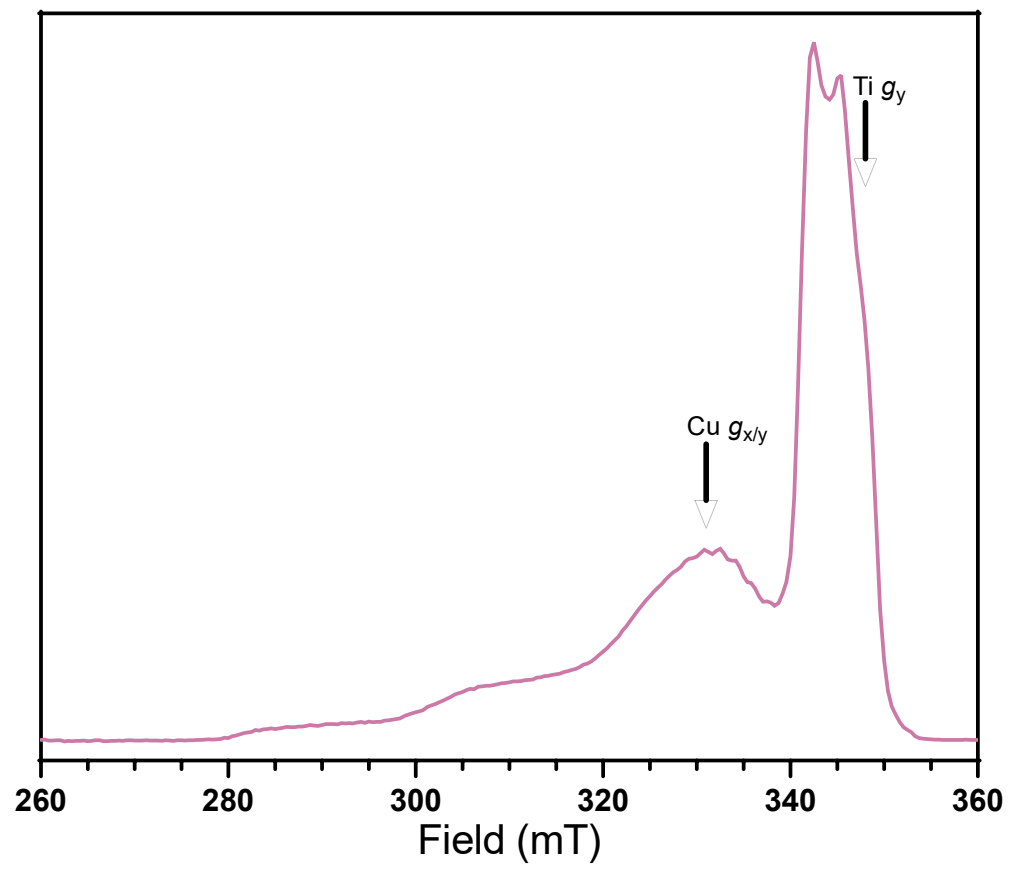

Figure S4 | EDFS EPR spectrum of 1 in frozen toluene solution at $20 \mathrm{~K}$ and $9.5072 \mathrm{GHz}$, indicating field positions of $T_{1}$ and $T_{\mathrm{m}}$ measurements at the $\mathrm{Cu}^{2+} g_{\mathrm{x} / \mathrm{y}}$ and $\mathrm{Ti}^{3+} g_{\mathrm{y}}$ transitions. 


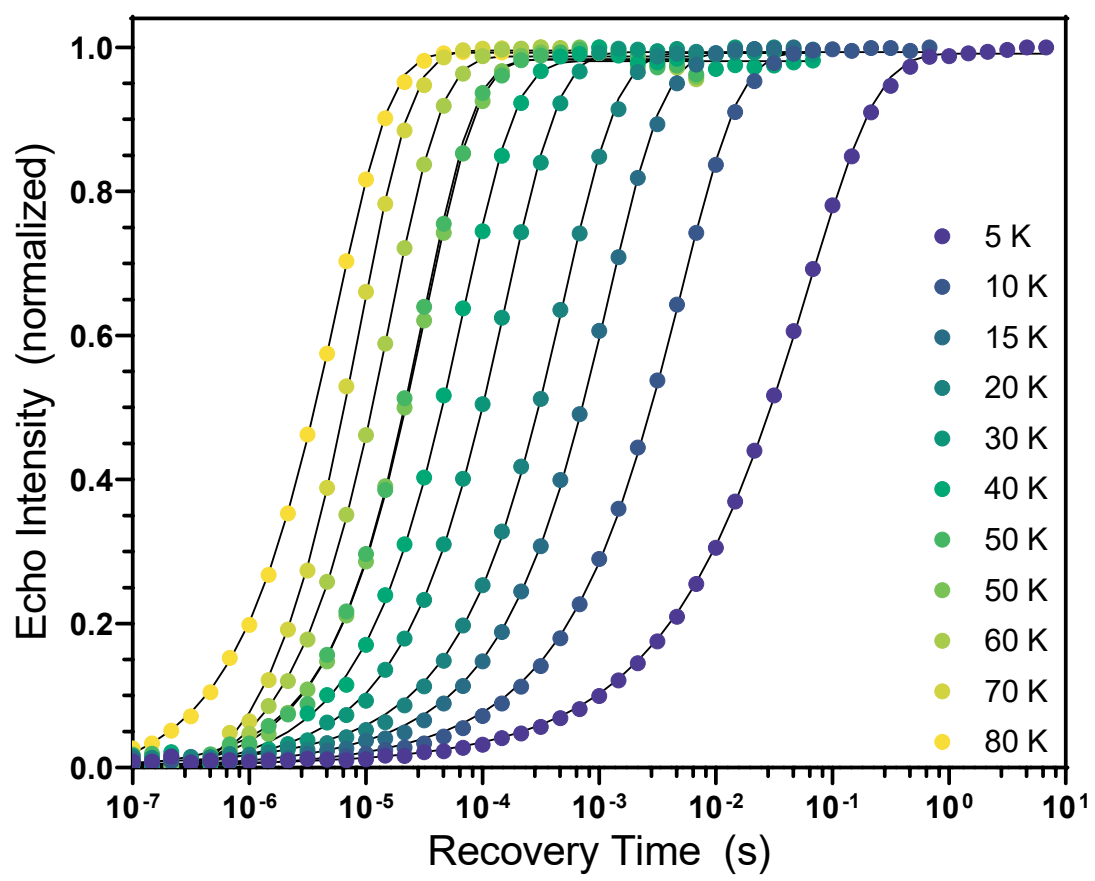

Figure S5 | Variable temperature saturation recovery data for $\mathbf{1}$ at $331 \mathrm{mT}$ and $9.5072 \mathrm{GHz}\left(\mathrm{Cu}^{2+} g_{\mathrm{x} / \mathrm{y}}\right)$ in toluene.

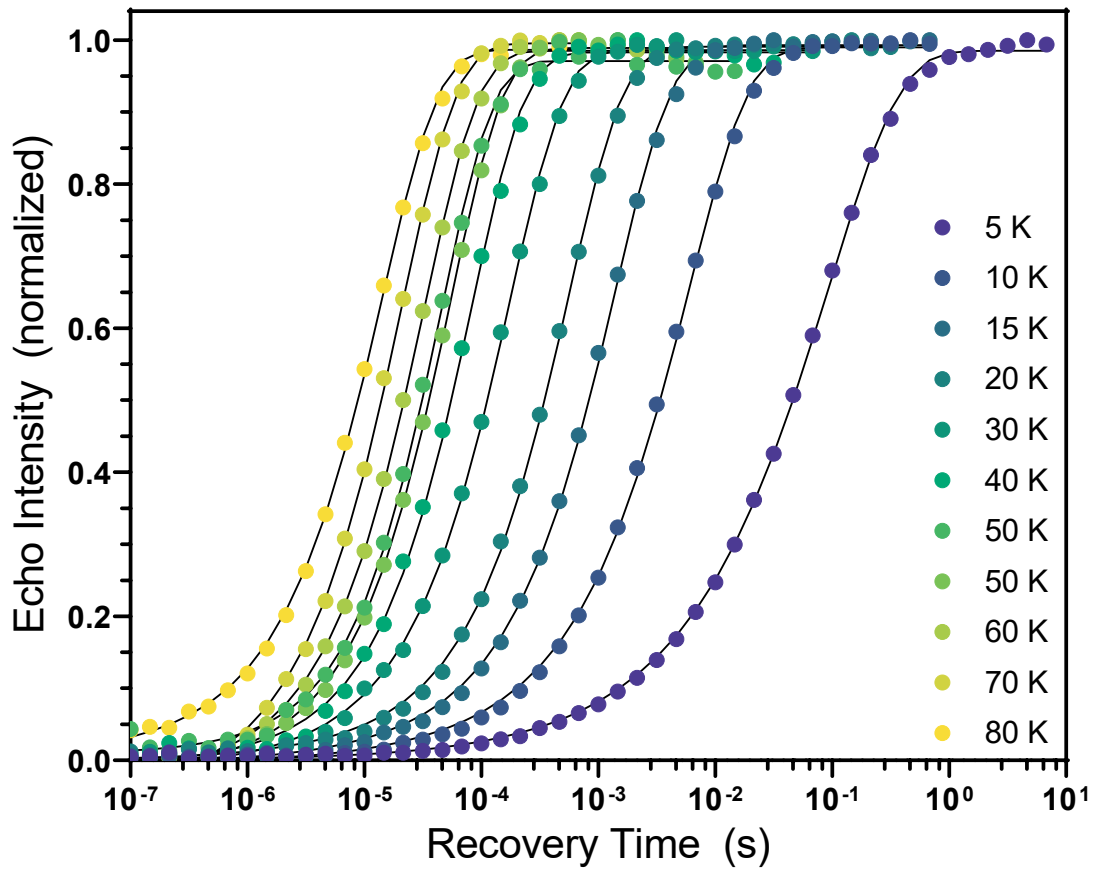

Figure S6 | Variable temperature saturation recovery data for $\mathbf{1}$ at $348 \mathrm{mT}$ and $9.5072 \mathrm{GHz}\left(\mathrm{Ti}^{3+} g_{\mathrm{y}}\right)$ in toluene. 


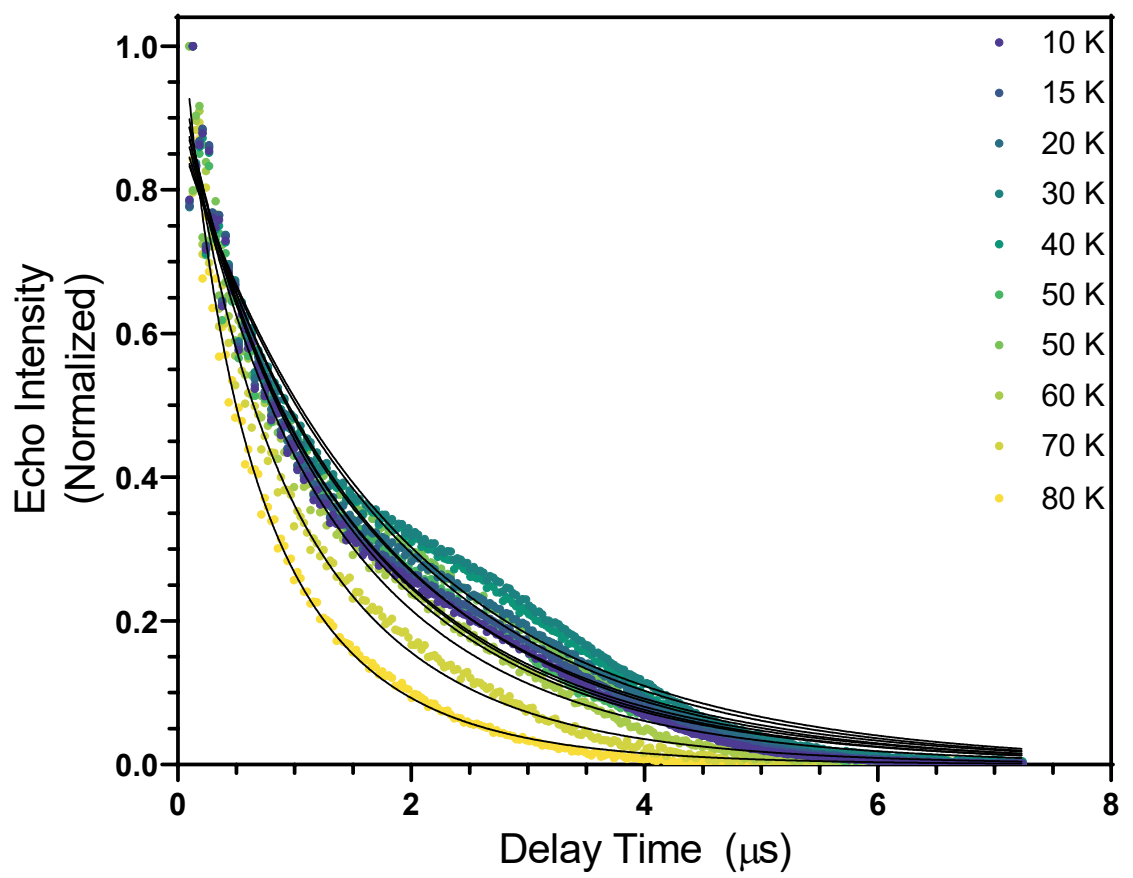

Figure S7 | Variable temperature two-pulse Hahn echo data for 1 at $331 \mathrm{mT}$ and $9.5072 \mathrm{GHz}\left(\mathrm{Cu}^{2+} g_{\mathrm{x} / \mathrm{y}}\right)$ in toluene.

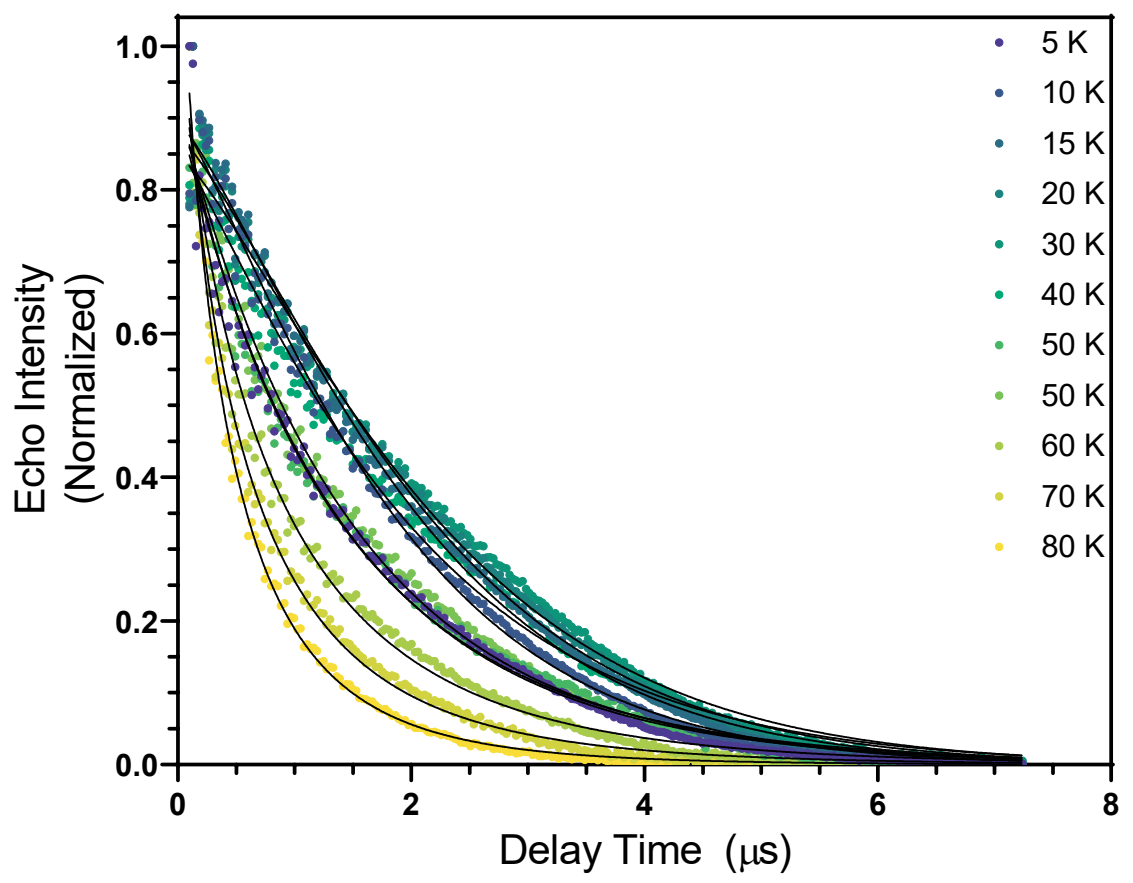

Figure S8 | Variable temperature two-pulse Hahn echo data for 1 at $348 \mathrm{mT}$ and $9.5072 \mathrm{GHz}\left(\mathrm{Ti}^{3+} g_{\mathrm{y}}\right)$ in toluene. 


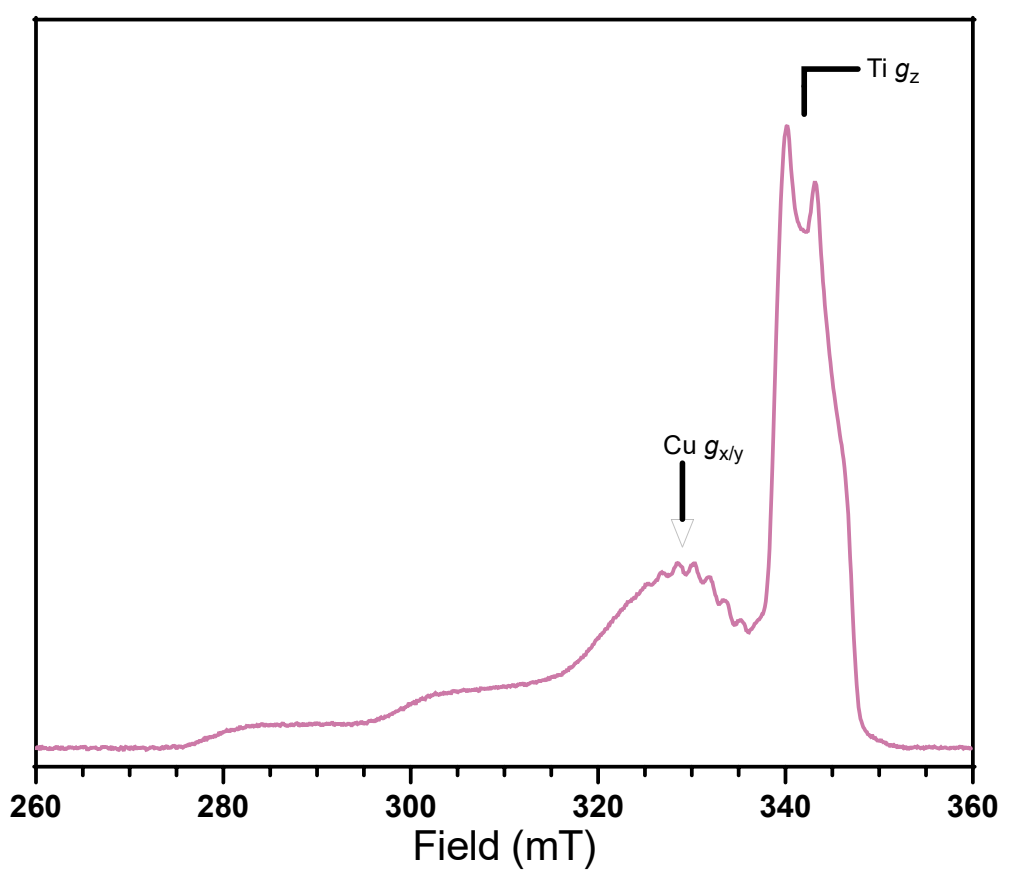

Figure S9 | EDFS EPR spectrum of 1 in frozen 1:1 $\mathrm{CS}_{2}:$ toluene- $d_{8}$ solution at $30 \mathrm{~K}$ and $9.4921 \mathrm{GHz}$, indicating field positions of $T_{1}$ and $T_{\mathrm{m}}$ measurements at the $\mathrm{Cu}^{2+} g_{\mathrm{x} / \mathrm{y}}$ and $\mathrm{Ti}^{3+} g_{\mathrm{z}}$ transitions.

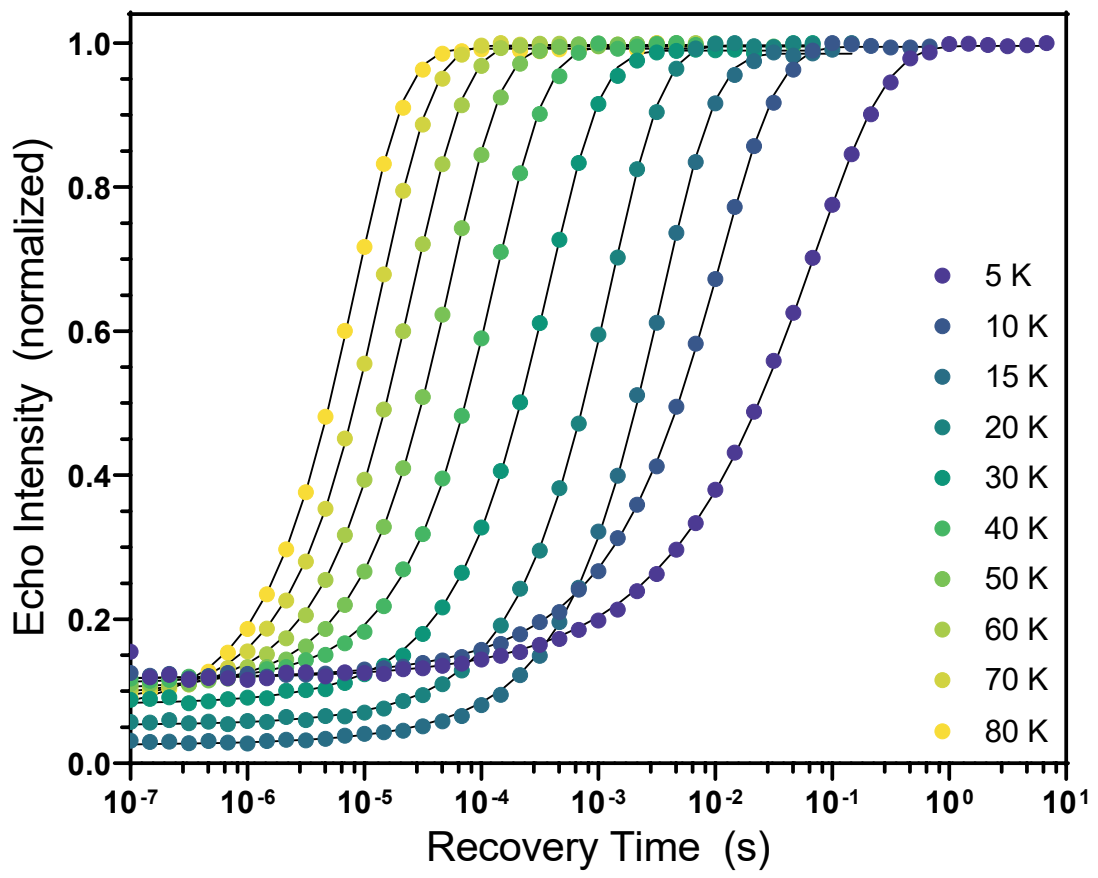

Figure S10 | Variable temperature saturation recovery data for $\mathbf{1}$ at $329 \mathrm{mT}$ and $9.4921 \mathrm{GHz}\left(\mathrm{Cu}^{2+} g_{\mathrm{x} / \mathrm{y}}\right)$ in $1: 1 \mathrm{CS}_{2}:$ toluene- $d_{8}$. 


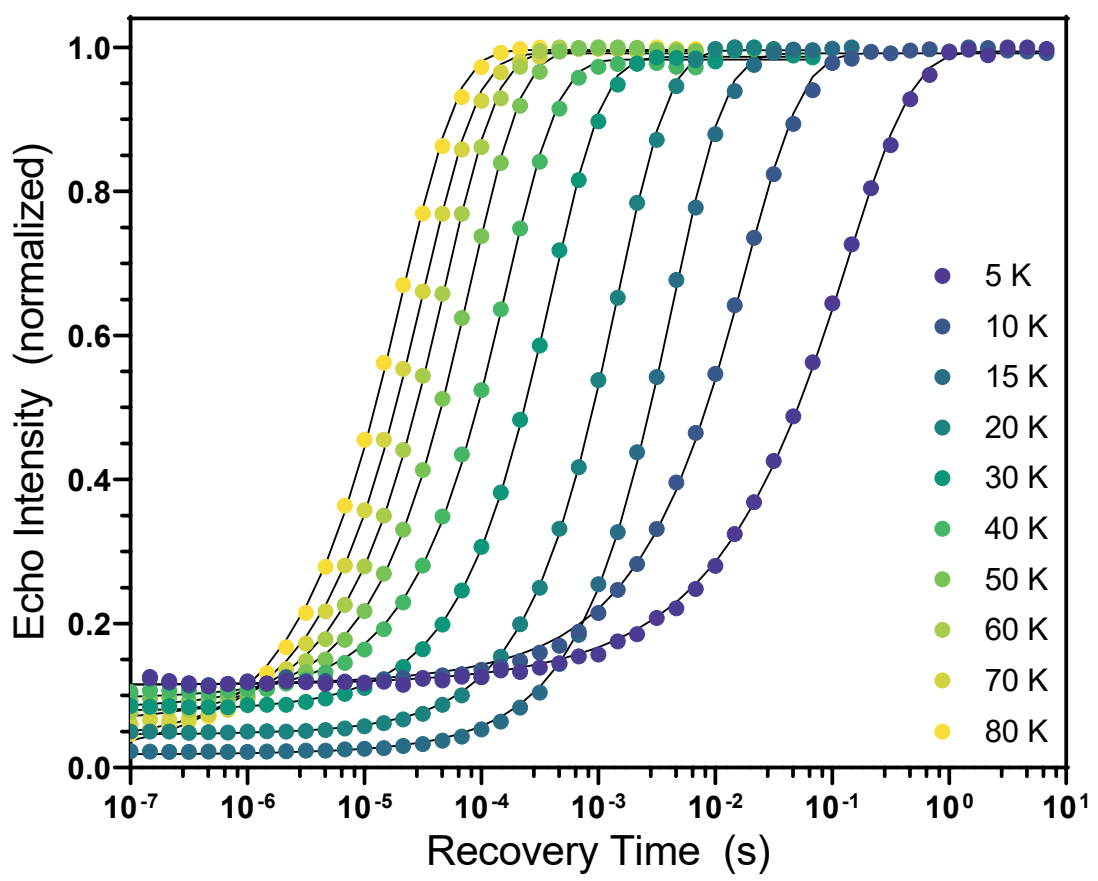

Figure S11 | Variable temperature saturation recovery data for 1 at $342 \mathrm{mT}$ and $9.4921 \mathrm{GHz}\left(\mathrm{Ti}^{3+} g_{\mathrm{z}}\right)$ in 1:1 $\mathrm{CS}_{2}$ :toluene- $d_{8}$.

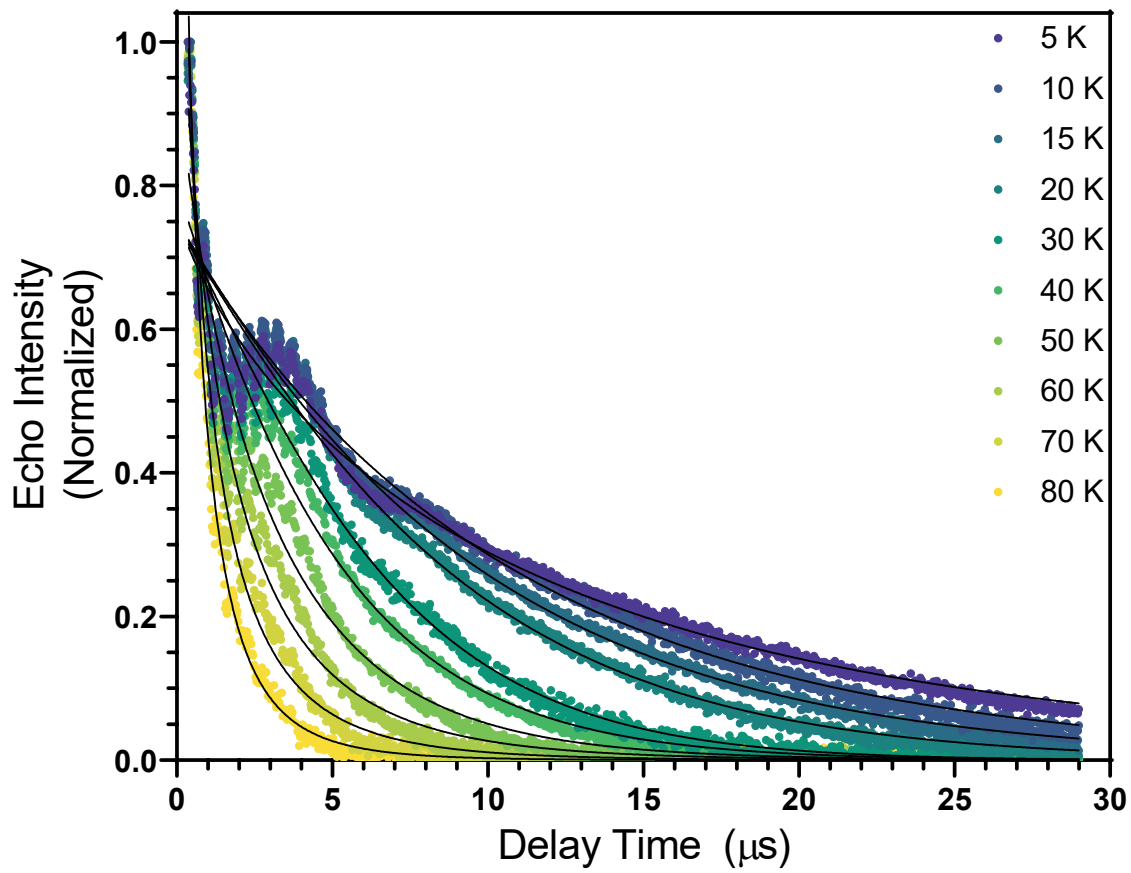

Figure S12 | Variable temperature two-pulse Hahn echo data for 1 at $329 \mathrm{mT}$ and $9.4921 \mathrm{GHz}\left(\mathrm{Cu}^{2+} g_{\mathrm{x} / \mathrm{y}}\right)$ in $1: 1 \mathrm{CS}_{2}$ :toluene- $d_{8}$. 


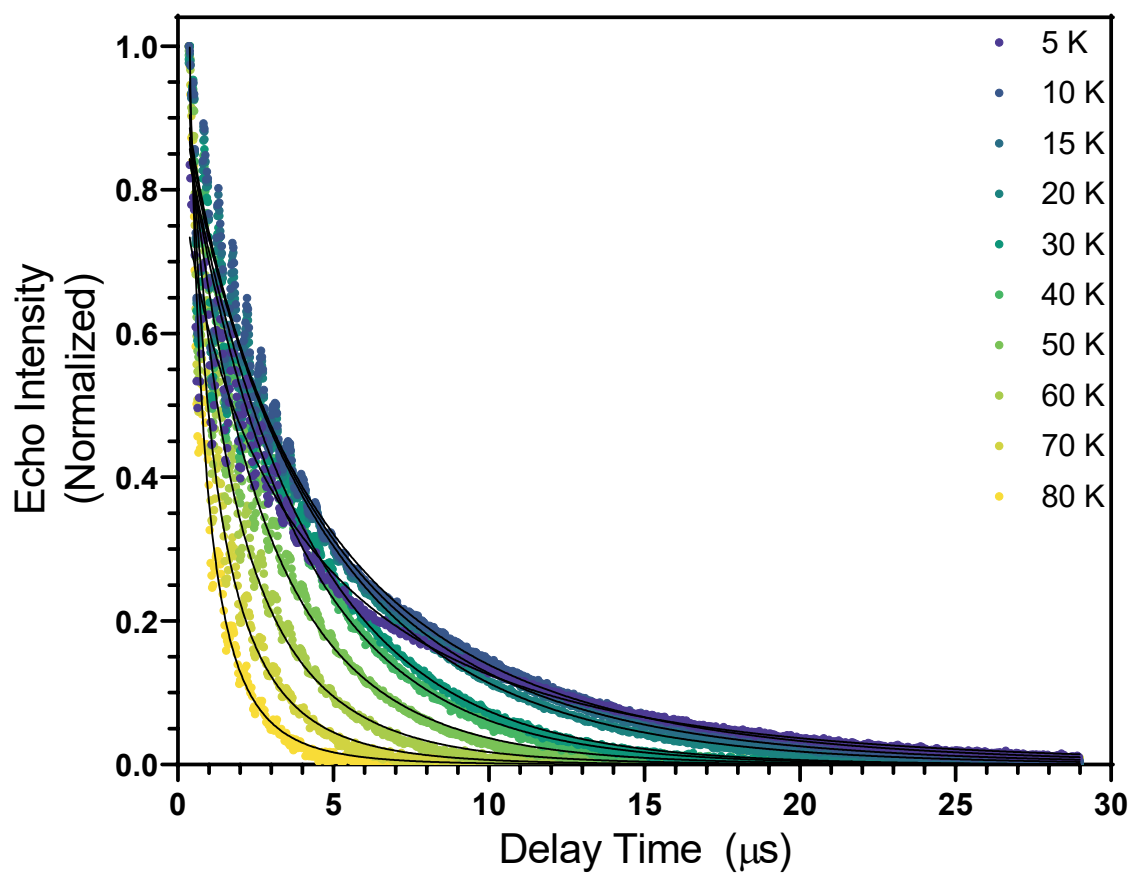

Figure S13 | Variable temperature two-pulse Hahn echo data for 1 at $342 \mathrm{mT}$ and $9.4921 \mathrm{GHz}\left(\mathrm{Ti}^{3+} g_{\mathrm{z}}\right)$ in 1:1 $\mathrm{CS}_{2}:$ toluene- $d_{8}$.

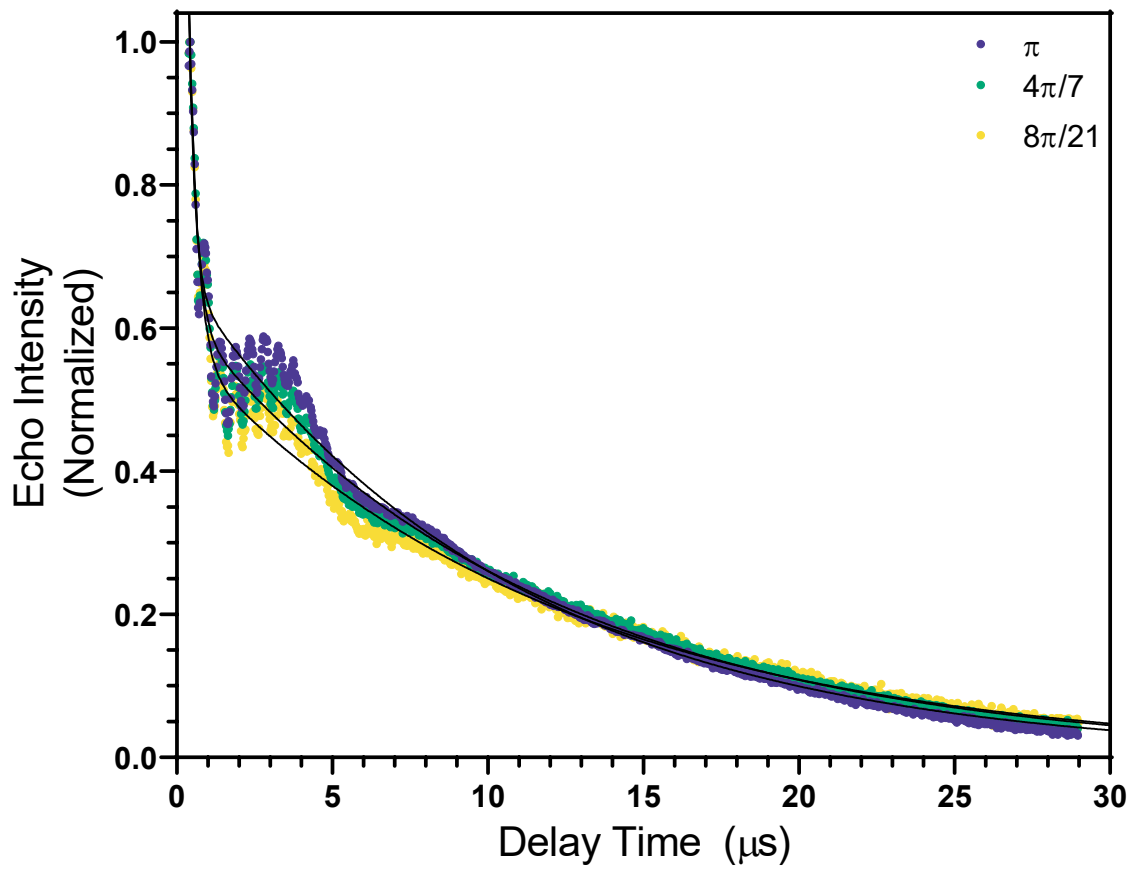

Figure S14 | Variable turning angle two-pulse $\left(\frac{\theta}{2}, \theta\right)$ Hahn echo data for $\mathbf{1}$ at $324 \mathrm{mT}$ and $9.3673 \mathrm{GHz}$ $\left(\mathrm{Cu}^{2+} g_{\mathrm{x} / \mathrm{y}}\right)$ in 1:1 $\mathrm{CS}_{2}:$ toluene- $d_{8}$ at $10 \mathrm{~K}$. 


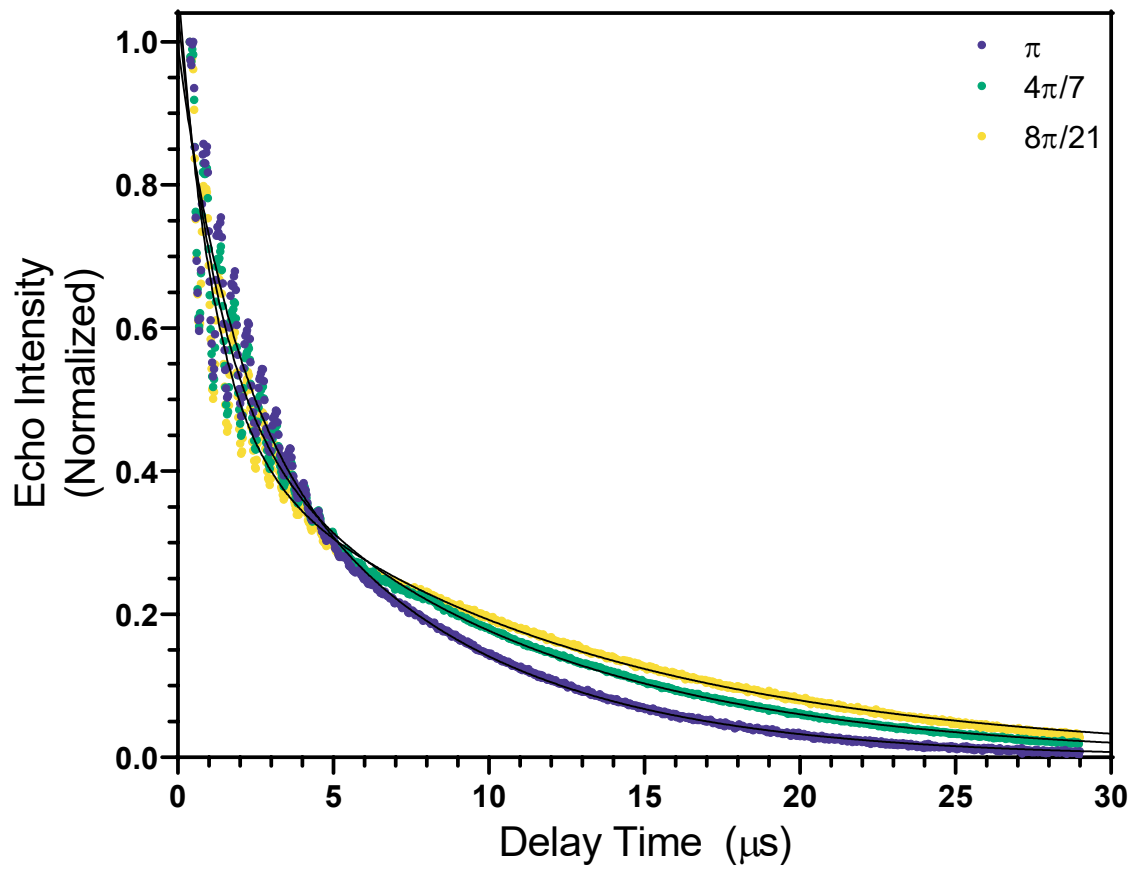

Figure S15 | Variable turning angle two-pulse $\left(\frac{\theta}{2}, \theta\right)$ Hahn echo data for 1 at $334 \mathrm{mT}$ and $9.3673 \mathrm{GHz}$ $\left(\mathrm{Ti}^{3+} g_{\mathrm{z}}\right)$ in 1:1 $\mathrm{CS}_{2}:$ toluene- $d_{8}$ at $10 \mathrm{~K}$.

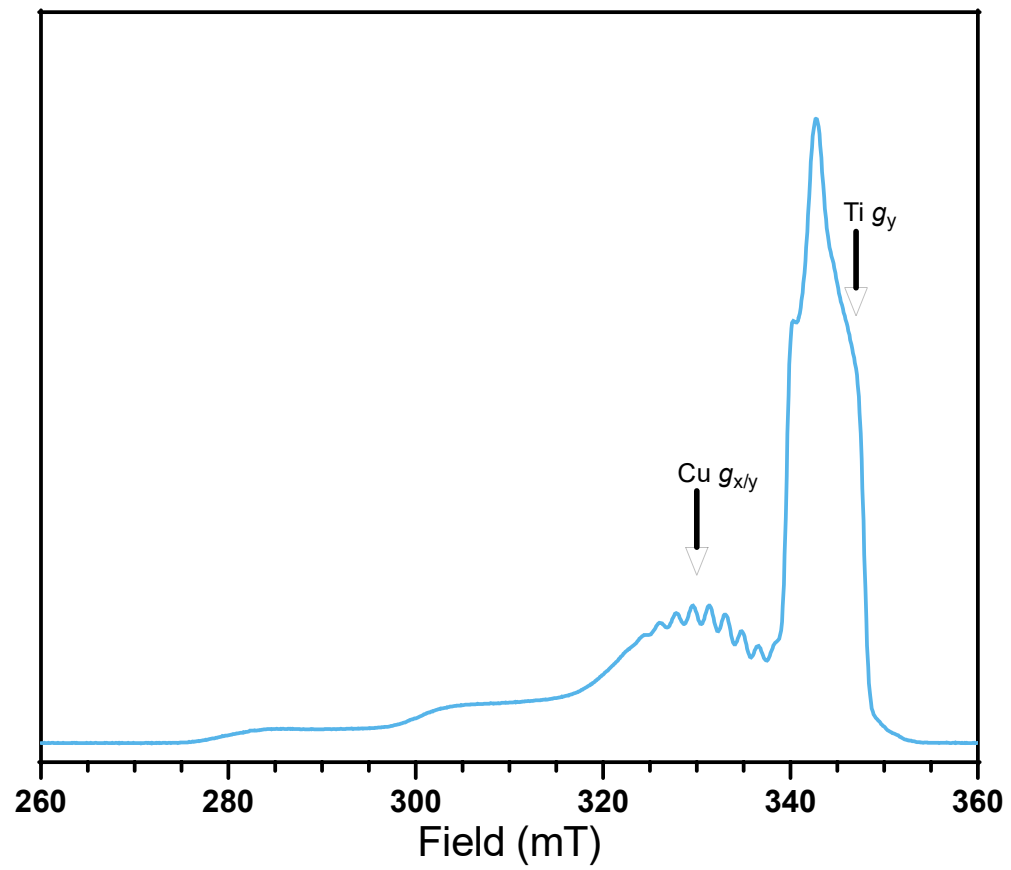

Figure S16. EDFS EPR spectrum of 2 in frozen toluene solution at $20 \mathrm{~K}$ and $9.4985 \mathrm{GHz}$, indicating field positions of $T_{1}$ and $T_{\mathrm{m}}$ measurements at the $\mathrm{Cu}^{2+} g_{\mathrm{x} / \mathrm{y}}$ and $\mathrm{Ti}^{3+} g_{\mathrm{y}}$ transitions. 


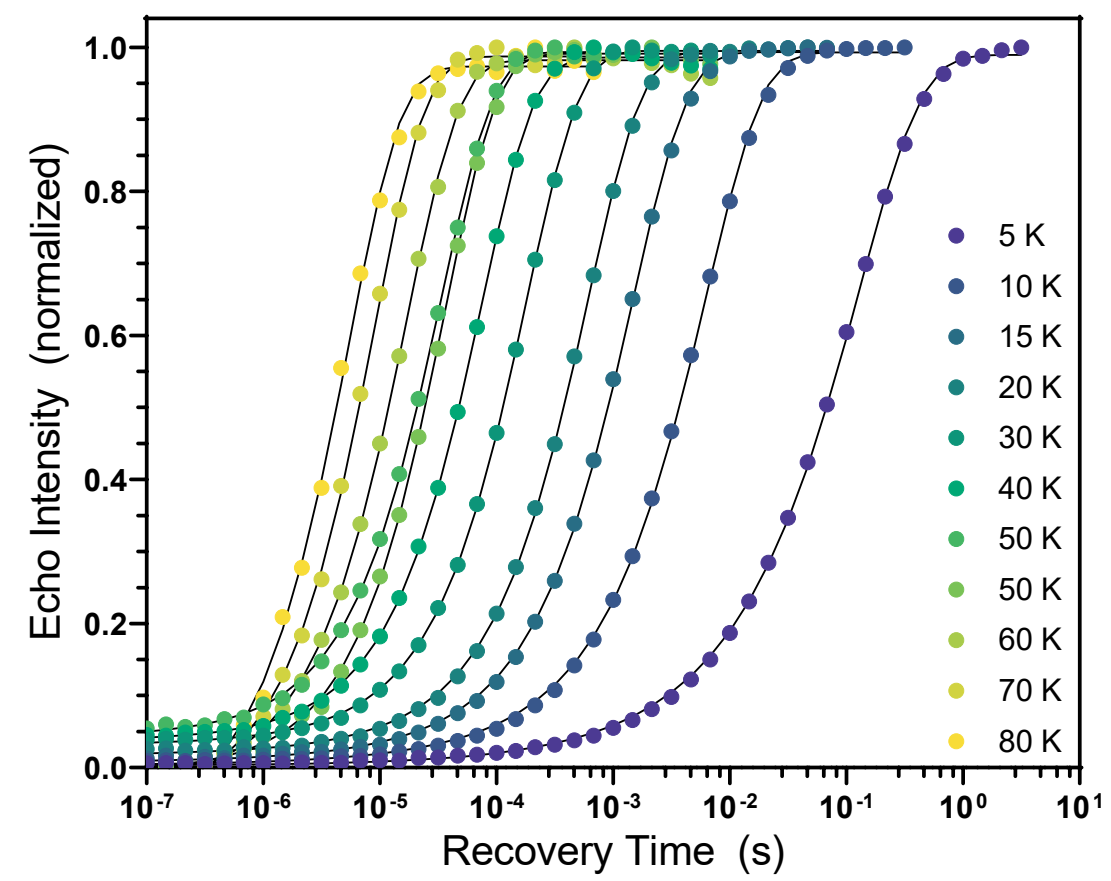

Figure S17 | Variable temperature saturation recovery data for 2 at $330 \mathrm{mT}$ and $9.4985 \mathrm{GHz}\left(\mathrm{Cu}^{2+} g_{\mathrm{x} / \mathrm{y}}\right)$ in toluene.

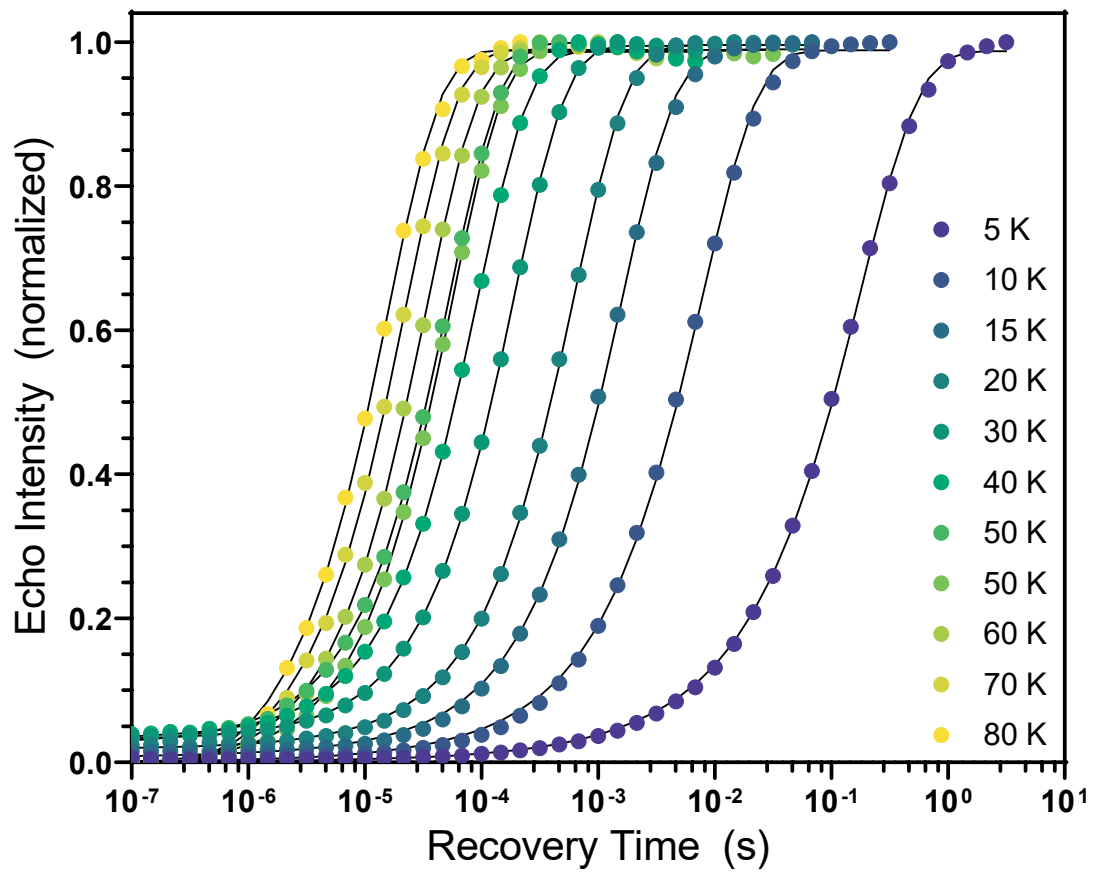

Figure S18 | Variable temperature saturation recovery data for 2 at $347 \mathrm{mT}$ and $9.4985 \mathrm{GHz}\left(\mathrm{Ti}^{3+} g_{\mathrm{y}}\right)$ in toluene. 


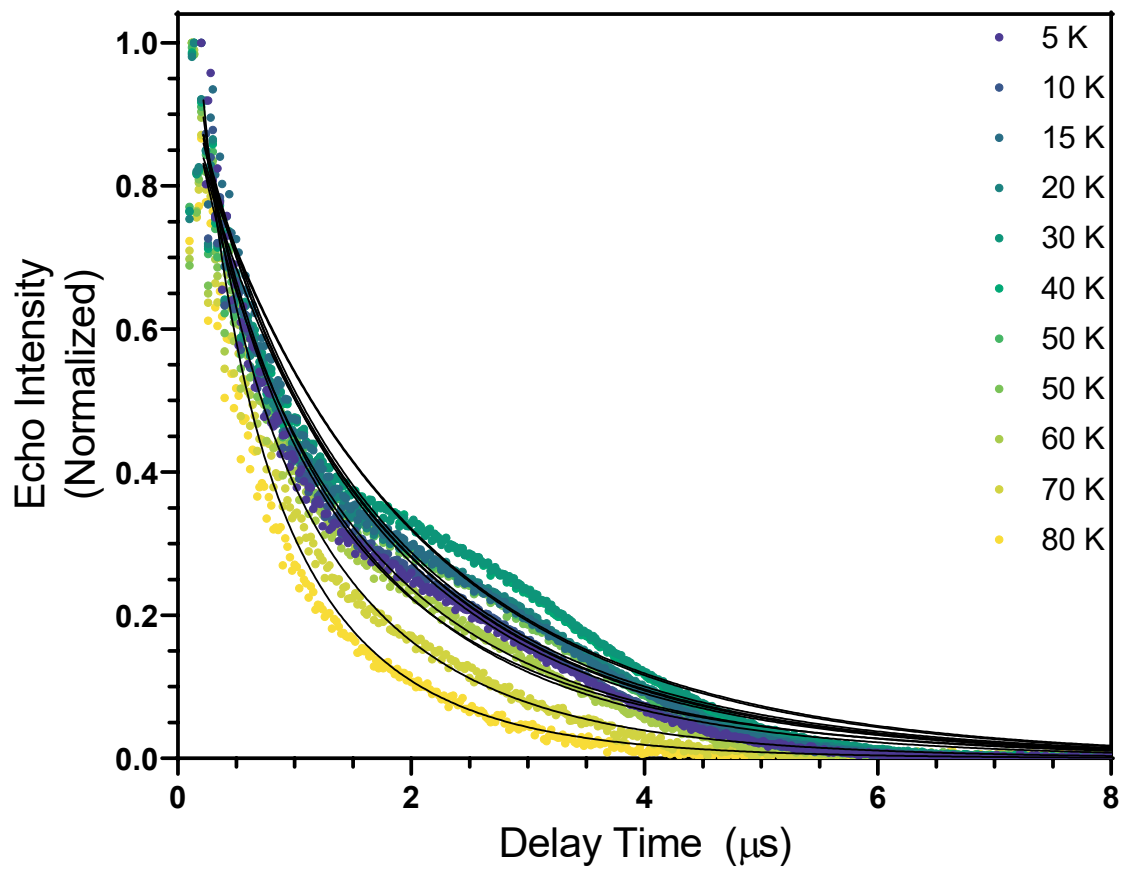

Figure S19 | Variable temperature two-pulse Hahn echo data for 2 at $330 \mathrm{mT}$ and $9.4985 \mathrm{GHz}\left(\mathrm{Cu}^{2+} g_{\mathrm{x} / \mathrm{y}}\right)$ in toluene.

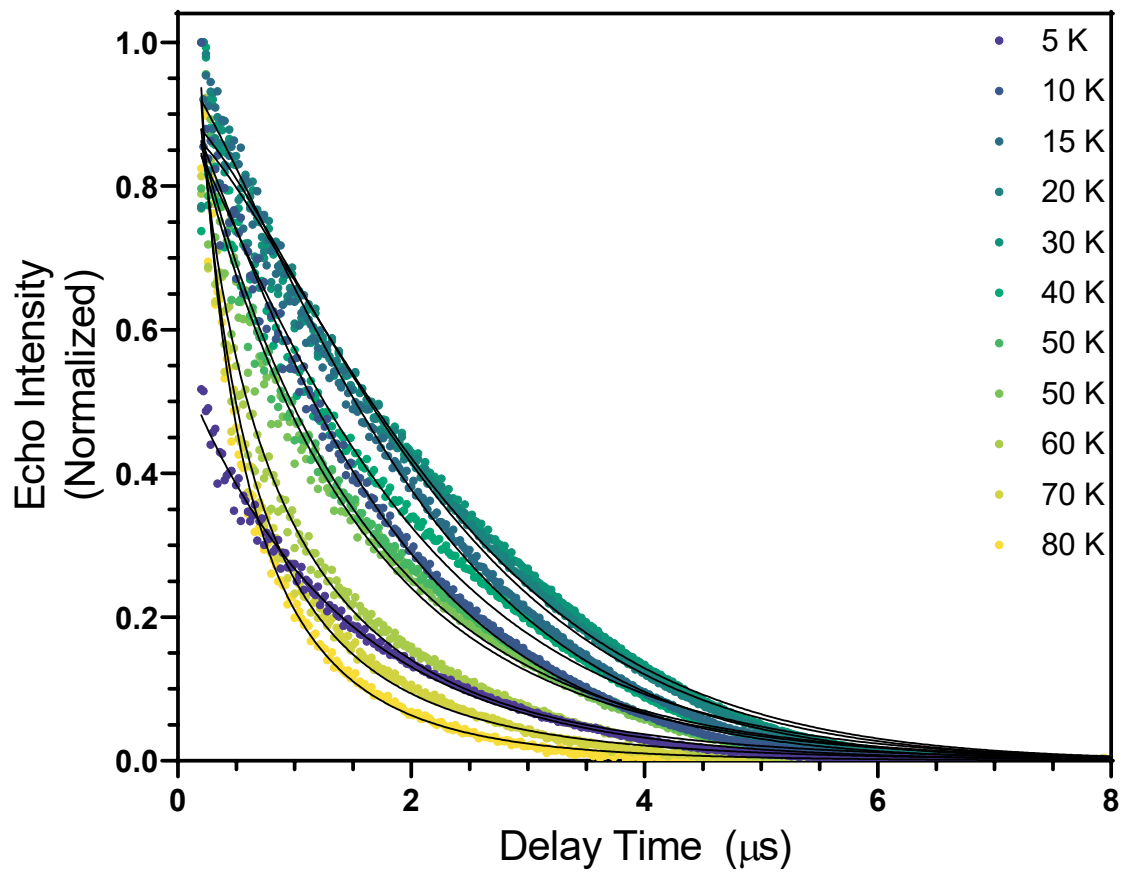

Figure S20 | Variable temperature two-pulse Hahn echo data for 2 at $347 \mathrm{mT}$ and $9.4985 \mathrm{GHz}\left(\mathrm{Ti}^{3+} g_{\mathrm{y}}\right)$ in toluene. 


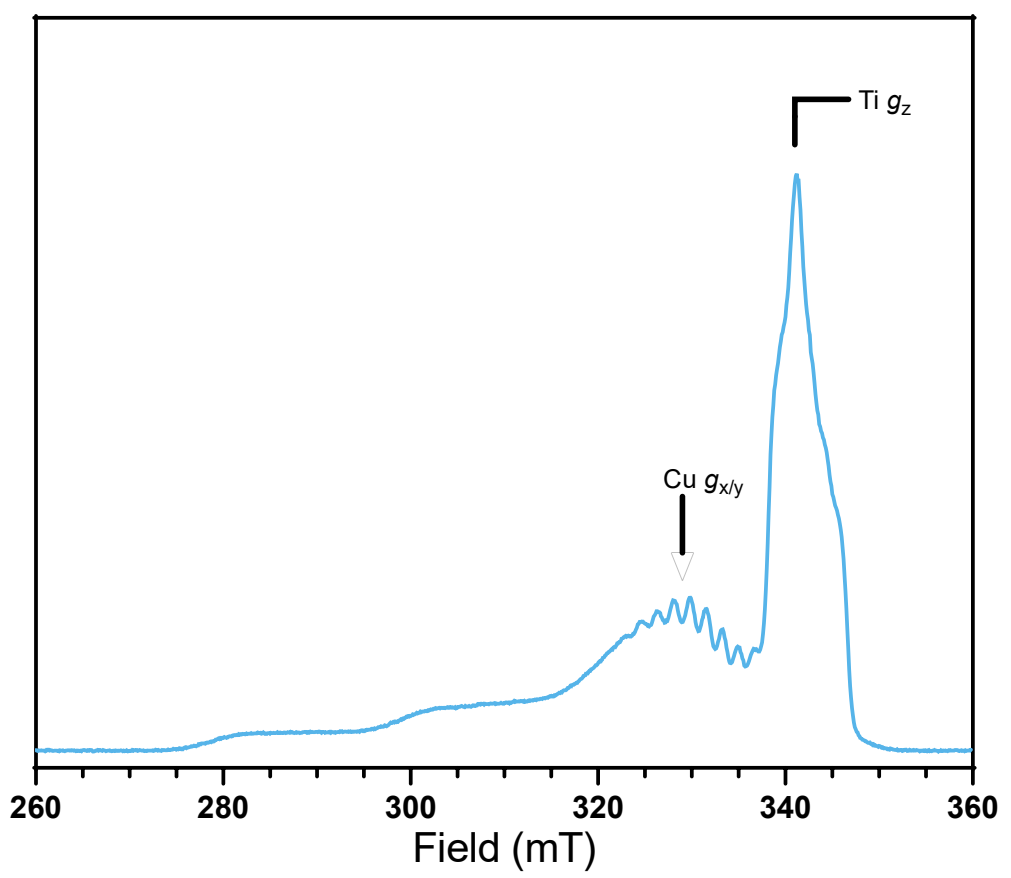

Figure S21 | EDFS EPR spectrum of 2 in frozen 1:1 CS 2 :toluene- $d_{8}$ solution at $30 \mathrm{~K}$ and $9.4798 \mathrm{GHz}$, indicating field positions of $T_{1}$ and $T_{\mathrm{m}}$ measurements at the $\mathrm{Cu}^{2+} g_{\mathrm{x} / \mathrm{y}}$ and $\mathrm{Ti}^{3+} g_{\mathrm{z}}$ transitions.

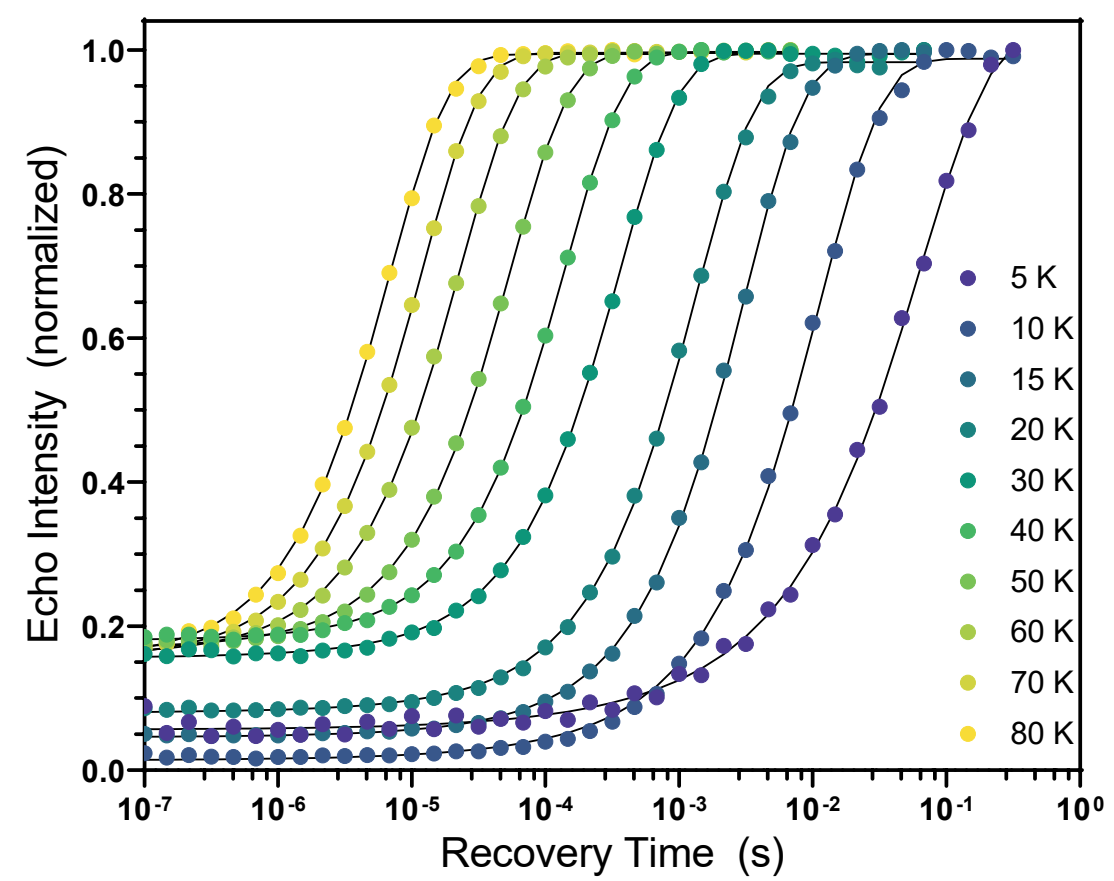

Figure S22 | Variable temperature saturation recovery data for 2 at $329 \mathrm{mT}$ and $9.4798 \mathrm{GHz}\left(\mathrm{Cu}^{2+} g_{\mathrm{x} / \mathrm{y}}\right)$ in 1:1 $\mathrm{CS}_{2}$ :toluene- $d_{8}$. 


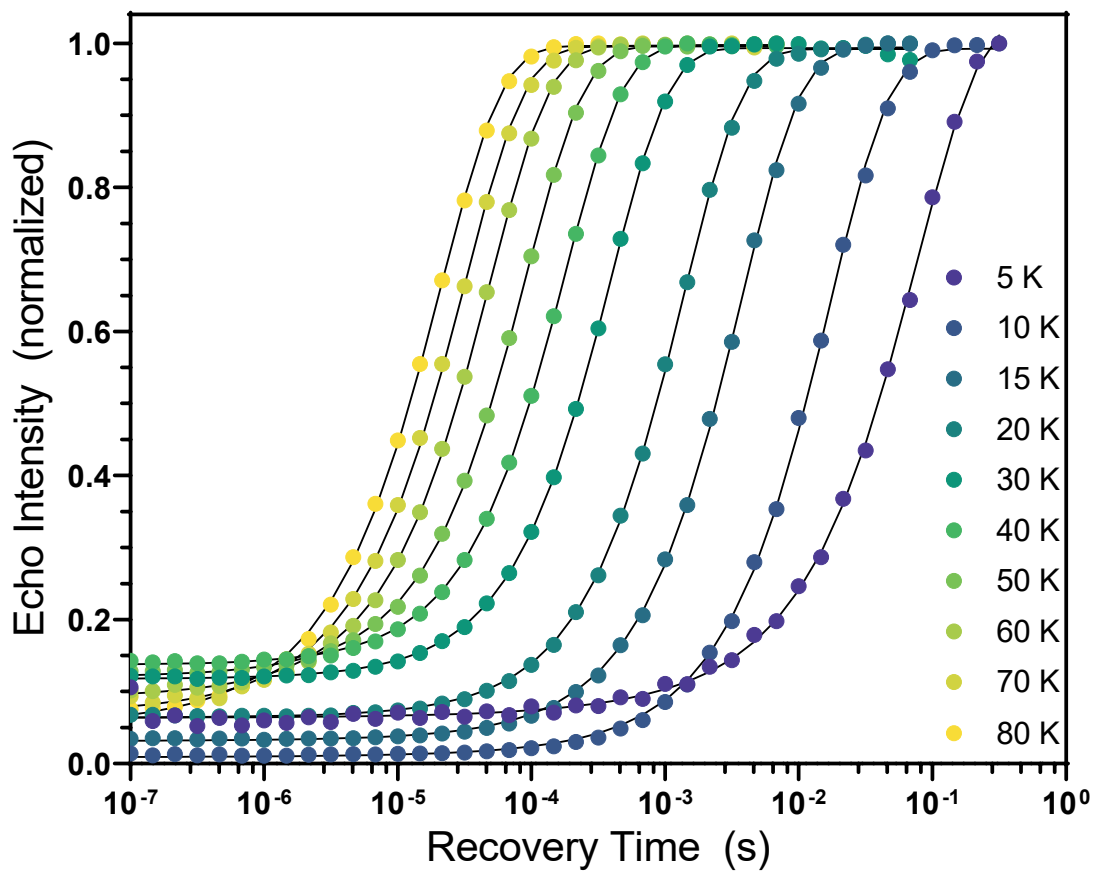

Figure S23 | Variable temperature saturation recovery data for 2 at $341 \mathrm{mT}$ and $9.4798 \mathrm{GHz}\left(\mathrm{Ti}^{3+} g_{z}\right)$ in 1:1 $\mathrm{CS}_{2}$ :toluene- $d_{8}$.

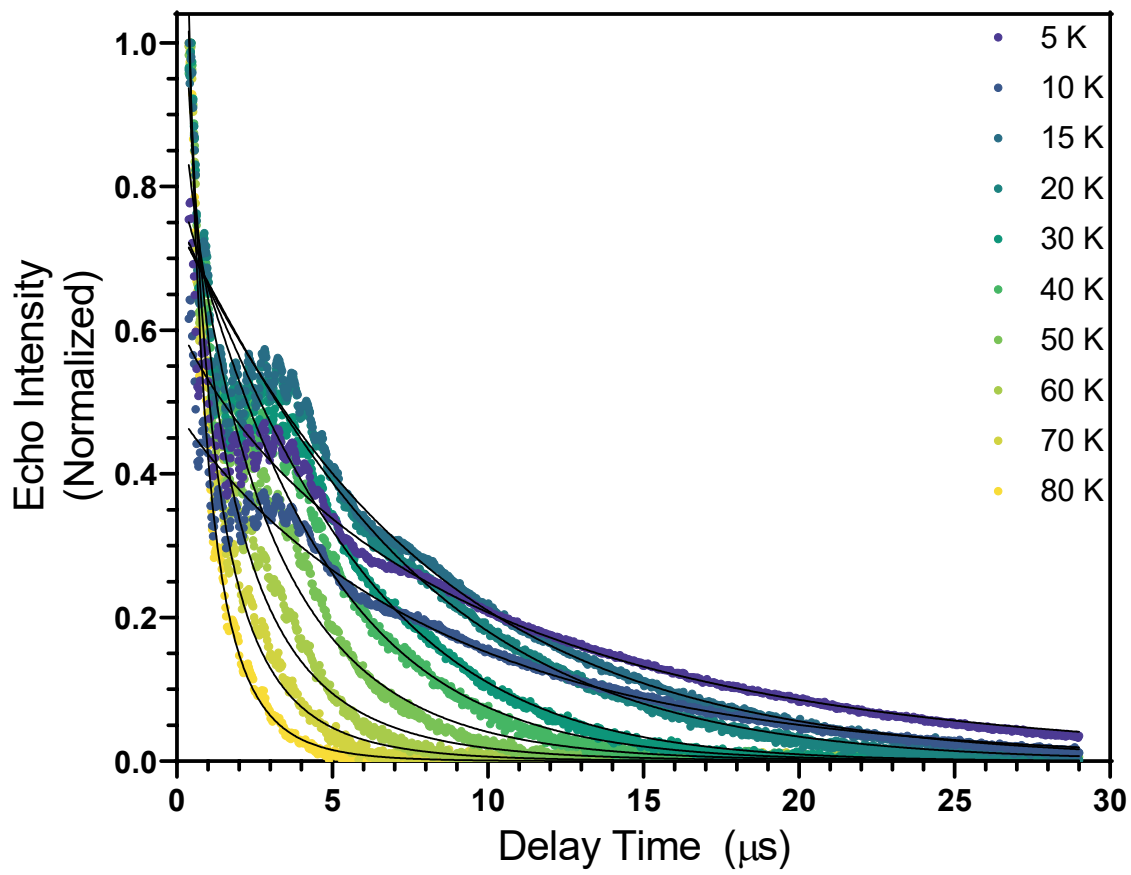

Figure S24 | Variable temperature two-pulse Hahn echo data for 2 at $329 \mathrm{mT}$ and $9.4798 \mathrm{GHz}\left(\mathrm{Cu}^{2+} g_{\mathrm{x} / \mathrm{y}}\right)$ in $1: 1 \mathrm{CS}_{2}$ :toluene- $d_{8}$. 


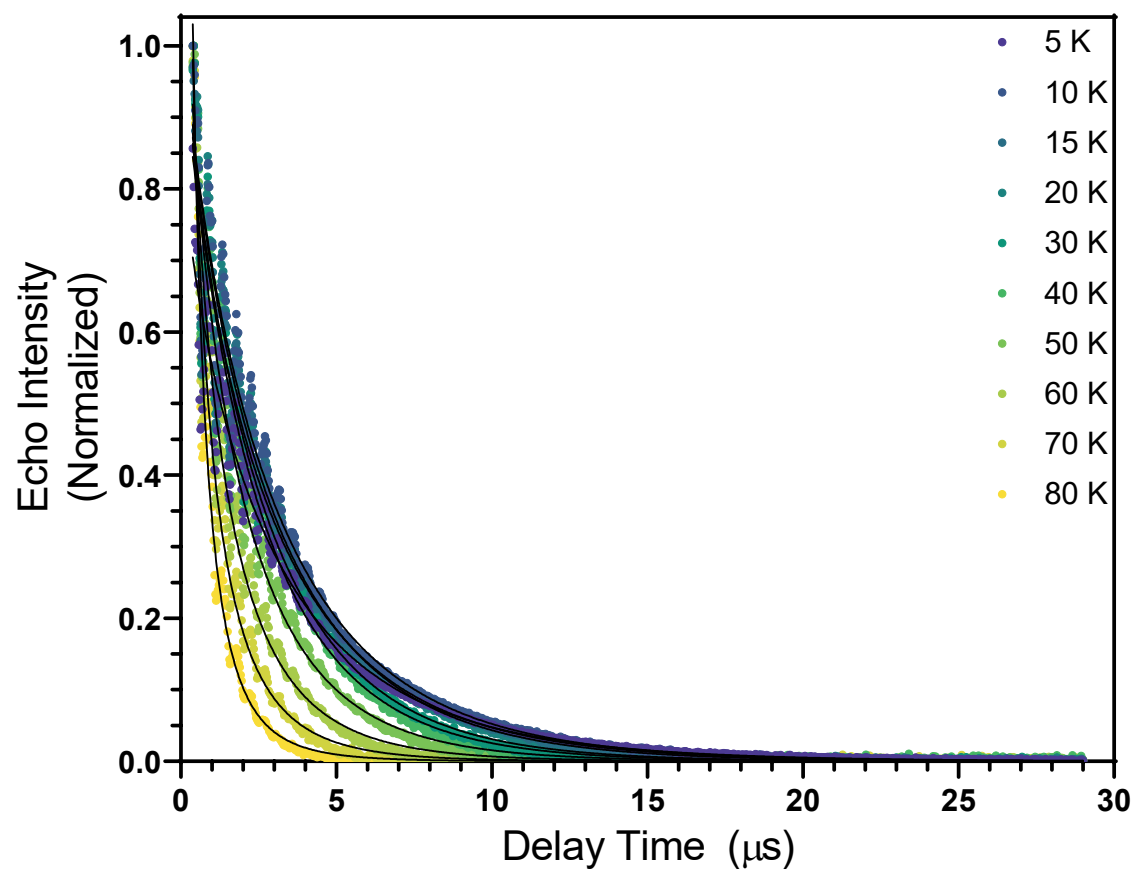

Figure S25 | Variable temperature two-pulse Hahn echo data for 2 at $341 \mathrm{mT}$ and $9.4798 \mathrm{GHz}\left(\mathrm{Ti}^{3+} g_{\mathrm{z}}\right)$ in $1: 1 \mathrm{CS}_{2}$ :toluene- $d_{8}$.

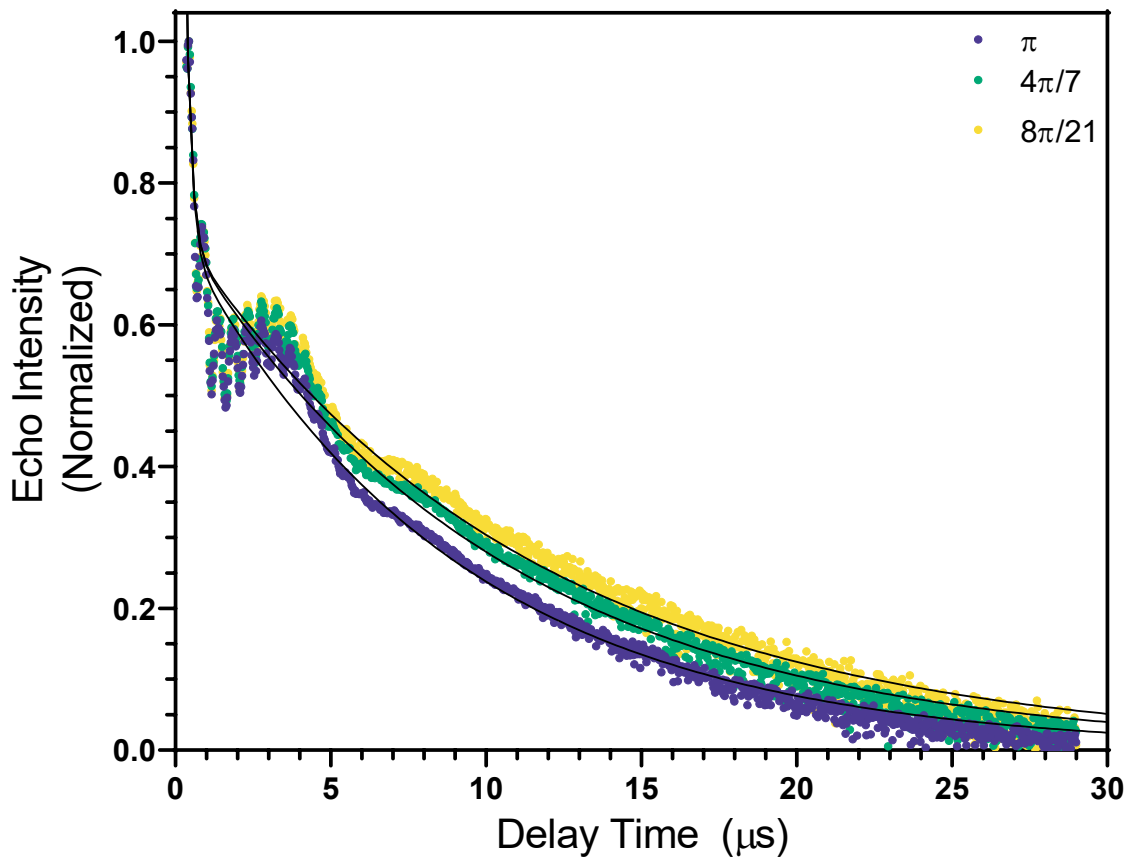

Figure S26 | Variable turning angle two-pulse $\left(\frac{\theta}{2}, \theta\right)$ Hahn echo data for 2 at $328 \mathrm{mT}$ and $9.4906 \mathrm{GHz}$ $\left(\mathrm{Cu}^{2+} g_{\mathrm{x} / \mathrm{y}}\right)$ in $1: 1 \mathrm{CS}_{2}:$ toluene- $d_{8}$ at $10 \mathrm{~K}$. 


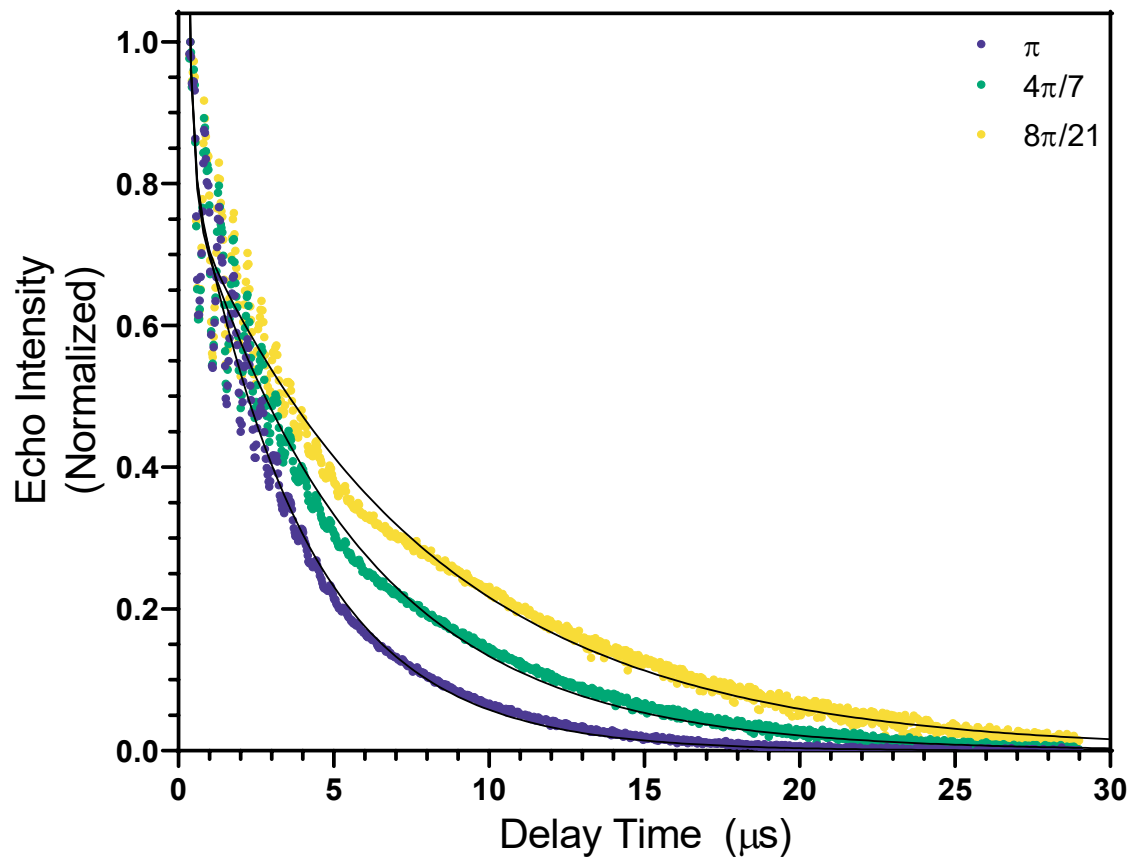

Figure S27 | Variable turning angle two-pulse $\left(\frac{\theta}{2}, \theta\right)$ Hahn echo data for 2 at $342 \mathrm{mT}$ and $9.4906 \mathrm{GHz}$ $\left(\mathrm{Ti}^{3+} g_{\mathrm{z}}\right)$ in $1: 1 \mathrm{CS}_{2}:$ toluene- $d_{8}$ at $10 \mathrm{~K}$.

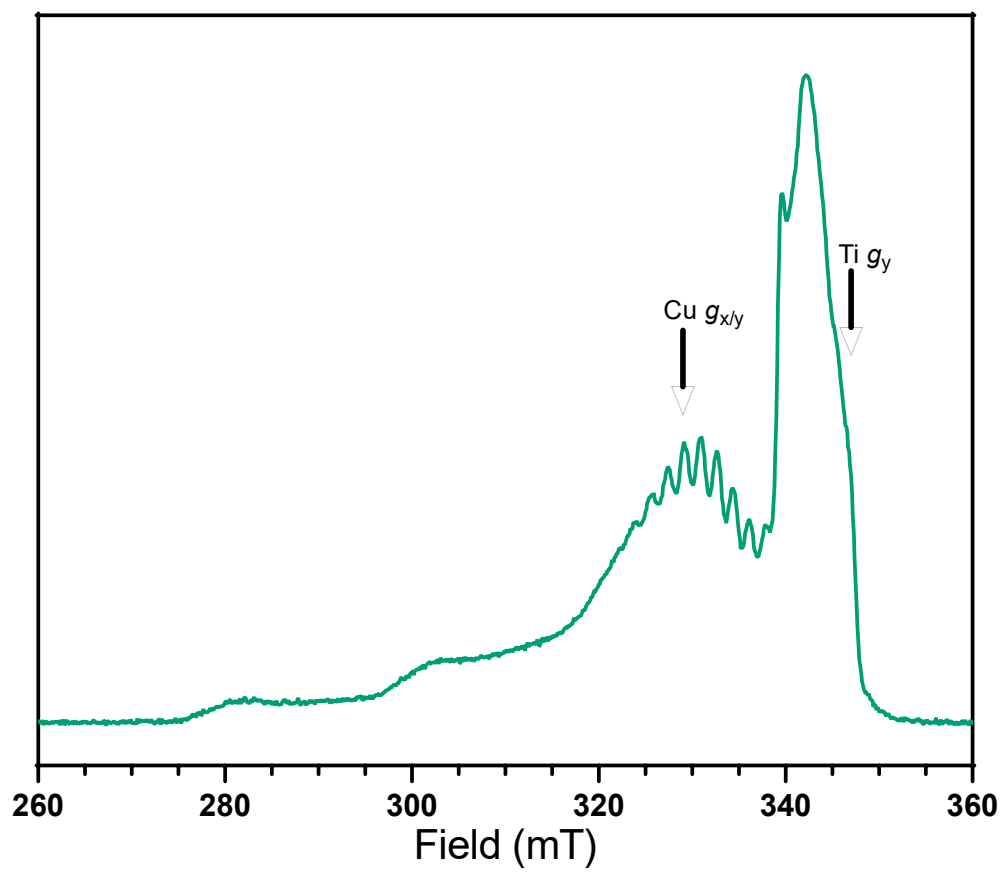

Figure S28 | EDFS EPR spectrum of $\mathbf{3}$ in frozen toluene solution at $80 \mathrm{~K}$ and $9.4990 \mathrm{GHz}$, indicating field positions of $T_{1}$ and $T_{\mathrm{m}}$ measurements at the $\mathrm{Cu}^{2+} g_{\mathrm{x} / \mathrm{y}}$ and $\mathrm{Ti}^{3+} g_{\mathrm{y}}$ transitions. 


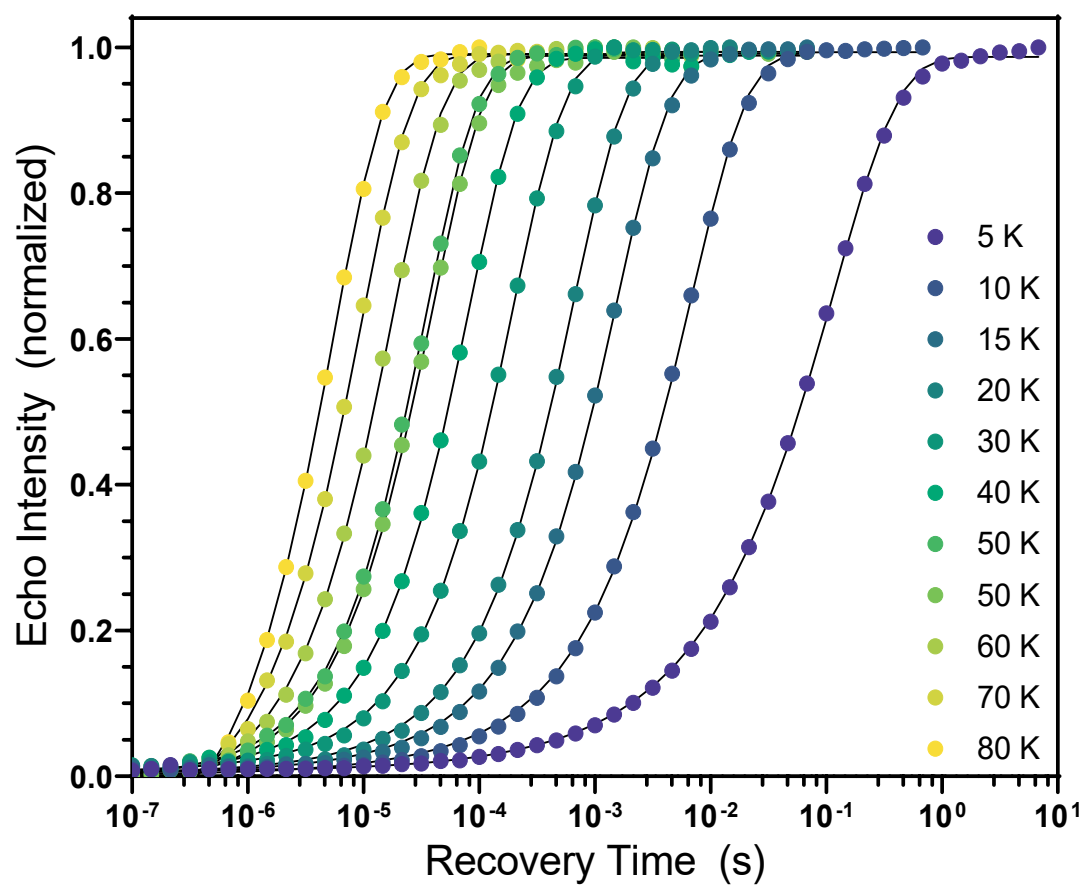

Figure S29 | Variable temperature saturation recovery data for 3 at $329 \mathrm{mT}$ and $9.4990 \mathrm{GHz}\left(\mathrm{Cu}^{2+} g_{\mathrm{x} / \mathrm{y}}\right)$ in toluene.

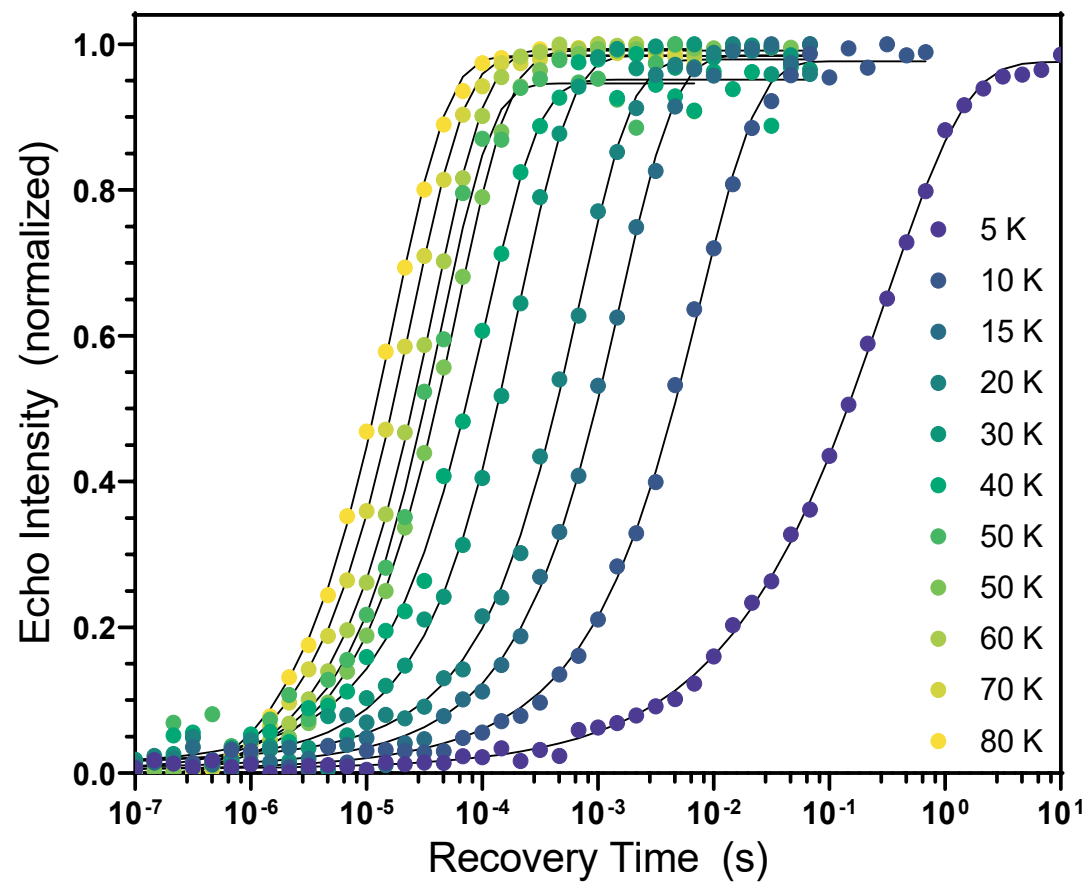

Figure S30 | Variable temperature saturation recovery data for 3 at $347 \mathrm{mT}$ and $9.4990 \mathrm{GHz}\left(\mathrm{Ti}^{3+} g_{\mathrm{y}}\right)$ in toluene. 


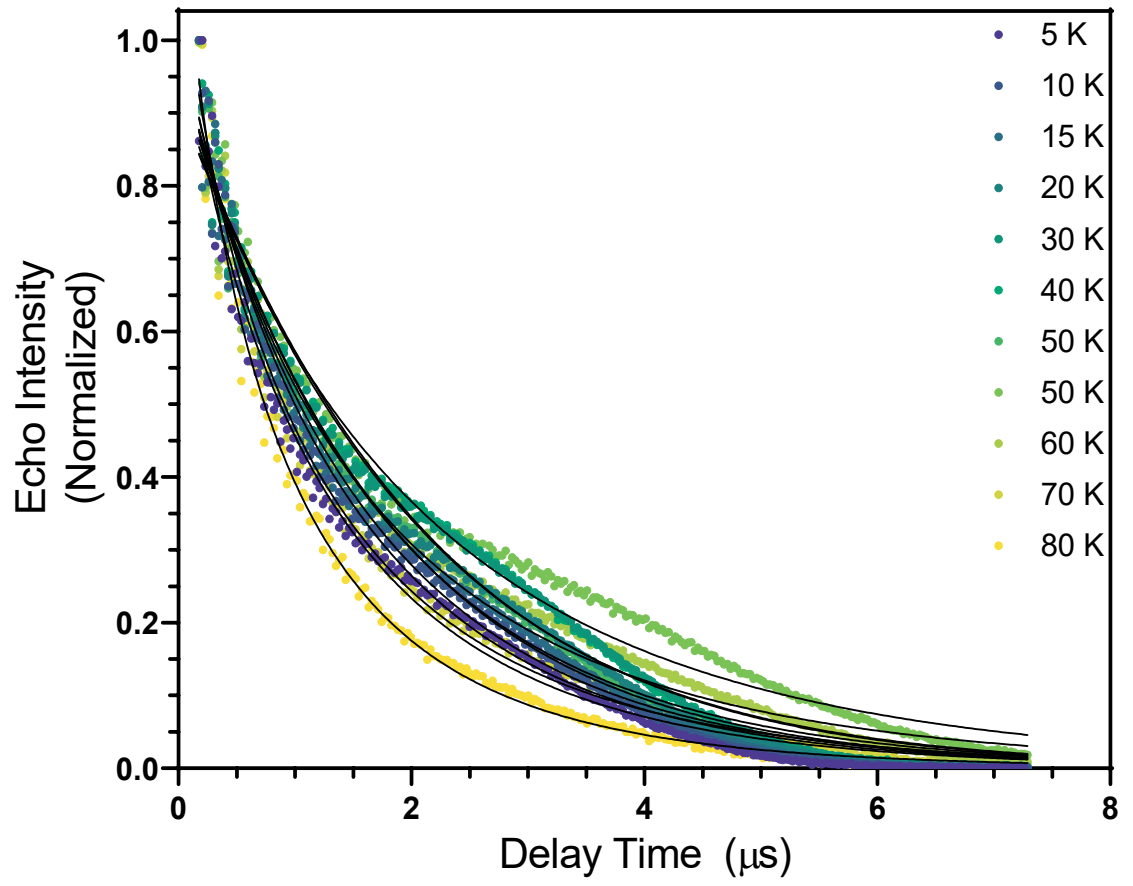

Figure S31 | Variable temperature two-pulse Hahn echo data for 3 at $329 \mathrm{mT}$ and $9.4990 \mathrm{GHz}\left(\mathrm{Cu}^{2+} g_{\mathrm{x} / \mathrm{y}}\right)$ in toluene.

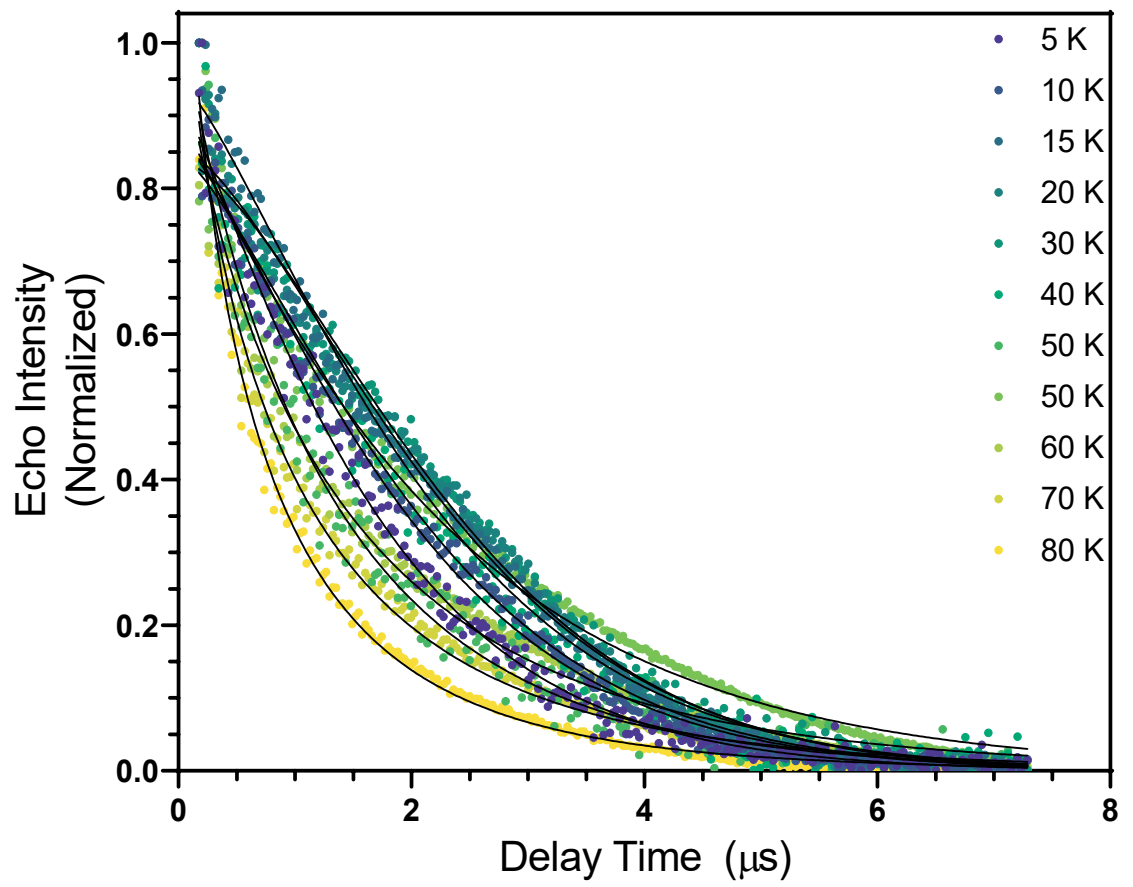

Figure S32 | Variable temperature two-pulse Hahn echo data for 3 at $347 \mathrm{mT}$ and $9.4990 \mathrm{GHz}\left(\mathrm{Ti}^{3+} g_{\mathrm{y}}\right)$ in toluene. 


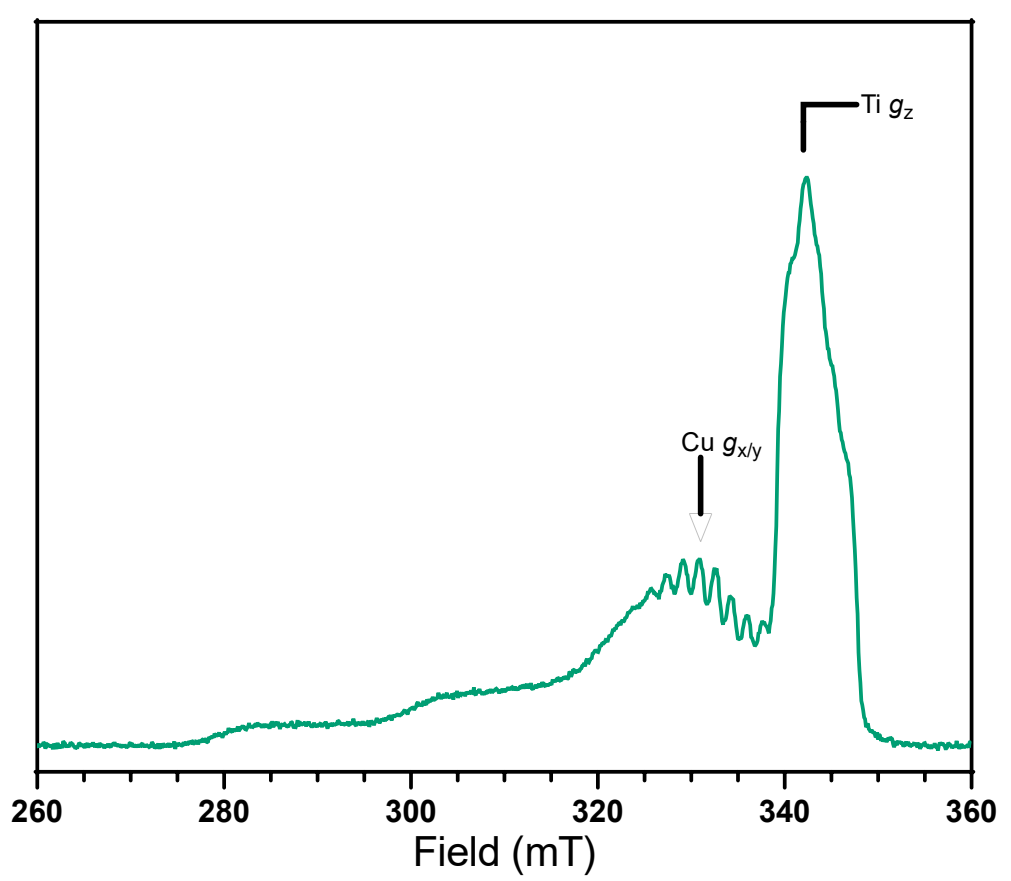

Figure S33 | EDFS EPR spectrum of 3 in frozen 1:1 $\mathrm{CS}_{2}$ :toluene- $d_{8}$ solution at $30 \mathrm{~K}$ and $9.5128 \mathrm{GHz}$, indicating field positions of $T_{1}$ and $T_{\mathrm{m}}$ measurements at the $\mathrm{Cu}^{2+} g_{\mathrm{x} / \mathrm{y}}$ and $\mathrm{Ti}^{3+} g_{\mathrm{z}}$ transitions.

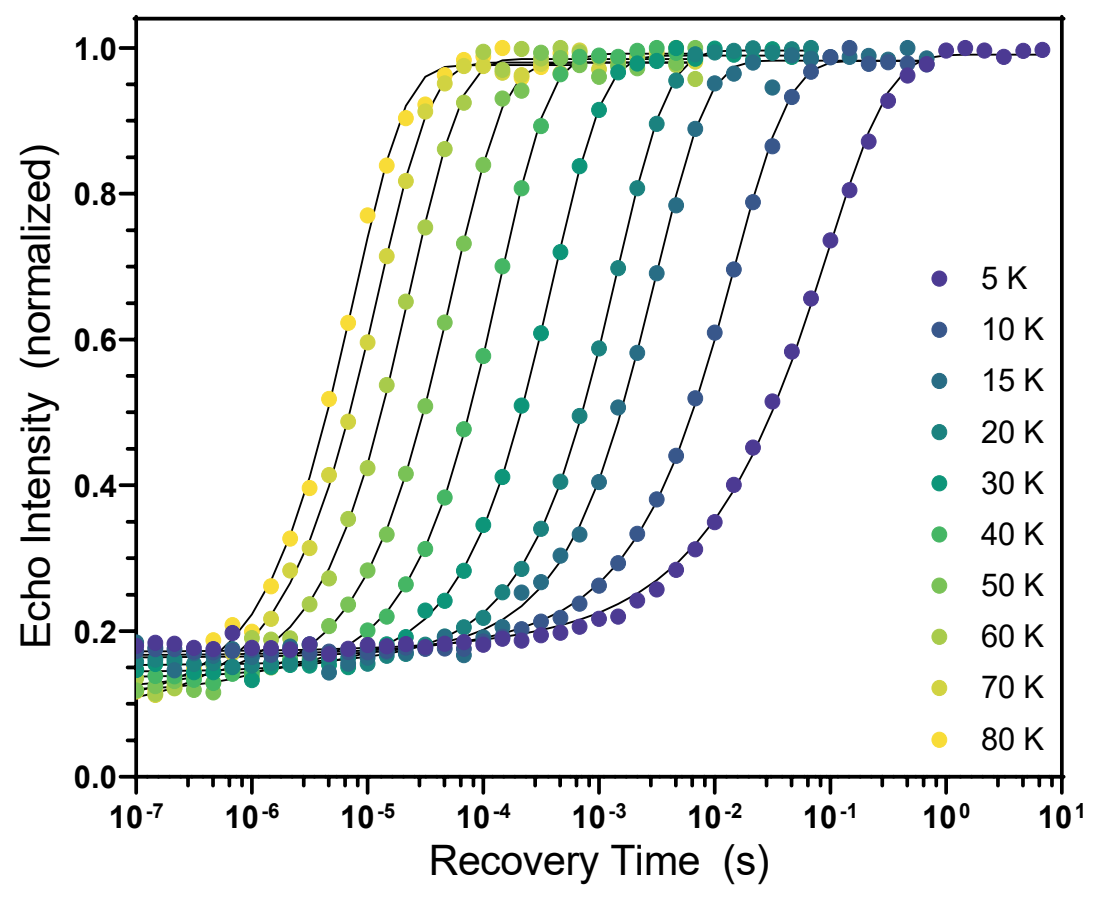

Figure S34 | Variable temperature saturation recovery data for 3 at $331 \mathrm{mT}$ and $9.5128 \mathrm{GHz}\left(\mathrm{Cu}^{2+} g_{\mathrm{x} / \mathrm{y}}\right)$ in 1:1 CS 2 :toluene- $d_{8}$. 


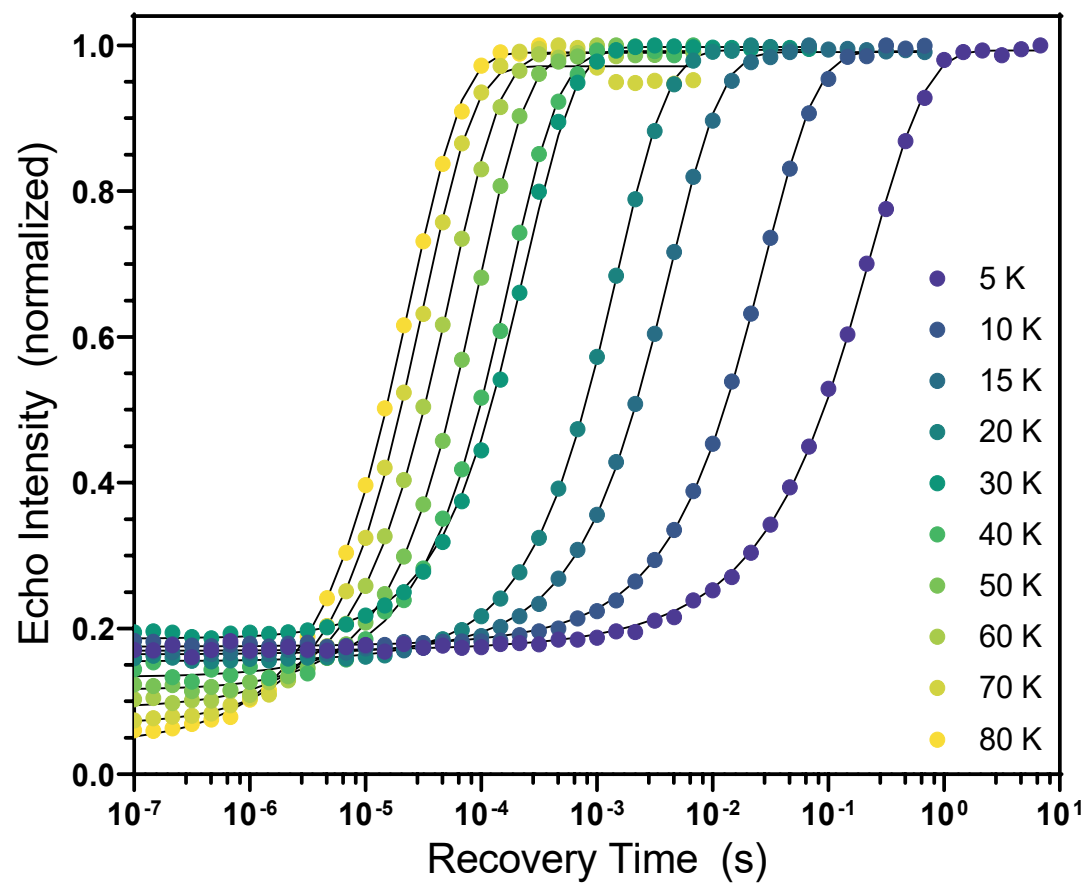

Figure S35 | Variable temperature saturation recovery data for 3 at $342 \mathrm{mT}$ and $9.5128 \mathrm{GHz}\left(\mathrm{Ti}^{3+} g_{\mathrm{z}}\right)$ in 1:1 $\mathrm{CS}_{2}$ :toluene- $d_{8}$.

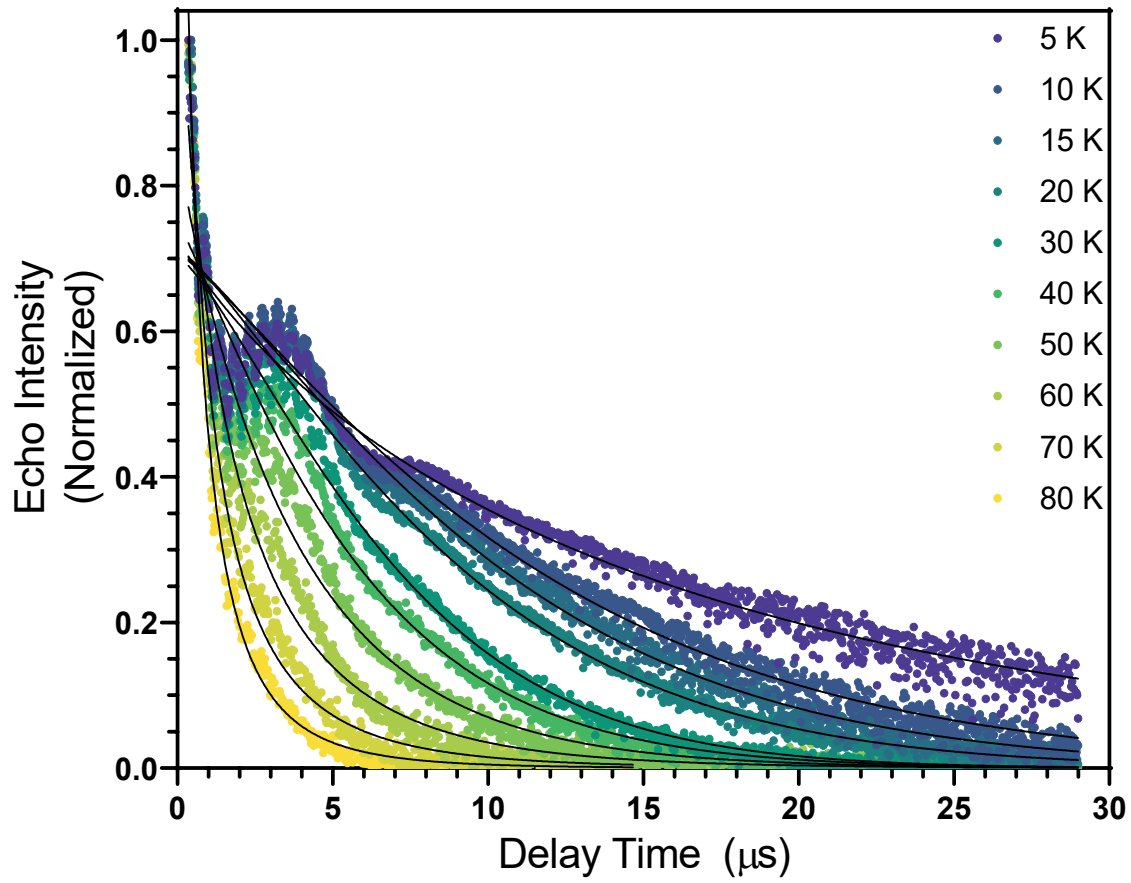

Figure S36 | Variable temperature two-pulse Hahn echo data for 3 at $331 \mathrm{mT}$ and $9.5128 \mathrm{GHz}\left(\mathrm{Cu}^{2+} g_{\mathrm{x} / \mathrm{y}}\right)$ in $1: 1 \mathrm{CS}_{2}$ :toluene- $d_{8}$. 


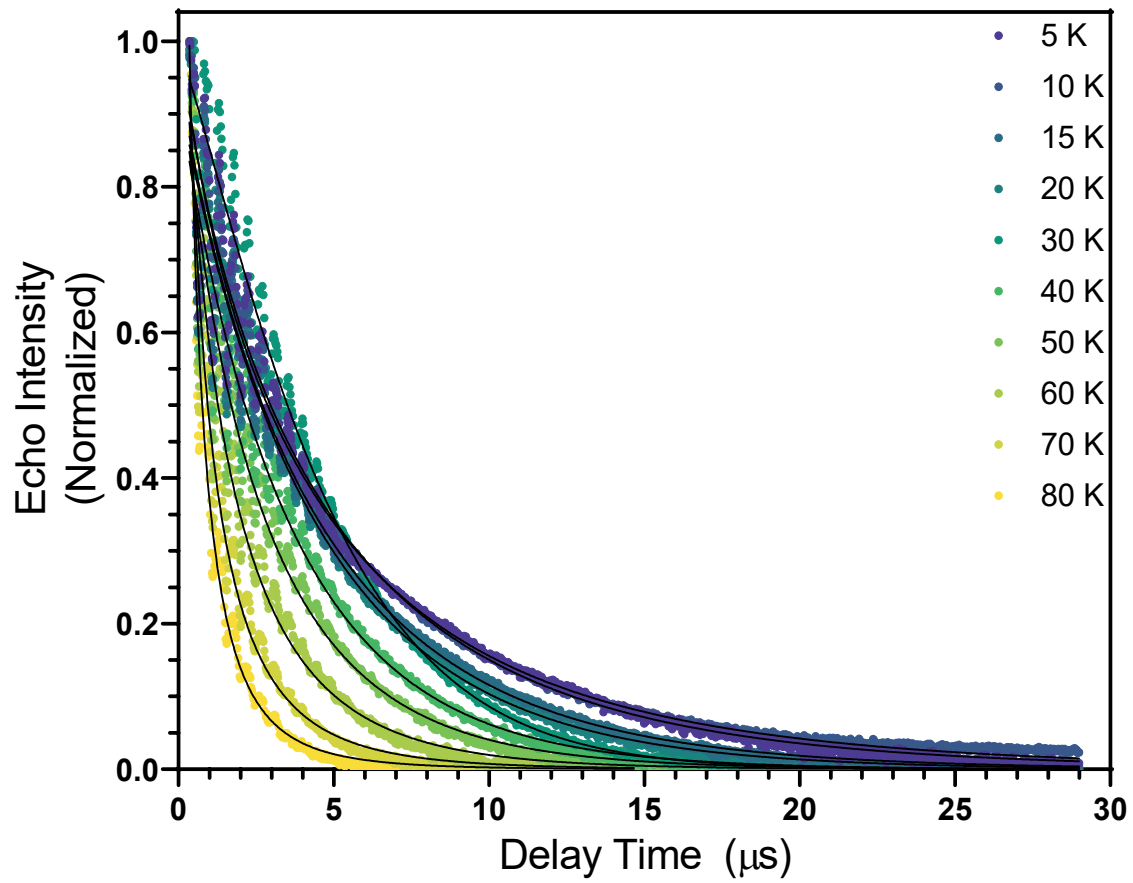

Figure S37 | Variable temperature two-pulse Hahn echo data for 3 at $342 \mathrm{mT}$ and $9.5128 \mathrm{GHz}\left(\mathrm{Ti}^{3+} g_{\mathrm{z}}\right)$ in 1:1 $\mathrm{CS}_{2}$ :toluene- $d_{8}$.

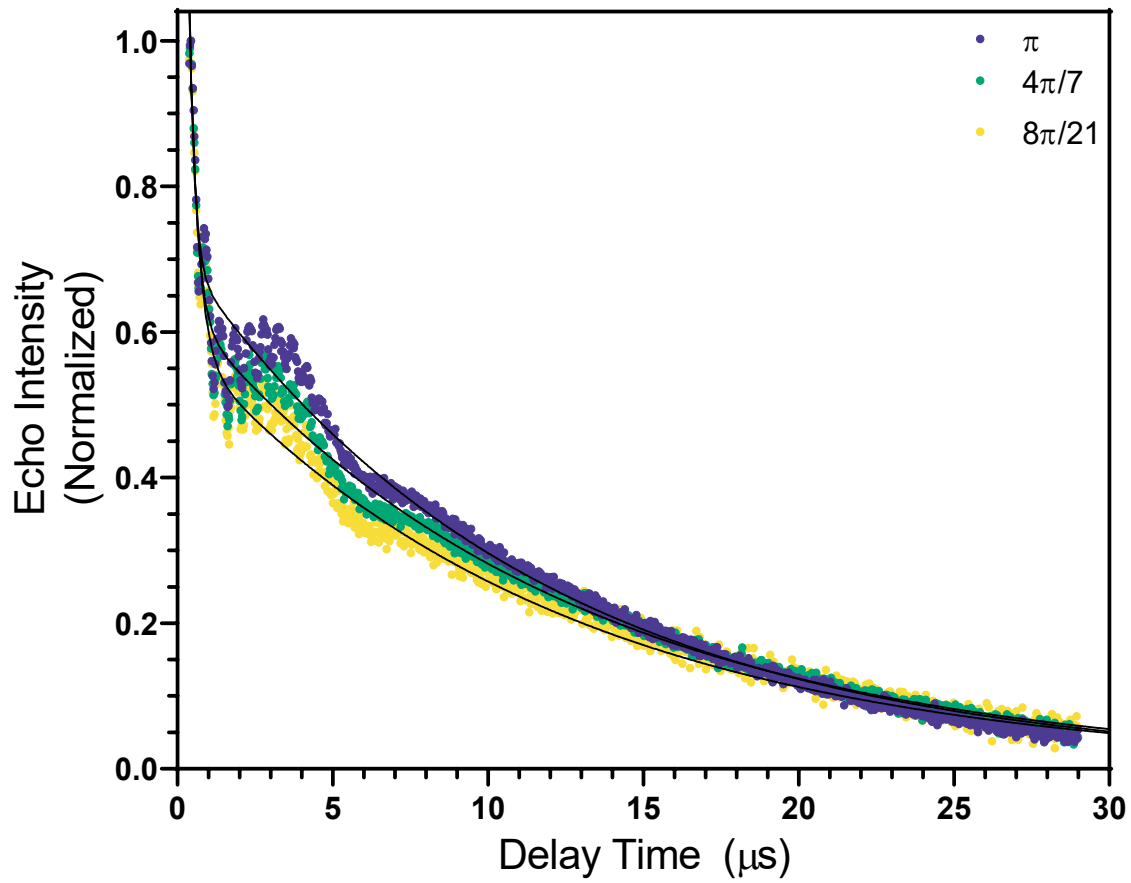

Figure S38 | Variable turning angle two-pulse $\left(\frac{\theta}{2}, \theta\right)$ Hahn echo data for 3 at $328 \mathrm{mT}$ and $9.4907 \mathrm{GHz}$ $\left(\mathrm{Cu}^{2+} g_{\mathrm{x} / \mathrm{y}}\right)$ in $1: 1 \mathrm{CS}_{2}:$ toluene- $d_{8}$ at $10 \mathrm{~K}$. 


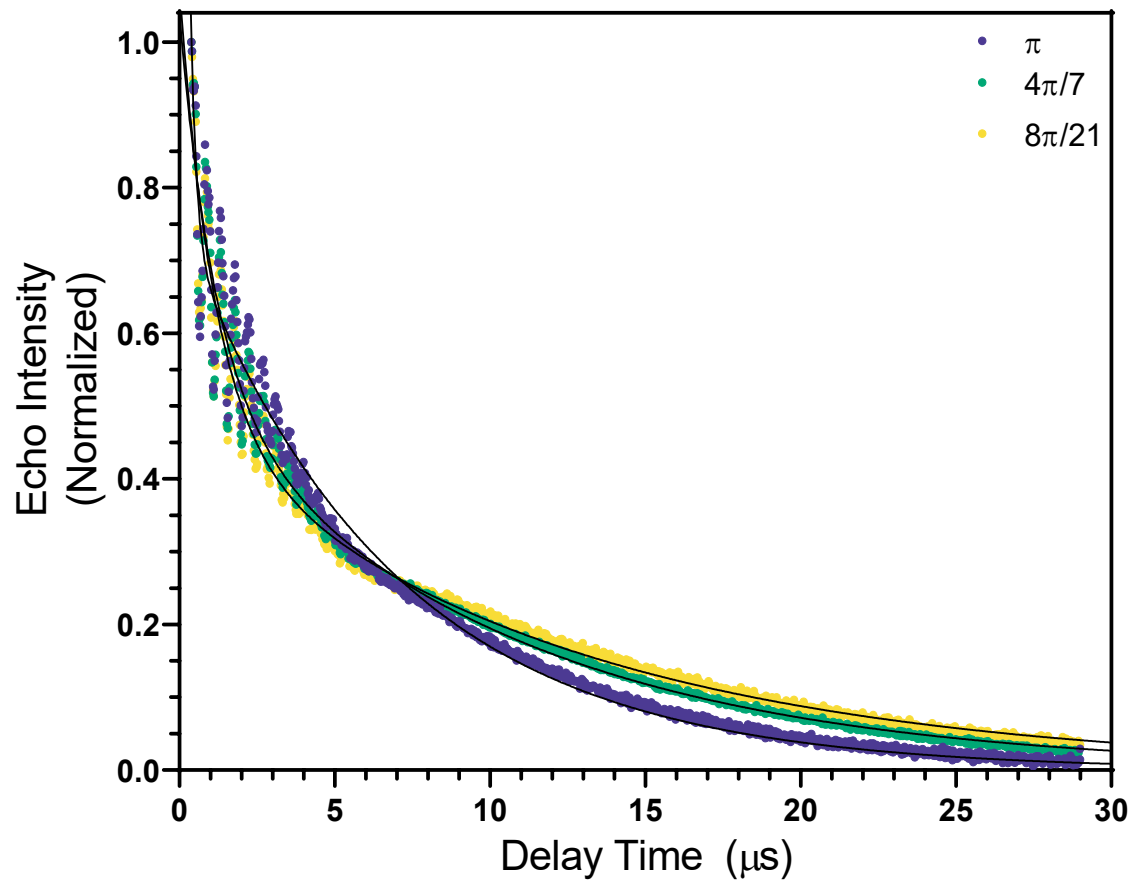

Figure S39 | Variable turning angle two-pulse $\left(\frac{\theta}{2}, \theta\right)$ Hahn echo data for 3 at $342 \mathrm{mT}$ and $9.4907 \mathrm{GHz}$ $\left(\mathrm{Ti}^{3+} g_{\mathrm{z}}\right)$ in 1:1 $\mathrm{CS}_{2}:$ toluene- $d_{8}$ at $10 \mathrm{~K}$.

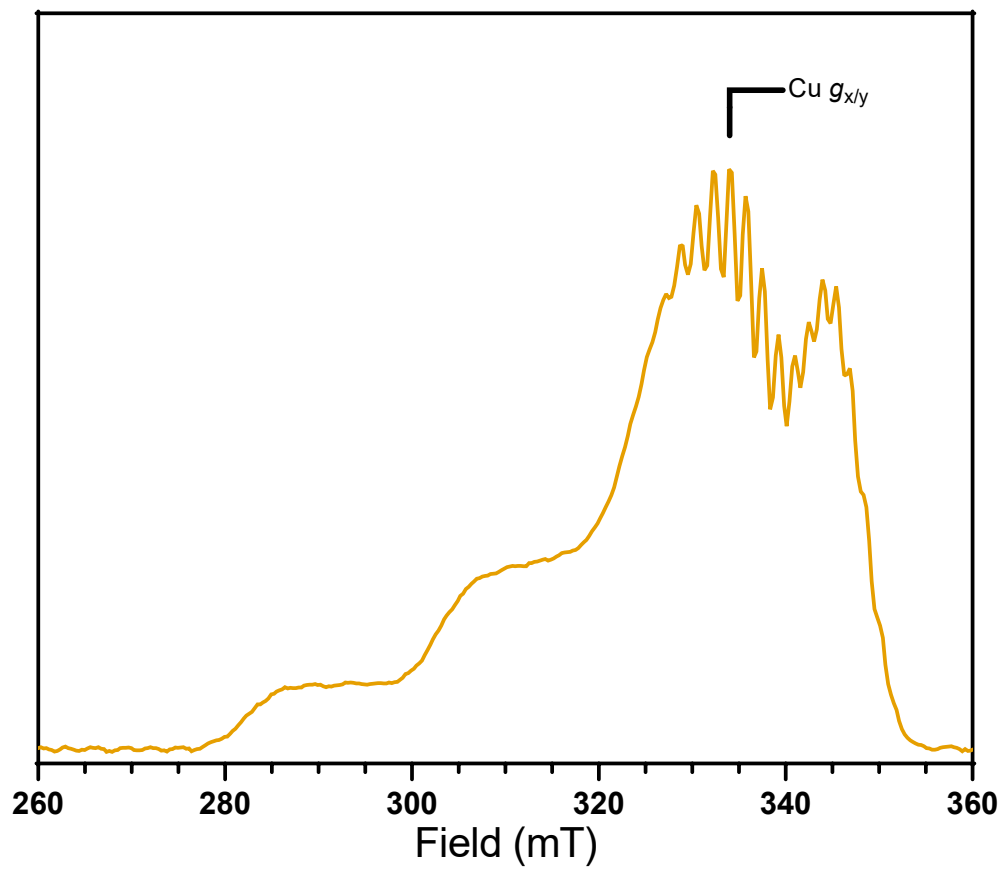

Figure S40 | EDFS EPR spectrum of 2a in frozen toluene solution at $20 \mathrm{~K}$ and $9.5090 \mathrm{GHz}$, indicating field position of $T_{1}$ and $T_{\mathrm{m}}$ measurements at the $\mathrm{Cu}^{2+} g_{\mathrm{x} / \mathrm{y}}$ transition. 


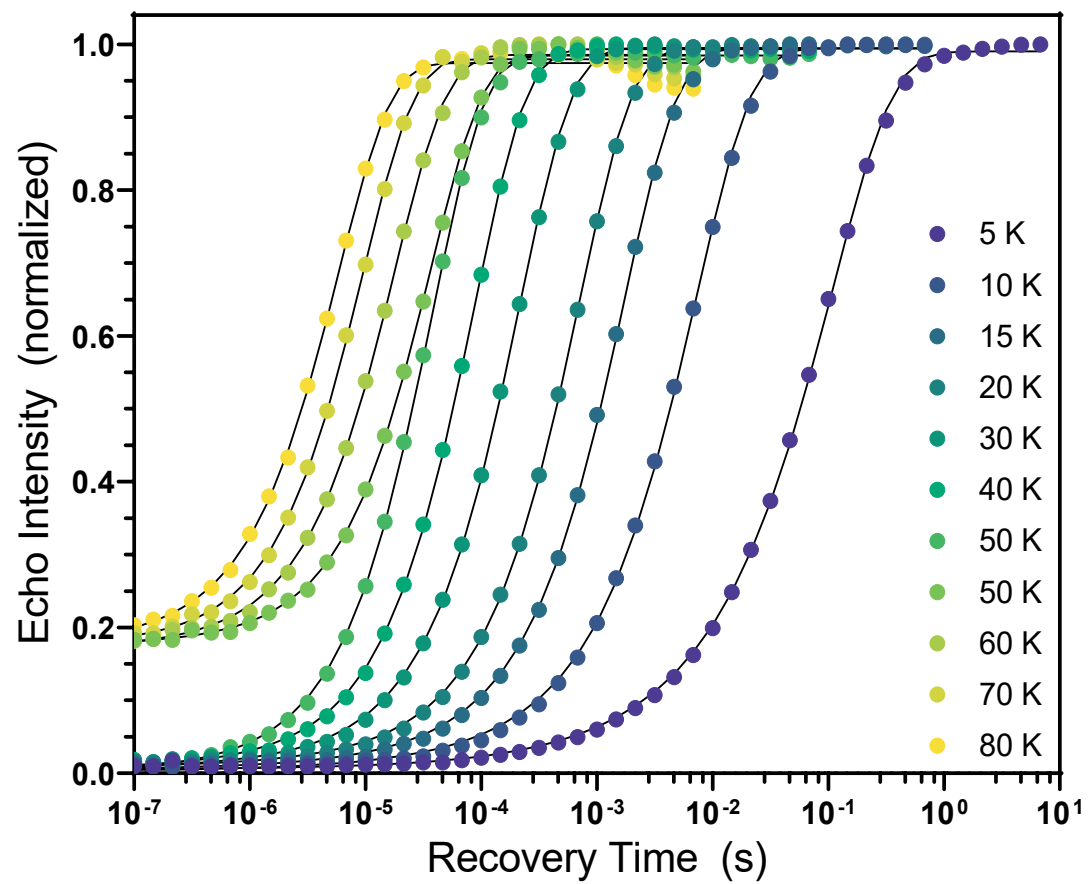

Figure S41 | Variable temperature saturation recovery data for $\mathbf{2 a}$ at $334 \mathrm{mT}$ and $9.5090 \mathrm{GHz}\left(\mathrm{Cu}^{2+} g_{\mathrm{x} / \mathrm{y}}\right)$ in toluene. Data 50-80 K acquired on a second day of experiments show incomplete saturation due to imperfect picket fence calibration, which does not affect the resulting saturation recovery behavior.

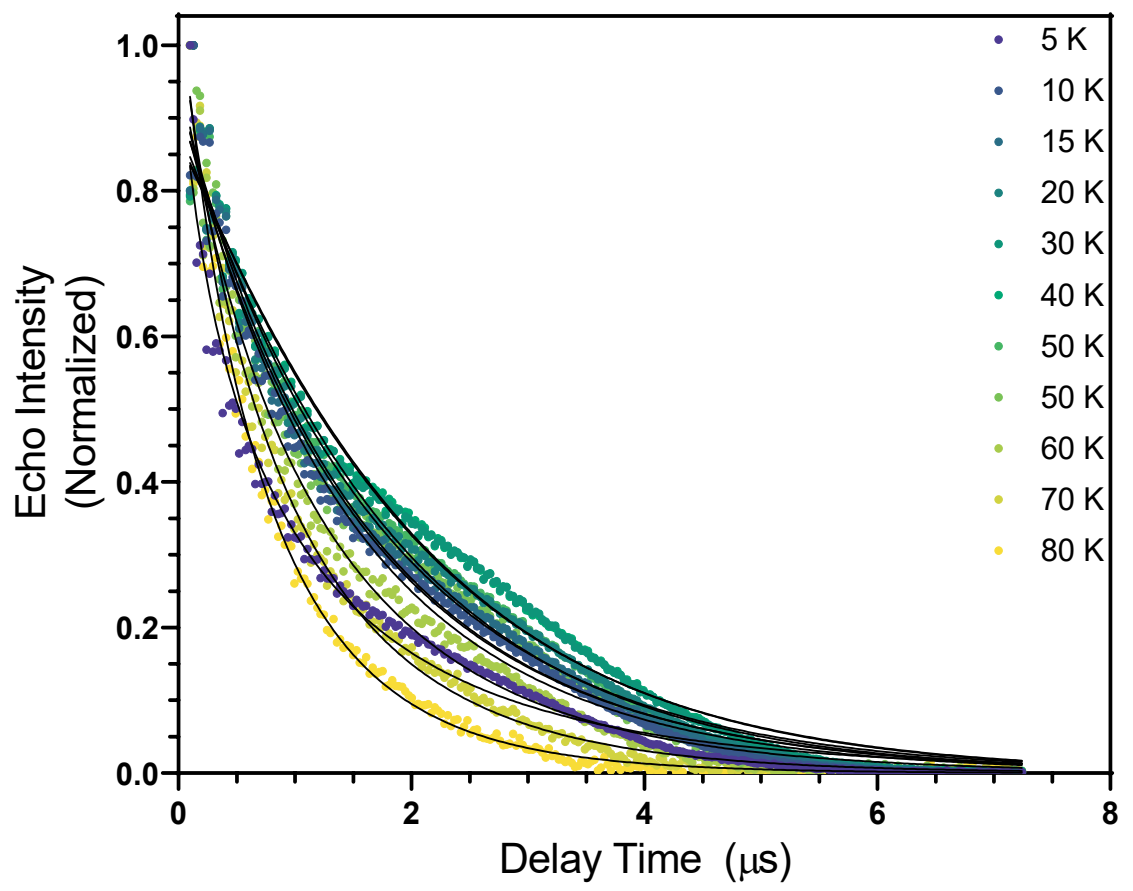


Figure S42 | Variable temperature two-pulse Hahn echo data for $\mathbf{2 a}$ at $334 \mathrm{mT}$ and $9.5090 \mathrm{GHz}\left(\mathrm{Cu}^{2+} g_{\mathrm{x} / \mathrm{y}}\right)$ in toluene.

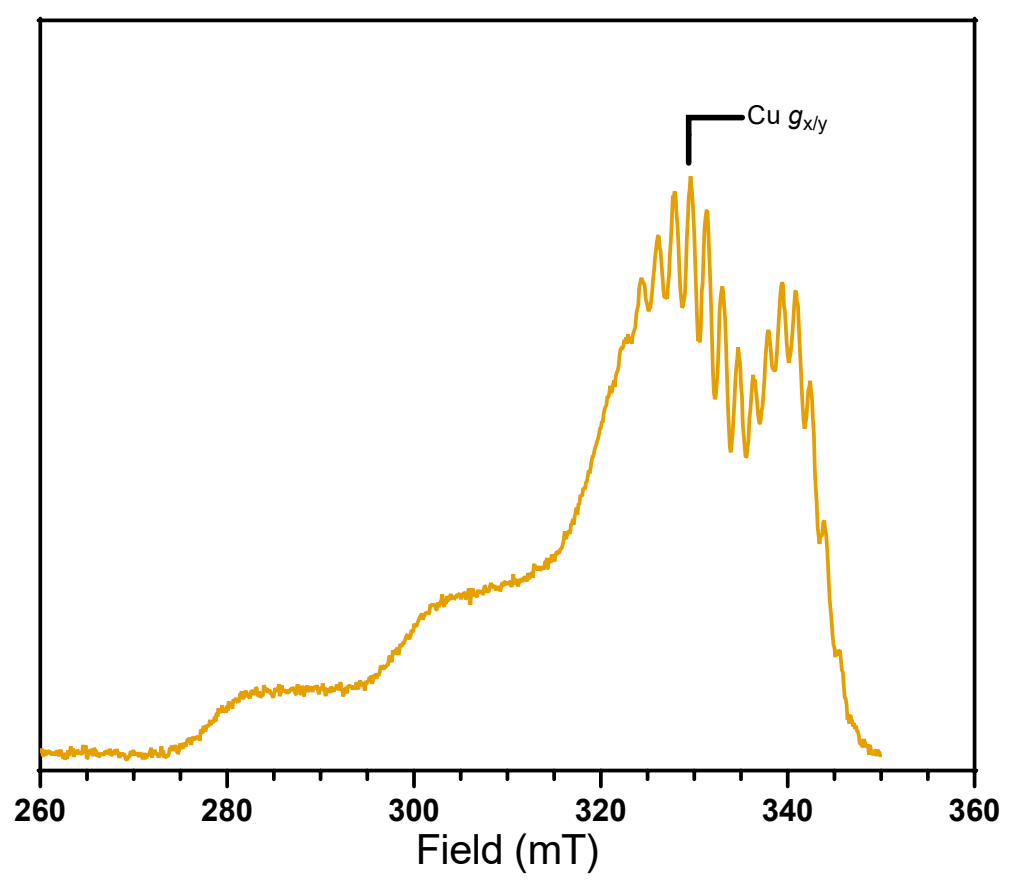

Figure S43 | EDFS EPR spectrum of 2a in frozen 1:1 $\mathrm{CS}_{2}$ :toluene- $d_{8}$ solution at $30 \mathrm{~K}$ and $9.4544 \mathrm{GHz}$, indicating field position of $T_{1}$ and $T_{\mathrm{m}}$ measurements at the $\mathrm{Cu}^{2+} g_{\mathrm{x} / \mathrm{y}}$ transition.

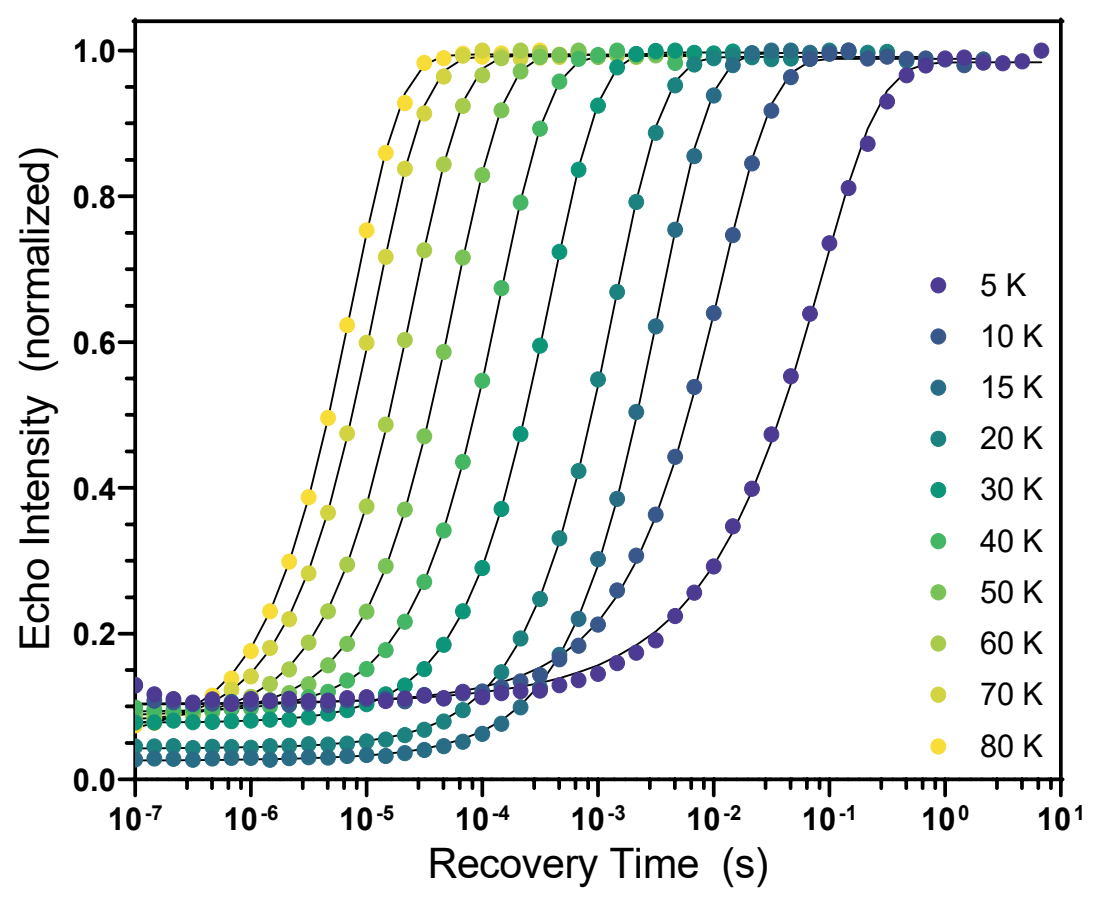


Figure S44 | Variable temperature saturation recovery data for $\mathbf{2 a}$ at $334 \mathrm{mT}$ and $9.4544 \mathrm{GHz}\left(\mathrm{Cu}^{2+} g_{\mathrm{x} / \mathrm{y}}\right)$ in $1: 1 \mathrm{CS}_{2}:$ toluene- $d_{8}$.

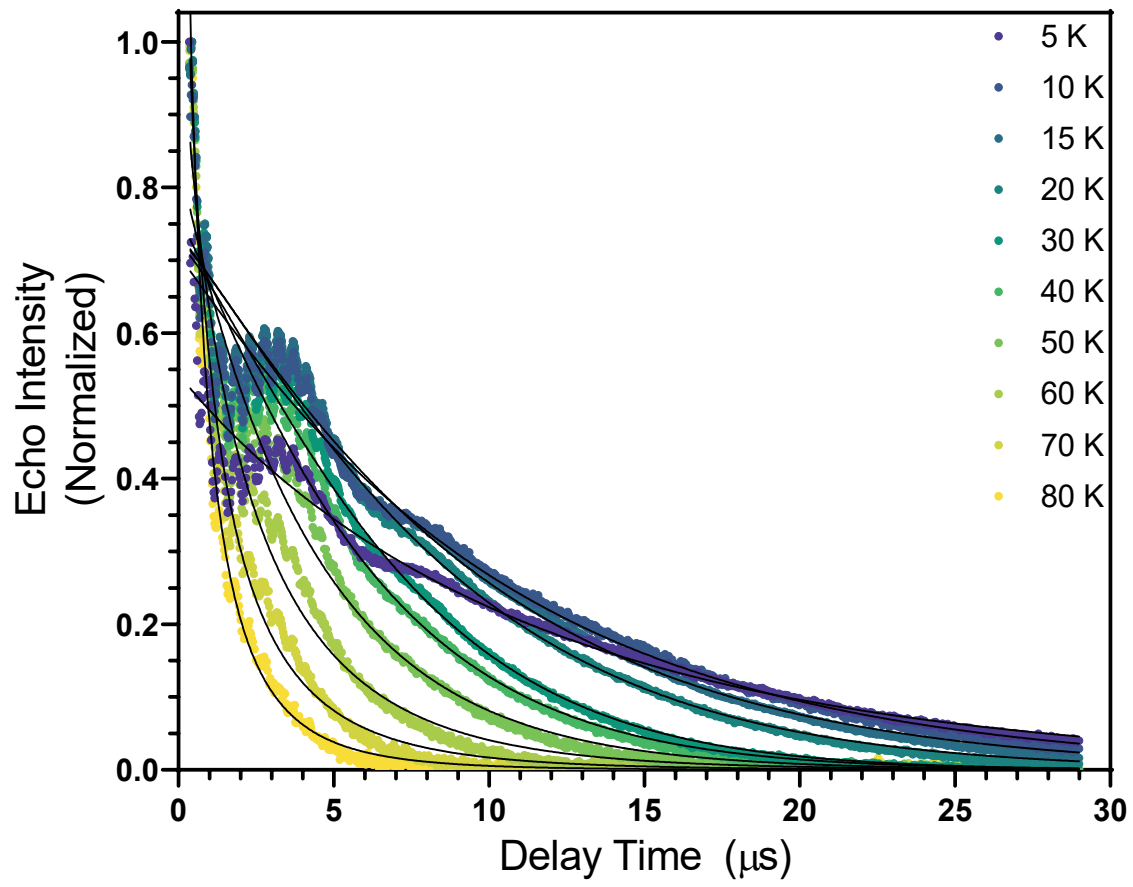

Figure S45 | Variable temperature two-pulse Hahn echo data for $\mathbf{2 a}$ at $334 \mathrm{mT}$ and $9.4544 \mathrm{GHz}\left(\mathrm{Cu}^{2+} g_{\mathrm{x} / \mathrm{y}}\right)$ in 1:1 CS $2:$ toluene- $d_{8}$.

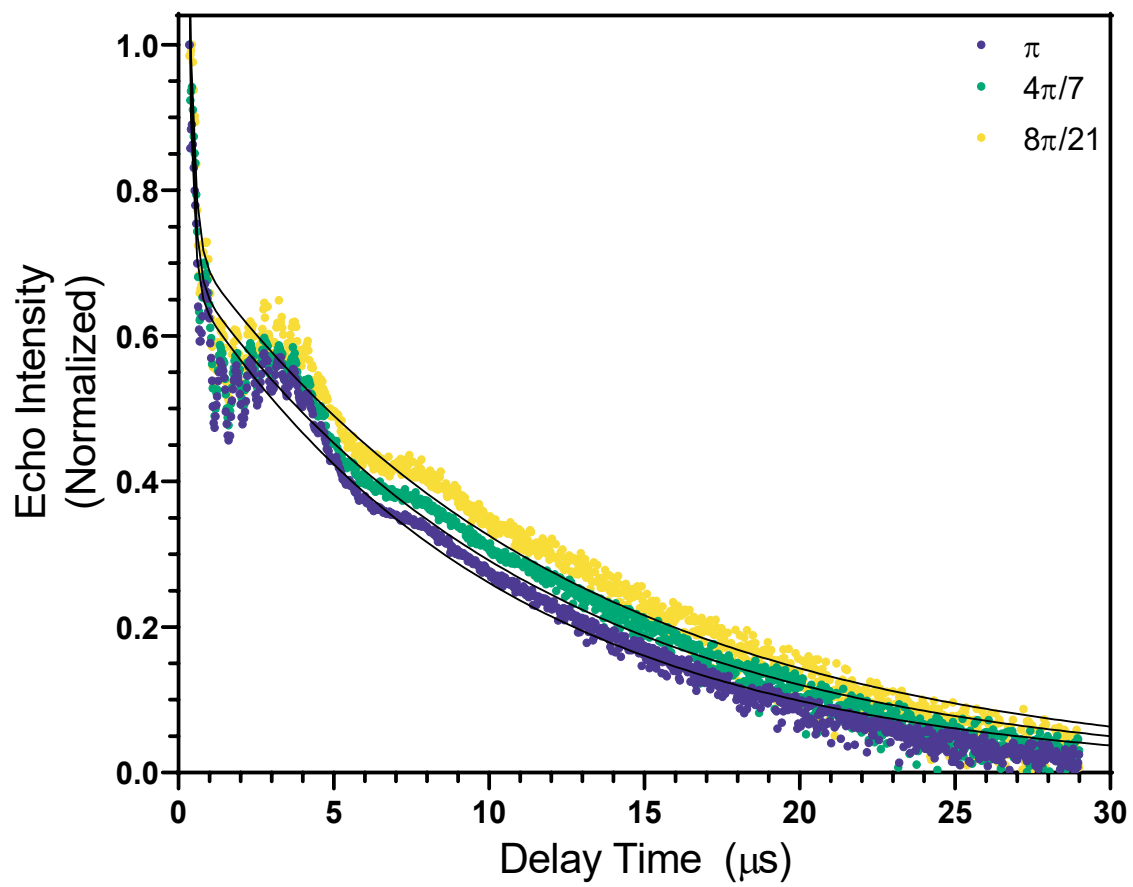


Figure S46 | Variable turning angle two-pulse $\left(\frac{\theta}{2}, \theta\right)$ Hahn echo data for $\mathbf{2 a}$ at $323 \mathrm{mT}$ and $9.4908 \mathrm{GHz}$ $\left(\mathrm{Cu}^{2+} g_{\mathrm{x} / \mathrm{y}}\right)$ in $1: 1 \mathrm{CS}_{2}:$ toluene- $d_{8}$ at $10 \mathrm{~K}$.

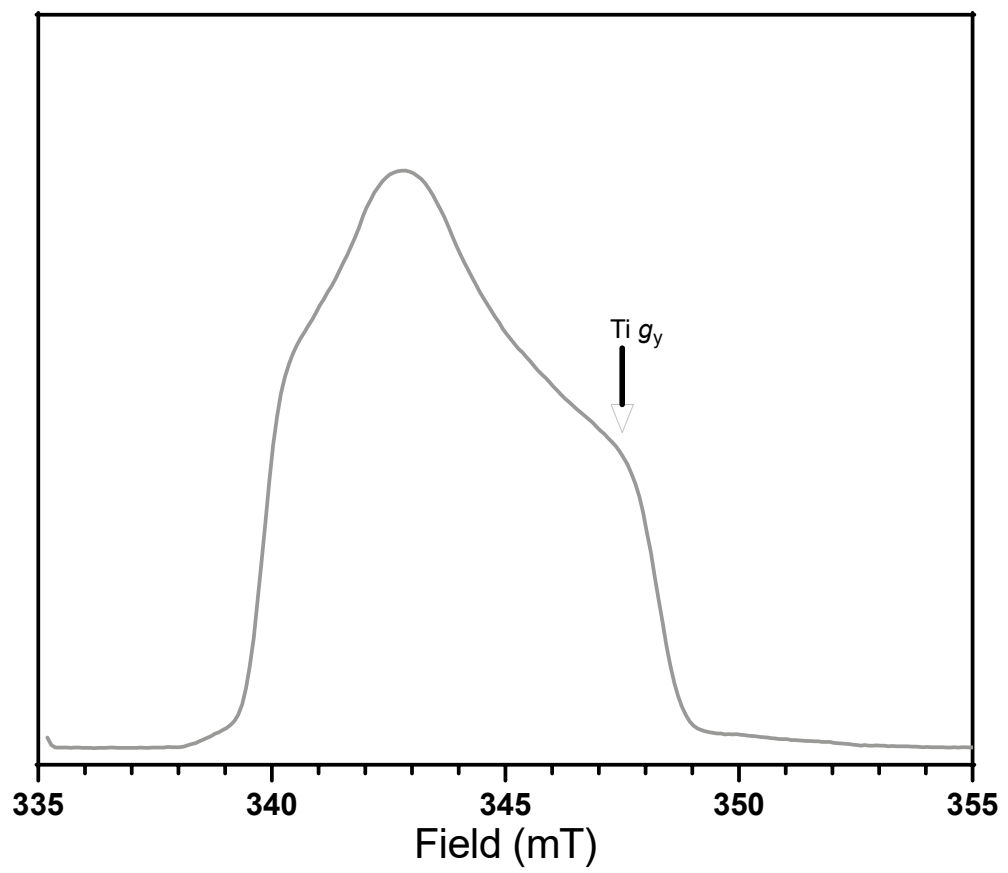

Figure S47 | EDFS EPR spectrum of $\mathbf{2 b}$ in frozen toluene solution at $20 \mathrm{~K}$ and $9.5006 \mathrm{GHz}$, indicating field positions of $T_{1}$ and $T_{\mathrm{m}}$ measurements at the Ti $g_{\mathrm{y}}$ transition.

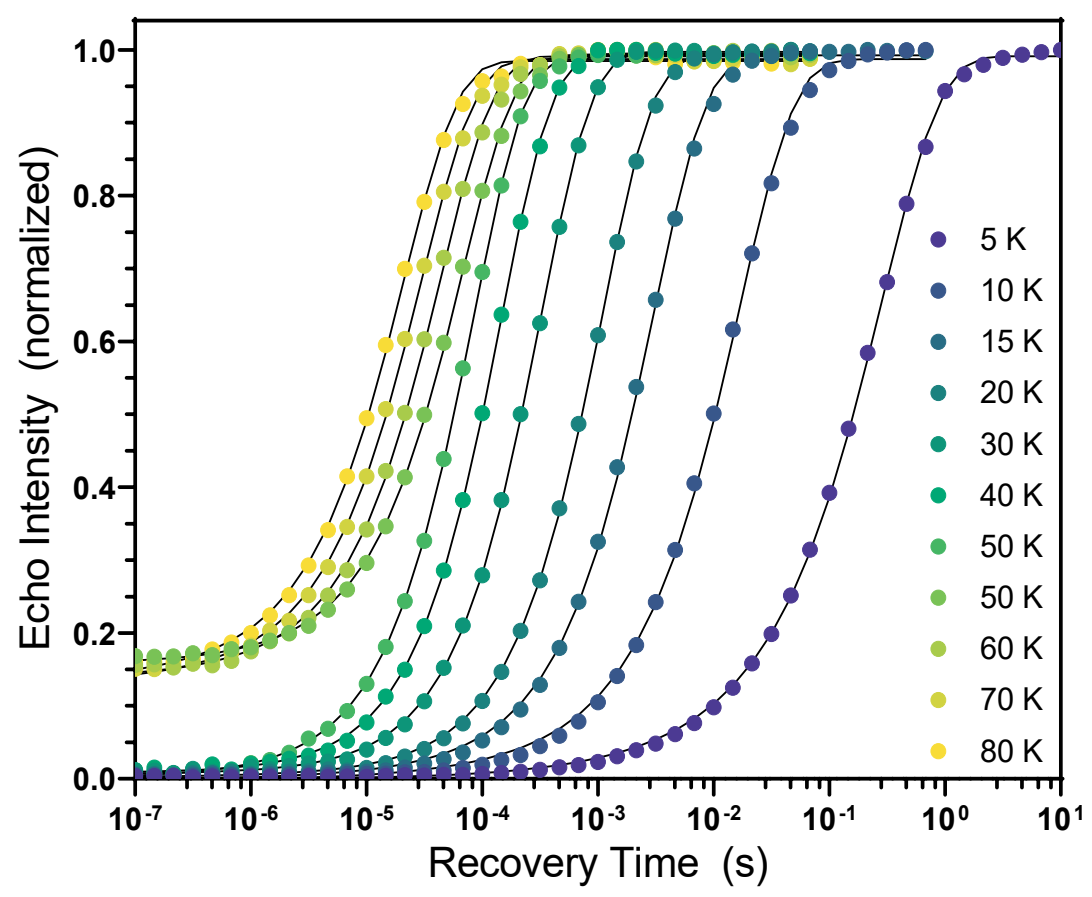


Figure S48 | Variable temperature saturation recovery data for $\mathbf{2 b}$ at $348 \mathrm{mT}$ and $9.5006 \mathrm{GHz}\left(\mathrm{Ti}^{3+} g_{\mathrm{z}}\right)$ in toluene. Data 50-80 K acquired on the second day of experiments show incomplete saturation due to imperfect picket fence calibration, which does not affect the resulting saturation recovery behavior.

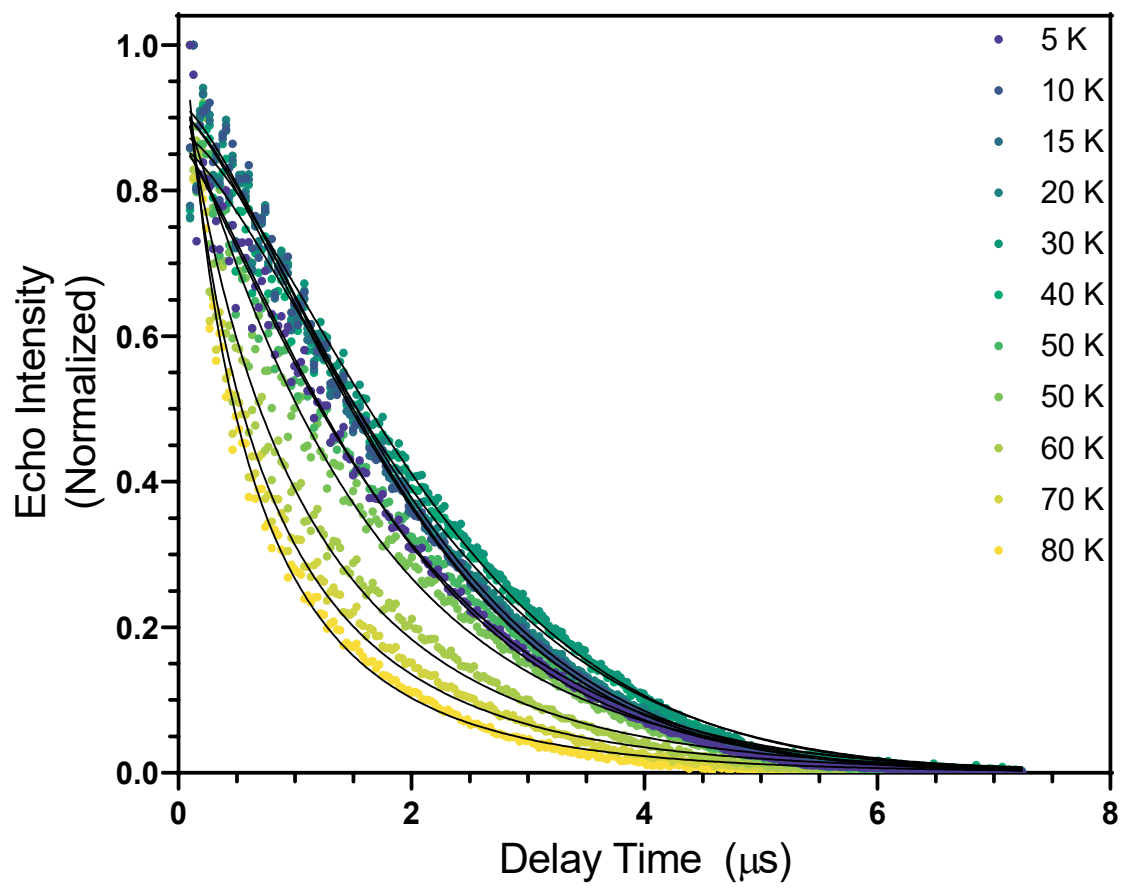

Figure S49 | Variable temperature two-pulse Hahn echo data for $\mathbf{2 b}$ at $348 \mathrm{mT}$ and $9.5006 \mathrm{GHz}\left(\mathrm{Ti}^{3+} g_{\mathrm{z}}\right)$ in toluene.

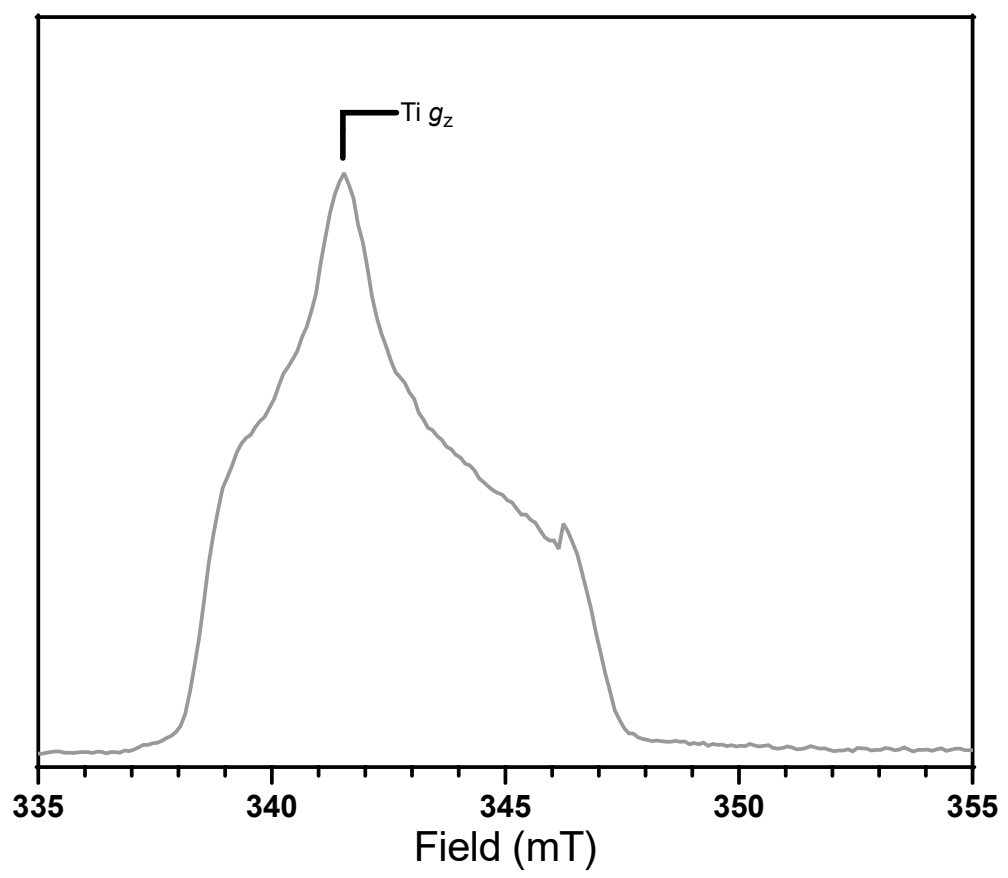


Figure S50 | EDFS EPR spectrum of $\mathbf{2 b}$ in frozen 1:1 $\mathrm{CS}_{2}$ :toluene- $d_{8}$ solution at $30 \mathrm{~K}$ and $9.4892 \mathrm{GHz}$, indicating field position of $T_{1}$ and $T_{\mathrm{m}}$ measurements at the $\mathrm{Ti}^{3+} g_{\mathrm{z}}$ transition. The feature at $346.5 \mathrm{mT}$ is an artifact.

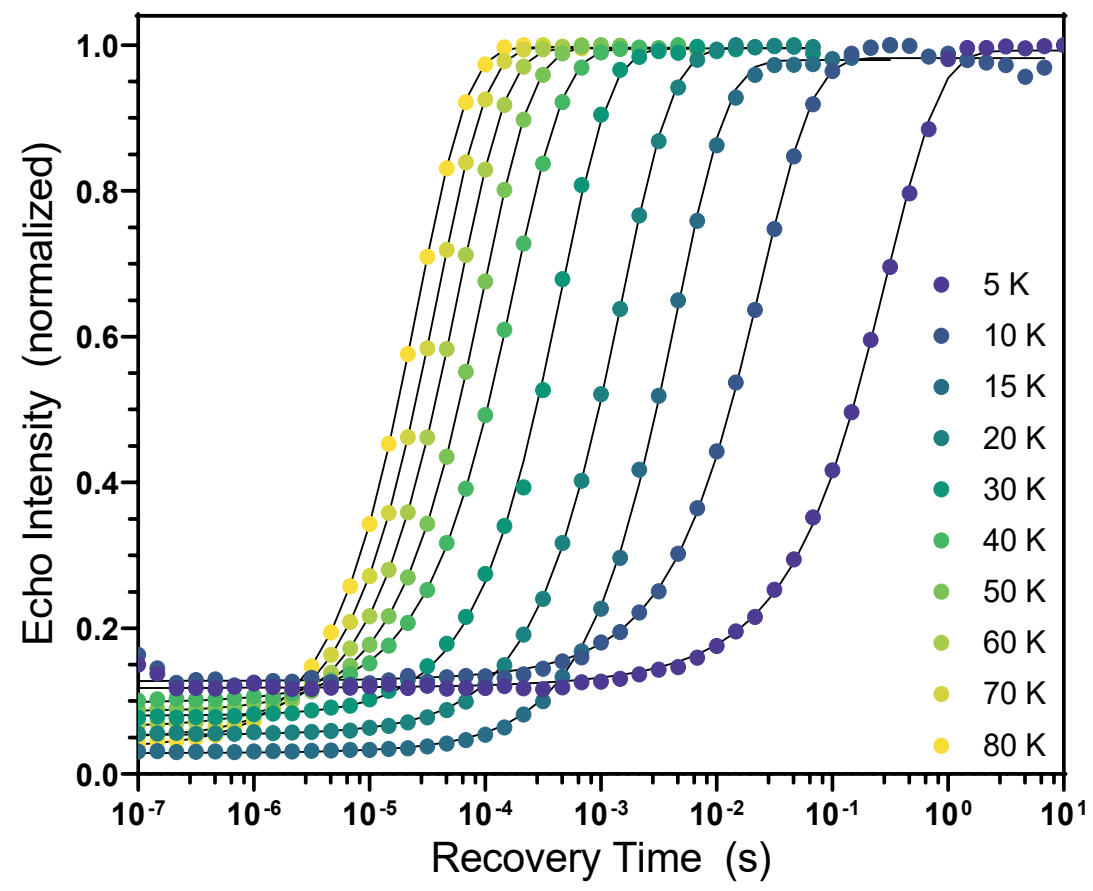

Figure S51 | Variable temperature saturation recovery data for $\mathbf{2 b}$ at $342 \mathrm{mT}$ and $9.4892 \mathrm{GHz}\left(\mathrm{Ti}^{3+} g_{\mathrm{z}}\right)$ in 1:1 CS 2 :toluene- $d_{8}$. 


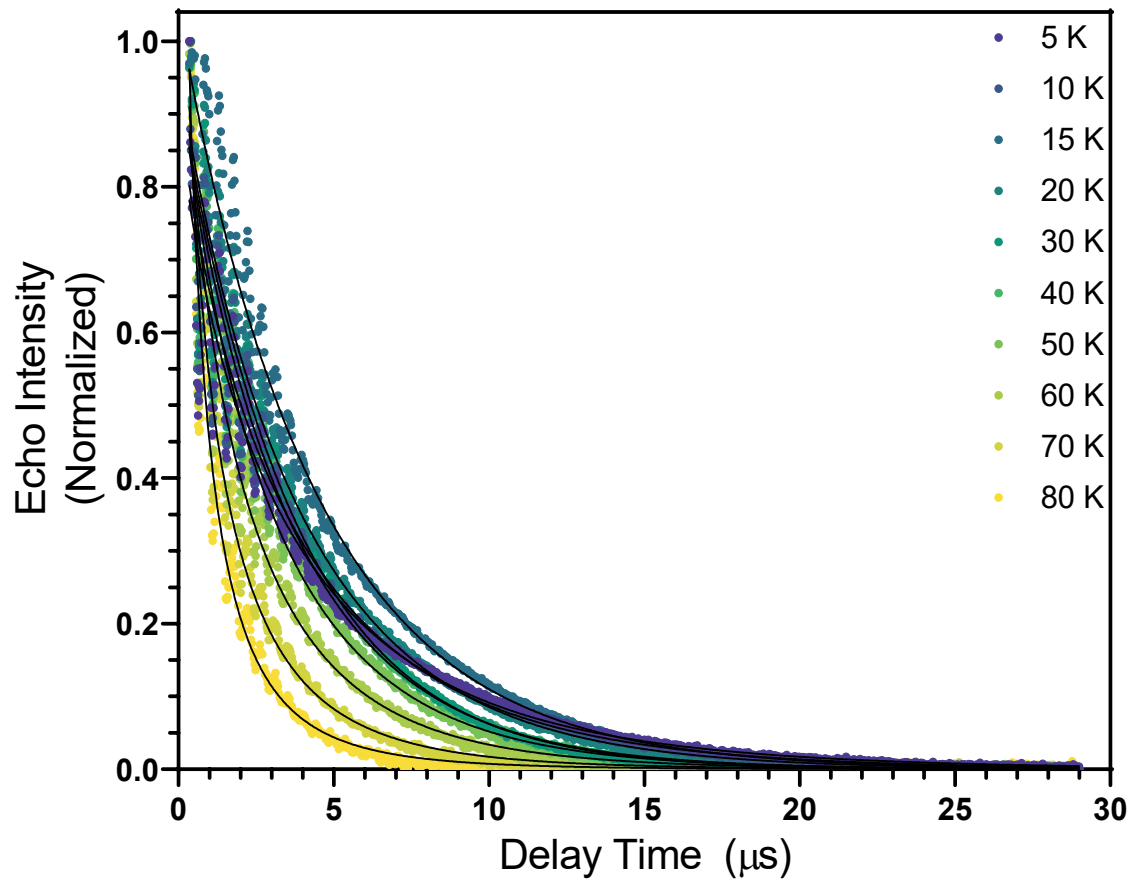

Figure S52 | Variable temperature two-pulse Hahn echo data for $\mathbf{2 b}$ at $342 \mathrm{mT}$ and $9.4892 \mathrm{GHz}\left(\mathrm{Ti}^{3+} g_{\mathrm{z}}\right)$ in 1:1 CS 2 :toluene- $d_{8}$.

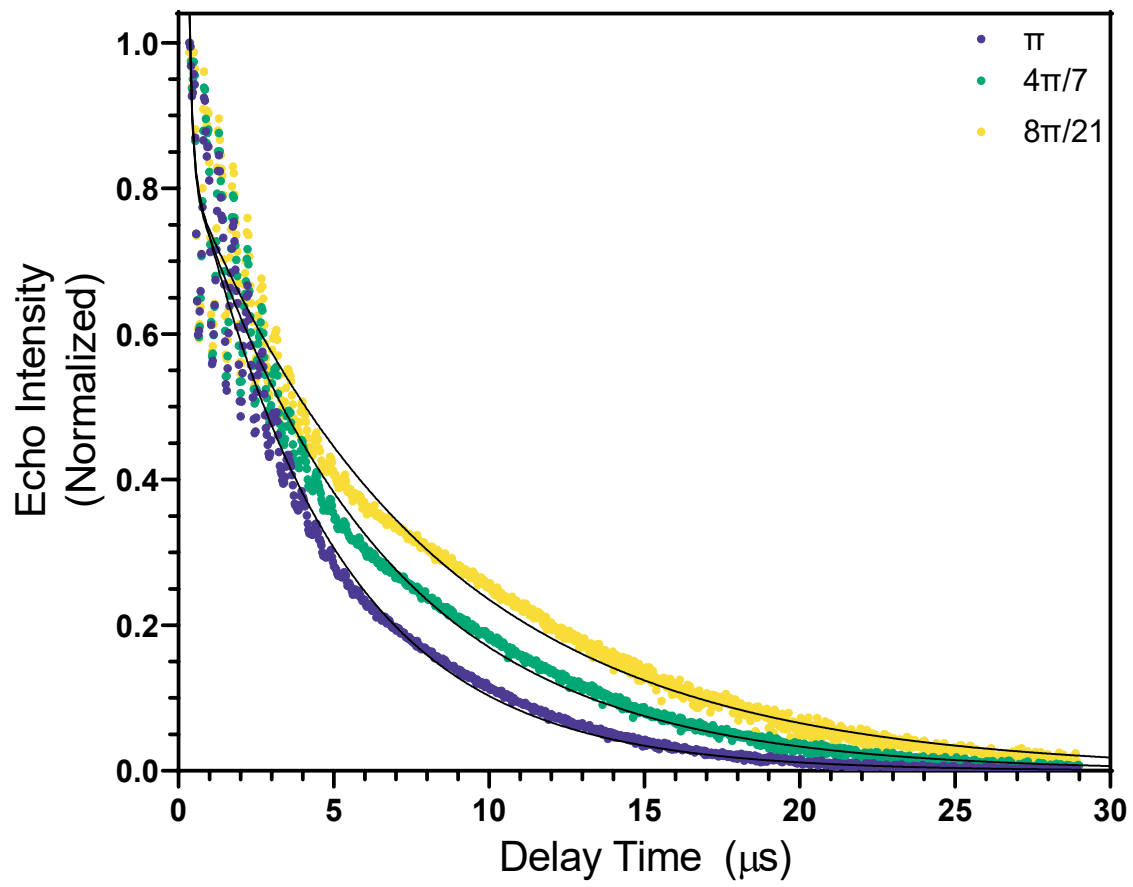

Figure S53 | Variable turning angle two-pulse $\left(\frac{\theta}{2}, \theta\right)$ Hahn echo data for $\mathbf{2 b}$ at $342 \mathrm{mT}$ and $9.4892 \mathrm{GHz}$ $\left(\mathrm{Ti}^{3+} g_{\mathrm{z}}\right)$ in 1:1 $\mathrm{CS}_{2}:$ toluene- $d_{8}$ at $10 \mathrm{~K}$. 


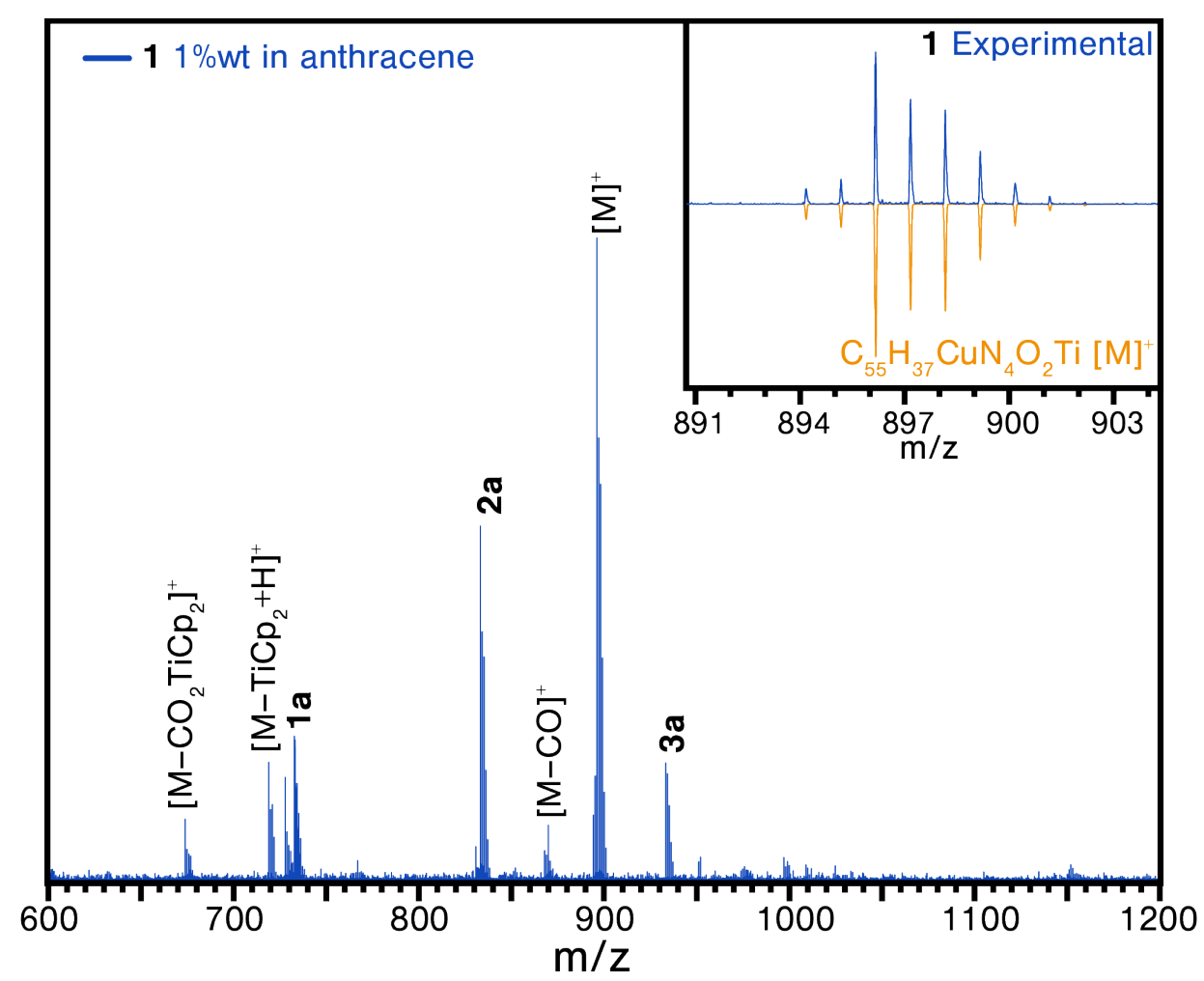

Figure S54 | MALDI-TOF MS of $\mathbf{1}$ 1\%wt in anthracene containing $0.01 \%$ wt standards 1a, 2a and 3a.

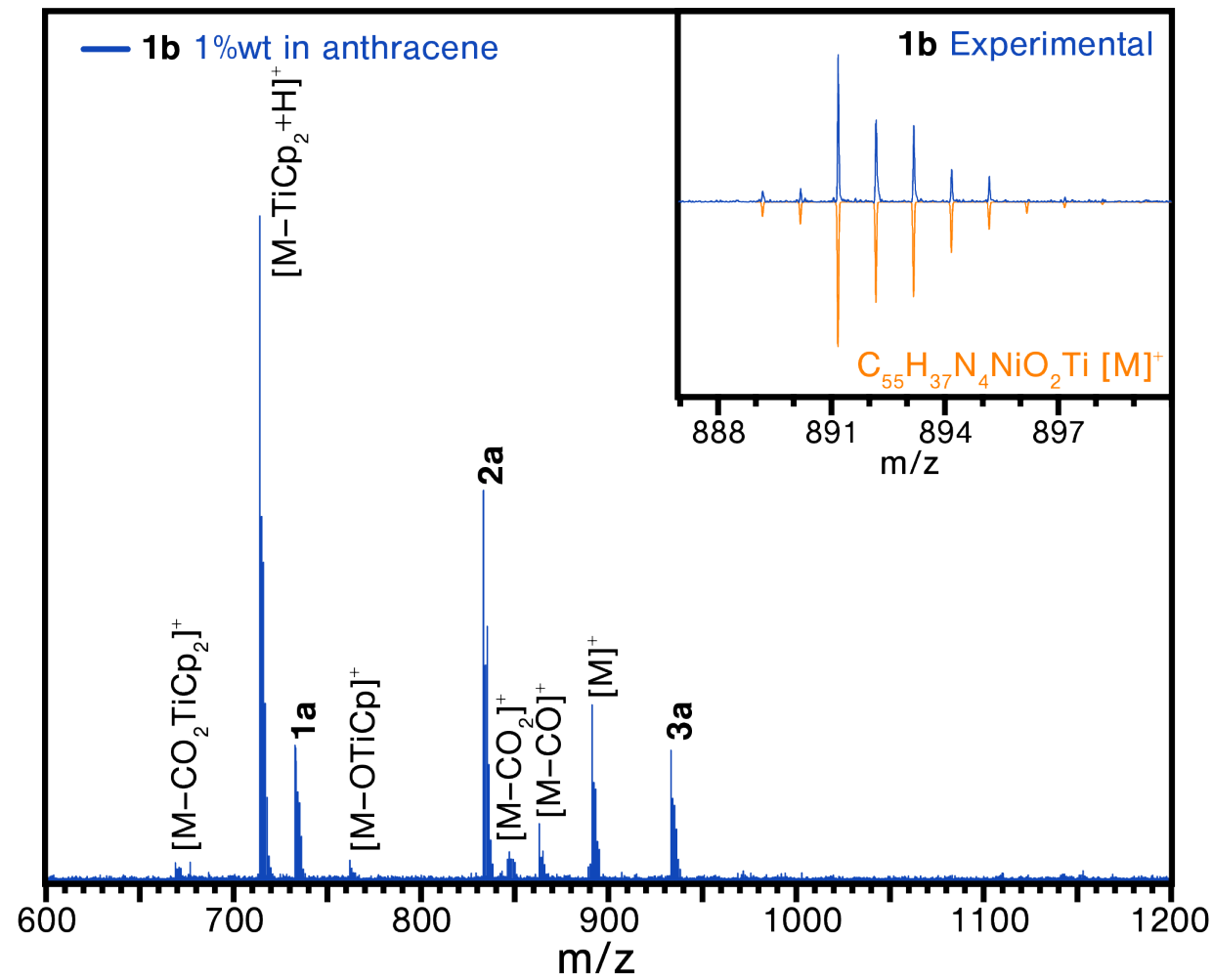

Figure S55 | MALDI-TOF MS of 1b 1\%wt in anthracene containing 0.01\%wt standards 1a, 2a and 3a. 


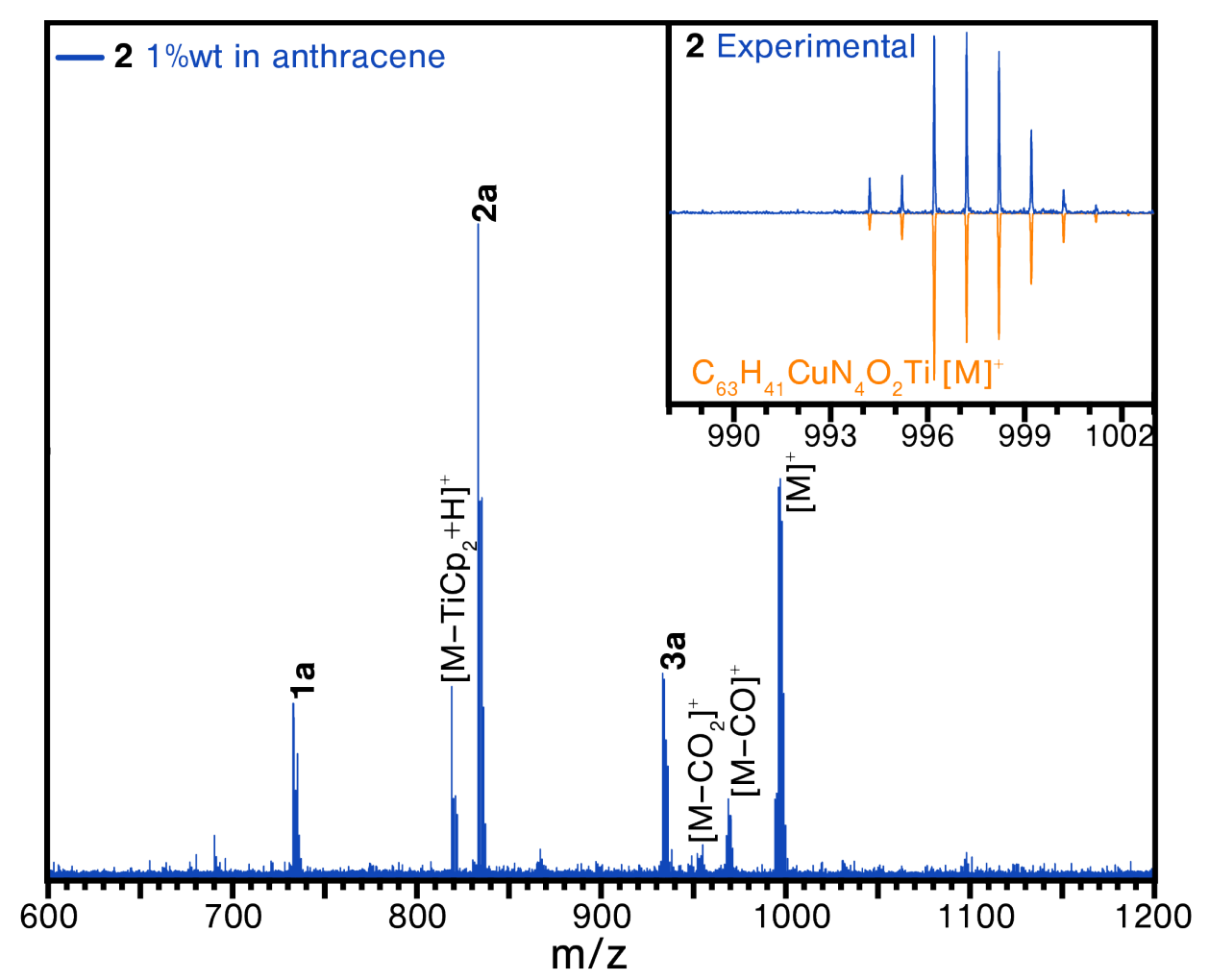

Figure S56 | MALDI-TOF MS of 2 1\%wt in anthracene containing $0.01 \%$ wt standards 1a, 2a and 3a.

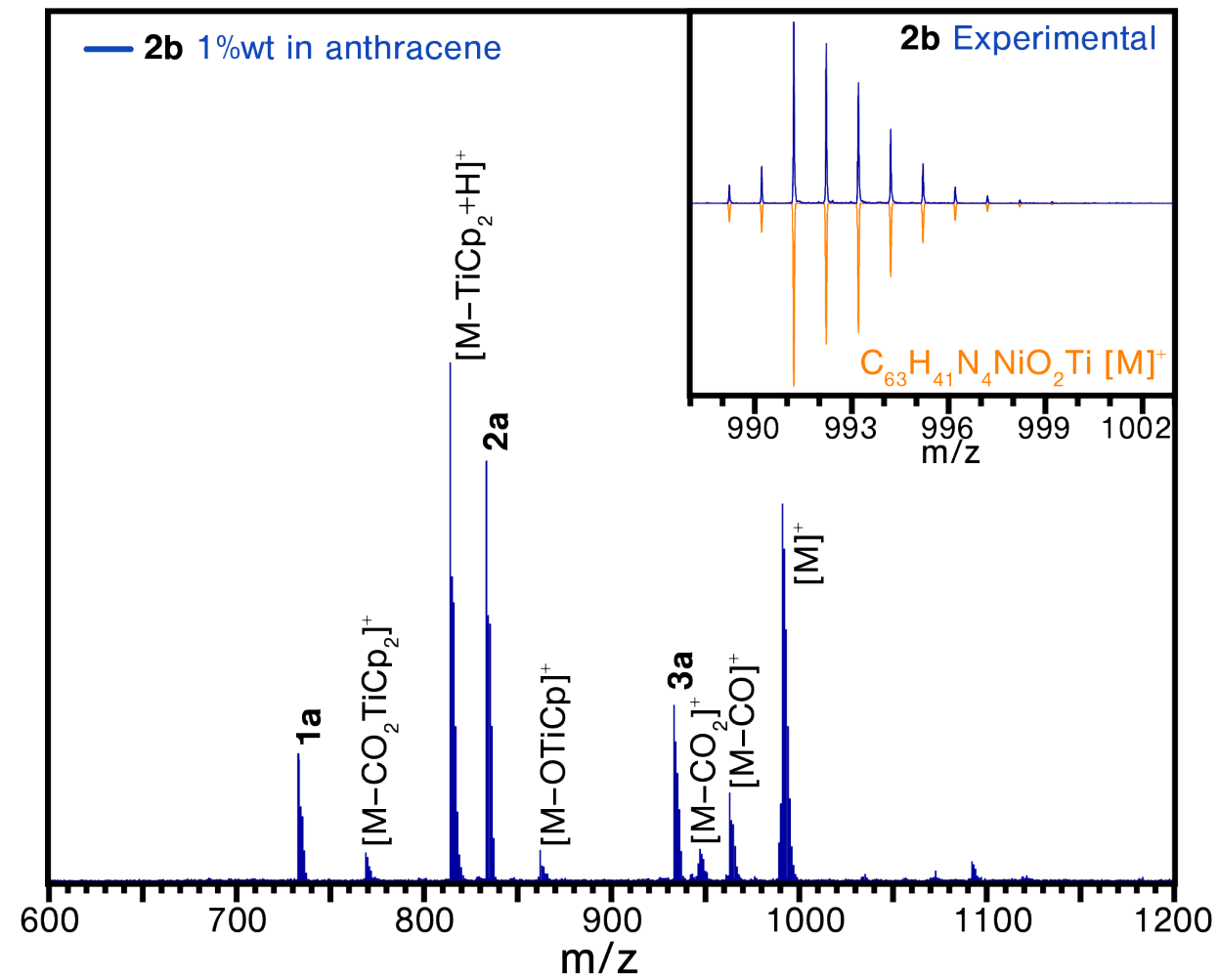

Figure S57 | MALDI-TOF MS of 2b 1\%wt in anthracene containing 0.01\%wt standards 1a, 2a and 3a. 


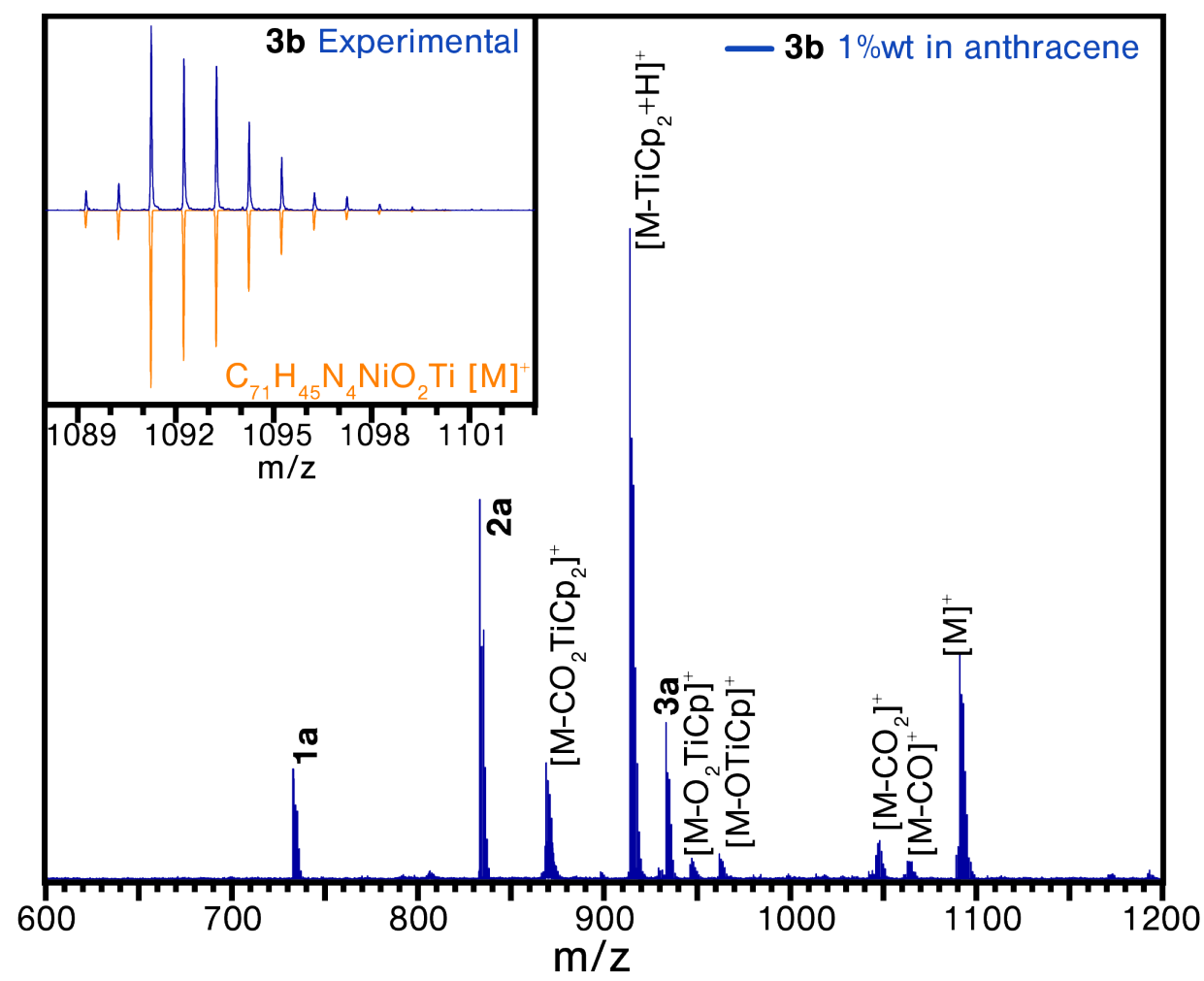

Figure S58 $\mid$ MALDI-TOF MS of 3 1\%wt in anthracene containing $0.01 \%$ wt standards 1a, 2a and 3a.

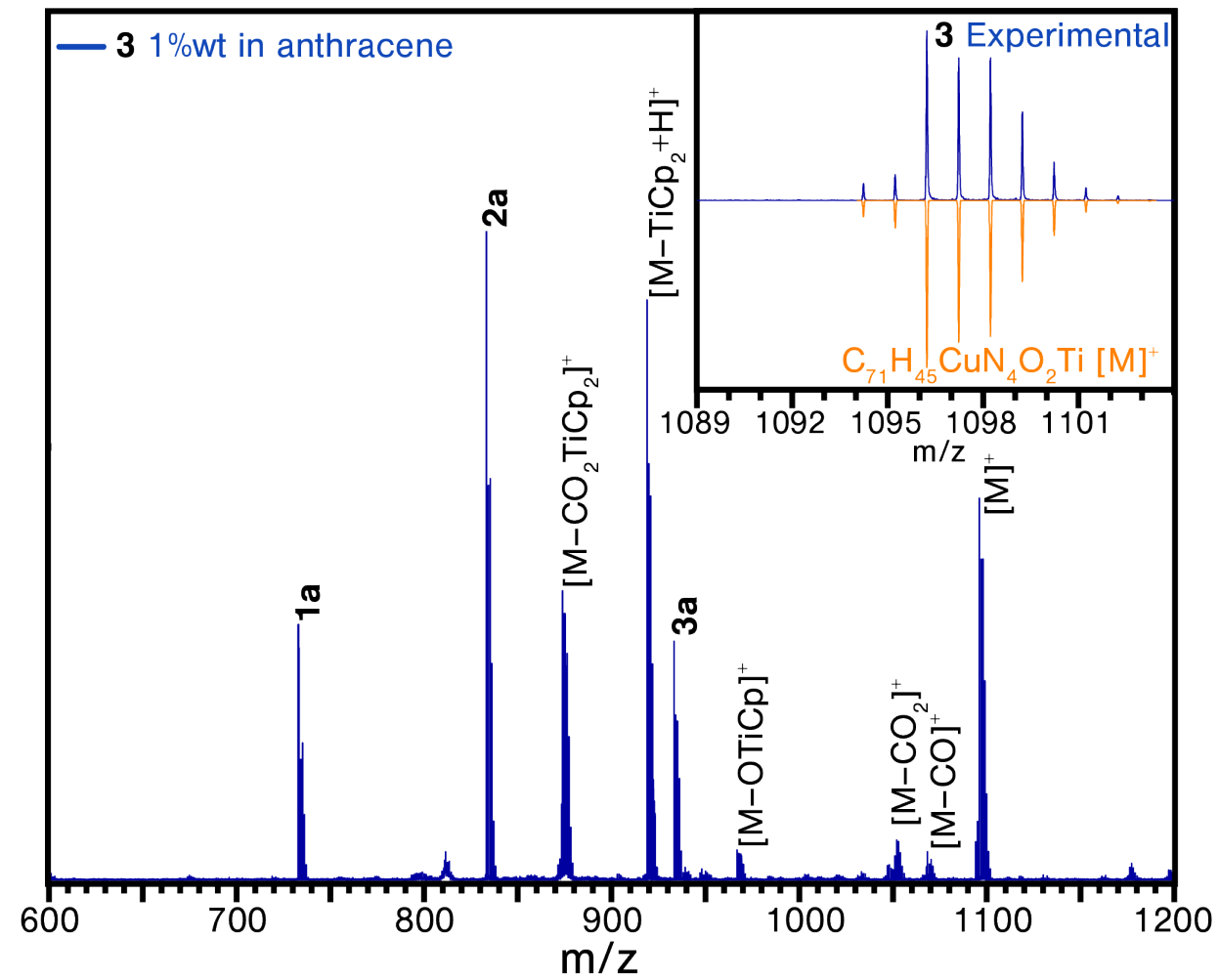

Figure S59 | MALDI-TOF MS of 3b 1\%wt in anthracene containing 0.01\%wt standards 1a, 2a and 3a. 


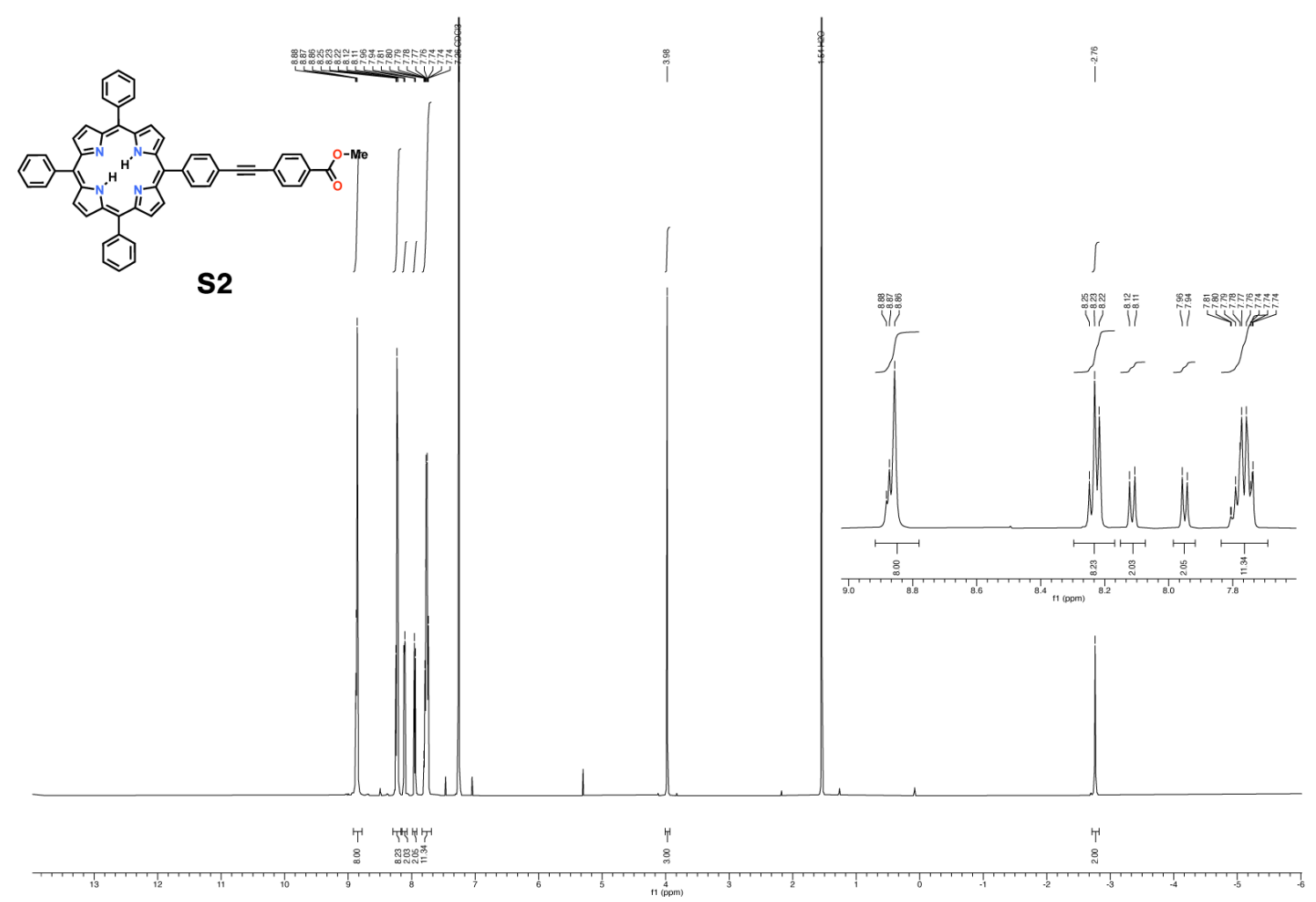

Figure S60 $\mid{ }^{1} \mathrm{H}$ NMR $\left(500 \mathrm{MHz}, \mathrm{CDCl}_{3}\right)$ of $\mathbf{S 2}$.
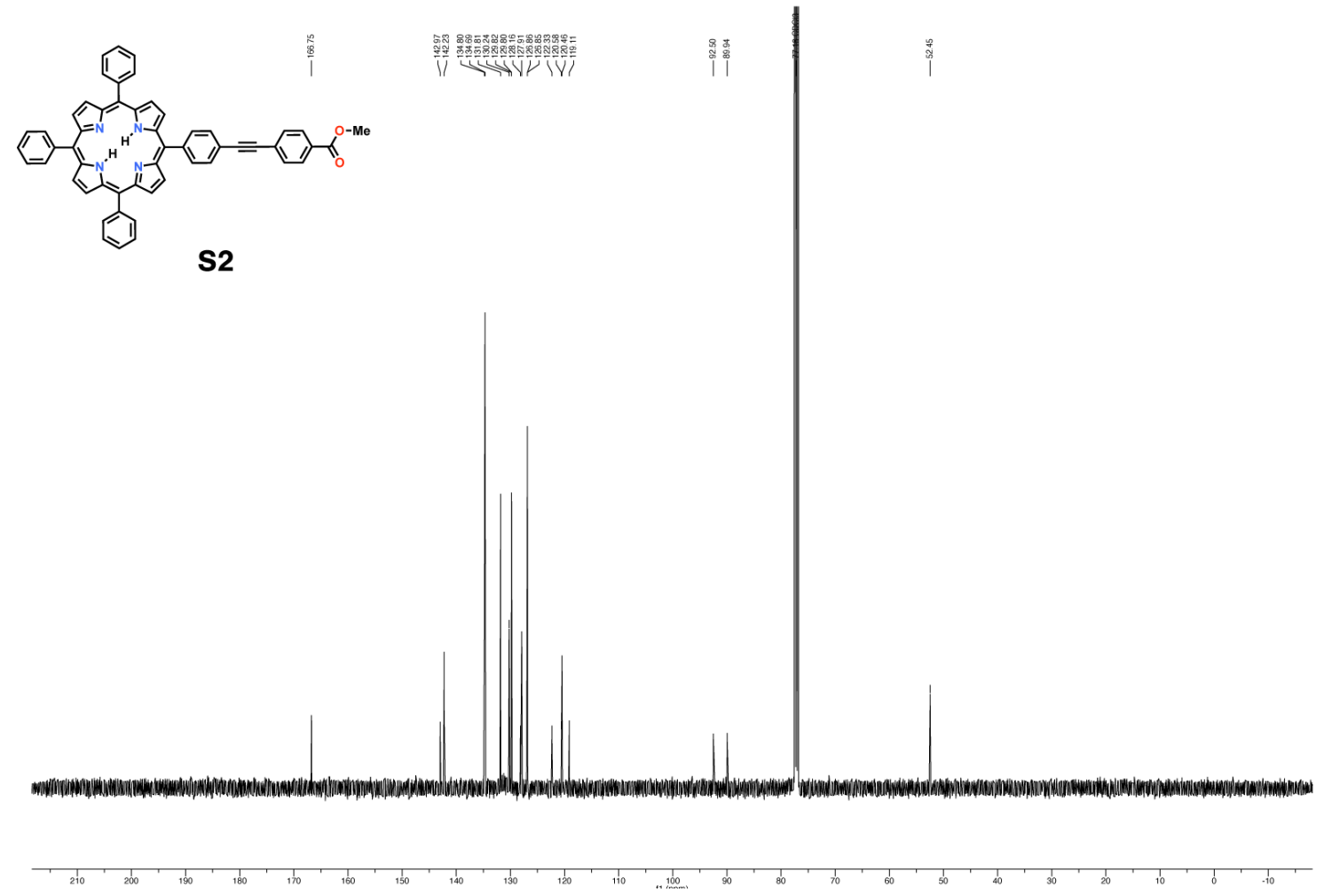

Figure S61 $\mid{ }^{13} \mathrm{C}\left\{{ }^{1} \mathrm{H}\right\} \mathrm{NMR}\left(126 \mathrm{MHz}, \mathrm{CDCl}_{3}\right)$ of $\mathbf{S 2}$. 


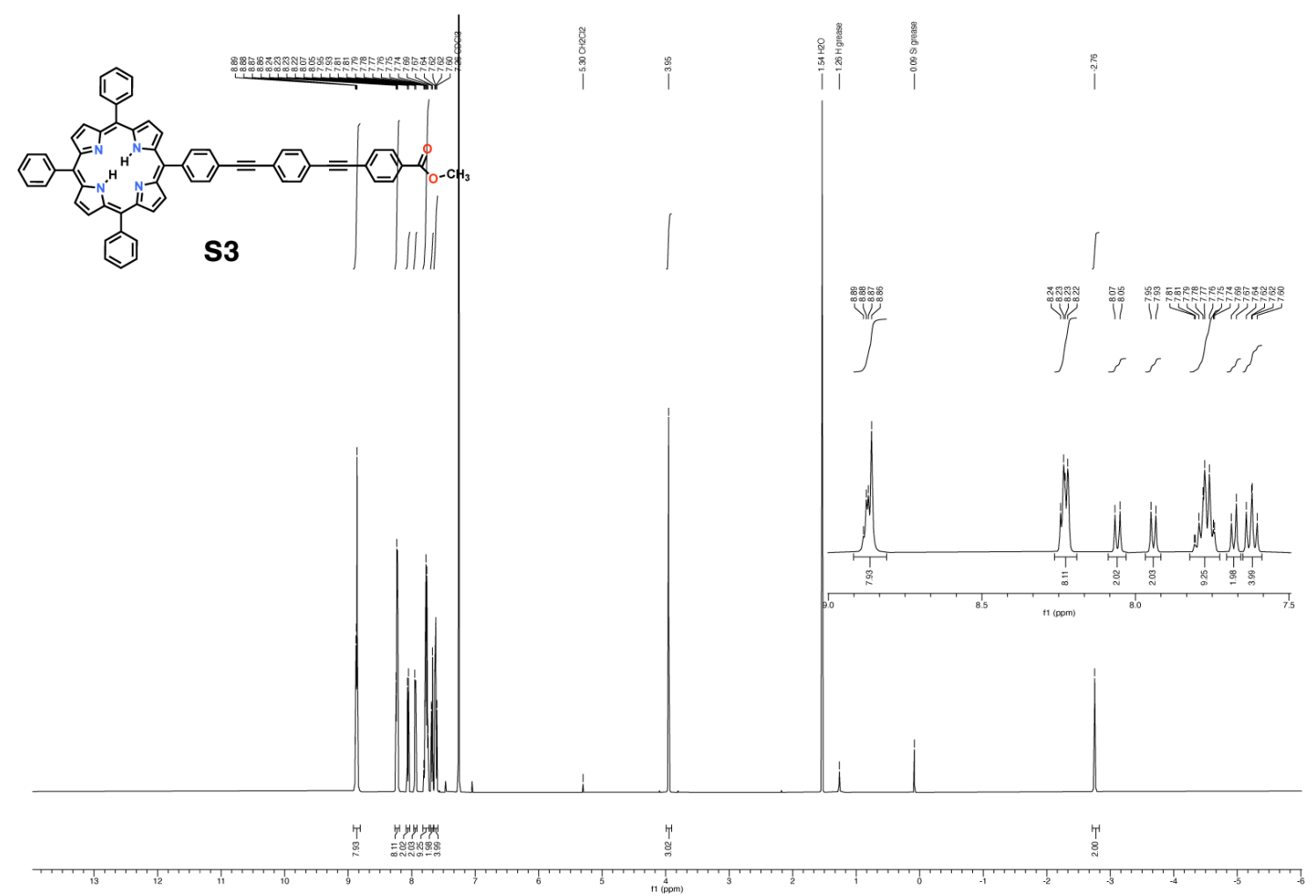

Figure S62 $\mid{ }^{1} \mathrm{H}$ NMR $\left(500 \mathrm{MHz}, \mathrm{CDCl}_{3}\right)$ of $\mathbf{S 3}$.
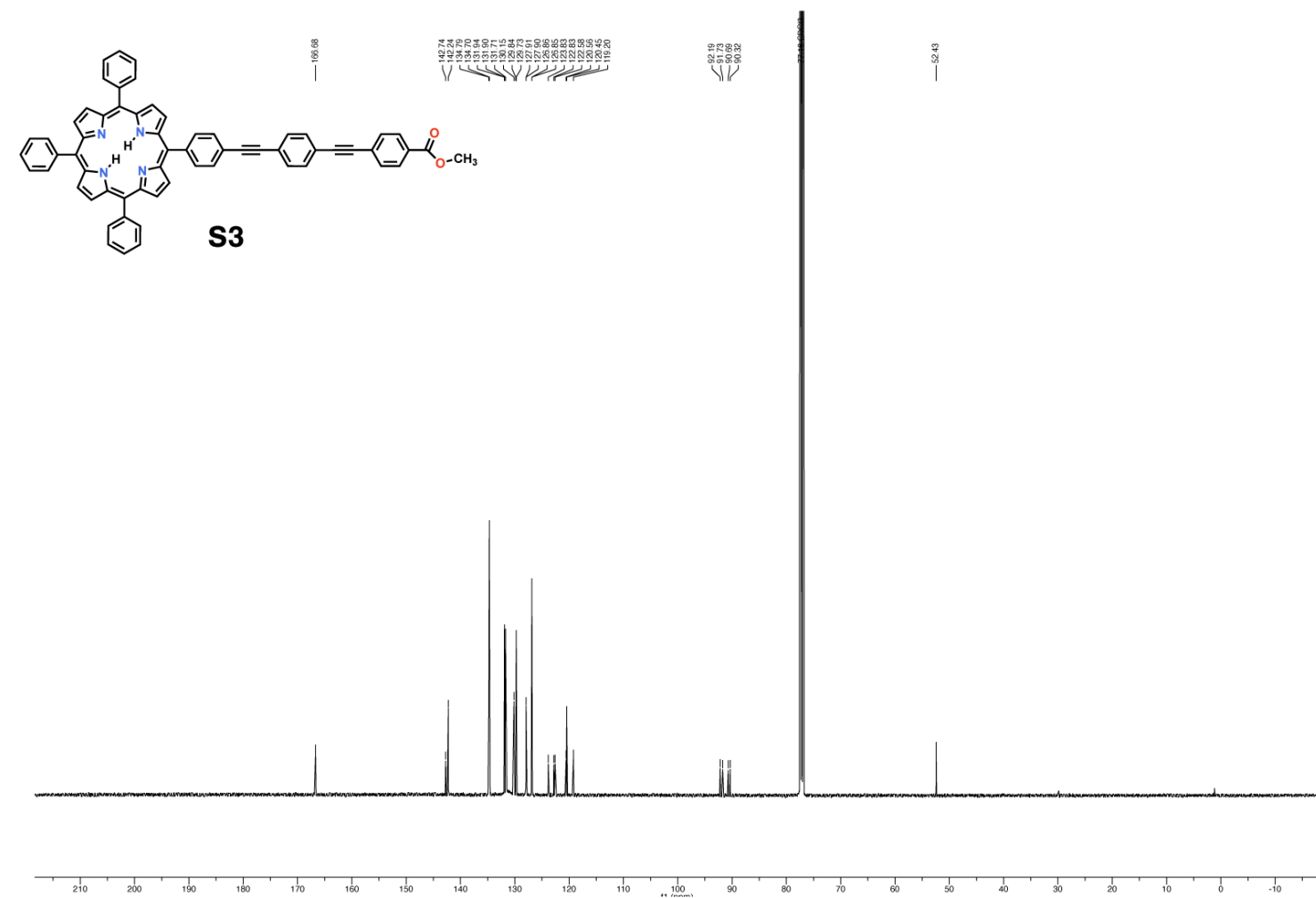

Figure S63 $\mid{ }^{13} \mathrm{C}\left\{{ }^{1} \mathrm{H}\right\} \mathrm{NMR}\left(126 \mathrm{MHz}, \mathrm{CDCl}_{3}\right)$ of $\mathbf{S 3}$. 


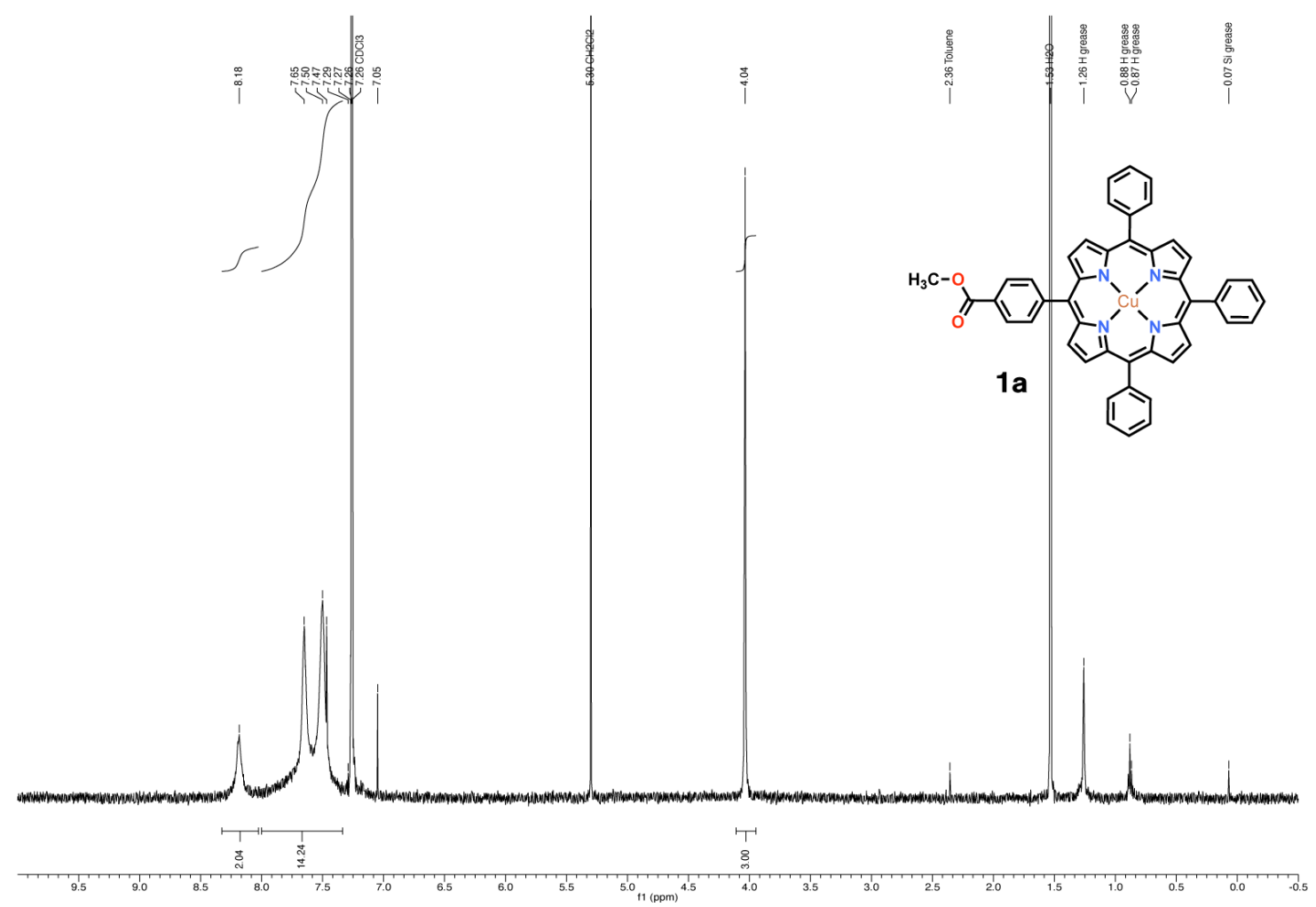

Figure S64 $\mid{ }^{1} \mathrm{H}$ NMR $\left(500 \mathrm{MHz}, \mathrm{CDCl}_{3}\right)$ of $\mathbf{1 a}$.

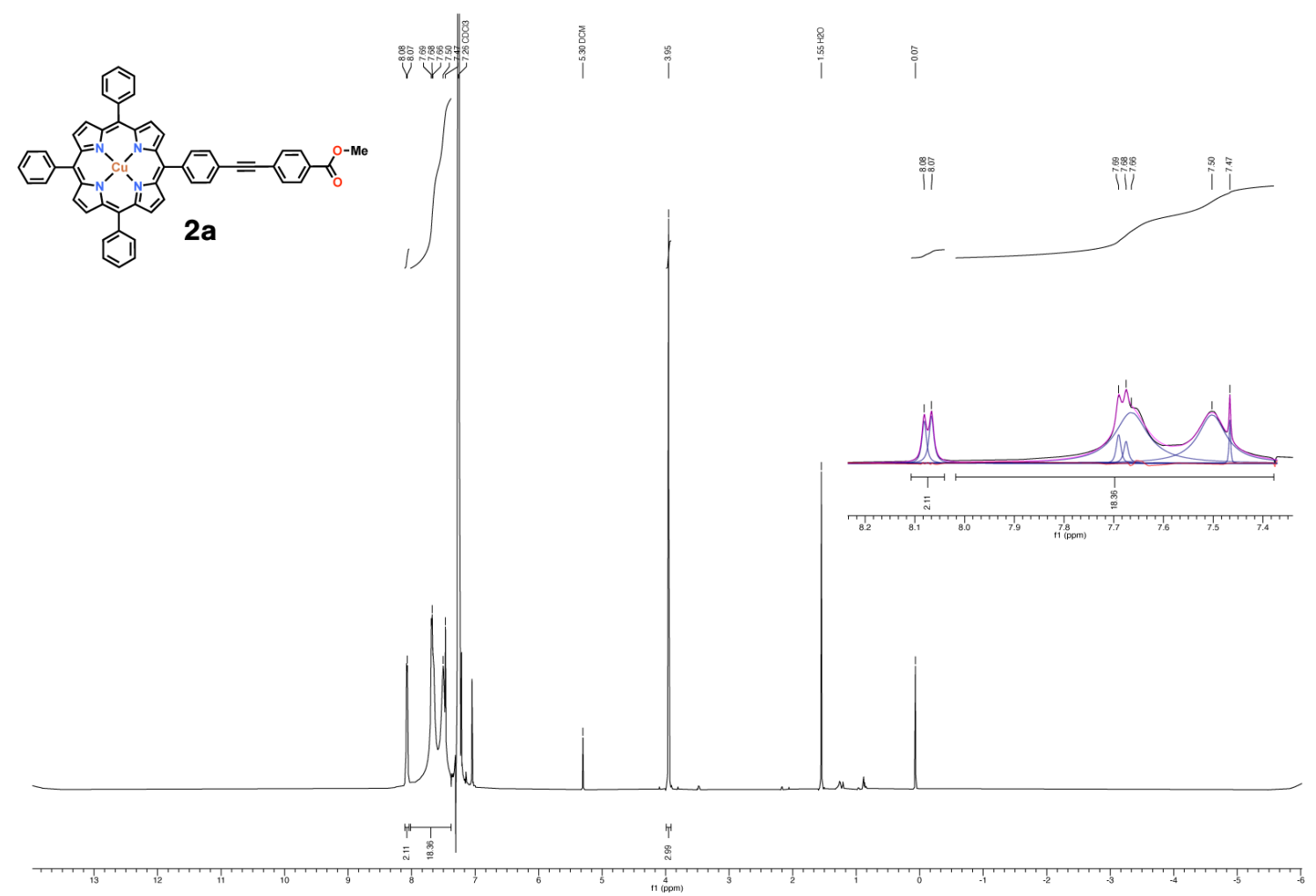

Figure S65 $\mid{ }^{1} \mathrm{H}$ NMR $\left(500 \mathrm{MHz}, \mathrm{CDCl}_{3}\right)$ of $\mathbf{2 a}$. 

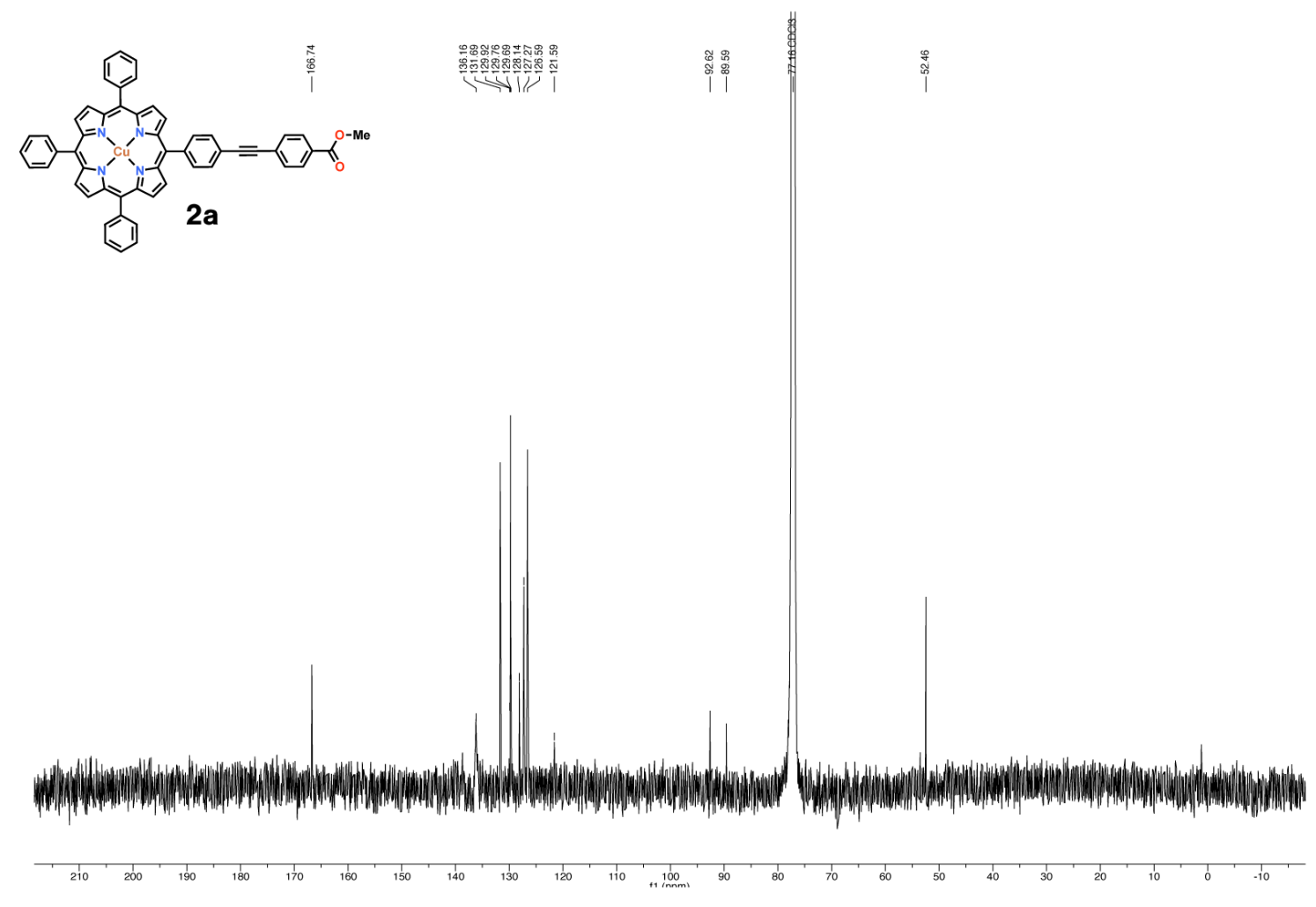

Figure S66 $\mid{ }^{13} \mathrm{C}\left\{{ }^{1} \mathrm{H}\right\} \mathrm{NMR}\left(126 \mathrm{MHz}, \mathrm{CDCl}_{3}\right)$ of $\mathbf{2 a}$.

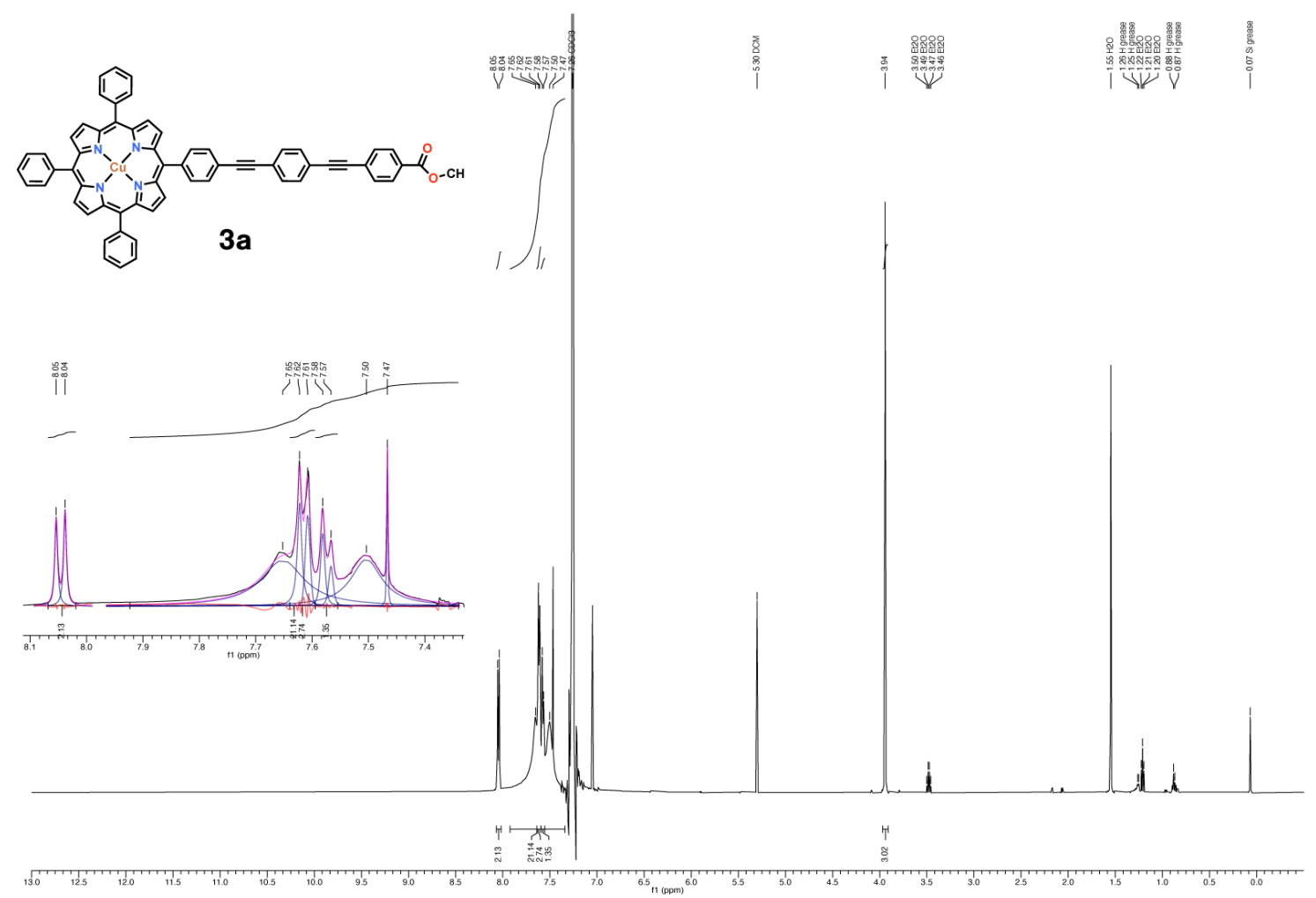

Figure S67 $\mid{ }^{1} \mathrm{H}$ NMR (500 MHz, $\left.\mathrm{CDCl}_{3}\right)$ of $\mathbf{3 a}$. 

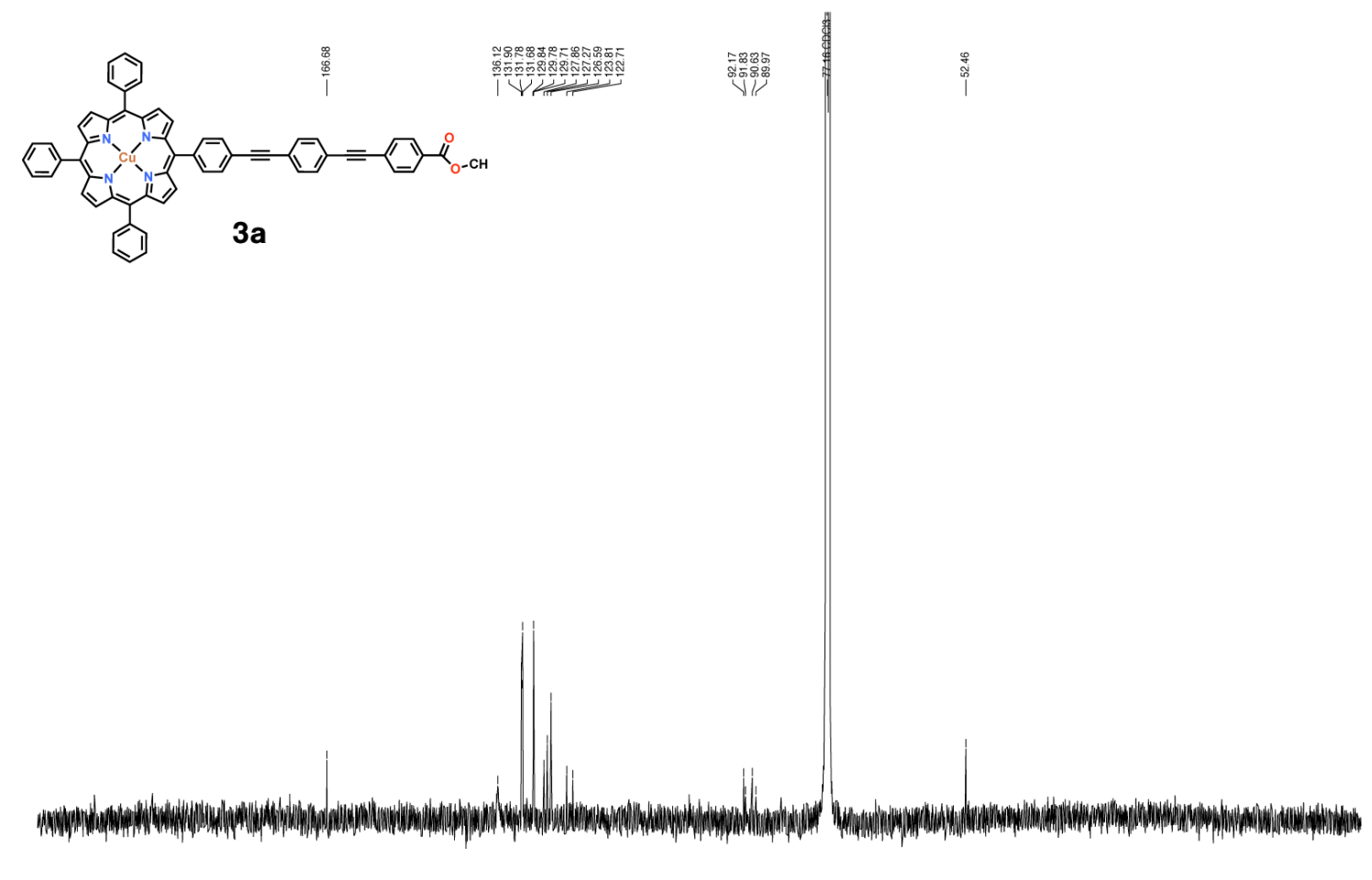

Figure S68 $\mid{ }^{13} \mathrm{C}\left\{{ }^{1} \mathrm{H}\right\} \mathrm{NMR}\left(126 \mathrm{MHz}, \mathrm{CDCl}_{3}\right)$ of $\mathbf{3 a}$.

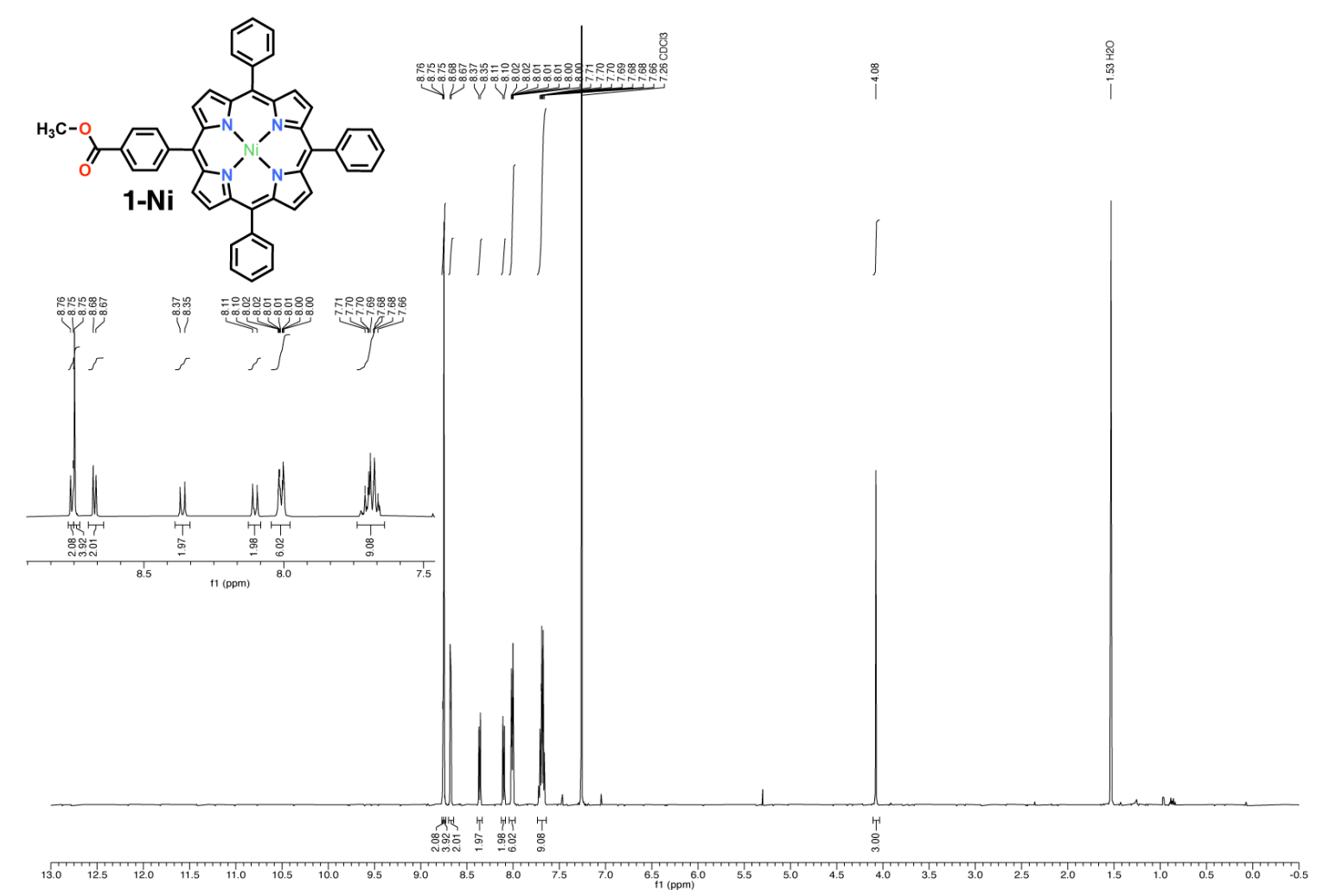

Figure S69 | ${ }^{1} \mathrm{H}$ NMR (500 MHz, $\left.\mathrm{CDCl}_{3}\right)$ of $\mathbf{1 - N i . ~}$ 


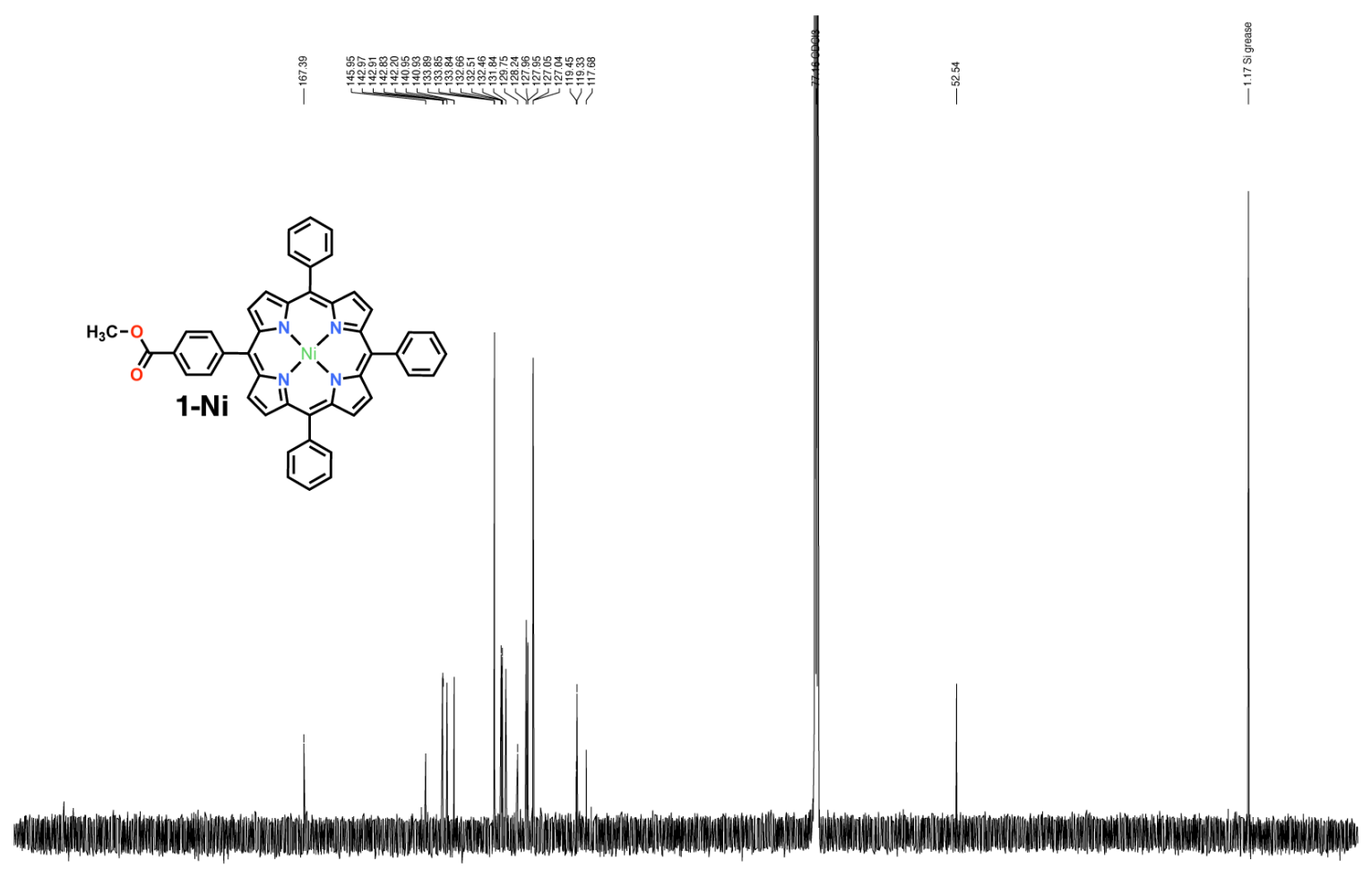

Figure $\mathbf{S 7 0} \mid{ }^{13} \mathrm{C}\left\{{ }^{1} \mathrm{H}\right\}$ NMR $\left(126 \mathrm{MHz}, \mathrm{CDCl}_{3}\right)$ of $\mathbf{1}-\mathbf{N i}$.

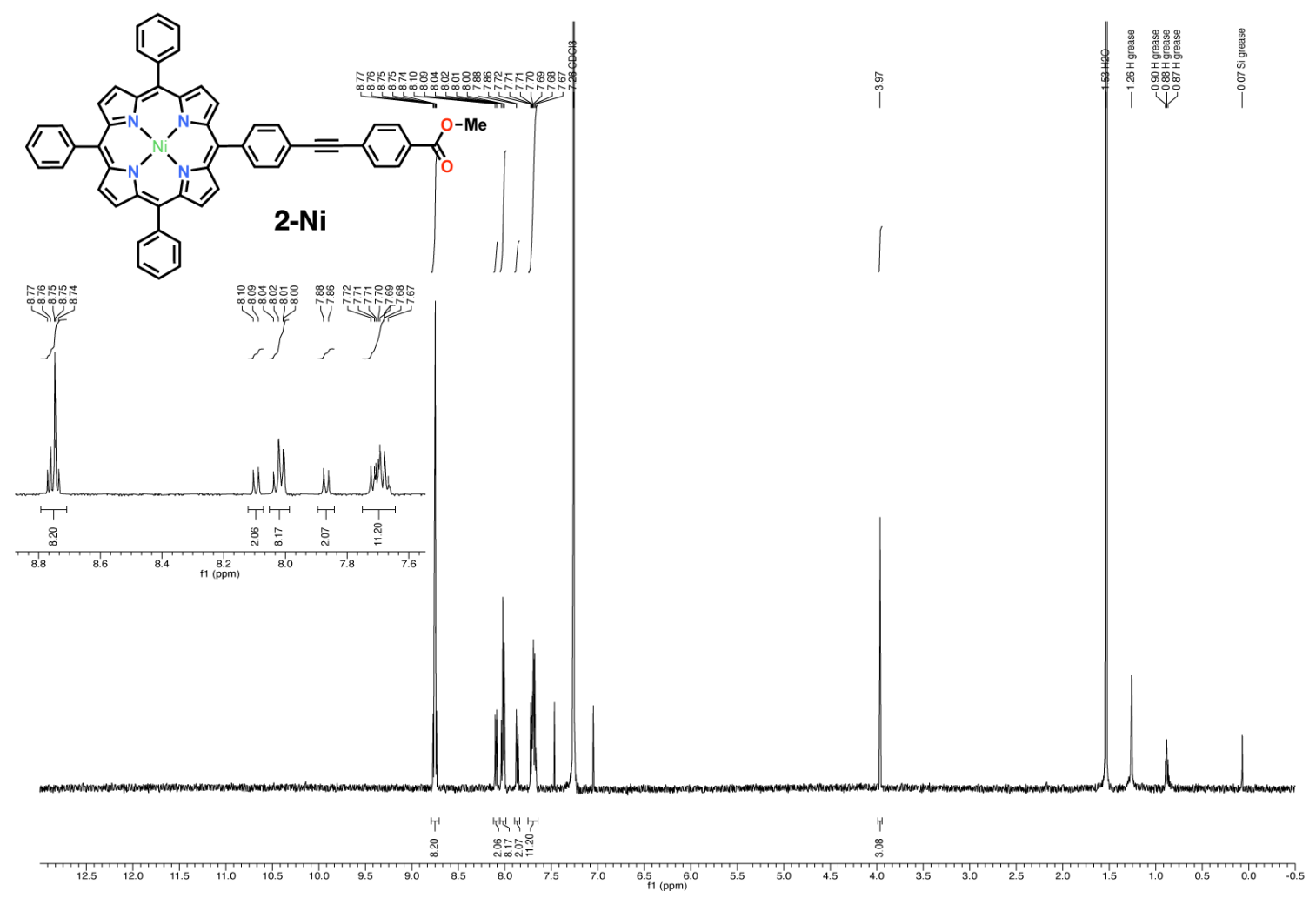

Figure S71 | ${ }^{1} \mathrm{H}$ NMR (500 MHz, $\left.\mathrm{CDCl}_{3}\right)$ of 2-Ni. 

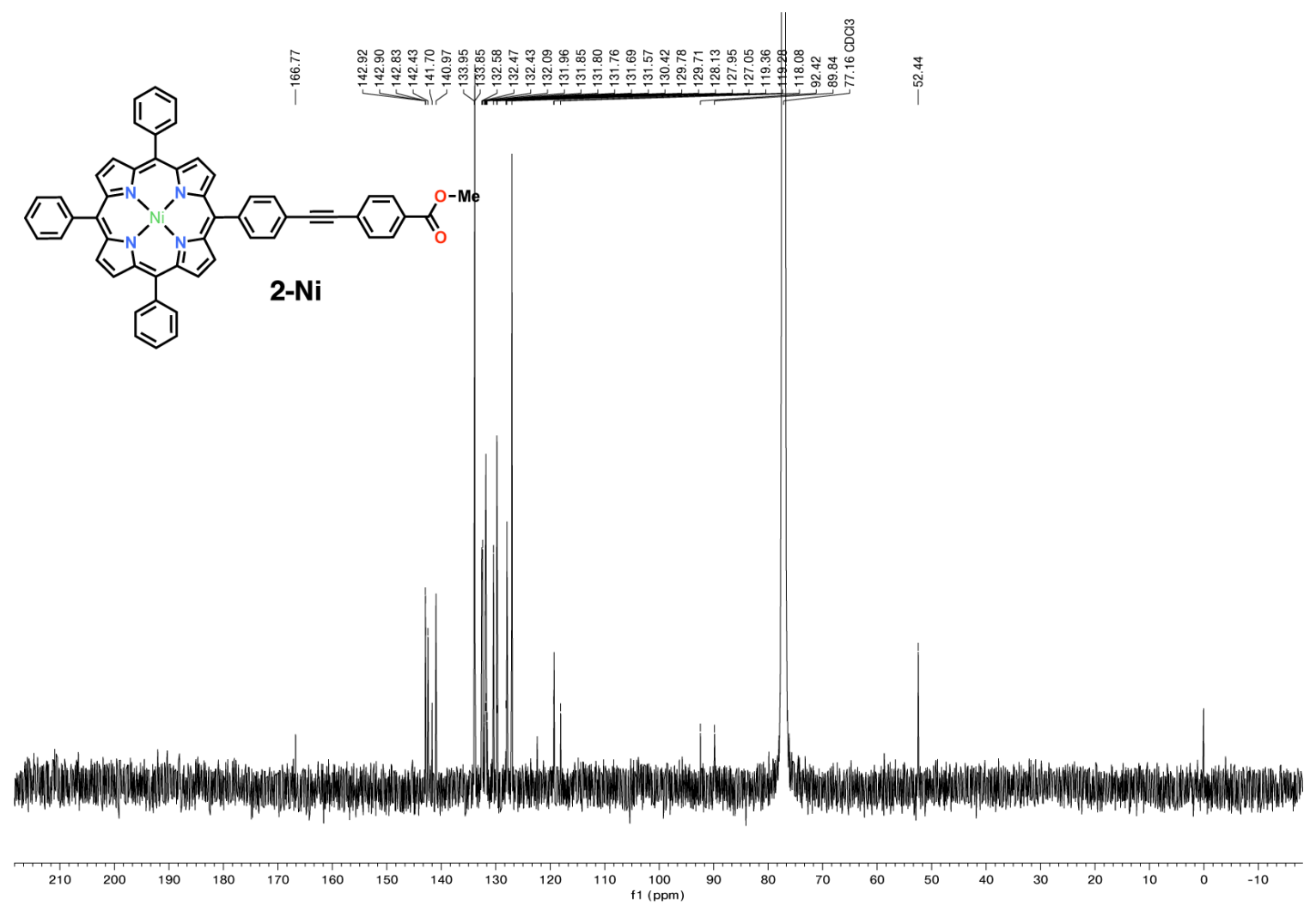

Figure S72 $\mid{ }^{13} \mathrm{C}\left\{{ }^{1} \mathrm{H}\right\}$ NMR $\left(126 \mathrm{MHz}, \mathrm{CDCl}_{3}\right)$ of $\mathbf{2}-\mathbf{N i}$.

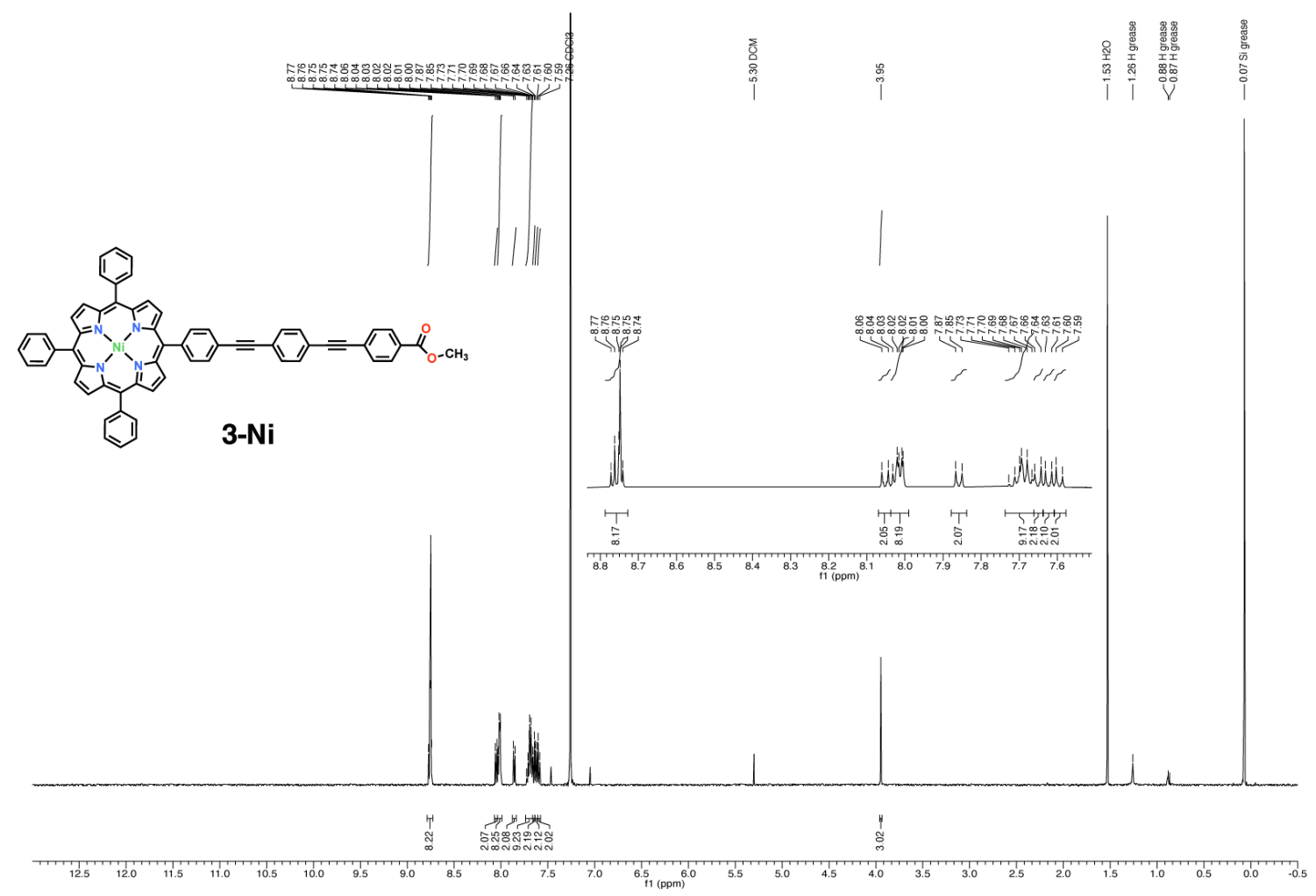

Figure $\mathbf{S 7 3} \mid{ }^{1} \mathrm{H}$ NMR $\left(500 \mathrm{MHz}, \mathrm{CDCl}_{3}\right)$ of 3-Ni. 

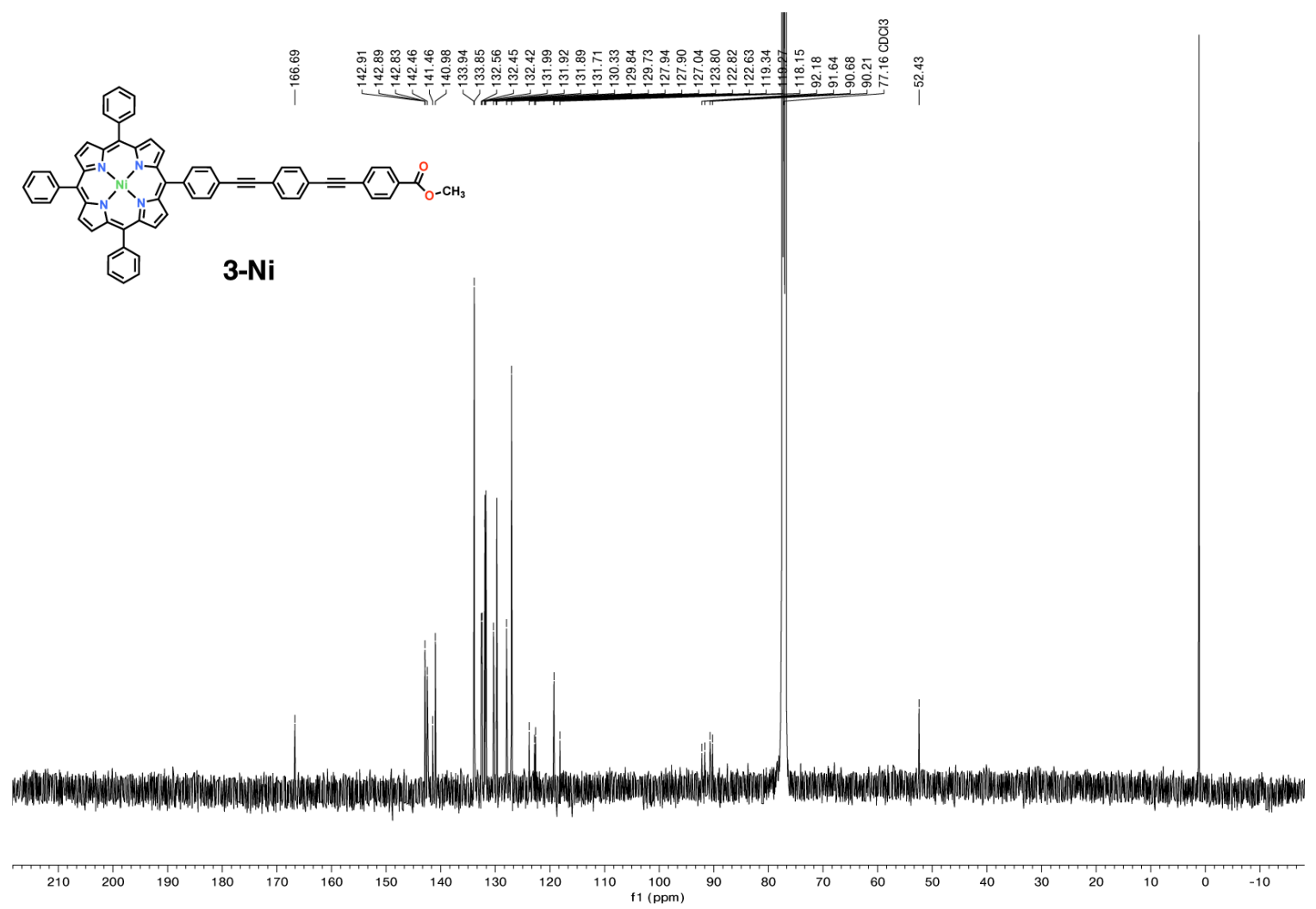

Figure $\mathbf{S 7 4} \mid{ }^{13} \mathrm{C}\left\{{ }^{1} \mathrm{H}\right\}$ NMR $\left(126 \mathrm{MHz}, \mathrm{CDCl}_{3}\right)$ of 3-Ni.

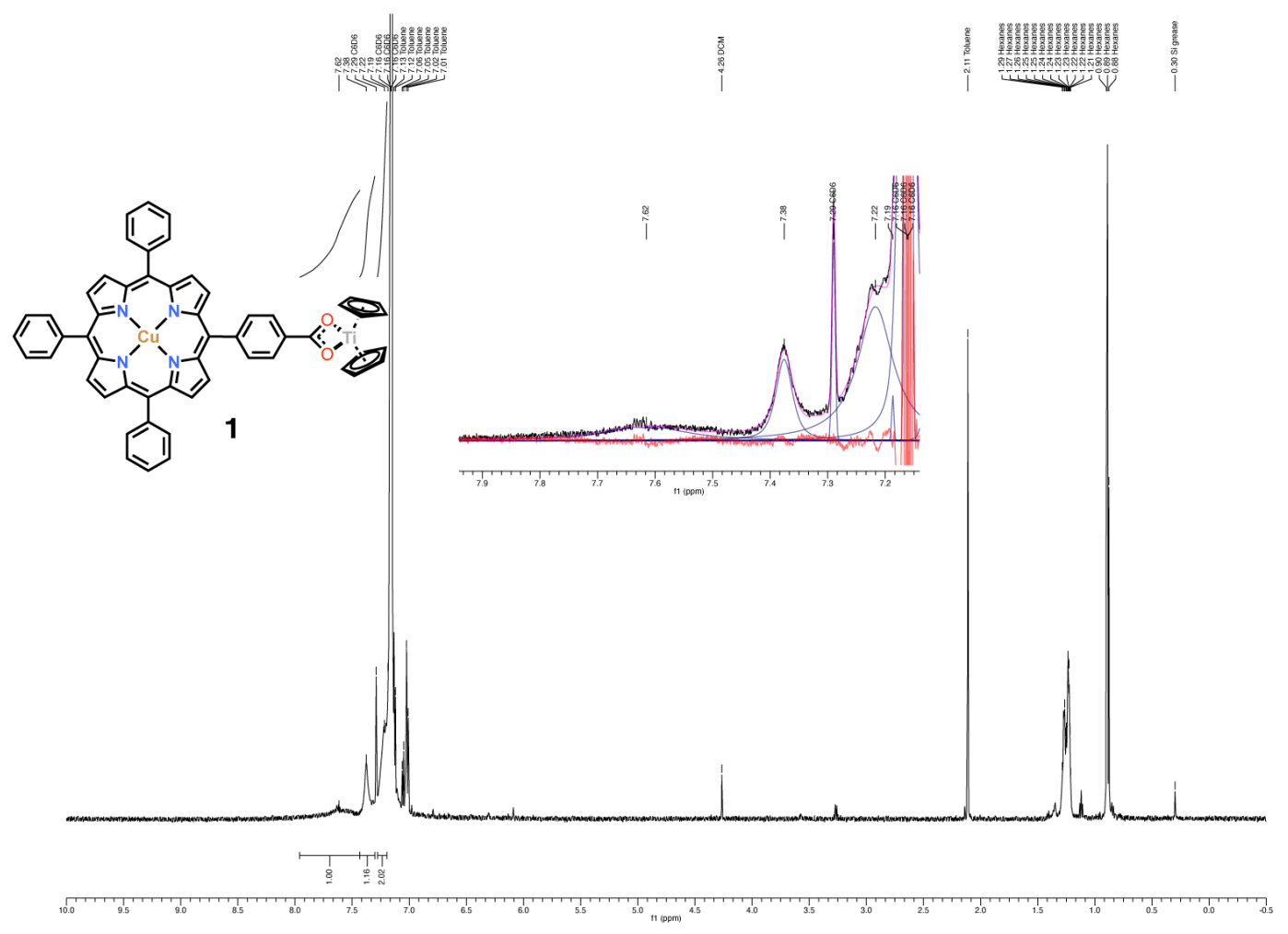

Figure S75 $\mid{ }^{1} \mathrm{H}$ NMR $\left(600 \mathrm{MHz}, \mathrm{C}_{6} \mathrm{D}_{6}\right)$ of $\mathbf{1}$. 


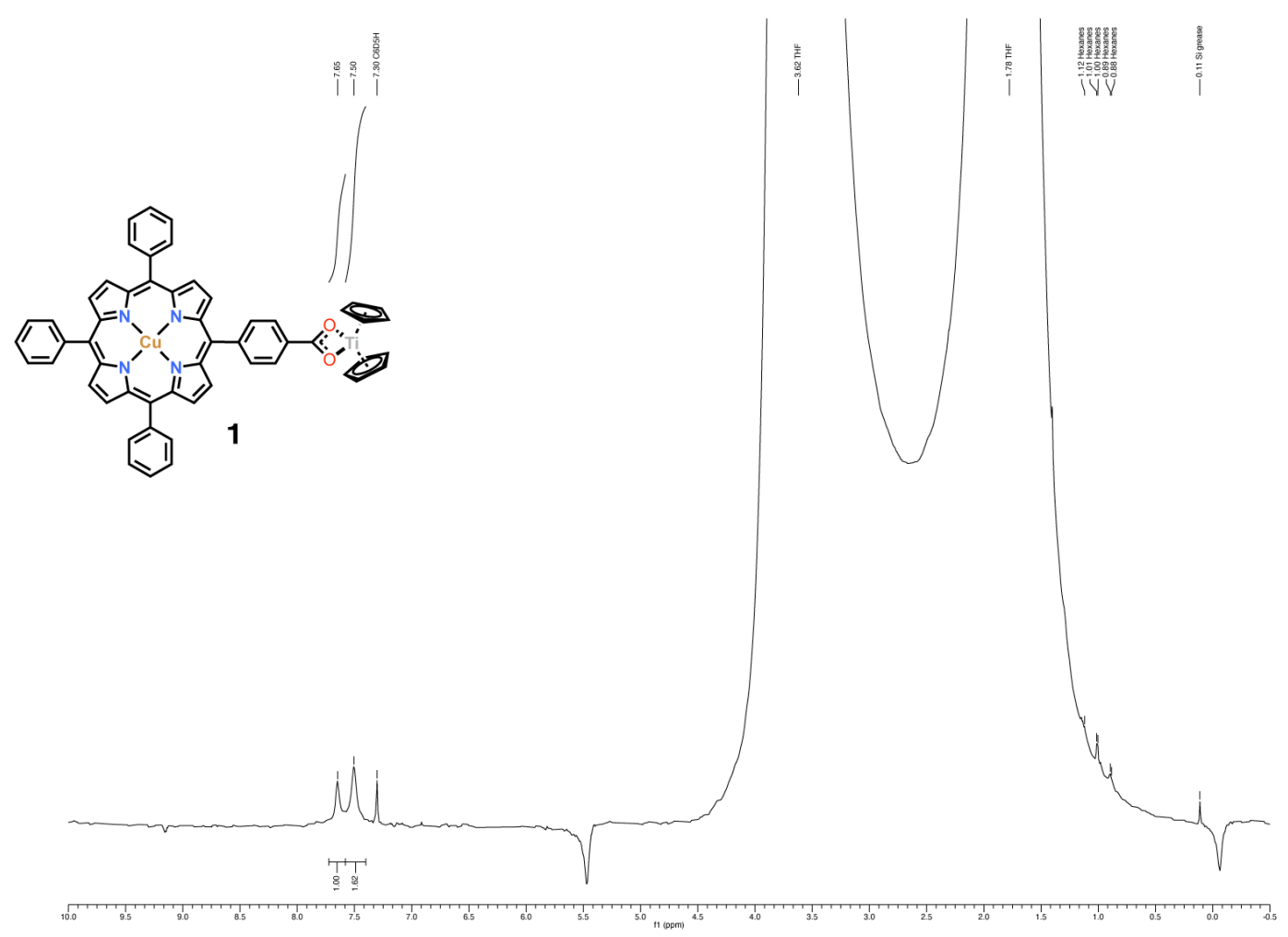

Figure S76 $\mid{ }^{1} \mathrm{H}$ NMR (600 MHz, protio-THF) of 1.

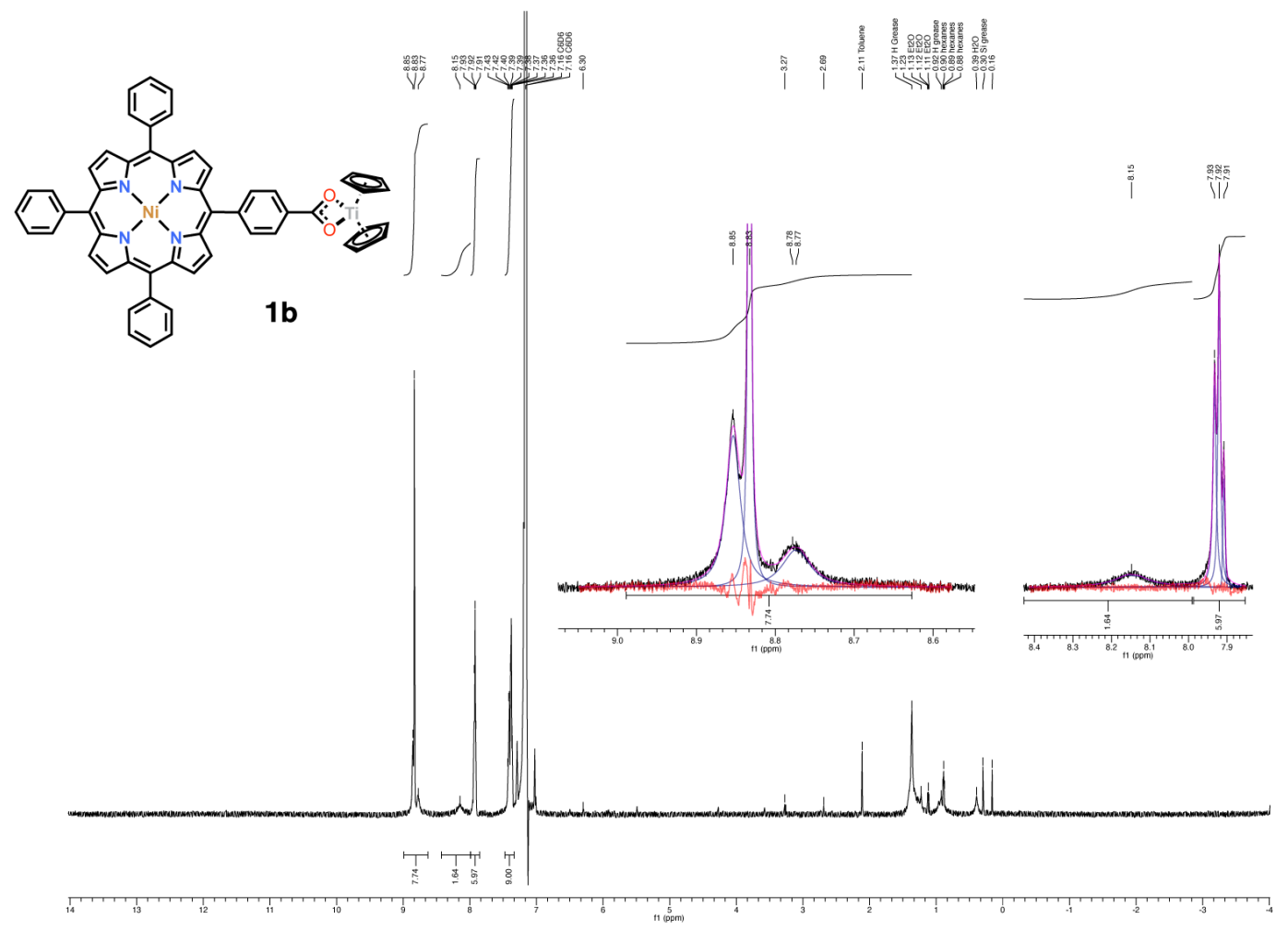

Figure S77 $\mid{ }^{1} \mathrm{H}$ NMR (600 MHz, $\left.\mathrm{C}_{6} \mathrm{D}_{6}\right)$ of $\mathbf{1 b}$. 


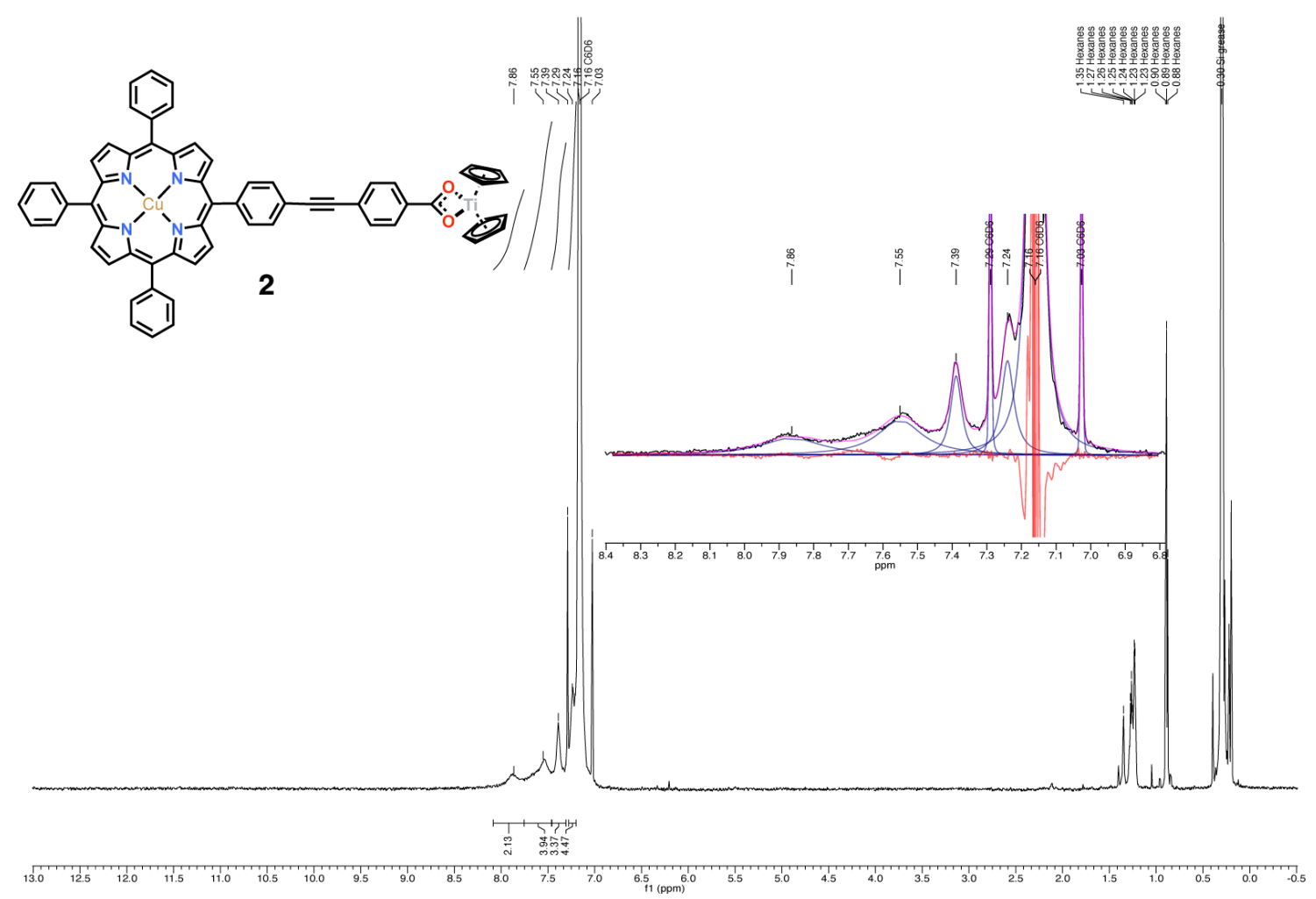

Figure S78 $\mid{ }^{1} \mathrm{H}$ NMR (600 MHz, $\left.\mathrm{C}_{6} \mathrm{D}_{6}\right)$ of 2.

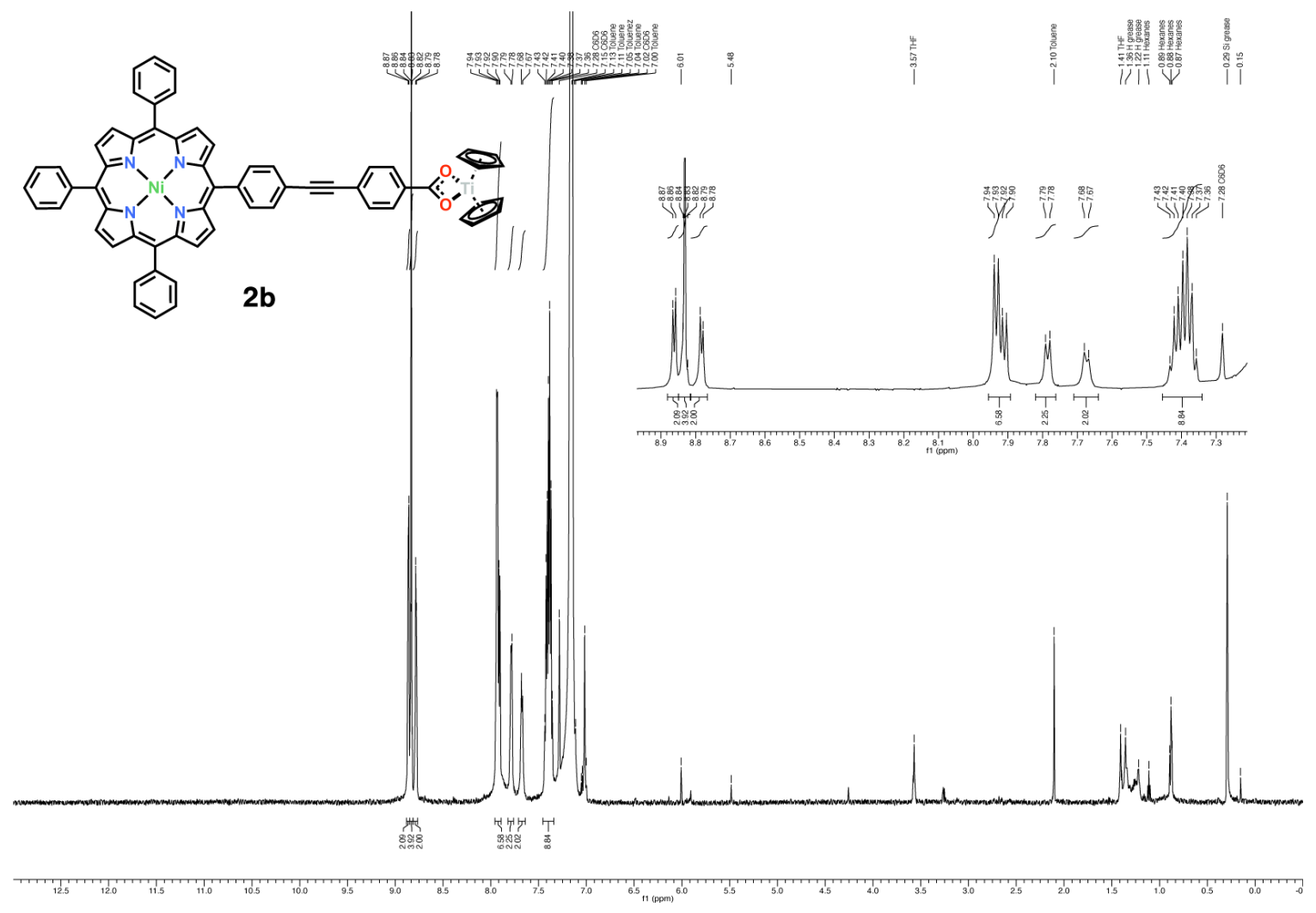

Figure $\mathbf{S 7 9} \mid{ }^{1} \mathrm{H}$ NMR $\left(600 \mathrm{MHz}, \mathrm{C}_{6} \mathrm{D}_{6}\right)$ of $\mathbf{2 b}$. 


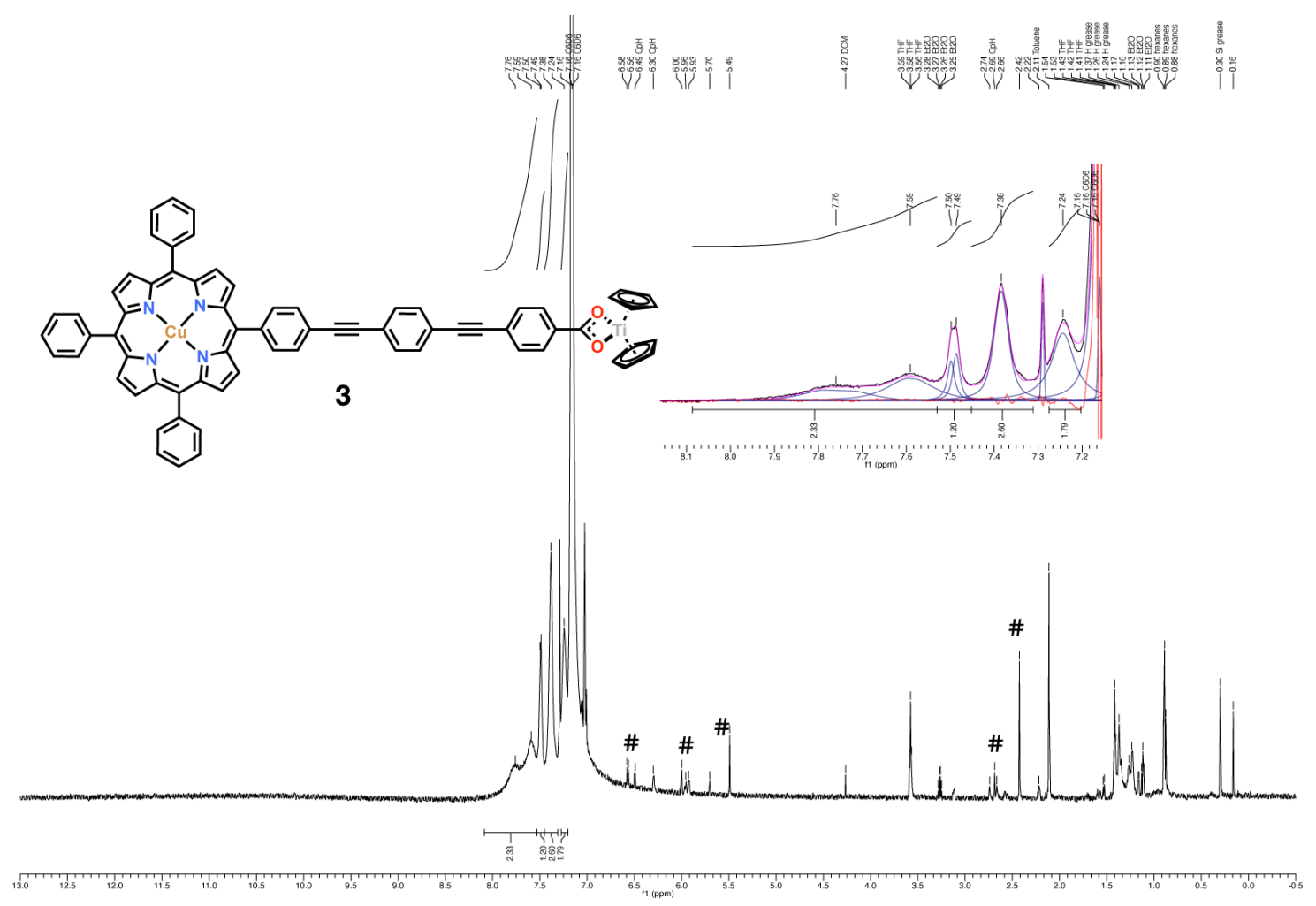

Figure S80 $\mid{ }^{1} \mathrm{H}$ NMR $\left(600 \mathrm{MHz}, \mathrm{C}_{6} \mathrm{D}_{6}\right)$ of 3. Resonances from a small amount of oxidized and/or hydrolyzed 3 indicated by \# consists of liberated cyclopentadiene and its further degradation products.

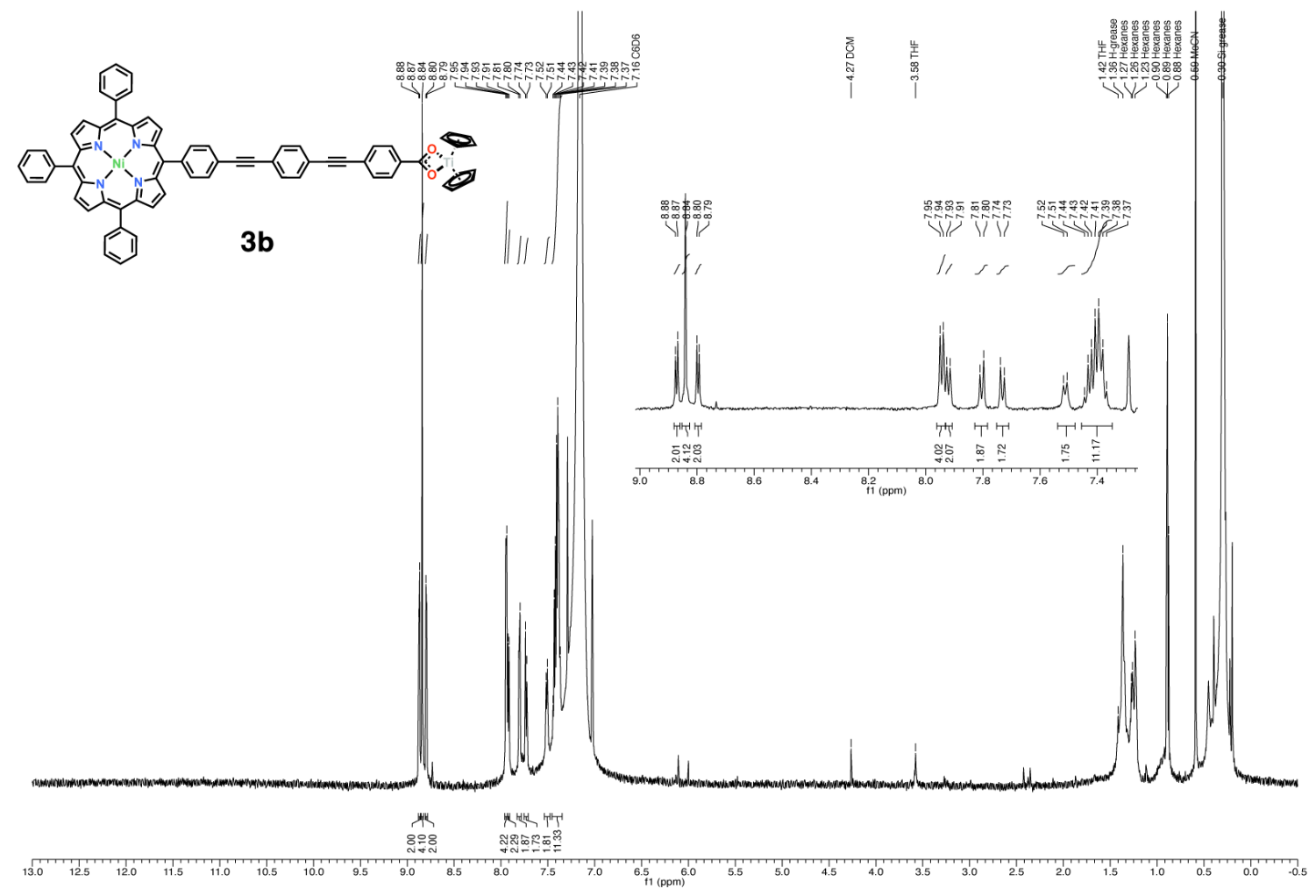

Figure S81 | ${ }^{1} \mathrm{H}$ NMR $\left(600 \mathrm{MHz}, \mathrm{C}_{6} \mathrm{D}_{6}\right)$ of $\mathbf{3 b}$. 


\section{Supplementary References}

(1) Allain, C.; Schaming, D.; Karakostas, N.; Erard, M.; Gisselbrecht, J.-P.; Sorgues, S.; Lampre, I.; Ruhlmann, L.; Hasenknopf, B. Synthesis, Electrochemical and Photophysical Properties of Covalently Linked Porphyrin-Polyoxometalates. Dalton Trans. 2013, 42 (8), 2745-2754. https://doi.org/10.1039/C2DT31415K.

(2) Luguya, R.; Jaquinod, L.; Fronczek, F. R.; Vicente, M. G. H.; Smith, K. M. Synthesis and Reactions of Meso-(p-Nitrophenyl)Porphyrins. Tetrahedron 2004, 60 (12), 2757-2763. https://doi.org/10.1016/j.tet.2004.01.080.

(3) Tummatorn, J.; Punjajom, K.; Rodphon, W.; Ruengsangtongkul, S.; Chaisan, N.; Lumyong, K.; Thongsornkleeb, C.; Nimnual, P.; Ruchirawat, S. Chemoselective Synthesis of 1,1-Disubstituted Vinyl Triflates from Terminal Alkynes Using TfOH in the Presence of TMSN3. Org. Lett. 2019, 21 (12), 4694-4697. https://doi.org/10.1021/acs.orglett.9b01576.

(4) Arp, H.; Zirngast, M.; Marschner, C.; Baumgartner, J.; Rasmussen, K.; Zark, P.; Müller, T. Synthesis of Oligosilanyl Compounds of Group 4 Metallocenes with the Oxidation State +3 . Organometallics 2012, 31 (11), 4309-4319. https://doi.org/10.1021/om3001873.

(5) Hondros, C. J.; Aravindu, K.; Diers, J. R.; Holten, D.; Lindsey, J. S.; Bocian, D. F. Effects of Linker Torsional Constraints on the Rate of Ground-State Hole Transfer in Porphyrin Dyads. Inorg. Chem. 2012, 51 (20), 11076-11086. https://doi.org/10.1021/ic301613k.

(6) Strohalm, M.; Kavan, D.; Novák, P.; Volný, M.; Havlíček, V. MMass 3: A Cross-Platform Software Environment for Precise Analysis of Mass Spectrometric Data. Anal. Chem. 2010, 82 (11), 46484651. https://doi.org/10.1021/ac100818g.

(7) Eelman, M. D.; Blacquiere, J. M.; Moriarty, M. M.; Fogg, D. E. Shining New Light on an Old Problem: Retooling MALDI Mass Spectrometry for Organotransition-Metal Catalysis. Angew. Chem. Int. Ed. 2008, 47 (2), 303-306. https://doi.org/10.1002/anie.200704489.

(8) Bailey, G. A.; Fogg, D. E. Confronting Neutrality: Maximizing Success in the Analysis of Transition-Metal Catalysts by MALDI Mass Spectrometry. ACS Catal. 2016, 6 (8), 4962-4971. https://doi.org/10.1021/acscatal.6b01105.

(9) Sheldrick, G. M. SHELXT - Integrated Space-Group and Crystal-Structure Determination. Acta Cryst A 2015, 71 (1), 3-8. https://doi.org/10.1107/S2053273314026370.

(10) Sheldrick, G. M. Crystal Structure Refinement with SHELXL. Acta Cryst C 2015, 71 (1), 3-8. https://doi.org/10.1107/S2053229614024218. 
(11) Dolomanov, O. V.; Bourhis, L. J.; Gildea, R. J.; Howard, J. a. K.; Puschmann, H. OLEX2: A Complete Structure Solution, Refinement and Analysis Program. J Appl Cryst 2009, 42 (2), 339341. https://doi.org/10.1107/S0021889808042726.

(12) Perdew, J. P.; Burke, K.; Ernzerhof, M. Generalized Gradient Approximation Made Simple. Phys. Rev. Lett. 1996, 77 (18), 3865-3868. https://doi.org/10.1103/PhysRevLett.77.3865.

(13) Kresse, G.; Furthmüller, J. Efficiency of Ab-Initio Total Energy Calculations for Metals and Semiconductors Using a Plane-Wave Basis Set. Computational Materials Science 1996, 6 (1), 1550. https://doi.org/10.1016/0927-0256(96)00008-0.

(14) Blöchl, P. E.; Jepsen, O.; Andersen, O. K. Improved Tetrahedron Method for Brillouin-Zone $\begin{array}{lllllll}\text { Integrations. } & \text { Phys. } & \text { Rev. } & B & \text { 1994, } & 49 & \text { (23), }\end{array}$ https://doi.org/10.1103/PhysRevB.49.16223.

(15) Stoll, S.; Schweiger, A. EasySpin, a Comprehensive Software Package for Spectral Simulation and Analysis in EPR. Journal of Magnetic Resonance 2006, 178 (1), 42-55. https://doi.org/10.1016/j.jmr.2005.08.013.

(16) Richert, S.; Kuprov, I.; Peeks, M. D.; Suturina, E. A.; Cremers, J.; Anderson, H. L.; Timmel, C. R. Quantifying the Exchange Coupling in Linear Copper Porphyrin Oligomers. Physical Chemistry Chemical Physics 2017, 19 (24), 16057-16061. https://doi.org/10.1039/C7CP01787A.

(17) Bencini, A.; Gatteschi, D. The Effect of Antisymmetric Exchange on the E.P.R. Spectra of Coupled Pairs of Transition Metal Ions. Molecular Physics 1982, 47 (1), 161-169. https://doi.org/10.1080/00268978200100112.

(18) Brown, T. G.; Hoffman, B. M. 14N, 1H, and Metal ENDOR of Single Crystal Ag(II)(TPP) and $\mathrm{Cu}(\mathrm{II})(\mathrm{TPP}) . \quad$ Molecular $\quad$ Physics $\quad$ 1980, $39 \quad$ (5), https://doi.org/10.1080/00268978000100911.

(19) Clauss, A. W.; Wilson, S. R.; Buchanan, R. M.; Pierpont, C. G.; Hendrickson, D. N. Magnetic Exchange Interactions Propagated by Saturated Bridges in Binuclear Dicyclopentadienyltitanium(III) Complexes. Inorg. Chem. 1983, 22 (4), 628-636. https://doi.org/10.1021/ic00146a012.

(20) Chen, H.; Maryasov, A. G.; Rogozhnikova, O. Y.; Trukhin, D. V.; Tormyshev, V. M.; Bowman, M. K. Electron Spin Dynamics and Spin-Lattice Relaxation of Trityl Radicals in Frozen Solutions. Phys. Chem. Chem. Phys. 2016, 18 (36), 24954-24965. https://doi.org/10.1039/C6CP02649D.

(21) Hoult, D. I.; Richards, R. E. Critical Factors in the Design of Sensitive High Resolution Nuclear Magnetic Resonance Spectrometers. Proceedings of the Royal Society of London. A. Mathematical and Physical Sciences 1975, 344 (1638), 311-340. https://doi.org/10.1098/rspa.1975.0104. 